\title{
Analytical Coordination Chemistry Section:
} Summary of Activities July 1970 to June 1971

U.S. ARTMENT OF DMMERCE QC 100 05753 10.584 
The National Bureau of Standards ${ }^{1}$ was established by an act of Congress March 3, 1901. The Bureau's overall goal is to strengthen and advance the Nation's science and technology and facilitate their effective application for public benefit. To this end, the Bureau conducts research and provides: (1) a basis for the Nation's physical measurement system, (2) scientific and technological services for industry and government, (3) a technical basis for equity in trade, and (4) technical services to promote public safety. The Bureau consists of the Institute for Basic Standards, the Institute for Materials Research, the Institute for Applied Technology, the Center for Computer Sciences and Technology, and the Office for Information Programs.

THE INSTITUTE FOR BASIC STANDARDS provides the central basis within the United States of a complete and consistent system of physical measurement; coordinates that system with measurement systems of other nations; and furnishes essential services leading to accurate and uniform physical measurements throughout the Nation's scientific community, industry, and commerce. The Institute consists of a Center for Radiation Research, an Office of Measurement Services and the following divisions:

Applied Mathematics-Electricity-Heat-Mechanics-Optical Physics-Linac Radiation ${ }^{2}$ - Nuclear Radiation ${ }^{2}$ - Applied Radiation ${ }^{2}$-Quantum Electronics ${ }^{3}$ Electromagnetics ${ }^{3}$-Time and Frequency ${ }^{3}$ - Laboratory Astrophysics ${ }^{3}-$ Cryogenics ${ }^{3}$.

THE INSTITUTE FOR MATERIALS RESEARCH conducts materials research leading to improved methods of measurement, standards, and data on the properties of well-characterized materials needed by industry, commerce, educational institutions, and Government; provides advisory and research services to other Government agencies; and develops, produces, and distributes standard reference materials. The Institute consists of the Office of Standard Reference Materials and the following divisions:

Analytical Chemistry-Polymers-Metallurgy-Inorganic Materials-Reactor Radiation-Physical Chemistry.

THE INSTITUTE FOR APPLIED TECHNOLOGY provides technical services to promote the use of available technology and to facilitate technological innovation in industry and Government; cooperates with public and private organizations leading to the development of technological standards (including mandatory safety standards), codes and methods of test; and provides technical advice and services to Government agencies upon request. The Institute also monitors NBS engineering standards activities and provides liaison between NBS and national and international engineering standards bodies. The Institute consists of the following technical divisions and offices:

Engineering Standards Services-Weights and Measures-Flammable FabricsInvention and Innovation-Vehicle Systems Research-Product Evaluation Technology-Building Research-Electronic Technology-Technical AnalysisMeasurement Engineering.

THE CENTER FOR COMPUTER SCIENCES AND TECHNOLOGY conducts research and provides technical services designed to aid Government agencies in improving cost effectiveness in the conduct of their programs through the selection, acquisition, and effective utilization of automatic data processing equipment; and serves as the principal focus within the executive branch for the development of Federal standards for automatic data processing equipment, techniques, and computer languages. The Center consists of the following offices and divisions:

Information Processing Standards-Computer Information-Computer Services - Systems Development-Information Processing Technology.

THE OFFICE FOR INFORMATION PROGRAMS promotes optimum dissemination and accessibility of scientific information generated within NBS and other agencies of the Federal Government; promotes the development of the National Standard Reference Data System and a system of information analysis centers dealing with the broader aspects of the National Measurement System; provides appropriate services to ensure that the NBS staff has optimum accessibility to the scientific information of the world, and directs the public information activities of the Bureau. The Office consists of the following organizational units:

Office of Standard Reference Data-Office of Technical Information and Publications-Library-Office of Public Information-Office of International Relations.

\footnotetext{
1 Headquarters and Laboratories at Gaithersburg, Maryland, unless otherwise noted; mailing address Washington, D.C. 20234.

2 Part of the Center for Radiation Research.

${ }^{3}$ Located at Boulder, Colorado 80302.
} 


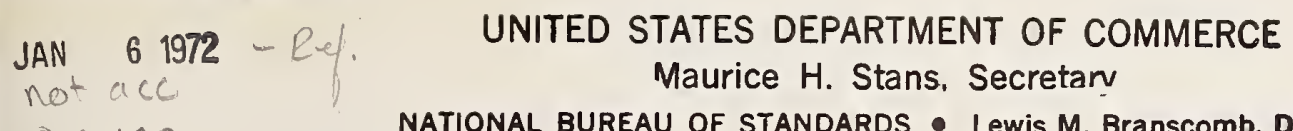

NATIONAL BUREAU OF STANDARDS - Lewis M. Branscomb, Director

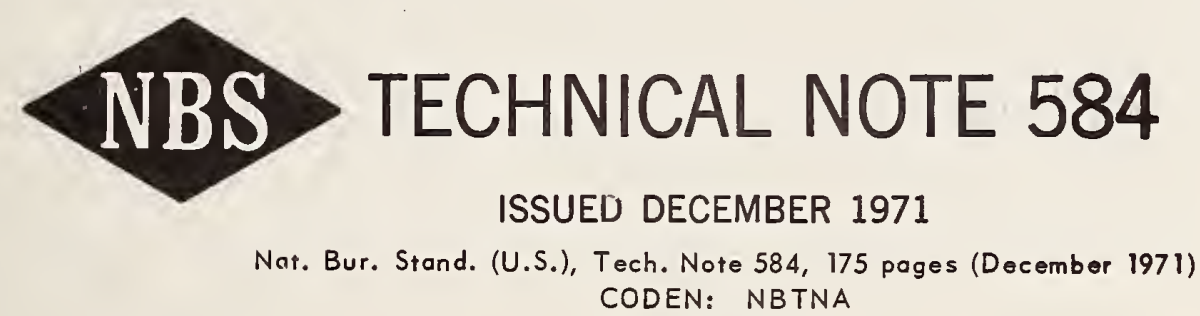

\title{
Analytical Coordination Chemistry Section:
}

\author{
Summary of Activities \\ July 1970 to June 1971
}

O. Menis and J. I. Shultz, Editors

Analytical Coordination Chemistry Section

Analytical Chemistry Division Institute for Materials Research

National Bureau of Standards

Washington, D.C. 20234

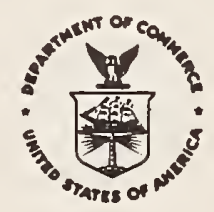

NBS Technical Notes are designed to supplement the Bureau's regular publications program. They, :vide a means for making available scientific data that are of transient or limited interest. Technical Notes may be listed or referred to in the open literature.

For sale by the Superintendent of Documents, U.S. Government Printing Office, Washington, D.C., 20402. (Order by SD Catalog No. C 13.46:584). Price $\$ 1.50$ 

The Analytical Chemistry Division was established as a separate division at the National Bureau of Standards on September 1, 1963, and became part of the Institute for Materials Research in the February 1, 1964, reorganization. It consists at present of nine Sections and about 100 technical personnel encompassing some 45 different analytical competences from activation analysis and atomic absorption to vacuum fusion and $\mathrm{x}$-ray spectroscopy. These competences, and in turn the Sections which they comprise, are charged with research at the forefront of analysis as well as awareness of the practical sample, be it standard reference material or service analysis. In addition it is their responsibility to inform others of their efforts.

Formal publication in scientific periodicals is a highly important output of our laboratories. In addition, however, it has been our experience that informal, annual summaries of progress describing efforts of the past year can be very valuable in disseminating information about our programs. A word is perhaps in order about the philosophy of these yearly progress reports. In any research program a large amount of information is obtained and techniques developed which never find their way into the literature. This includes the "negative results" which are so disappointing and unspectacular but which can often save others considerable work. Of importance also are the numerous small items which are often explored in a few days and which are not important enough to warrant publication -- yet can be of great interest and use to specialists in a given area. Finally there are the experimental techniques and procedures, the designs and modifications of equipment, etc., which often require months to perfect and yet all too often must be covered in only a line or two of a journal article. 
Thus our progress reports endeavor to present this information which we have struggled to obtain and which we feel might be of some help to others. Certain areas which it appears will not be treated fully in regular publications are considered in some detail here. Other results which are being written up for publication in the journal literature are covered in a much more abbreviated form.

At the National Bureau of Standards publications such as these fit logically into the category of a Technical Note. We plan to issue these summaries for all of our sections. The following is the seventh annual report on progress of the Analytical Coordination Chemistry Section.

W. Wayne Meinke, Chief Analytical Chemistry Division 
PREFACE

The seventh annual progress report of the Analytical Coordination Chemistry Section describes the research and development activities related to the needs of the Standard Reference Materials Program. The current report reflects the continuation of high accuracy measurements in the fields of spectrophotometry and spectrofluorometry which are applicable to problems in clinical chemistry and environmental studies. It provides background information on the two new Standard Reference Materials, SRM-930, solid filters, and SRM-931, liquid filters, issued for the purpose of calibrating the photometric scales of spectrophotometers. As a progress report, it is fragmentary and only indicates the areas of work undertaken by the Section. Inquiries and suggestions regarding these efforts are solicited.

To adequately describe experimental procedures, it is occasionally necessary to identify commercial products and equipment by the manufacturer's name or label. In no instances does such identification imply recommendation or endorsement by the National Bureau of Standards, nor does it imply that the particular product or equipment is necessarily the best available for that purpose.

The assistance of Mrs. Rosemary Maddock is gratefully acknowledged. Also, we acknowledge the invaluable assistance of Mrs. Mary Pantazis, Section Secretary, who performs a wide variety of duties essential to the work of this section, and for her tireless efforts in typing and assembling this report.

Oscar Menis, Chief

Analytical Coordination Chemistry

James I. Shultz, Assistant Chief Analytical Coordination Chemistry 
1. SPECTROPHOTOMETRY . . . . . . . . . . . . . . 1

A. Introduction. . . . . . . . . . . . . . . . 1

B. Solid Standard Reference Materials to Check

the Photometric Scale of Spectrophotometers -

R. Mavrodineanu and J. R. Baldwin . . . . . 2

1. Study of Surface Properties of Filters. . 6

2. Ultraviolet Region. . . . . . . . . . 7

3. Cooperative Study of Colored Neutral

Glass Filters. . . . . . . . . . 7

C. Instrument Development - R. Mavrodineanu. . . 9

Description of the NBS Instrument . . . 10

a. The Light Source. . . . . . . . . 11

b. The Monochromator . . . . . . . 12

c. Sample Carrying Unit. . . . . . . . 13

d. System to Check the Accuracy of the Photometric Reading . . . . . . . 13

e. Integrating Sphere and Photomultiplier Arrangement . . . . . . . 16

D. Experimental Results. . . . . . . . . . 18

E. Studies of Liquid Filters as Potential

Absorbance Standards - R. W. Burke and

E. R. Deardorff. . . . . . . . . . 21

1. Solutions of Inorganic Salts. . . . . . 21

2. Composite Mixtures. . . . . . . . . 22

3. Organic Dyes. . . . . . . . . . . 24

F. The Use of Chromium(VI) Solutions as Spectrophotometric Absorbance Standards - R. W.

Burke, E. R. Deardorff and D. S. Bright . . 27

1. Introduction. . . . . . . . . . . . 27

2. Chromium(VI) Equilibria . . . . . . . 29

3. Redetermination of $\mathrm{K}_{3}$, the Dimerization

Constant for the Reaction: $2 \mathrm{HCrO}_{4}{ }^{-}=$ $\mathrm{Cr}_{2} \mathrm{O}_{7}{ }^{=}+\mathrm{H}_{2} \mathrm{O}$........... 30

Experimental . . . . . . . . . . 31

4. Absorption Spectra of $\mathrm{HCrO}_{4}^{-}$and $\mathrm{Cr}_{2} \mathrm{O}_{7}=$

5. Agreement Between Experimental and

Calculated Values of Apparent Molar

Absorptivity. . . . . . . . . . 36

6. Using Acidic Dichromate Solutions to

Check Linearity in the Ultraviolet. . . 39

7. Optimum $\mathrm{pH}$ and Choice of Acid for

Preparing Acidic Chromium(VI) Solutions 41

8. Effect of Temperature on the Absorbance of $\mathrm{K}_{2} \mathrm{Cr}_{2} \mathrm{O}_{7}$ at $\mathrm{pH}$ 3........... 42 
9. $\mathrm{K}_{2} \mathrm{Cr}_{2} \mathrm{O}_{7}$ in $0.05 \mathrm{M} \mathrm{Na}_{2} \mathrm{HPO}_{4}$ and $0.05 \mathrm{M} \mathrm{KOH} .43$

10. Conclusion. . . . . . . . . . 44

G. The Absorptivity of Bilirubin, NBS-SRM 916 -

R. W. Burke and E. R. Deardorff . . . . 45

1. Introduction. . . . . . . . . . 45

2. Experimental. . . . . . . . . . 45

a. Procedure . . . . . . . . 46

b. Results.......... 46

3. Conclusions . . . . . . . . . . 46

H. Spectrophotometric Study of the Dye Ratio in
Sample of Ballpoint Ink - R. W. Burke. . . 47

1. Introduction. . . . . . . . . . 47

2. Experimental ......... . 47

a. Calibration ......... . 48

b. Analysis of Composite Dye Solutions . 49

c. Analysis of the Bulk Ink. . . . . 50

d. Analysis of Bulk Ink After Application

to Bond Paper. . . . . . . 50

e. Dye Composition of Manufacturer's

f. Light Fastness. . . . . . . . . . . . . 51

3. Conclusion. . . . . . . . . 52

2. FLUORESCENCE •. . . . . . . . . . . . 53

A. Introduction. . . . . . . . . . . . 53

B. Instrumentation Evaluation - R. A. $\quad$ Velapoldi 54

C. Fluorescence - Inorganic Ions in Glass

Matrices - R. A. Velapoldi and R. Reisfeld. 61

D. Inorganic Ions with Broad Spectra . . . . . 61

1. General . . . . . . . . . 61

2. Quantitative and Qualitative Analysis . 62

3. Matrix Effects. . . . . . . . . 63

4. Quantum Efficiencies. . . . . . . 67

5. Future Research . . . . . . . . . 71

E. Lanthanides . . . . . . . . . . . . 71

1. Analytical. . . . . . . . . . . 71

2. Matrix Effects. . . . . . . . . 72

3. Quantum Efficiency Determinations of

Eu(III) in Silicate Matrix. . . . . 74

F. Energy Transfer . . . . . . . . . . . 79

G. Data and Spectra Storage. . . . . . . . . . 81

H. Computer Programs - R. A. Velapoldi... . . 83 
3. ANALYTICAL FLAME SPECTROSCOPY. . . . . . . 84

A. Introduction . . . . . . . . . . . . 84

B. Evaluation of the Multichannel Direct

Reading Spectrometer - R. Mavrodineanu . 84

C. Long Path Flames . . . . . . . . . . 87

D. A Triple Pass On-Axis Optical System for Analytical Flame Spectroscopy -

R. Mavrodineanu and $W$. Müller-Herget .

E. Premixed Acetylene-Oxygen Flame Supplied

Through an Ultrasonic Spraying System -

$L$. Owen ana $R$. Mavrodineanu

F. Flame Emission Spectrometry With Optical

Scanning - T. C. Rains . . . . . . 93

G. High-Precision Atomic Absorption

Spectrometry for Major Components -

T. C. Rains. . . . . . . . . . .

H. Effect of Spectral Bandwidth in Atomic

Absorption Spectrometry - T. C. Rains. . 102

I. Analytical Application to Standard

Reference Materials - T. A. Rush and

T. C. Rains.

1. Determination of Calcium, Magnesium,

Silver and Zinc in Special Steel.

2. Determination of Calcium, Potassium,

Magnesium, Sodium, Rubidium, Cadmium,

Zinc and Manganese in Orchard Leaves -

T. C. Rains and T. A. Rush . . . . 104

a. Preparation of Samples . . . . 106

b. Determination of Constituents. . . 107

3. Determination of Mercury in Orchard

Leaves - T. C. Rains . . . . . . 108

a. Dissolution of Sample . . . . 110

b. Reduction of Mercury . . . . . . 111

c. Trapping of Volatile Vapors. . . . 112

d. Absorption Cells . . . . . . 112

e. Contamination Problems . . . . . 112

f. Measurement. . . . . . . . . 113

4. Service Analysis - T. A. Rush and

T. C. Rains. . . . . . . . . 113

4. THERMAL ANALYSIS . . . . . . . . . . 116

A. Introduction . . . . . . . . . . . . 116

B. Certification of SRM's for Calibrating the

Temperature Scale of DTA Apparatus -

D. S. Bright and O. Menis. . . . . . 117

C. Scanning Calorimetry - D. S. Bright,

E. Prosen and O. Menis... . . . . . 119 
I. Introduction. . . . . . . . . . 119

Certificates for NBS-ICTA

Standard Reference Materials 758 ,

759, and 760........ 120

2. Principle and Measurements. . . . 128

3. Apparatus . . . . . . . . . . 131

a. Sample Holder . . . . . . . . 131

b. Copper Block and Housing for

Heater and Thermocouples. . . 132

4. Electrical Calibration. . . . . . 132

5. Observations. . . . . . . . . . 133

6. Conclusion. . . . . . . . . . 139

5. STANDARD REFERENCE MATERIALS. . . . . . . . 140

A. Introduction - J. I. Shultz. . . . . . 140

B. Standard Reference Materials Information

and Summary . . . . . . . . . . 141

1. Stainless Steels 12ld and 1171... . 141

2. Stainless Steels $123 \mathrm{c}$ and $1172 . .9142$

3. Special Steels 361, 1261; 362, 1262;

363,$1263 ; 1264 . . . . . .143$

6. PERSONNEL AND ACTIVITIES. . . . . . . . 145

7. REFERENCES. . . . . . . . . . . . 152 
TABLE NO.

1. Comparative \% T measurements performed by four laboratories on three Schott NG-4 colored glass filters

2. Transmittance measurements on a Schott NG-4 glass filter with the NBS high accuracy spectrophotometer.

3. Repeatability of \% T measurements performed with the NBS high accuracy spectrophotometer on three colored glass filters. . . . . . .

4. Comparison of \% $T$ measurements performed on a Schott NG-4 filter using the NBS high accuracy instrument and a conventional spectrophotometer provided with a quartz prism double monochromator in a double beam arrangement. . . . .

5. Apparent molar absorptivity of nickel(II) solutions at $25{ }^{\circ} \mathrm{C}$. . . . . . . . . . . .

6. Format of the interlaboratory evaluation of two liquid filters, designated $T$ and NBS, as potential absorbance standarads. . . . . . . .

7. Absorbance of $\mathrm{K}_{2} \mathrm{Cr}_{2} \mathrm{O}_{7}$ solutions as measured in $1.023 \mathrm{~mm}$ cuvette at $25^{\circ} \mathrm{C} ; \mathrm{pH}=2.92 \pm 0.02$ $\left(\mathrm{HClO} \mathrm{O}_{4}\right)$

8. Apparent molar absorptivities of $\mathrm{K}_{2} \mathrm{Cr}_{2} \mathrm{O}_{7}$ solutions as a function of chromium(VI) concentration at $25{ }^{\circ} \mathrm{C} ; \mathrm{pH}=2.92 \pm 0.02\left(\mathrm{HClO}_{4}\right)$......

9. $\mathrm{K}_{3}$ at $25{ }^{\circ} \mathrm{C}$ as determined at various wavelengths

10. Provisional molar absorptivities of $\mathrm{HCrO}_{4}^{-}$and $\mathrm{Cr}_{2} \mathrm{O}_{7}=$ at $25{ }^{\circ} \mathrm{C}$

11. Experimental and calculated values (E, C) of apparent molar absorptivity, $\varepsilon_{m}$, at $25^{\circ} \mathrm{C} .$.

12. $\alpha, 1-\alpha$, and apparent weight factors at $25^{\circ} \mathrm{C}$ for selected concentrations of $\mathrm{K}_{2} \mathrm{Cr}_{2} \mathrm{O}_{7}$.

13. Tentative molar absorptivity values of $\mathrm{K}_{2} \mathrm{Cr}_{2} \mathrm{O}_{7}$ in $0.05 \mathrm{M} \mathrm{Na}_{2} \mathrm{HPO}_{4}$ and $0.05 \mathrm{M} \mathrm{KOH}$ at $25{ }^{\circ} \mathrm{C} .{ }^{\circ} \cdot$.

14. Apparent absorptivity of SRM 916, Bilirubin, in chloroform at $25^{\circ} \mathrm{C}$. 
15. Analysis of known mixtures of Methyl Violet DY Base (MV) and Victoria Pure Blue BO Base (VB) . 50

16. Analysis of bulk ink. . . . . . . . . . . 50

17. Analysis of bulk ink following application and elution from bond paper... . . . . . . . 51

18. Analysis of ink on manufacturer's scribble chart

19. Variation of relative dye concentration after exposure to light . . . . . . . . . 52

20. Reproducibility of preparation and measurement of quinine sulfate solutions in $0.1 \mathrm{~N} \mathrm{H}_{2} \mathrm{SO}_{4}$ peakheight measurements

21. Statistical analysis of instrumental stabilities using quinine sulfate and uranium glass as standards

22. Statistical analysis for eleven fluorescence determinations of quinine sulfate during an eight hour span using a corrected spectrofluorometer.

23. Emission and excitation wavelength dependence on matrix for lead, cerium and thallium. . . . . 62

24. Ionic field strengths of cations in glasses. . 65

25. Infrared stretching frequencies and bond lengths for active ion-oxygen interactions in the matrix 67 26. Oscillator strengths for TICl in KCl. . . . . 70

27. Excitation and emission wavelengths for lanthanides in glass matrices yielding maximum emission intensities. . . . . . . . . . . 72

28. Shifts of major europium, samarium and thulium emission peaks as a function of matrix. . . . .

29. Average fluorescence lifetimes of rare earths in various matrices. . . . . . . . . . . 74

30. Effects of glass matrix on fluorescence intensities of the rare earth ions. . . . . . . 74

31. Major emission peaks for europium(III) in water and silicate matrices . . . . . . . . . . .

32. Transition assignments and relative intensities of major emission and excitation bands for europium(III) in silicate and phosphate matrices 
TABLE NO.

33. Accuracy of analytical results for magnesium, potassium, calcium and sodium determined simultaneously . . . . . . . . . . . . 8 86

34. Determination of aluminum in $0.4 \%$ carbon steel by flame emission spectrometry . . . . . . 100

35. Determination of zinc in SRM 124d (ounce metal)101

36. Determination of chromium in SRM 12ld. . . . 102

37. Summary of SRM analyses by flame emission and atomic absorption spectrometry . . . . . 105

38. Determination of mercury in orchard leaves by flameless atomic absorption . . . . . . 113

39. Analytical conditions and concentration ranges for trace elements in water effluents with and without NTA . . . . . . . . 115

40. Mean values of onset heat temperatures of ICTA substances. . . . . . . . . . . 117

41. Calibration data - determination of proportionality coefficient, $k$, for transition (melting) on heating. . . . . . . . . 134

42. Stainless Steels $121 d$ and 1171 . . . . . . . 143

43. Stainless Steels $123 \mathrm{c}$ and 1172 . . . . . . 143 
FIGURE NO.

PAGE

1. Set of three glass filters with the corresponding provisional certificate constituting SRM-930 . .

2. Schematic description of the NBS high accuracy spectrophotometer.

3. NBS high accuracy spectrophotometer. At right, the light source, at upper left, the $1 \mathrm{~m}$ monochromator. The optical bench at the exit slit of the monochromator carries an achromate; the sample platform; a second achromate followed by the integrating sphere and photomultiplier

4. NBS high accuracy spectrophotometer. Same arrangement as in figure 3 except for the aperture system which is now placed after the exit slit of the monochromator. This arrangement is used when making linearity measurements . . .

5. Ampouled filters now undergoing evaluation in cooperating clinical laboratories.

6. Comparison of absorption spectra of $1.0 \times 10^{-4} \mathrm{M}$ $\mathrm{K}_{2} \mathrm{Cr}_{2} \mathrm{O}_{7}$ in $0.001 \mathrm{~N} \mathrm{HClO}_{4}$ and $0.05 \mathrm{~N} \mathrm{KOH}$.

7. Difference spectrum of $391 \mathrm{mg} \mathrm{K}_{2} \mathrm{Cr}_{2} \mathrm{O}_{7} /$ liter in $1.023 \mathrm{~mm}$ cuvette and $40.0 \mathrm{mg} \mathrm{K}_{2} \mathrm{Cr}_{2} \mathrm{O}_{7} /$ liter in $10.00 \mathrm{~mm}$ cuvette; $\mathrm{pH}=3 . . . . . . . . .33$

8. Least squares determination of $\mathrm{K}_{3} \cdot$. . . . . . 35

9. Absorption spectra of $\mathrm{HCrO}_{4}{ }^{-}$and $\mathrm{Cr}_{2} \mathrm{O}_{7}=$ from

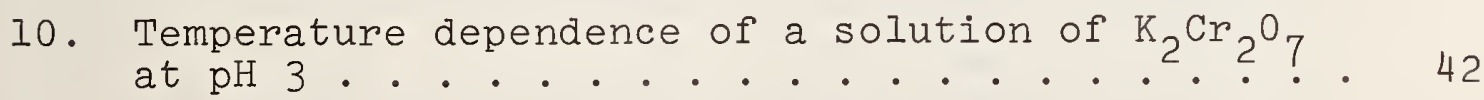

11. Absorption spectra of acidified ethanolic solutions of Methyl Violet DY Base (MV) and Victoria Pure Blue BO Base (VB). . . . . . . . .

12. Corrected and uncorrected emission and excitation spectra of quinine sulfate in $0.1 \mathrm{~N} \mathrm{H}_{2} \mathrm{SO}_{4} . . \cdot .55$

13. Emission peak height is directly proportional to emission peak area. . . . . . . . . . 56

14. Relative fluorescence intensity versus quinine sulfate concentration showing "concentration quenching" . . . . . 
FIGURE NO

15. Instrumental stability and reproducibility as a function of time using liquid and solid samples.

16. Typical warm-up times for a commercial instrument in uncorrected mode using aluminum foil as reflecting sample. . . . . . . . . . . . . .

17. Relative fluorescence intensity versus concentration in weight percent for cerium(III), lead(II) and thallium(I) . . . . . . . . 63

18. Wavelength dependence of emission peaks on matrix for cerium, lead and thallium . . . . . 64

19. Matrix dependent ligand field effects on degenerate and ion-degenerate states . . . . . 66

20. Fluorescence intensity dependence on sample angle for thallium(I) in $\mathrm{KCl}$ and quinine sulfate in $0.1 \mathrm{~N}_{2} \mathrm{SO}_{4}$..........

21. Relative fluorescence intensity versus rare earth concentration in weight percent. . . . . . . . 71

22. Corrected excitation, emission and absorbance spectra for europium(III) in a silicate matrix . . 73

23. Major emission peaks of europium(III) in silicate matrix and water solution. . . . . . . . . 76

24. Gaussian Analysis for absorpance spectra of europium in silicate ${ }^{7} \mathrm{~F}_{0,1} \rightarrow{ }^{5} \mathrm{D}_{0}$ transitions . . . 77

25. Fluorescence intensity enhancement of europium(III) by energy transfer from samarium(III) to europium(III), $\lambda_{\text {exc }}=402.0 \mathrm{~nm}$. . . . . .

26. Fluorescence intensity enhancement of terbium(III) by energy transfer from gadolinium(III) to terbium(III), $\lambda_{\text {exc }}=275.0 \mathrm{~nm} .$. . . .

27. Excitation spectra obtained showing gadolinium(III) spectra ( $275.0,312.0 \mathrm{~nm}$ ) when monitoring terbium(III) emission at $490.0 \mathrm{~nm},{ }^{5} \mathrm{D}_{4} \rightarrow^{7} \mathrm{~F}_{6}$ transition . . . . 81

28. Proposed system and basic dimensions for the triple pass, on-axis optical arrangement (dimensions in $\mathrm{mm}$ ) . . . . . . . . . . . . . .

29. Schematic drawing of the on-axis triple pass system .................... 90

30. Premixed $\mathrm{C}_{2} \mathrm{H}_{2}-\mathrm{O}_{2}$ burner and ultrasonic nebulizer 92 
31. The unit from figure 30 in operation. ... . 93

32. The unit from figures 30 and 31 placed on the optical bench in front of a lm grating spectrometer; shown here for measurements in the atomic mode. At right, the hollow cathode followed by a lens and a chopper. At lower right, the generator, which drives the ultrasonic generator and the electrically operated sample pump which supplies the ultrasonic sprayer with the analytical sample solution.9 94

33. Flame emission spectra of aluminum。over wavelength region of 3925 to 3970 A from a nitrous oxide-acetylene flame. . . . . . 95

34. Calibration curve for aluminum using repetitive optical scanning . . . . . . . . 96

35. Comparison of flame emission spectrum of $0.1 \mu \mathrm{g} /$ $\mathrm{ml}$ of aluminum and $\mathrm{H}_{2} \mathrm{O}$ using a nitrous oxideacetylene flame. Conditions: Time constant, I sec; voltage applied to photomultiplier tube, $1000 \mathrm{~V}$; amplifier gain, I mV; flame, fuel rich (1-1/2 inch pink plume) . . . . . 97

36. Relative intensity of aluminum using repetitive optical scanning.

(A) Optical conditions the same as in figure 35.

(B) Voltage applied to photomultiplier tube increased to $1200 \mathrm{~V}$.

37. Relative intensity of 0.1 and $0.2 \mu \mathrm{g}$ of aluminum with repetitive optical scanning using a nitrous oxide-acetylene flame. Conditions: Same as in figure 35, except voltage applied to photomultiplier tube, 1300

38. Effect of flame cell path-length on the absorbance of zinc at $2138 \mathrm{~A}$. . . . . . 100

39. Effect of spectral bandwidth on absorbance of iron at $2483 \mathrm{~A}$. . . . . . . . . . 103

40. Schematic diagram of flameless atomic absorption apparatus for mercury determination . . . . . . . . . . . . . 109

41. Data from 34 cooperating investigators for each of the 10 substances (submitted to the Standards Committee of ICTA). 
FIGURE NO.

42. Deviations from the mean value as reported by the 34 investigators (submitted to the Standards Committee of ICTA) . . . . . . 118

43. Cross section of calorimeter chamber . . . . 129

44. Cross section of copper block. . . . . . 130

45. Proportionality coefficient, k, vs temperature... . . . . . . . . . 136

46. Electrical calibration curve . . . . . . . 137

47. Tin heating curve. . . . . . . . . . . 138

48. Benzoic acid heating curve . . . . . . . 139

49. Types of Standard Reference Materials characterized............. . 142 
Progress in research and development in spectrophotometry, spectrofluorometry, flame emission, atomic ábsorption, thermal analysis and the related program for the certification of Standard Reference Materials is described. Efforts. to improve the accuracy in spectrophotometric measurements led to the construction of a NBS high accuracy spectrophotometer, the certification of glass filters (SRM 930) in the visible region of the spectrum, establishment of a more accurate value or molar absorptivity of the acid dichromate system, and the evaluation of spectrally neutral filters of interest in automation for clinical studies. A single beam high accuracy spectrophotometer was constructed and its linearity was calibrated by the light addition technique. The glass filters, Schott NG-4 type were then calibrated at, four wavelengths with an uncertainty of 0.5 percent relative, based on the sum of random errors and biases between instruments, as well as material stability. New data for the dichromate system in diluted perchloric acid led to new values for the dimerization equilibrium constant of 32.8 . Also, programs for evaluating neutral gray solutions of inorganic salts are described. Other spectrophotometric studies included the measurement of molar absorptivity of bilirubin and the dye ratio of a commercial ink. Fluorescence studies involved determination of criteria for the evaluation of instrumental performance of proposed SRVI's.

Studies were made of new solid fluorescence filters incorporating $\mathrm{TI}(\mathrm{I}), \mathrm{Ce}(\mathrm{II})$ and $\mathrm{Pb}(\mathrm{II})$ and rare earths in borate, phosphate and silicate glass matrices. Quantum efficiencies of thallium in potassium chloride and europium in a silicate matrix were determined. The latter, measured by two independent methods, was $0.93 \pm .05$. Also, computer handling of the data is briefly described. 
In analytical flame spectroscopy, developments in instrumentation and methodology led to increased sensitivity, improved precision and accuracy in methodology and certification for several important trace elements in SRM's. Data were obtained with the multichannel direct reading spectrometer for elements: magnesium, calcium, potassium and sodium, with an accuracy of one to three percent relative standard deviation. A triple pass on-axis optical system offered an increase in signal of over 150 percent. An ultrasonic spraying system provided a 50 percent efficiency in the nebulization of sample. The repetitive optical scanning of flame emission overcame matrix and flame background problems for the determination of 0.04 percent aluminum in carbon steel with a relative standard deviation of 1.6 percent. Calcium, magnesium, silver and zinc were determined in special steels. Nine trace elements, including mercury, were determined in SRM botanical, orchard leaves. The studies of the variables in the determination of mercury by the flameless atomic absorption method led to an improved accuracy in the certification of a mercury value at 160 nanograms level in orchard leaves. In the area of thermal analysis, the final certification of eight new materials in cooperation with the International Confederation on Thermal Analysis was carried out. A scanning calorimeter was constructed and tested for enthalpy measurements on a number of DTA standards up to $300{ }^{\circ} \mathrm{C}$.

Finally, a brief discussion is presented of a variety of materials that have been characterized as Standard Reference Materials. Part of the activities resulted in the certification of carbon, stainless and high-silicon steels, high temperature alloys, orchard leaves, cholesterol, bilirubin, sodium chloride, and DTA standards. 


\section{SPECTROPHOTOMETRY}

A. Introduction

During the past year considerable progress was made in the three-pronged program outlined in last year's progress report. These efforts included the construction and measurements with the high accuracy spectrophotometer, development and certification of glass filters for use in the calibration of the photometric scale in the visible region of the spectrum, and studies with liquid filters for checking the accuracy of spectrophotometric measurements which will be useful in automated clinical measurements. Last year's report discussed extensively the overall philosophy, need and the justification for the various approaches that were contemplated. The current report covers the details of the construction of the new high accuracy spectrophotometer, its calibration, and its application to the certification of Standard Reference Material 930, Glass Filters. These filters are suitable for calibrating the photometric scale in the region of the spectrum from $400 \mathrm{~nm}$ to $700 \mathrm{~nm}$. The report also describes new studies leading to more accurate molar absorptivity values of the acid dichromate system and further progress in the development of spectrally neutral liquid filters.

Significant advances have been made in providing the basis for more accurate spectrophotometric measurements. The NBS single beam spectrophotometer now provides transmittance accuracy of at least 3 parts per thousand based on the stability of its components and an independent physical measurement of the linearity of transmittance. The accuracy value of 0.5 percent relative standard deviation assigned to the SRM 930, Glass Filter, is limited at present by the quality of the material.

A restudy of the acid dichromate systems led to a tenfold improvement in the values for the equilibrium 
formation of the dichromate dimer and provides a basis for measurement and recalculating of the molar absorptivity of the complex in the visible and UV regions of the spectrum and to provide flexible systems for calibrating multielement analysis in automated systems.

A major need is to improve the accuracy of the data being collected in the field of clinical chemistry. In addition to standards, improved methodology is needed to attain higher accuracy in this field. The present efforts in the area of standardization need to be extended to include stray light, bandpass, cell path calibrations, and ultimately a definite Standard Reference Material incorporating the multicomponent material of interest in health or pollution problems. To focus on the overall problem, a conference on Spectrophotometry and Luminescence Analysis has been planned for March 22-24, 1972 at NBS. Papers will be presented by experts in these measurement areas and also by panelists whose concern is primarily with improvement of health and alleviation of pollution.

B. Solid Standard Reference Materials to Check the

Photometric Scale of Spectrophotometers - R. Mavrodineanu and J.R. Baldwin

The need for providing means and materials to check the proper functioning of a spectrophotometer was discussed in some detail in a previous publication [1]. At that time it was established that the accuracy of the photometric scale is critical, and the most demanding parameter in spectrophotometric measurements. Hence, particular attention was given to a number of ways for checking this parameter. Investigations have indicated that solid colored glass filters, exhibiting optical neutrality over the spectral range from $400.0 \mathrm{~nm}$ to $700.0 \mathrm{~nm}$, would constitute an acceptable Standard Reference Material. From the various colored glass filters available, Schott NG 4 "neutral glass" was selected, prepared and characterized and is now being 


\author{
R. Mavrodineanu and J. R. Baldwin
}

This standard reference material is intended as a reference source for the calibration of the photometric scale of spectrophotometers. It consists of three individual filters. Each filter bears an identification number, and the upper left corner has been removed to indic ate correct placing in the metal holder.

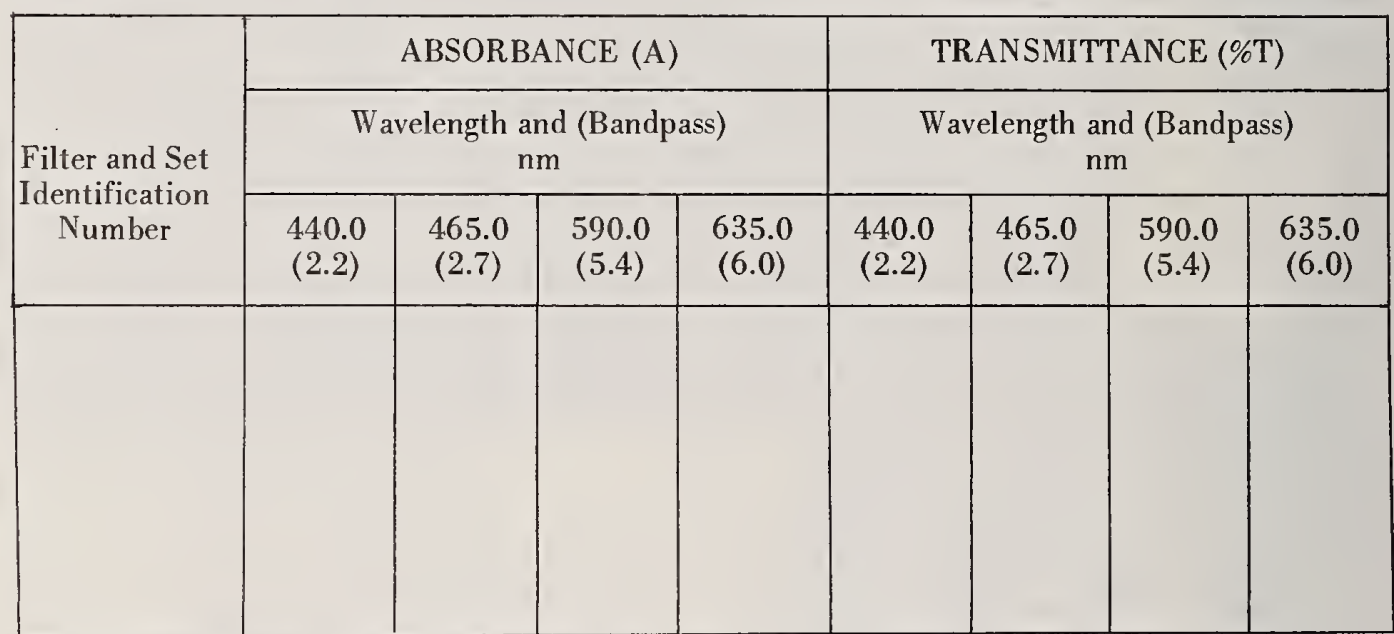

The transmittance values given are certified with a relative uncertainty of \pm 0.5 percent (example: a nominal value of absorbance of $0.500 \pm 0.0022$ ). This uncertainty is the sum of the random error of \pm 0.1 percent (2SD limit) and of estimated biases which are \pm 0.4 percent. These biases are due to possible systematic errors. Measurements were made at $24{ }^{\circ} \mathrm{C}$. Room temperature variations within several degrees Celsius of this temperature will not significantly affect the calibration of these filters.

It is recommended that the filters be handled only with soft plastic (polyethylene) gloves and optical lens tissue. When not in use they should be stored in their holders and in the box provided for this purpose. Extended exposure to laboratory atmosphere and dusty surroundings should be avoided.

The overall direction and coordination of the technical measurements leading to certification were performed under the chairmanship of O. Menis and J. I. Shultz.

The technical and support aspects involved in the preparation, certification and issuance of this standard reference material were coordinated through the Office of Standard Reference Materials by T. W. Mears.

Washington, D. C. 20234

February 24, 1971
J. Paul Cali, Chief

Office of Standard Reference Materials 
The transmittanee measurements were made with a double-beam spectrophotometer eontaining a quartz double monoehromator. The photometrie seale of the instrument is divided into 1000 divisions, each division representing 0.1 pereent transmittanee. A corresponding absorbanee seale is also provided on the instrument. The aeeuraey of the photometrie seale was eonfirmed by the high-aceuraey speetrophotometer designed and construeted at the National Bureau of Standards. The aceuraey of this instrument was cstablished by light-addition measurements.

The neutral NG-4 glass for the filters was provided by Sehott of Mainz, Germany and is designated as "Jena Colored and Filter Glass." Nominal transmittanee for a filter $1.5 \mathrm{~mm}$ thiek is 20 pereent at $400.0 \mathrm{~nm}$ wavelength and 32 pereent at $700.0 \mathrm{~nm}$ wavelength. Between these limits the transmittanee varies in a monotoncus manner [1].

The filter holder and the size and shape of the filters were seleeted to eonform to the dimensions of the sample eompartment of most eonventional speetrophotometers. The filters are approximately $1.0,1.5$, and $2.0 \mathrm{~mm}$ thiek. Corresponding to these thieknesses are nominal transmittances of 30,20 , and 10 pereent, respectively. These thieknesses were seleeted to provide a means for calibrating the photometric seale at three different levels.

The transmittanee of filters depends on the intrinsie properties of the material. Spectral bandpass, wavelength $[1,2]$, geometry of the optical beam, surface eonditions, and positioning of the filter also affeet the transmittance values, and ean lead to further biases. The eertified data will be reprodueed when transmittance measurements are made under similar eonditions. The effeetive speetral band passes used to determine the eertified values are given on the face of the eertifieate.

Prior to the eertification measurements, each filter was examined for surface defeets and thoroughly cleaned. If, through handling, the surfaee of the filter beeomes contaminated with dust, it may be eleaned with a small soft brush attached to a rubber tube connected to a vacuum source [3]. If the surface becomes eontaminated with fingerprints, they must be eliminated before making measurements. This may be accomplished by removing the filter from its holder, breathing lightly on it, and rubbing the surface gently with optical lens tissue. The clean filter is then replaced in its proper position in its holder. To remove and replace the filter in the metal holder, the spring-loaded plate should be lifted with eare to prevent damage to the filter. As little handling as possible is recommended.

NOTE: The eheek of the calibration of photometrie scales defines only one of the parameters required for obtaining aeeurate transmittanee values and molar absorptivities. Other faetors that also must be established are wavelength aeeuraey, stray light, ecll parameters, fluorescenee, polarization, reflection, and temperature eoeffieient. Some of these variables are diseussed in NBS Teehnical Notes [1]. It is planned to summarize various aspeets of accurate speetrophotometric measurements in an NBS-260 Special Publieation whieh would provide additional data on specific standard reference materials. In the interim, SRM 930, should be used as deseribed in the eertificate. Consult the manufacturer of the instrument if differenees are obtained that exceed those speeified by the manufaeturer.

We wish to acknowledge the cooperation of George N. Bowers, Jr., M.D., of Hartford Hospital, Hartford, Conneetieut; Royden N. Rand, Ph.D., of the Hospital of the University of Pennsylvania, Philadelphia, Pennsylvania; and Donald S. Young. M.B., Ph.D., of the National Institutes of Heal th, Bethesda, Maryland.

I. R. Mavrodineanu, Solid Materials to Cheek the Photometrie Seale of Speetrophotometers, NBS Tech. Note 544, O. Nenis and J. I. Shultz, ed., pp. 6-17, U. S. Government Printing Office, Washington, D. C. 20402 (Sept. 1970), ibid. NBS Teeh. Note 584, 1971 (to be issued).

2. K. S. Gibson, Speetrophotometry, NBS Cire. 484, (Sept. 1949).

3. J. R. Edisbury, Practical Hints on Absorption Speetrophotometry, Plenum Press, New York (1967). 
which accompanies these filters and which gives the absorbance and transmittance values together with certain information concerning the handling of the filters, is reproduced on pages 4 and 5 .

1. Study of Surface Properties of Filters

The transmittance data given in the certificate depend not only on the intrinsic properties of the glass, but also on the surface condition of the glass. This parameter varies with time and exposure conditions. When glass is exposed to normal room atmosphere and temperature, its surface is corroded to an extent depending on the composition, time of exposure, concentration, temperature and nature of the glass surface and acting agents. This action produces a change in the reflecting and transmitting properties of the material $[2,3,4]$. For instance, one of the factors which can produce such changes is called "blooming" of the glass which is due to the formation of an Sio layer at the surface of the glass. This layer, which increases the transmittance, acts as an antireflection coating. The speed with which such a layer is formed varies with the composition of the glass, the atmosphere and time. Generally speaking, several years are needed for a fresh surface to reach an equilibrium. This and similar phenomena are presently being studied, along with means to stabilize the surface state of glass filters. Until more information is acquired in this field, we recommend that the colored glass filters be rechecked annually to determine whether any physico-chemical changes, which might affect the transmittance values, have occurred.

Another important factor is the need for a clean

surface. Until now the final cleaning of the NG-4 filters was made with redistilled ethyl alcohol and pure water (thermally distilled and deionized). Other cleaning procedures are under consideration and the use of isopropyl alcohol in vapor or liquid form is being investigated [5]. 
2. Ultraviolet Region

The Schott NG-4 type glass now in use has a transmittance which is limited to the visible region of the spectrum. Since the ultraviolet region, from about $200 \mathrm{~nm}$, is also important to the analyst who uses spectrophotometric methods, exploratory work is underway to select and certify solid materials for checking the photometric scale in this spectral region.

3. Cooperative Study of Colored Neutral Glass Filters

A cooperative study was carried out in collaboration with three clinical laboratories to determine the reproducibility of transmittance measurements on the Schott NG-4 neutral glass filters. Three filters having nominal transmittances of 10,20 and 30 percent were measured at four wavelengths on a conventional spectrophotometer at the NBS. The same filters were then sent to laboratories $A$, $B$ and $C$ describing the technique to be used in measuring their transmittances. The results obtained are summarized in table $I$ and include the percent transmittance (\% $T$ ) values,

Table 1. Comparative \% T measurements performed by four laboratories on three Schott $\mathrm{NG}-4$ colored glass filters.

Laboratory A Measurement

\begin{tabular}{|c|c|c|c|c|c|}
\hline No. & $\begin{array}{l}\text { Ave. } \\
\text { S.D. } \\
\% \text { S.D. } \\
\text { Diff. \% }\end{array}$ & $\begin{array}{c}\frac{440 \mathrm{~nm}}{12.91} \\
0.0063 \\
.049 \\
-.4\end{array}$ & $\begin{array}{c}465 \mathrm{~nm} \\
14.99 \\
0.004 \\
.027 \\
-.07\end{array}$ & $\begin{array}{c}590 \mathrm{~nm} \\
1.68 \\
0.008 \\
.070 \\
-.6\end{array}$ & 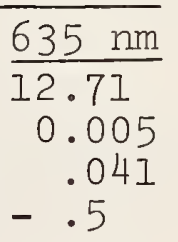 \\
\hline 2 & $\begin{array}{l}\text { Ave. } \\
\text { S.D. } \\
\% \text { S.D. } \\
\text { Diff. \% }\end{array}$ & $\begin{array}{r}19.61 \\
0.004 \\
.021 \\
-\quad .5\end{array}$ & $\begin{array}{rl}22 & .37 \\
0 . & .010 \\
& .046 \\
- & .3\end{array}$ & $\begin{array}{c}19.06 \\
0.004 \\
.022 \\
-\quad .3\end{array}$ & $\begin{array}{c}20.50 \\
- \\
- \\
-0.1\end{array}$ \\
\hline 3 & $\begin{array}{l}\text { Ave. } \\
\text { S.D } \\
\% \text { S.D. } \\
\text { Diff. } \%\end{array}$ & $\begin{array}{c}32.81 \\
0.0080 \\
.023 \\
+\quad .3\end{array}$ & $\begin{array}{c}35.44 \\
0.0080 \\
.023 \\
+\quad .2\end{array}$ & $\begin{array}{c}31.12 \\
0.0050 \\
.017 \\
+\quad .1\end{array}$ & $\begin{aligned} & 32 . 58 \\
& 0.0050 \\
& .016 \\
&+ .2\end{aligned}$ \\
\hline
\end{tabular}




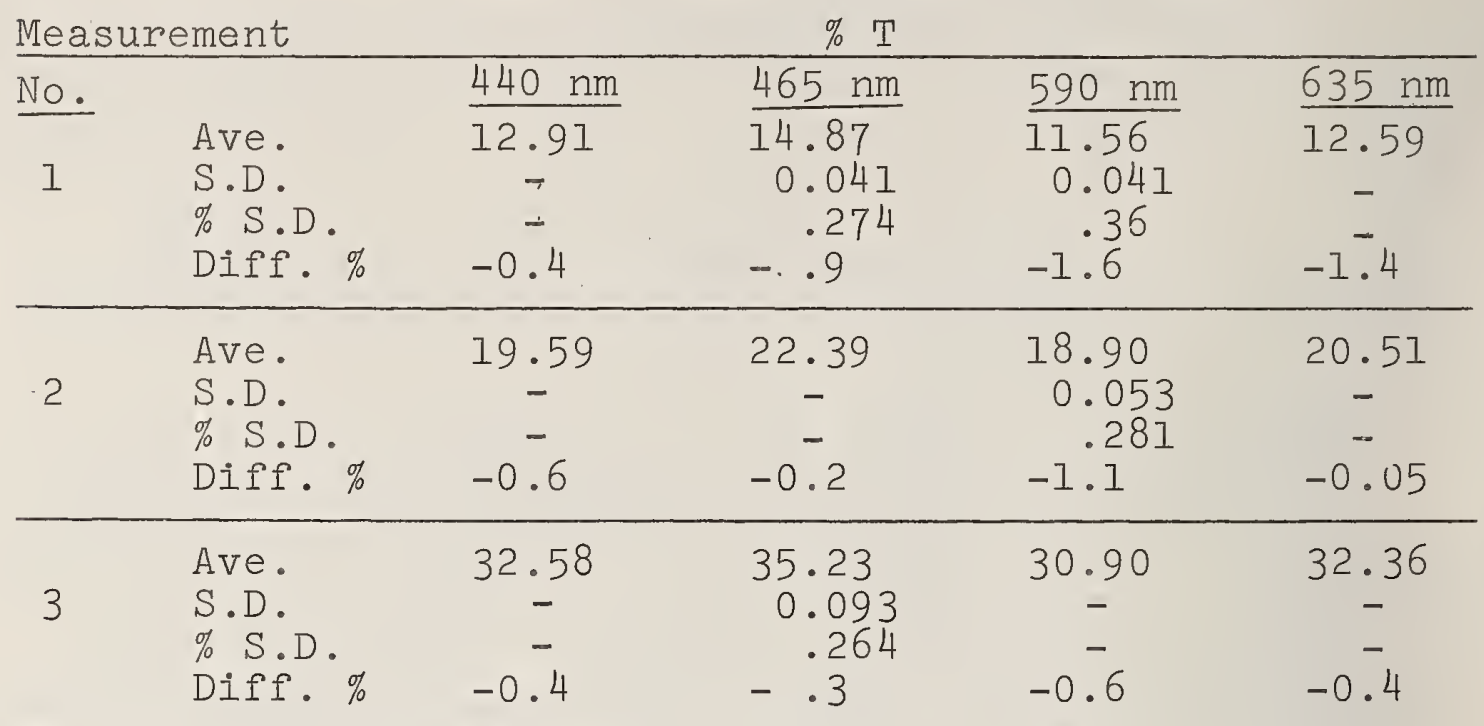

Laboratory Measurement No. 1

Ave.

S.D.

\% S.D.

Diff. \%

$\frac{\mathrm{C}}{\% \mathrm{~T}}$

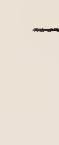

2

Ave

2 S.D.

\begin{tabular}{llc} 
& Diff. $\%$ & -0.9 \\
\hline 3 & Ave. & 32.88 \\
S.D. & - \\
\% S.D. & - \\
Diff. \% & +0.5 \\
\hline
\end{tabular}


Measurement $\%$ T

\begin{tabular}{|c|c|c|c|c|c|}
\hline No. & $\begin{array}{l}\text { Ave. } \\
\text { S.D. } \\
\% \text { S.D. } \\
\text { Diff. \% }\end{array}$ & $\begin{array}{c}\frac{440 \mathrm{~nm}}{12.96} \\
0.0053 \\
.041 \\
-\end{array}$ & $\begin{array}{c}\frac{465 \mathrm{~nm}}{15.00} \\
0.0037 \\
.024 \\
-\end{array}$ & $\begin{array}{c}590 \mathrm{~nm} \\
11.75 \\
0.0048 \\
.041 \\
-\end{array}$ & $\begin{array}{c}\frac{635 \mathrm{~nm}}{12.77} \\
0.0057 \\
.045 \\
-\end{array}$ \\
\hline 2 & $\begin{array}{l}\text { Ave. } \\
\text { S.D. } \\
\% \text { S.D. } \\
\text { Diff. } \%\end{array}$ & $\begin{array}{c}19.71 \\
0.0049 \\
.025 \\
-\end{array}$ & $\begin{array}{c}22.44 \\
0.0052 \\
.023 \\
-\end{array}$ & $\begin{array}{c}19.11 \\
0.0038 \\
.020 \\
-\end{array}$ & $\begin{array}{c}20.52 \\
0.0049 \\
.024 \\
-\end{array}$ \\
\hline 3 & $\begin{array}{l}\text { Ave. } \\
\text { S.D. } \\
\% \text { S.D. } \\
\text { Diff. \% }\end{array}$ & $\begin{array}{c}32.72 \\
0.0045 \\
.014 \\
-\end{array}$ & $\begin{array}{c}35.35 \\
0.0056 \\
.016 \\
-\end{array}$ & $\begin{array}{c}31.09 \\
0.0040 \\
.013 \\
-\end{array}$ & $\begin{array}{c}32.50 \\
0.0043 \\
.013 \\
-\end{array}$ \\
\hline
\end{tabular}

the standard deviation (S. D.), the percent standard deviation (\% S. D.), and the percent difference (\% difference). This difference was calculated using the NBS data as a reference. In this study, the cooperation of George N. Bowers, Jr., M. D., of Hartford Hospital, Hartford, Connecticut, Royden N. Rand, Ph.D., of the Hospital of the University of Pennsylvania, Philadelphia, Pennsylvania, and Donald S. Young, M.D., Ph.D., of the National Institutes of Health, Bethesda, Maryland is gratefully acknowledged.

C. Instrument Development - R. Mavrodineanu

The decision to provide solid and liquid filters to check the photometric scale of spectrophotometers implicitly required that the certified transmittance data assigned to these filters be given with a known accuracy.

Since conventional spectrophotometers cannot readily provide such information, the design and construction of a research instrument on which transmittance data could be measured with known accuracy was initiated. After a comprehensive examination of the existing literature 
in this field, (Ref. 6 to 34 arranged in chronological order) a decision was made to construct an instrument similar in design to the instrument at the National Physical Laboratories (NPL), Teddington, England, where a long tradition in high accuracy spectrophotometry exists. A visit was arranged with Dr. Frank J. J. Clarke, Head of Colorimetry and Photometry Section, Metrology Centre at NPL. During this visit, the NPL high accuracy spectrophotometer was examined in detail and work was performed with the instrument. Furthermore, detailed discussions with Dr. Clarke and his associates, Mr. G. Lambert and Anne Compton, provided valuable scientific information for use in our work.

1. Description of the NBS Instrument

The NBS high accuracy spectrophotometer is a single beam instrument which contains the following elements: (A) a constant light source, (B) a monochromator, (C) a sample holder, (D) a system to check the accuracy of the photometric data and $(E)$ an integrating sphere attached to a photomultiplier - digital voltmeter unit. Figure 2 illustrates

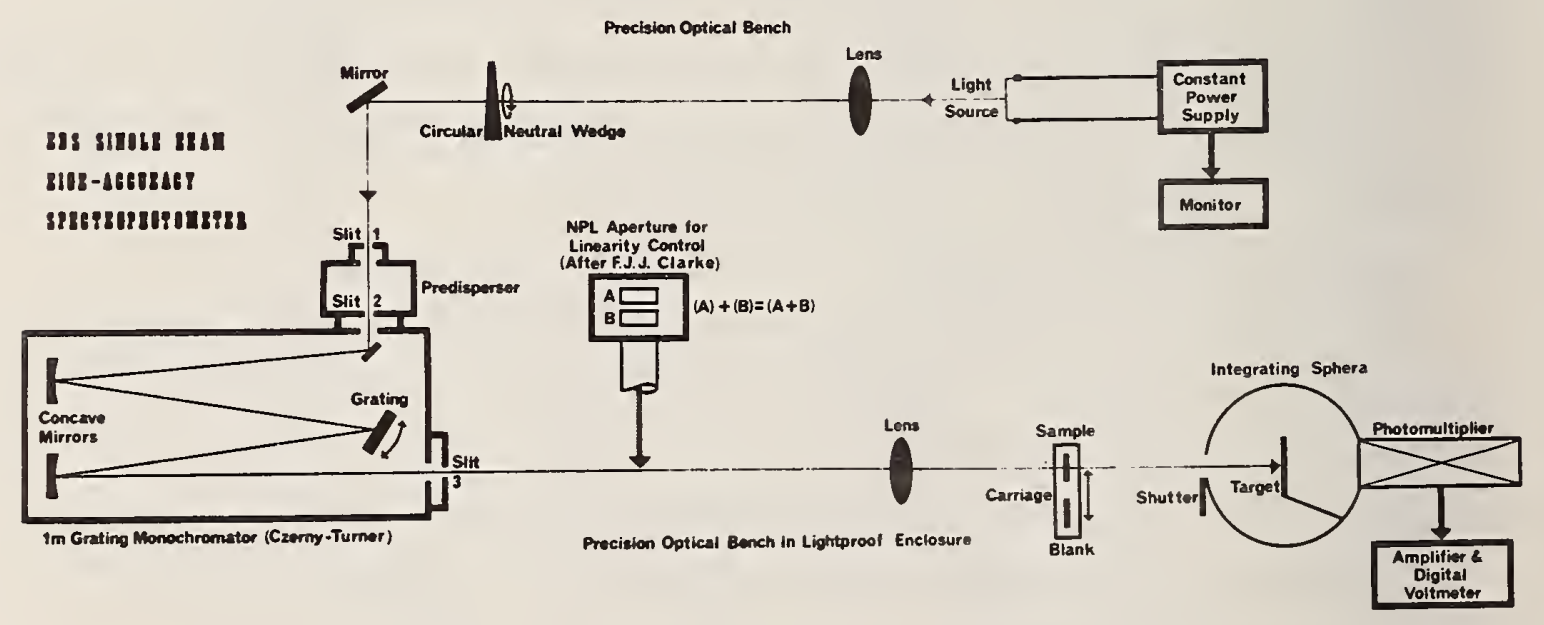

Figure 2. Schematic description of the NBS high accuracy spectrophotometer. 
schematically the arrangement of these various components. A neutral wedge is placed after the light source to select various levels of radiation intensities required for measurements. A description of the components is presented in the following sections.

a. The Light Source. Since the instrument is a single beam type it is essential that the radiation source be constant and homogeneous. Additional desirable conditions are: (1) capability of monitoring the current supplied to the source and (2) black-body type radiation. The source which was selected was designed and used at NBS by H. J. Kostkowski and R. D. Lee of the Institute for Basic Standards in their radiation studies. This source was duplicated in our instrument with considerable assistance from its developers.

The source corsists of a tungsten incandescent filament lamp and includes a tungsten ribbon $8 \mathrm{~mm} \times 2 \mathrm{~mm}$. The current used to operate this lamp at approximately $3000^{\circ} \mathrm{K}$ is $6 \mathrm{~V}$ and $18 \mathrm{amp}$; our source is operated at $5 \mathrm{~V}$ and $13 \mathrm{amp}$. The power supply is capable of delivering $15 \mathrm{~V}$ and $50 \mathrm{amp}$, when operated in the constant current mode. To achieve this mode of operation, an external sensing resistor of $0.1 \Omega$ and 50 amp and a current control circuit is placed in series with the supply. A feedback across this resistor is connected to the power supply sensing system. The characteristic of this operation is the ability to automatically change its output voltage so as to maintain a constant current to the load resistor, which, in our case, is the lamp source. The nominal current regulation obtained is better than 0.01 percent and the stability over an 8 hour period, at constant load temperature, is better than 0.02 percent. The stability of the current delivered to the lamp is monitored with a high accuracy potentiometer having a range from 0 to $1.6110 \mathrm{~V}$ to 0 to $0.16110 \mathrm{~V}$ and a corresponding limit of error of \pm 0.01 percent $\pm 20 \mu \mathrm{V}$ to 0.015 percent 
$\pm 0.5 \mu \mathrm{V}$. This potentiometer is used in conjunction with a null meter which is sensitive to variations in the current supplied to the lamp from 1 part in 1000 to 1 part in $1,000,000$ per division. The potentiometer is connected to the current source across a resistor of $0.01 \Omega$ and $100 \mathrm{amp}$, and placed in series with the lamp.

The demagnified (2 to 1 ) image of the ribbon filament is projected on the entrance slit of the predisperser by a glass achromate whose focal distance is $254 \mathrm{~mm}$ and diameter is $44 \mathrm{~mm}$. This achromate, as well as the other two achromates used in the optical system, was calculated and selected by K. Mielenz, of the Institute for Basic Standards. A circular neutral wedge is placed between the light source and the predisperser. This wedge, evaporated Inconel on a glass disk ( $150 \mathrm{~mm}$ diam.), is linear in density and provides a light attenuation of 100 to 1 . The wedge can be rotated by an electrical motor ( $I \mathrm{rev}$. per sec) to select proper radiation intensity levels as required by the measurements.

b. The Monochromator. The monochromator is a l-m Czerny-Turner type grating instrument. The flat grating has 1200 grooves per $\mathrm{mm}$ over a surface of $100 \times 100 \mathrm{~mm}$. The monochromator is provided with a predispersing attachment to reduce the stray light. This predisperser is a small quartz prism monochromator connected to the scanning system of the I-m instrument. According to the data provided by the manufacturer, the stray light of the predisperser-monochromator unit is less than I part in 10,000,000. A wavelength counter permits readings to $1 \mathrm{~A}$ and the scanning speed can be varied from 0.5 to $2000 \AA / m i n$ through a 12 speed synchronous electric motor.

The optical components are placed on precision lathebed type optical benches, 120 and $160 \mathrm{~cm}$ long, and are equipped with appropriate carriers provided with $x-y-z$ adjustments. 
c. Sample Carrying Unit. The sample carrying unit consists of a platform provided with two holders which can accept $3 / 4$ in. rods and a variety of sample supports. These holders can be moved laterally through a rack and pinion arrangement. The platform is mounted on 4 ball bushings which run on two horizontal rods and can be moved pneumatically across the optical axis. The use of a pneumatically operated motion was recommended by G. E. Moore and J. T. Sterling of the Institute for Applied Technology and by L. Owen. The total travel is $8 \mathrm{in}$. and the linear movement is smooth. The position of the platform can be reproduced within $0.025 \mathrm{~mm}$. This unit is illustrated in figure 3 and is located between the two achromates. The sample holder is designed to accept conventional solid or liquid filter holders which fit most spectrophotometers. The holders are provided with a thermostated jacket.

\section{d. System to Check the Accuracy of the Photometric}

Reading. Since the high accuracy spectrophotometer is single beam, accurate photometric data are obtained when there is a linear relation between the radiation flux and the corresponding response of the photodetector.

Linearity of photodetectors can be measured by several means: the inverse square law $[8,16]$, the use of optical elements having a known transmittance which can be determined by other means [18] and the light addition principle using a plurality of light sources $[6,7,9,10,11,14,19,20,21$, $29,32,33,34]$ or multiple apertures $[12,13,15,17,22$, $24,26,27,28,31]$. A novel approach to the problem of accurate photometric measurements was described by 0 . C. Jones and F.J.J. Clarke $[25,30]$. A critical discussion of some aspects of accurate spectrophotometry will be found in an NBS manuscript by Gibson and Associates [23]. The light addition principle, using two apertures with one source of radiation, was chosen in our work. The aperture method for checking the linearity of photometric data was used in 1936 at the 


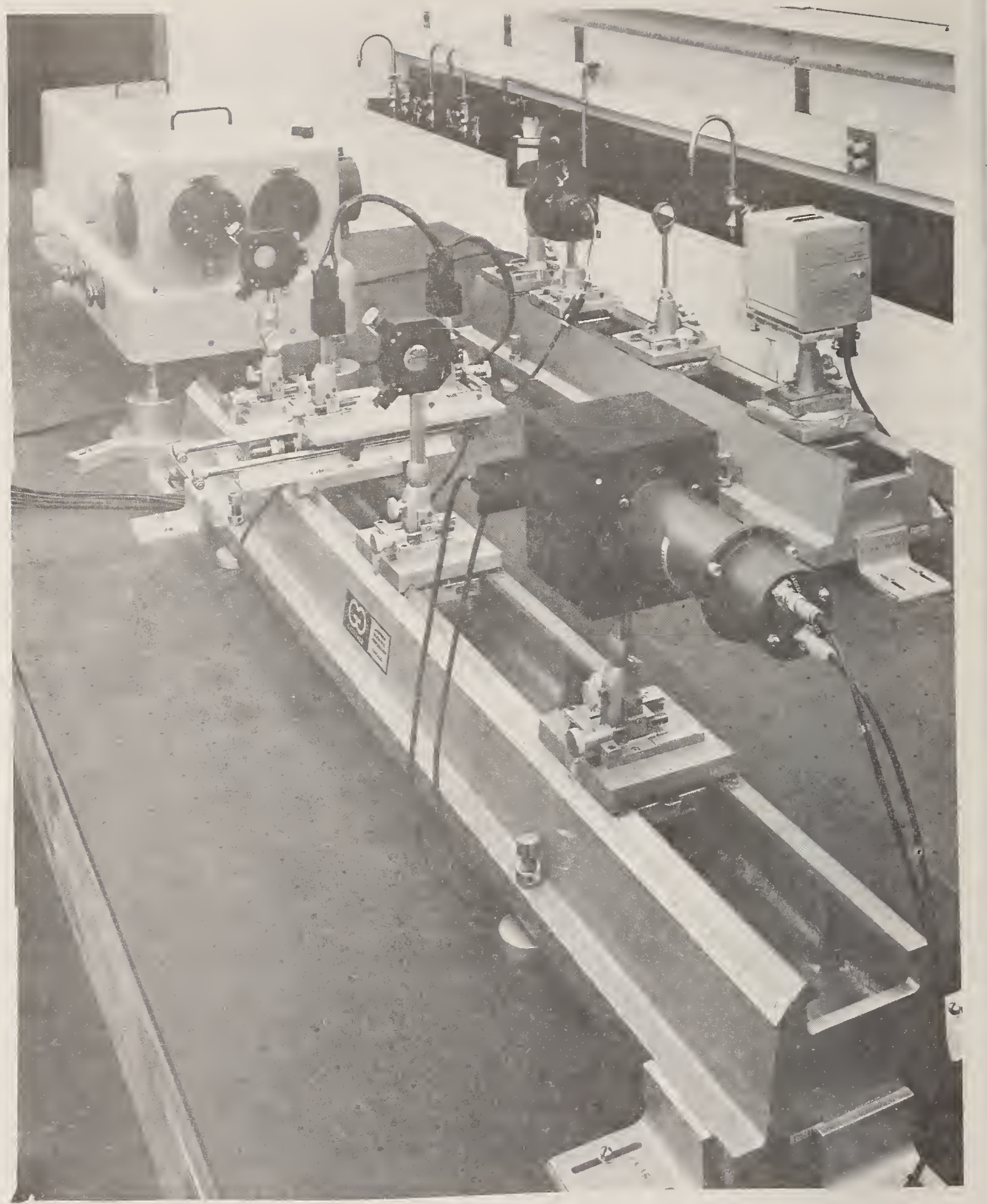

Figure 3. NBS high accuracy spectrophotometer. At right, the light source, at upper left, the Im monochromator The optical bench at the exit slit of the monochromator carries an achromate; the sample platform; a second achromate followed by the integrating sphere and photomultiplier assembly. 
NPL by Preston and Cuckow [12] in conjunction with a single beam spectrophotometer, employing a five-aperture screen. One year later, Buchmüller and König [13] described and used, among others, a two-aperture unit. At NBS, Barbrow [15] used a ten-aperture arrangement, while Harding [17] and Cordle and Habell [26] at the NPL described a two-aperture system. Multiapertures were used by Hoppman [22], Bischoff [24], Sanders [27] and Nonaka and Kashima [28]. Finally, Clarke [31] discussed in detail the use of a twoaperture system to check the accuracy of photometric data obtained on his spectrophotometer at NPL. It is this system which was reproduced and used at NBS.

The two-aperture unit consists of a metal plate (130 $\mathrm{mm}$ by $100 \mathrm{~mm}$ ) containing 2 rectangular windows, $A$ and $B$, (20 mm by $8 \mathrm{~mm}$ ) located one above the other. Each aperture can be closed by a light-tight shutter which is operated pneumatically by remote control. The aperture plate is placed in the optical path after the exit slit of the monochromator and within the optical solid angle of the instrument. The image of the apertures is then projected on the target of the integrating sphere. A glass achromate with a focal distance of $190 \mathrm{~mm}$ and a diameter of $60 \mathrm{~mm}$ is used for this purpose. The arrangement is illustrated in figure 4. No optical element should be placed between the aperture plate and the monochromator. The linearity check consists of measuring the photocurrent produced when aperture $A$ is open, then closed and then aperture $B$ is open and then closed. The value of $A+B$ is then compared with the values obtained with both apertures $(A+B)$ open. If the system is linear (or accurate) these two values should be identical:

$$
(A)+(B) \equiv(A+B)
$$

If this is not the case, the system shows nonlinearity which is proportional to the amount by which the sum of 


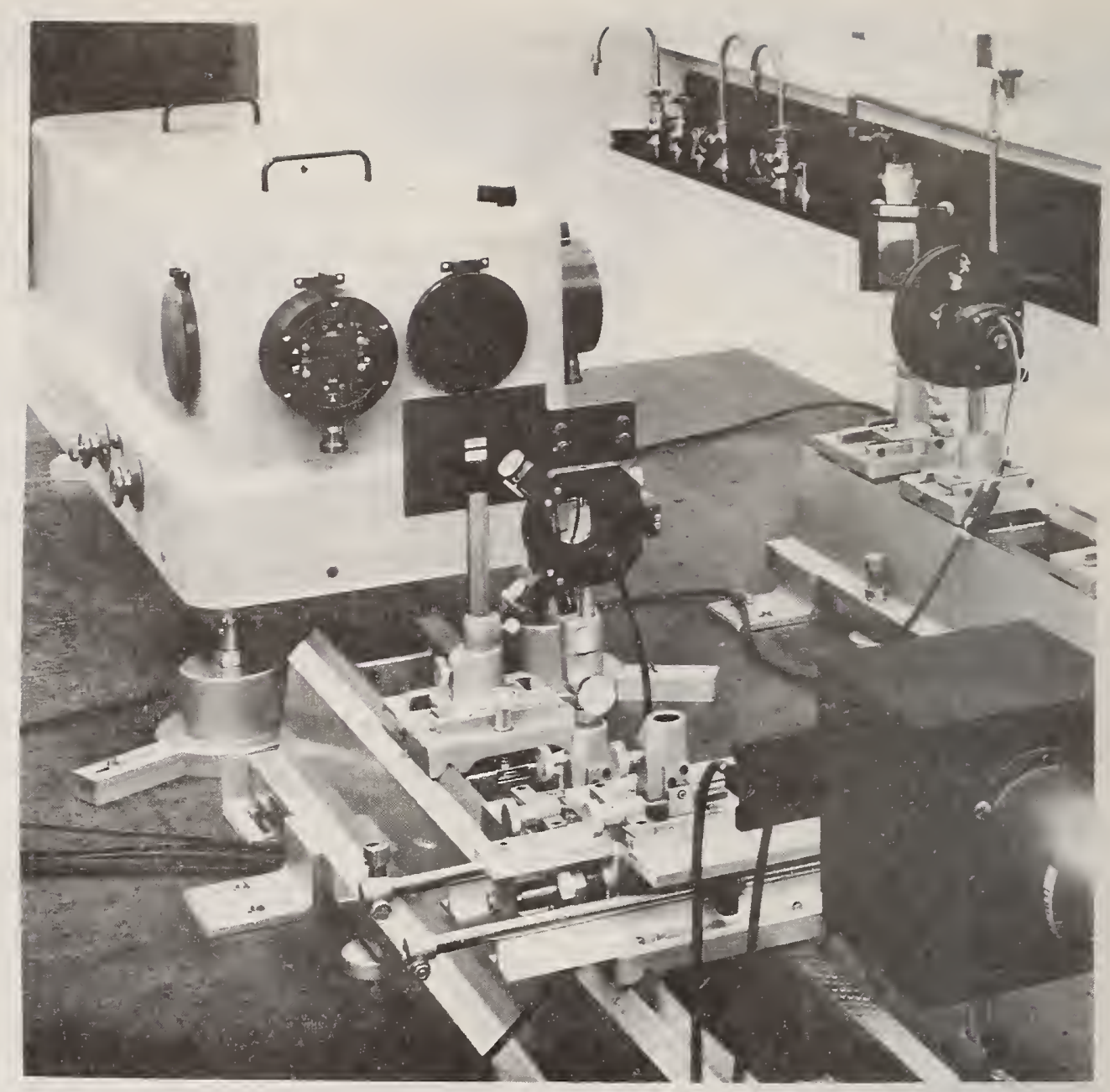

Figure 4. NBS high accuracy spectrophotometer. Same arrangement as in figure 3 except for the aperture system which is now placed after the exit slit of the monochromator. This arrangement is used when making linearity measurements.

$(A)+(B)$ differs from $(A+B)$. This difference is then used to correct the transmittance values measured on the solid or liquid filters.

e. Integrating Sphere and Photomultiplier Arrangement. Radiations are passed through the aperture or the filter and are then received on the target of the integrating sphere. This sphere is illustrated in figures 3 and 4 . A rectangular block of aluminum made from identical halves was cut to produce a half sphere in each half block. Then the halves were joined together to form the hollow sphere. Its 
diameter is $125 \mathrm{~mm}$. A target made from a circular plate $35 \mathrm{~mm}$ in diameter, is located at the center of the sphere. The front surface of the sphere has a $20 \mathrm{~mm}$ diameter entrance opening which can be closed by a shutter that is operated remotely by a pneumatic system. A $50 \mathrm{~mm}$ diameter opening is at the opposite end to which the housing of the photomultiplier is attached by an "O" ring to provide a lighttight joint. The inside of the sphere is coated with a suspension of $\mathrm{BaSO}_{4}$; the outside is painted black ( 1 percent reflection).

The photomultiplier is a $50 \mathrm{~mm}$ flat-faced, end quartz window tube with a $44 \mathrm{~mm}$ cathode and 11 venetian blind dynodes having CsSb secondary emitting surfaces. The cathode is identified as $\mathrm{S}-20$ or tri-alkali type. The spectral range of this tube is from below $200.0 \mathrm{~nm}$ to $850.0 \mathrm{~nm}$. The operating voltage is $850 \mathrm{~V}$. The photomultiplier output is supplied to an operational amplifier and a series of high precision resistors rated at $10^{6}, 3 \times 10^{6}$, $10^{7}, 3 \times 10^{7}$ and $10^{8} \Omega$. A dark current compensation is also available. The output from the amplifier-resistors unit is supplied to a $10^{-5} \mathrm{~V}$ digital voltmeter. This electronic system was designed and assembled at NBS by R. J. Carpenter and K. W. Yee.

The optical components located after the exit slit of the monochromator, including the photomultiplier tube, are enclosed in a light-tight box $200 \mathrm{~cm}$ long, $70 \mathrm{~cm}$ wide and $76 \mathrm{~cm}$ deep. The front panel, which is removable, is provided with a sliding door to permit rapid access to the filter-holder system. The box contains outlets for the compressed air which operates the apertures, sample carriage and integrating sphere shutter, and the electrical connection from the photomultiplier. The inside walls are lined with thermal insulation painted black. When in use, all non-black metal parts are covered with a black cloth to reduce stray light. 
D. Experimental Results

The stability of the electronic system was determined with a tritium-activated phosphor. Because tritium has a long half-life ( 12.5 years), the light output is considered stable. This source was placed in front of the integrating sphere and four series of 20 measurements each were made. The average values obtained over a $10 \mathrm{~min}$ period were: $1.1340_{2} \mathrm{~V} ; 1.1342_{1} \mathrm{~V} ; 1.1342_{0} \mathrm{~V} ; 1.1342_{2}$ V. From these values it can be concluded that the stability of the photomultiplier tube, with its electronics, is better than 1 part in 10,000. When the ribbon filament lamp was used after a 2 hour warm-up, the measurements indicated a stability of several parts in 10,000.

The linearity of photometric data is a function of the photomultiplier, the voltage supplied, the load resistor and the amplifier. The wavelength at which the measurements are made is not critical.

A series of linearity measurements were made using $850 \mathrm{~V}$ at the photomultiplier and the $3 \times 10^{6} \Omega$ resistor. The results, expressed as a percent correction of the transmittance percent, indicate that a correction of -0.15 should be made at 50 percent transmittance, -0.22 at 25 percent transmittance, and -0.26 at 12.5 and 6.25 percent transmittance values. Interpolation between these values provides the correction at other transmittance values. In our work, linearity measurements were made at a wavelength of $560.0 \mathrm{~nm}$. A series of transmittance measurements were made on three Schott NG-4 filters having nominal transmittances of 10 , 20 and 30 percent. The optical arrangement used for the measurements is described in figure 3. The image of the exit slit (about $10 \mathrm{~mm}$ by $1.5 \mathrm{~mm}$ ) was projected at the surface of the filter and in its center. After passing through the filter, the radiations are projected on the target of the integrating sphere. The other parameters, 
such as photomultiplier voltage, resistor value, amplifier gain, and light source output, were the same as those used in the linearity measurements.

The transmittance measurements are made by determining the average voltage reading by the digital voltmeter which corresponds to the unattenuated radiation intensity, $I_{0}$, and corresponding to the attenuated radiation after passing through the filter, I. The ratio $\frac{I_{1}}{I_{0}}$ is the uncorrected transmittance of the filter at the selected wavelength. To minimize the inevitable variations during the measurements, a successive series of Io and I data are collected, averaged and ratioed. Such a series of data is illustrated in table 2. These transmittance measure-

\begin{tabular}{|c|c|c|c|c|c|}
\hline \multirow{2}{*}{$\begin{array}{l}\text { Table } 2 . \\
\text { Wavelength } \\
\text { nm }\end{array}$} & \multicolumn{3}{|c|}{$\begin{array}{l}\text { ransmittance measurements } \\
\text { G-4 glass filter with the } \\
\text { ccuracy spectrophotometer } \\
\text { Temperature }=23.50{ }^{\circ} \mathrm{C}\end{array}$} & \multicolumn{2}{|c|}{$\begin{array}{l}\text { on a Schott } \\
\text { NBS high }\end{array}$} \\
\hline & $I_{0}$ & I & $I_{0}$ & I & $I_{0}$ \\
\hline 440.0 & $\begin{array}{l}2.0030 \\
2.0015\end{array}$ & $\begin{array}{r}0.6620 \\
.6625\end{array}$ & $\begin{array}{l}2.0010 \\
2.0028\end{array}$ & $\begin{array}{r}0.6620 \\
.6630\end{array}$ & $\begin{array}{l}2.0010 \\
2.0045\end{array}$ \\
\hline 465.0 & $\begin{array}{l}2.0040 \\
2.0050\end{array}$ & $\begin{array}{l}.7156 \\
.7150\end{array}$ & $\begin{array}{l}2.0022 \\
2.0015\end{array}$ & $\begin{array}{l}.7150 \\
.7160\end{array}$ & $\begin{array}{l}2.0015 \\
2.0045\end{array}$ \\
\hline 590.0 & $\begin{array}{l}2.0028 \\
2.0048\end{array}$ & $\begin{array}{l}.6274 \\
.6275\end{array}$ & $\begin{array}{l}2.0047 \\
2.0028\end{array}$ & $\begin{array}{l}.6282 \\
.6270\end{array}$ & $\begin{array}{l}2.0067 \\
2.0050\end{array}$ \\
\hline 635.0 & $\begin{array}{l}2.0060 \\
2.0055\end{array}$ & $\begin{array}{l}.6570 \\
.6568\end{array}$ & $\begin{array}{l}2.0070 \\
2.0068\end{array}$ & $\begin{array}{l}.6573 \\
.6570\end{array}$ & $\begin{array}{l}2.0080 \\
2.0080\end{array}$ \\
\hline & & & & & \\
\hline
\end{tabular}
Average Average uncorrected corrected $I_{0} \quad I$

$\begin{array}{rrrrr}440.0 & 2.0023 & 0.6624 & 33.08 & 32.99 \\ 465.0 & 2.0031 & .7154 & 35.71 & 35.62 \\ 590.0 & 2.0045 & .6275 & 31.30 & 31.21 \\ 635.0 & 2.0069 & .6570 & 32.74 & 32.65\end{array}$


ments were repeated over a period of several weeks, using the same three filters. The summary of the results is given in table 3. Another series of transmittance measurements was made using another $\mathrm{NG}-4$ filter whose nominal transmittance is 30 percent. The results were compared with similar measurements made on a conventional spectrophotometer (see table 4). An average bias of $+0.23_{5}$ relative percent was found.

Table 3. Repeatability of \% T measurements performed with the NBS high accuracy spectrophotometer on three colored glass filters.

Wave-

length

$\mathrm{nm}$

Filter 10

$\% \mathrm{~T}$

Filter 20

$\% \mathrm{~T}$

Filter 30

$440.0 \quad 11.6211 .62 \quad 11.62$

$465.0 \quad 13.57 \quad 13.58 \quad 11.60$

$590.0 \quad 10.38 \quad 10.38 \quad 10.39$

19.8319 .8219 .91

22.6322 .5922 .69

$19.16 \quad 19.16 \quad 19.27$

$\% \mathrm{~T}$

$635.0 \quad 11.37 \quad 11.31 \quad 11.40$

Averages

440.0

465.0

590.0

635.0

11.62

13.58

10.38

11.36
Averages

19.85

22.63

19.20

20.63 $\begin{array}{llll}32.98 & 32.97 & 32.99\end{array}$

35.6635 .6735 .62

$31.1931 .18 \quad 31.21$

32.6132 .6132 .65

Table 4. Comparison of \% T measurements performed on a

Averages

32.98

35.65

31.19

32.62

\section{Schott NG-4 filter using the NBS high accuracy
instrument and a conventional spectrophotometer
provided with a quartz prism double monochromator \\ Schott NG-4 filter using the NBS high accuracy
instrument and a conventional spectrophotometer
provided with a quartz prism double monochromator \\ Schott NG-4 filter using the NBS high accuracy
instrument and a conventional spectrophotometer
provided with a quartz prism double monochromator in a double beam arrangement.} in a double beam arrangement.

$\begin{array}{cccccc}\begin{array}{l}\text { Wave- } \\ \text { length } \\ \text { nm }\end{array} & \begin{array}{c}\text { NBS } \\ \text { Instrument }\end{array} & \begin{array}{c}\text { Conventional } \\ \text { Instrument }\end{array} & \text { Diff. } & \begin{array}{c}\text { Relative } \\ \text { Diff. }\end{array} & \begin{array}{c}\text { Average } \\ \text { Relative } \\ \text { Diff. }\end{array} \\ 440.0 & 32.82 & 32.75 & +0.07 & +0.20 & \\ 465.0 & 35.51 & 35.40 & +.11 & +.30 & +0.23 \\ 590.0 & 30.98 & 30.93 & +.05 & +.16 & \\ 635.0 & 32.38 & 32.32 & +.06 & +.18 & \end{array}$


The data on the high accuracy spectrophotometer at NPL, as well as at NBS, are made by visual averaging and manual transfer. Such a method has bias which depends, among others, on the experience of the operator. This type of bias can be eliminated if the data acquisition is made through a computer interfaced with the digital voltmeter. In this manner many readings can be taken over a predetermined time interval and then averaged. A statistical evaluation of each set of results can also be obtained simultaneously. The design of such a computer data system was completed and the hardware procured. The use of this non-bias procedure to acquire and process the information given by the NBS high accuracy spectrophotometer was started during the early part of 1971 .

The optical components used in the present instrument are made of glass. This initial choice limits the use of the instrument to the visible part of the spectrum $(380.0 \mathrm{~nm}$ to $800.0 \mathrm{~nm})$. This spectral range will be extended to the ultraviolet region by providing a quartz optical system. E. Studies of Liquid Filters as Potential Absorbance Standards - R. W. Burke and E. R. Deardorff

A program involving the investigation of various liquid filters as potential absorbance standards was described in NBS Technical Note 544 [I]. Three types of filters were identified: ( 1 ) individual solutions of inorganic salts, (2) composite mixtures and (3) solutions of inorganic dyes. During the past year, additional studies were undertaken on each type of filter.

1. Solutions of Inorganic Salts

The need for ultraviolet absorbance standards, especially by clinical chemists, resulted in a critical investigation of the acidic potassium dichromate system. The results of this study are described in a subsequent section of this report. 
Additional studies on cobalt(II) solutions in sulfate and perchlorate media verified our earlier finding that the apparent molar absorptivity obtained in $0.1 \mathrm{M} \mathrm{H}_{2} \mathrm{SO}_{4}$ is higher than that observed for $0.1 \mathrm{M} \mathrm{HClO}_{4}$ solutions $\left(\varepsilon_{513}=4.88\right.$ and 4.82 liter mole $\mathrm{cm}^{-1}$, respectively). Similar behavior was observed for nickel(II) solutions (table 5). This enhancement is probably produced by the

Table 5. Apparent molar absorptivity of nickel(II) solutions at $25^{\circ} \mathrm{C}$.

\begin{tabular}{|c|c|c|c|}
\hline Solution & $\mathrm{pH}$ & $\lambda_{\max .}, \mathrm{nm}$ & $\varepsilon$, liter mole $\mathrm{cm}^{-1} \mathrm{~cm}^{-1}$ \\
\hline $\mathrm{NiSO} \overline{S O}_{4}-\mathrm{H}_{2} \mathrm{SO}_{4}$ & $\overline{1}$ & 394 & 5.17 \\
\hline $\mathrm{Ni}\left(\mathrm{ClO}_{4}\right)_{2}-\mathrm{HClO}_{4}$ & 1 & 394 & 5.11 \\
\hline
\end{tabular}

formation of aquo-metal-sulfate complexes. The cobalt and nickel solutions were prepared from metal shot (spectrographic purity $\geq 99.9$ percent).

Absorbance studies on potassium nitrate solutions showed that this system exhibits negative deviations from Beer's Law with increasing potassium nitrate concentrations. At $302 \mathrm{~nm}$, the apparent molar absorptivity of a solution containing approximately $2.8 \mathrm{~g} \mathrm{KNO}_{3}$ /liter was 7.20 liter mole $\mathrm{cm}^{-1}$ while, at a concentration of $14.0 \mathrm{~g} \mathrm{KNO}_{3} /$ liter a value of 7.11 liter mole $\mathrm{cm}^{-1}$ was obtained. Edisbury [35] has given 7.04-7.20 for the range of literature values. The non-conformity of this system to Beer's Law undoubtedly accounts for part of this disparity.

2. Composite Mixtures

The preparation and spectral properties of two empirical solutions (NBS composite and Thomson [36] solution) was discussed previously [1]. Each of these solutions exhibits a high degree of optical neutrality throughout the visible and near ultraviolet regions. Because of their neutrality, 
they are potentially useful for calibrating a wide variety of automated, flow-type spectrophotometers. During the past year, ampoules of these solutions were prepared and distributed to five clinical laboratories for evaluation (figure 5). Absorbance measurements were requested over a

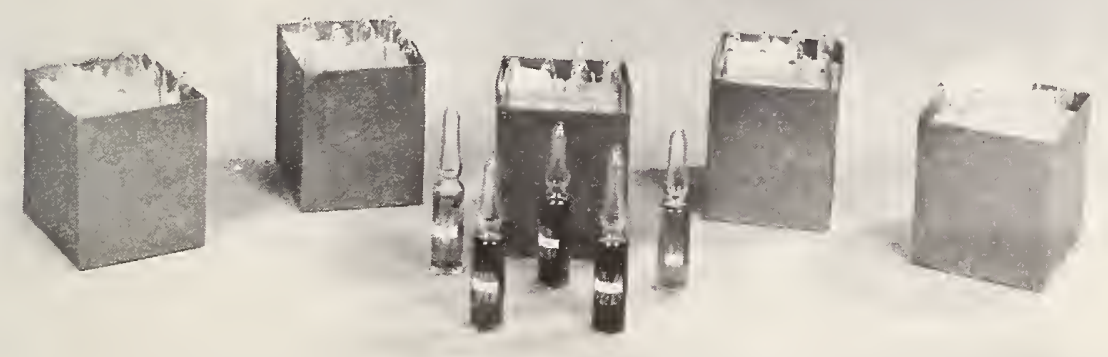

Figure 5. Ampouled filters now undergoing evaluation in cooperating clinical laboratories.

period of four months. The instructions and data sheets provided with the filters are reproduced in table 6 .

Although the final results have not been received, preliminary data indicate absorbance variations as large as 1 percent. The spectral instability of chromium(III) ion which is present in these two composite solutions is primarily responsible for these variations. Studies are continuing on ways for improving the stability of chromium(III) solutions. The principal variables being examined are the effects of refluxing, acidity and choice of complexing anions (see previous report [1] for some typical results).

\section{Organic Dyes}

On the basis of the previous study [1], three watersoluble organic dyes - Cibalan Black, Neolan Elack and Alizarin Light Grey - were selected for purification and fur- 
ther evaluation. Members of the Organic Chemistry Section have provided expertise in attempting to purify these materials. Relatively pure samples of each have been prepared on a milligram scale, but attempts to prepare gram quantities have not been successful. A procedure recently developed for the purification of Alizarin Light Grey, however, shows promise of yielding larger amounts of the dye. The crude material is dissolved in dimethylformamide, filtered twice through whatman No. 1 paper and precipitated with diethyl ether. A red impurity, estimated to be 15-20 percent of the original material, has been isolated by a Soxhlet extraction of the crude material with methanol. Work on this procedure is continuing so that a well-characterized material may be prepared.

Table 6. Format of the interlaboratory evaluation of two liquid filters, designated $\mathrm{T}$ and NBS, as potential absorbance standards.

Instructions for Use:

All absorbances are to be measured against an air reference at $25 \pm 1{ }^{\circ} \mathrm{C}$ in a covered, rectangular, 1.000cm quartz cuvette. When a cuvette has been selected, mark it so that a given orientation can be maintained, and use this cuvette for all subsequent measurements. Include any additional information regarding exact Path length of the cuvette under "comments" on the data sheets. Wavelength Calibration:

Use the holmium oxide filter enclosed to check the accuracy of your wavelength scale. If your maxima are different from the accepted values, change your dial settings accordingly (interpolate where necessary) so that the wavelengths requested on the data sheets are correct to $\pm 1 \mathrm{~nm}$. 
Slit Width:

For each wavelength, use the minimum slit width commensurable with the sensitivity and stability of your spectrophotometer. Also, please enclose with your first set of results a copy of the manufacturer's dispersion data.

Absorbance Measurements:

A minimum of two independent absorbance measurements are requested at each wavelength on successive aliquots of both the distilled water and the samples. Record these duplicate values on the data sheets. Check zero (air vs air) before each measurement.

DATA SHEET A

Date Received:

Date Measured:

Absorbances Obtained on Receipt (Within One Week)

Spectrophotometer Make and Model, including attachments:

Wavelength Calibration:

$\begin{array}{llllllll}\lambda_{\max } \text { (accepted), nm } & 536 & 452 & 418 & 361 & 334 & 279 \\ \lambda_{\max } \text { (found), } \mathrm{nm} & & & & & & \end{array}$

Thomson Solution (Labeled T)

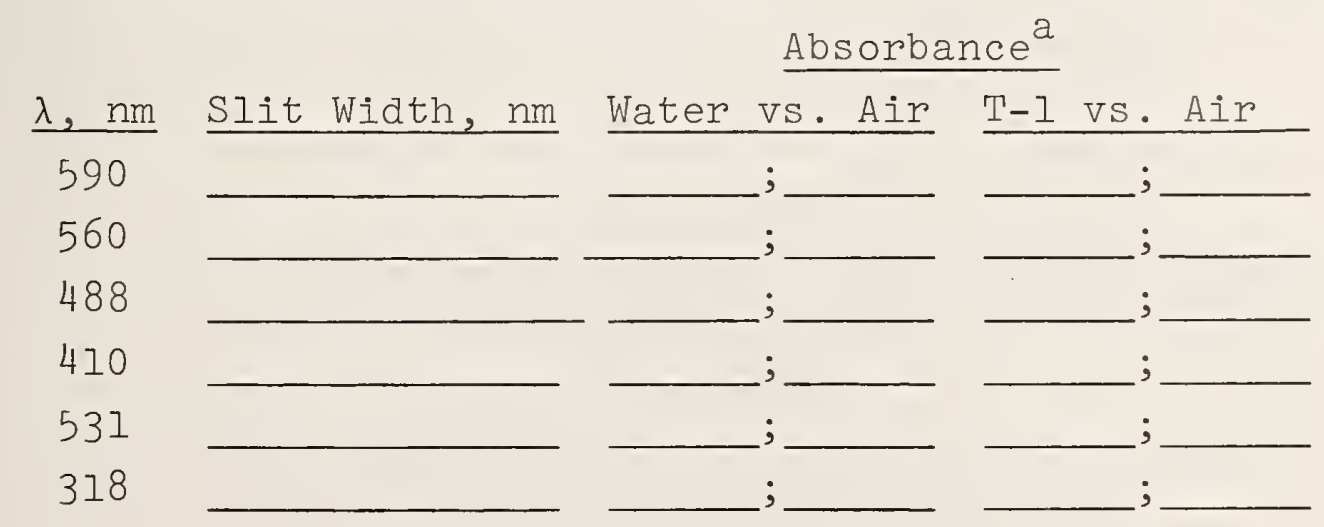

ampoules are prescored immediately beneath gold bands to facilitate opening. Disposable pipettes are recommended for rinsing and transferring samples into cuvettes. 
DATA SHEET A

Date Measured:

Absorbance Values

NBS Solution: Set 11- Green Tip Ampoules

Slit

$\lambda$, Width Dist. Water

$\mathrm{nm}$ nm

vis. Air

$\underline{\text { NBS }-1}$

Samples vs. Air

540
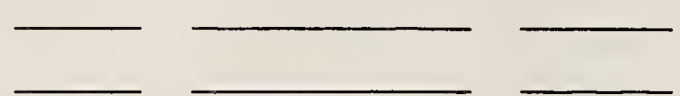

$\underline{N B S-2}$

NBS -3

$\underline{N B S-4}$

475
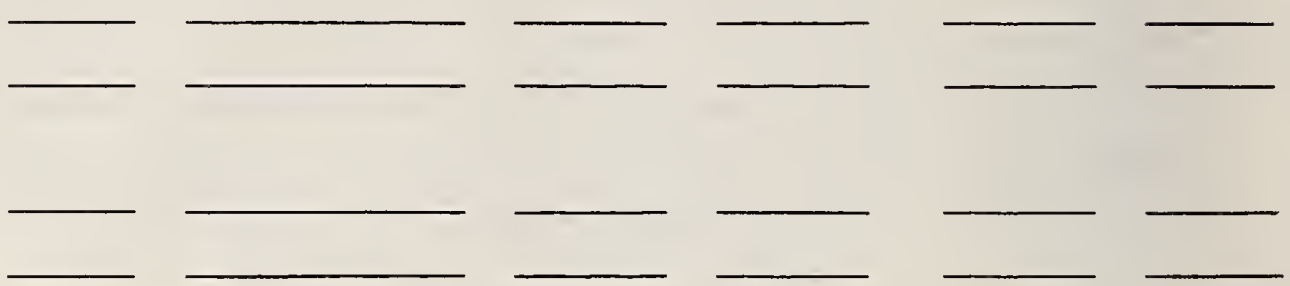

415
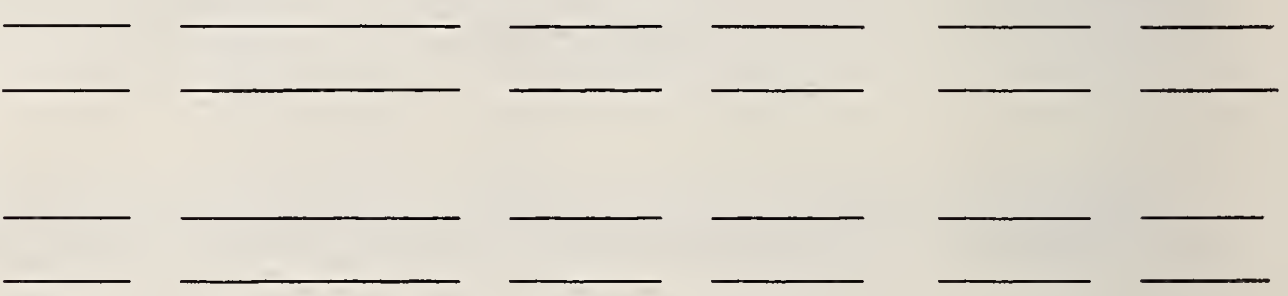

365
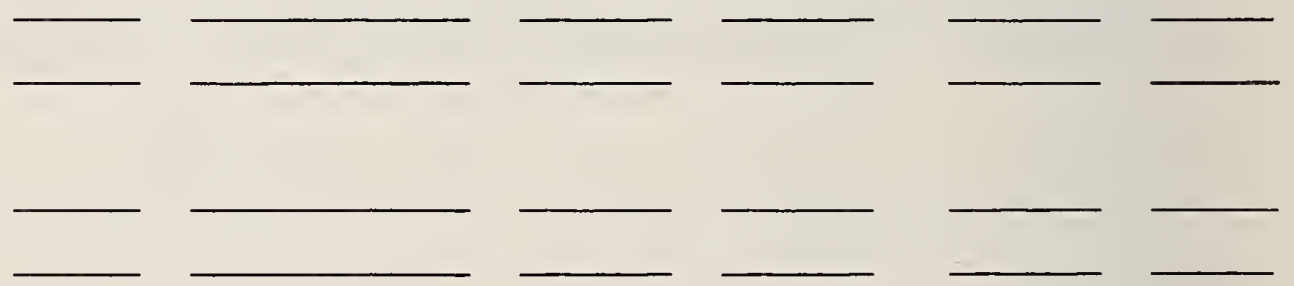

320
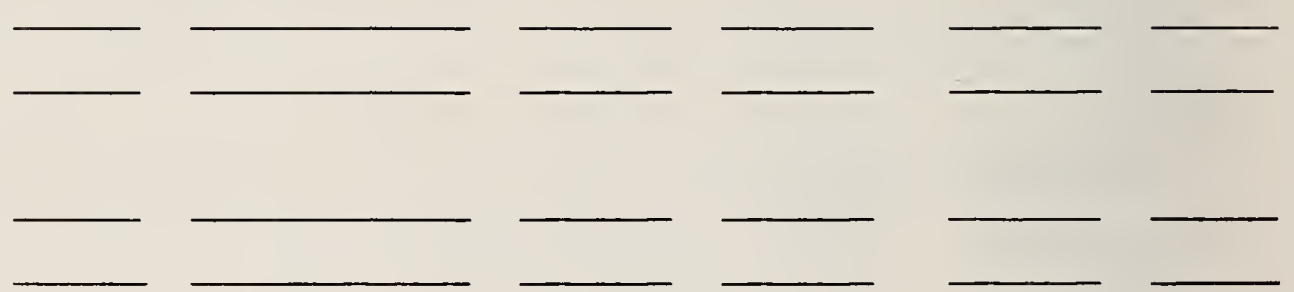

263
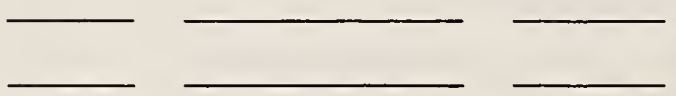

NBS Solution: Set I - Green Tip Ampoules 
Potasisum Dichromate Solution, 40 and $80 \mathrm{mg} /$ liter; pH $\sim$ in Perchloric Acid:

Slit

Width. Dist. Water

350

313

257

$$
\text { vs. Air }
$$

vs. Air ${ }^{\mathrm{m}}$

$\overline{\mathrm{pH}}$

VS.Air $m g$

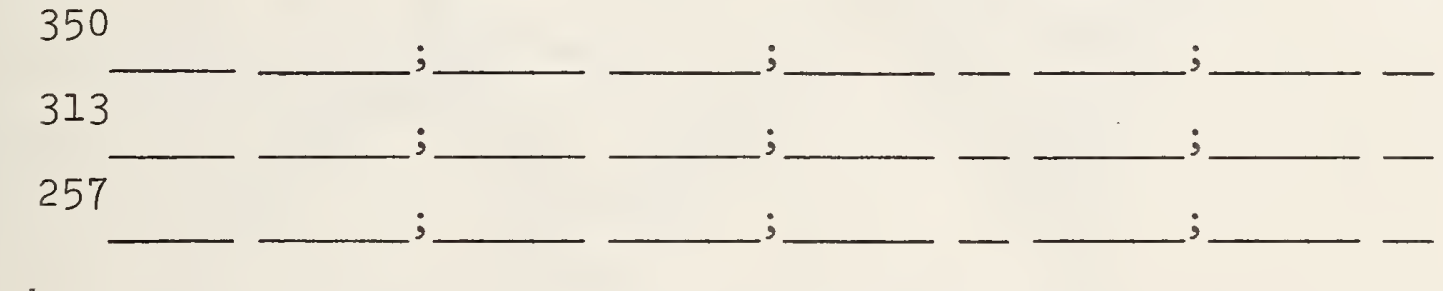

$\mathrm{b}_{3 \bar{\delta}-42}$ and $78-82 \mathrm{mg} \mathrm{K}_{2} \mathrm{Cr}_{2} \mathrm{O}_{7}$ weighed to nearest $0.01 \mathrm{mg}$. Dissolve in distilled water, add $1.00 \mathrm{ml}$ concentrated perchloric acid and dilute to mark at $25^{\circ} \mathrm{C}$ in Class A volumetric flask. Prepare fresh before use.

Comments (Difficulties, Recommendations, Usefulness, etc.):

F. The Use of Chromium(VI) Solutions as Spectrophotometric Absorbance Standards - R. W. Burke, E. R. Deardorff and D. S. Bright

1. Introduction

Both alkaline and acidic chromium(VI) solutions have been used for many years as spectrophotometric absorbance standards. Each has its advantages and limitations. Although Haupt [37] has shown that solutions prepared by dissolving potassium chromate in $0.05 \mathrm{~N}$ KOH are stable for several years when properly stored, many analysts, especially those involved in various collaborative tests [38], [39], [40], have preferred, instead, to use weakly acidic solutions of potasium dichromate.

The spectral properties of the alkaline ard acidic chromium(VI) systems are quite different, as shown in figure 6, with the latter giving the more desirable 


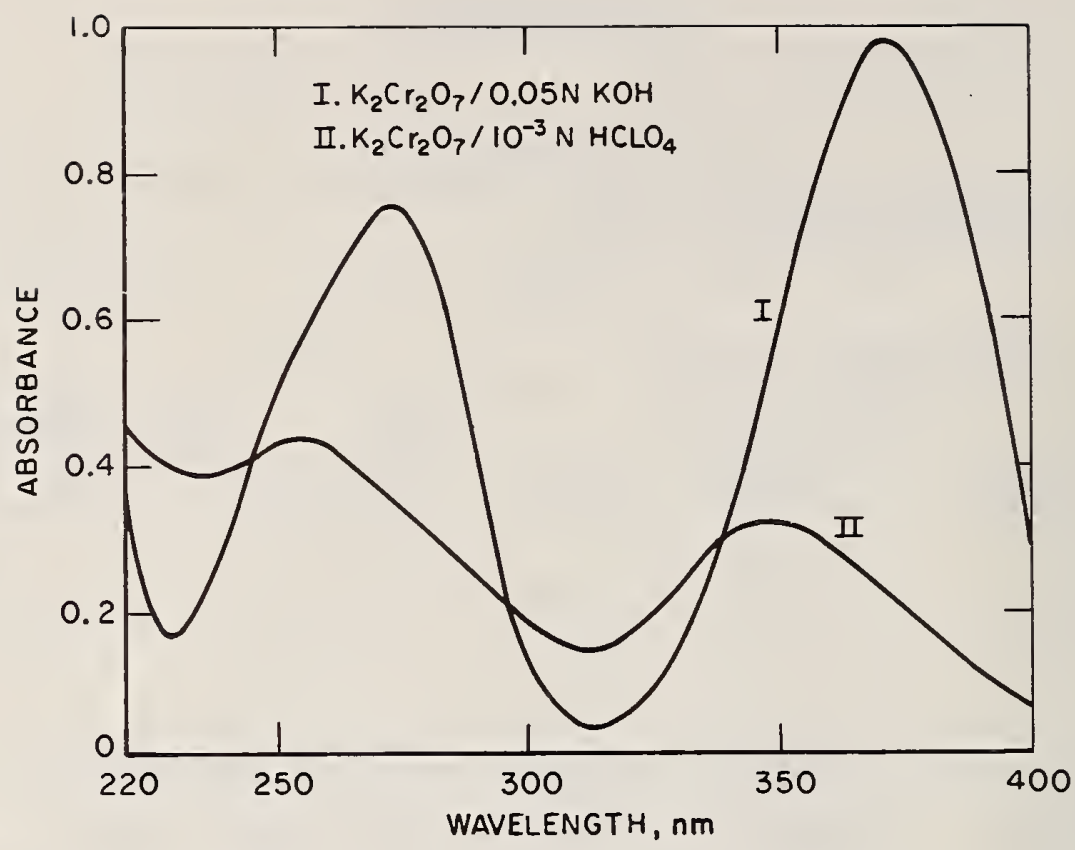

Figure 6. Comparison of absorption spectra of $1.0 \times 10^{-4} \mathrm{M}$ $\mathrm{K}_{2} \mathrm{Cr}_{2} \mathrm{O}_{7}$ in $0.001 \mathrm{~N} \mathrm{HClO}_{4}$ and $0.05 \mathrm{~N} \mathrm{KOH}$.

arrangement of maxima and minima. Furthermore, since the total chromium concentrations of the two solutions are equal, it is also apparent that the alkaline form is two to three times more sensitive than the acidic one. Thus, small errors in weighing the milligram quantities of material are more critical in the former than in the latter. A further disadvantage of the alkaline form is that the 0.01-0.05N KOH solutions normally recommended are corrosive and difficult to handle. Thus, from the standpoints of spectral properties, sensitivity, storage and handling characteristics, acidic chromium(VI) solutions appear superior to alkaline solutions. They possess one serious disadvantage. Chromium(VI) solutions in acidic media do not obey Beer's law. The remainder of this section will be concerned with the causes of these deviations. Specific points to be covered include: ( 1 ) the redetermination of the equilibrium constant for the reaction $2 \mathrm{HCrO}_{4}^{-}=$ 
$\mathrm{Cr}_{2} \mathrm{O}_{7}=+\mathrm{H}_{2} \mathrm{O}$, (2) the use of this constant to calculate the absorption spectra of the $\mathrm{HCrO}_{4}{ }^{-}$and $\mathrm{Cr}_{2} \mathrm{O}_{7}{ }^{2}$ ions,

(3) combining of the equilibrium and absorption data

to predict the absorbance of any weakly acidic chromium(VI)

solution, and (4) recommendations for using acidic

potassium dichromate solutions to check spectrophotometric linearity in the ultraviolet.

2. Chromium(VI) Equilibria

When a chromium(VI) salt is dissolved in water the following equilibria must be considered.

$$
\begin{aligned}
& \mathrm{H}_{2} \mathrm{CrO}_{4} \stackrel{\mathrm{K}_{1}}{=} \mathrm{H}^{+}+\mathrm{HCrO}_{4}^{-} \\
& \mathrm{HCrO}_{4}-\stackrel{\mathrm{K}_{2}}{=} \mathrm{H}^{+}+\mathrm{CrO}_{4}= \\
& 2 \mathrm{HCrO}_{4}-\stackrel{\mathrm{K}_{3}}{=} \mathrm{Cr}_{2} \mathrm{O}_{7}=+\mathrm{H}_{2} \mathrm{O}
\end{aligned}
$$

Reactions (1) and (2) are clearly pH dependent, whereas reaction (3) depends only on the total chromium concentration. The equilibrium constants $K_{1}, K_{2}$ and $K_{3}$ have been measured by various investigators and the following values have been reported at $25^{\circ} \mathrm{C}$ :

$\mathrm{K}_{1}=10$ mole liter $^{-1}[41] ; \mathrm{K}_{2}=35.5$ mole liter $^{-1}$ [42] and 33.0 mole liter ${ }^{-1}[43] ; K_{3}=3.2 \times 10^{-7}$ liter mole $e^{-1}[44]$ and $3.0 \times 10^{-7}$ liter mole $e^{-1}[45]$.

Based on these values of the equilibrium constants, several important conclusions can be drawn: (I) at a $\mathrm{pH} \geqq 10$, at least 99.9 percent of the total chromium is in the $\mathrm{CrO}_{4}=$ form, while (2) in dilute acid ( $\mathrm{pH} \sim 3), \mathrm{HCrO}_{4}{ }^{-}$is the predominant chromium(VI) species since the contribution by $\mathrm{H}_{2} \mathrm{CrO}_{4}$ does not exceed 0.1 percent; moreover, the fraction of $\mathrm{HCrO}_{4}$ - that undergoes dimerization to give $\mathrm{Cr}_{2} \mathrm{O}_{7}=$ 
(reaction 3) will depend on the total chromium concentration (at $1.36 \times 10^{-4}$ and $6.80 \times 10^{-4} \mathrm{M}$ chromium, for example, approximately 0.9 and 4.2 percent, respectively, of the total chromium is calculated to be in the $\mathrm{Cr}_{2} \mathrm{O}_{7}=$ form).

3. Redetermination of $\mathrm{K}_{3}$, the Dimerization Constant for

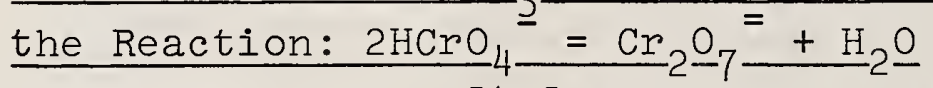

Tong and King's value [42] for $\mathrm{K}_{3}$ was determined by extrapolation of spectrophotometric equilibrium measurements to zero ionic strength, whereas Davies and Prue [43] employed a high precision, differential technique in which appropriate concentrations of alkaline $\mathrm{K}_{2} \mathrm{CrO}_{4}$ were used as standards to correct for the inaccuracy of their spectrophotometer. Both groups made absorbance measurements only in the wavelength region of $366-404 \mathrm{~nm}$ and neither reported the imprecision of their results. Because of the direct relationships between $\mathrm{K}_{3}$ and our need to establish accurately the individual absorption spectra of the $\mathrm{HCrO}_{4}^{-}$and $\mathrm{Cr}_{2} \mathrm{O}_{7}=$ ions, we considered it essential to redetermine this constant.

If $\mathrm{HCrO}_{4}{ }^{-}$and $\mathrm{Cr}_{2} \mathrm{O}_{7}=$ are the only absorbing $\mathrm{Cr}$ (VI) species present with molar absorptivities $\varepsilon_{1}$ and $\varepsilon_{2}$, respectively, the apparent molar absorptivity, $\varepsilon_{m}$, will be given by

$$
\varepsilon_{m}=(1-\alpha) \varepsilon_{1}+1 / 2 \cdot \alpha \varepsilon_{2}
$$

where $\alpha$ is the fraction of total chromium in the dichromate form. Rewriting equation ( 3 ),

$$
2 \mathrm{HCrO}_{4}-\stackrel{\mathrm{K}_{3}}{=} \mathrm{Cr}_{2} \mathrm{O}_{7}=+\mathrm{H}_{2} \mathrm{O}
$$

it is seen that the thermodynamic equilibrium constant is given by

$$
\mathrm{K}_{3}=\frac{\left[\mathrm{Cr}_{2} \mathrm{O}_{7}{ }^{-}\right]}{\left[\mathrm{HCrO}_{4}{ }^{-}\right]^{2}} \cdot \frac{\gamma_{2}}{\gamma_{1}^{2}}
$$


or in terms of $\alpha$

$$
\mathrm{K}_{3}=\frac{\alpha}{2(1-\alpha)^{2} \mathrm{Cr}_{\mathrm{T}}} \cdot \frac{\gamma_{2}}{\gamma_{1}^{2}}
$$

where $\gamma_{1}$ and $\gamma_{2}$ are the activity coefficients of the $\mathrm{HCrO}_{4}^{-}$ and $\mathrm{Cr}_{2} \mathrm{O}_{7}$ ions, respectively, and $\mathrm{Cr}_{\mathrm{T}}$ is the total chromium(VI) concentration. Because the ionic strength never exceeded 0.01 , the activity coefficients are given by the Debye-Hückel expression of the type [43]

$$
-\log \gamma_{i}=\frac{\mathrm{Az}^{2} \mathrm{I}^{1 / 2}}{I+I^{1 / 2}}
$$

where $\mathrm{z}$ is the ionic charge, $\mathrm{I}$ is the ionic strength and $\mathrm{A}$ has a value of $0.509 \mathrm{l} / \mathrm{mole}$ at $25^{\circ} \mathrm{C}$. Equations (4) and (6) can now be rewritten to give, respectively,

$$
\varepsilon_{\mathrm{m}}=\alpha\left(1 / 2 \cdot \varepsilon_{2}-\varepsilon_{1}\right)+\varepsilon_{1}
$$

and

$$
\log \mathrm{K}_{3}=\log \frac{\alpha}{2(1-\alpha)^{2} \mathrm{Cr} \mathrm{T}_{\mathrm{T}}}-\frac{2 \mathrm{AI} I^{1 / 2}}{1+I^{1 / 2}}
$$

Assuming a value of $\mathrm{K}_{3}$, one can calculate from equation (9) the $\alpha$ values at various total chromium concentrations. If the choice of $\mathrm{K}_{3}$ is correct, the measured values of $\varepsilon_{\mathrm{m}}$ shoulc lie on a straight line of slope $\left(1 / 2 . \varepsilon_{2}-\varepsilon_{1}\right)$ and intercept $\varepsilon_{1}$, as seen from equation (8). The best value of $K_{3}$ is then determined by the method of least squares.

a. Experimental. Absorbance measurements were performed on a commercial double-beam spectrophotometer containing a quartz double monochromator. The absorbances of solutions in regions of maxima or minima could be reproduced on this instrument with a precision of \pm 0.1 percent at the 95 percent confidence level. Linearity was 
checked at numerous wavelengths in the range of $375-600 \mathrm{~nm}$ by using various combinations of Chance ON-32A or Corning 5900 glass filters. These filters were tilted vertically approximately $10^{\circ}$ to the incoming beam to minimize reflection effects.

All absorbance measurements were made in a $1.023 \pm$ $0.003 \mathrm{~mm}$ cuvette, with air as a reference. This cuvette was rigidly supported in the standard $10 \mathrm{~mm}$ square holder supplied with the instrument by an anodized black aluminum adapter fabricated by the NBS Instrument Shop. In practice, only this adapter was touched when removing the cuvette from the instrument for emptying or refilling. Solvent and sample were introduced through the $1 \mathrm{~mm}$ circular neck by means of disposable, Pasteur-type pipettes. The casting surrounding the sample and reference areas and the $10 \mathrm{~mm}$ cuvette holder were thermostatted at $25.0 \pm 0.1{ }^{\circ} \mathrm{C}$ by a circulating water bath.

Chromium(VI) solutions were prepared from SRM-136c, Potassium Dichromate, which was dried at $110{ }^{\circ} \mathrm{C}$ for two hours. The distilled water was free of reducing impurities as indicated by titrating with a dilute potassium permanganate solution. Perchloric acid was used to maintain the $\mathrm{pH}$ at $3.0 \pm 0.1$

The optimum wavelength regions for determining $\mathrm{K}_{3}$ were selected as follows: Two solutions were prepared, one containing $391 \mathrm{mg} \mathrm{K}_{2} \mathrm{Cr}_{2} \mathrm{O}_{7} / \mathrm{I}$ and the other, $40.0 \mathrm{mg} \mathrm{K}_{2} \mathrm{Cr}_{2} \mathrm{O}_{7} / \mathrm{I}$. The more concentrated solution was placed in the $1.023 \mathrm{~mm}$ cuvette while the second was added to a $10.00 \mathrm{~mm}$ cuvette. A differential scan was then made on a recording spectrophotometer equipped with a 0-0.1 absorbance (full scale) slidewire, using the $391 \mathrm{mg} \mathrm{K}_{2} \mathrm{Cr}_{2} \mathrm{O}_{7} / \mathrm{l}$ solution as the sample. The resulting spectrum is shown in figure 7. Relatively large differences in absorbance are seen in the wavelength regions near 385 and $275 \mathrm{~nm}$ even though the total 


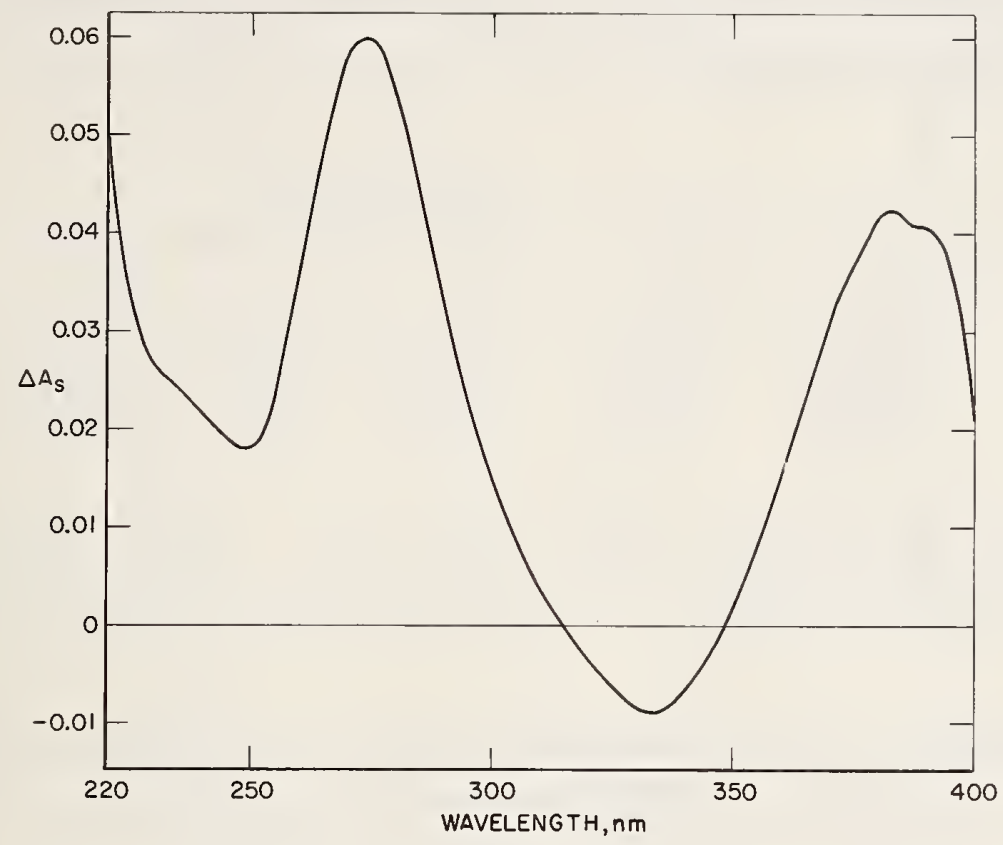

Figure 7. Difference spectrum of $391 \mathrm{mg} \mathrm{K}_{2} \mathrm{Cr}_{2} \mathrm{O}_{7}$ /liter in $1.023 \mathrm{~mm}$ cuvette and $40.0 \mathrm{mg} \mathrm{K}_{2} \mathrm{Cr}_{2} \mathrm{O}_{7}$ /liter in $10.00 \mathrm{~mm}$ cuvette; $\mathrm{pH}=3$.

chromium in each light path is the same. Thus, it is in these two regions that maximum deviations from Beer's Law should be observed. Three wavelengths were subsequently selected in each region for the determination of $K_{3}-390$, 385 and $380 \mathrm{rm}$ and 280, 275 and $270 \mathrm{~nm}$, respectively. Since we did not choose to measure absorbances below 0.05 or above 1.5 , this choice of wavelengths, combined with our decision to use only the $1 \mathrm{~mm}$ cuvette, restricted the concentration range of the potassium dichromate solutions from about $100 \mathrm{mg} \mathrm{K}_{2} \mathrm{Cr}_{2} \mathrm{O}_{7} / \mathrm{l}$ to approximately $1000 \mathrm{mg}$ $\mathrm{K}_{2} \mathrm{Cr}_{2} \mathrm{O}_{7} / \mathrm{l}$.

The absorbances of the four chromium(VI) concentrations selected for the determination of $\mathrm{K}_{3}$ are given in table 7 . 
Table 7. Absorbance of $\mathrm{K}_{2} \mathrm{Cr}_{2} \mathrm{O}_{7}$ solutions as measured in $1.023 \mathrm{~mm}$ cuvette at $25^{\circ} \mathrm{C} ; \mathrm{pH}=2.92 \pm 0.02\left(\mathrm{HClO}_{4}\right)$.

$\mathrm{K}_{2} \mathrm{Cr}_{2} \mathrm{O}_{7}$ Conc. $\mathrm{mg} / \mathrm{I}$

100.06
400.48
699.86
1000.27

$390 \mathrm{~nm}$

0.0410
.1989
.3924
.6093

Absorbance

$\underline{380 \mathrm{~nm}} \quad \underline{280 \mathrm{~nm}} \quad 275 \mathrm{~nm} \quad 270 \mathrm{~nm}$

0.0602

0.1099

0.1196

0.1309

0.0521

.2779

.5325

.4897

.9199

1.3831
.5332

.9995

1.5037
.5765

1.0747

1.6095

The $\mathrm{pH}$ of these solutions was $2.92 \pm 0.02$. The corresponding apparent molar absorptivities, $\varepsilon_{m}$, are given in table 8 .

Table 8. Apparent molar absorptivities of $\mathrm{K}_{2} \mathrm{Cr}_{2} \mathrm{O}_{7}$ solutions as a function of chromium(VI) concentration at $25^{\circ} \mathrm{C} ; \mathrm{pH}=2.92 \pm 0.02\left(\mathrm{HClO}_{4}\right)$.

$\mathrm{K}_{2} \mathrm{Cr}_{2} \mathrm{O}_{7}$ Conc. Apparent Molar Absorptivity, liter mole $\mathrm{cm}^{-1}$

\begin{tabular}{rrrrrrrr}
$\mathrm{mg} / 1$ & & $390 \mathrm{~nm}$ & $\underline{385 \mathrm{~nm}}$ & $\underline{380 \mathrm{~nm}}$ & $\underline{280 \mathrm{~nm}}$ & $\underline{275 \mathrm{~nm}}$ & $\underline{270 \mathrm{~nm}}$ \\
\cline { 1 - 2 } & & 589.2 & 748.7 & 865.1 & 1579.3 & 1718.6 & 1881.0 \\
400.06 & & 714.1 & 878.6 & 997.8 & 1758.2 & 1914.4 & 2069.8 \\
699.86 & & 806.2 & 973.8 & 1094.0 & 1890.0 & 2053.5 & 2208.0 \\
1000.27 & & 875.9 & 1045.6 & 1166.5 & 1988.2 & 2161.5 & 2313.6
\end{tabular}

Using the method of least squares, these $\varepsilon_{\mathrm{m}}$ values were plotted against the $\alpha$ fractions calculated from equation (9) for various assumed values of $\mathrm{K}_{3}$. The molar absorptivities were weighted according to the reproducibility of the absorbance data in table 7. The latter varied from +0.0002 at 0.05 absorbance to \pm 0.0005 near 1.5 absorbance. A computer was used to perform all computations.

A typical graph of the sum of the squares of the deviations of the experimental $\varepsilon_{m}$ values from the best straight line fit is shown in figure 8 for $K_{3}$ values of 28 through 36. The minimum in this curve is the best 


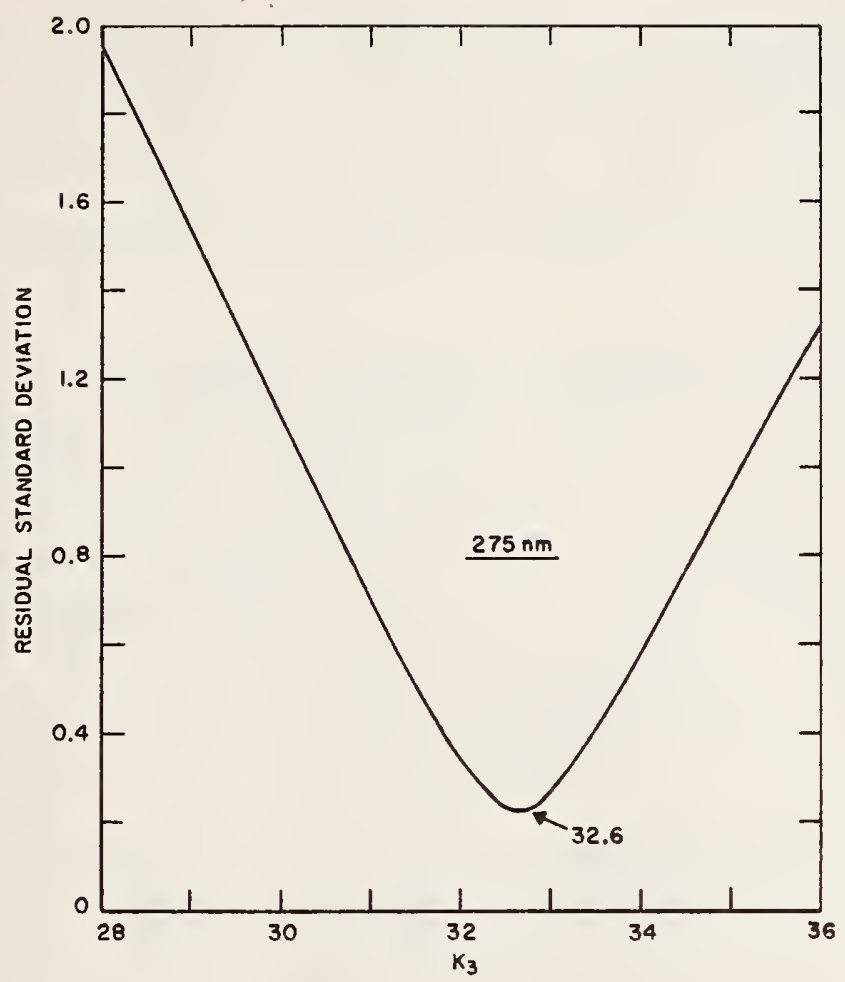

Figure 8. Least squares determination of $K_{3}$.

estimate of $\mathrm{K}_{3}$ and, for this wavelength, is 32.6. The $\mathrm{K}_{3}$ values obtained at the six wavelengths are summarized in table 9.

Table 9. $\mathrm{K}_{3}$ at $25^{\circ} \mathrm{C}$ as determined at various wavelengths.

Wavelength, nm

390

385

380

280

275

270
$\mathrm{K}_{3}$, liter mole $\mathrm{e}^{-1}$

32.4

33.3

33.8

33.5

32.6

31.6

Avg. 32.9

S.D. 0.82

Rel. S.D. 2.5\% 
The consistency of the $\mathrm{K}_{3}$ values in the two widely separated wavelength regions strongly supports the original assumption that, in perchloric acid media near $\mathrm{pH} 3, \mathrm{HCrO}_{4}{ }^{-}$and $\mathrm{Cr}_{2} \mathrm{O}_{7}{ }^{=}$are the only absorbing chromium(VI) species measurable.

4. Absorption Spectra of $\mathrm{HCrO}_{4}^{-}$and $\mathrm{Cr}_{2}{ }_{-7}=$

The absorbances of three chromium(VI) solutions containing nominally 20,40 and $60 \mathrm{mg} \mathrm{K}_{2} \mathrm{Cr}_{2} \mathrm{O}_{7} / 1(\mathrm{pH}=3.0 \pm 0.1$ in $\mathrm{HClO}_{4}$ ) were measured in a $10.00 \mathrm{~mm}$ cuvette at $5 \mathrm{~nm}$ increments over the wavelength range of $220-400 \mathrm{~nm}$. A close approximation of $\varepsilon\left(\mathrm{HCrO}_{4}{ }^{-}\right)$was then obtained by extrapolating the apparent molar absorptivity values calculated for these three concentrations to zero chromium concentration. This extrapolation is simplified since the variation of $\alpha$ over this concentration range $\left(20-60 \mathrm{mg} \mathrm{K}_{2} \mathrm{Cr}_{2} \mathrm{O}_{7} / \mathrm{I}\right)$ is nearly linear. Similar absorbance measurements were performed on three solutions containing $1000 \mathrm{mg} \mathrm{K}_{2} \mathrm{Cr}_{2} \mathrm{O}_{7} / \mathrm{I}$, using the $1.023 \mathrm{~mm}$ cuvette, and the corresponding $\alpha$ values were calculated from equation (9), with $\mathrm{K}_{3}=32.9$. The first approximation of the $\varepsilon\left(\mathrm{Cr}_{2} \mathrm{O}_{7}=\right.$ ) values were obtained by substituting the extrapolated $\varepsilon\left(\mathrm{HCrO}_{4}{ }^{-}\right)$and the above $\alpha$ values into equation (8). These $\varepsilon\left(\mathrm{HCrO}_{4}{ }^{-}\right)$and $\varepsilon\left(\mathrm{Cr}_{2} \mathrm{O}_{7}{ }^{=}\right)$ values were then refined by successive approximations. Only one recycling was necessary. The resulting individual absorption spectra are shown in figure 9. The molar absorptivity values for $\mathrm{Cr}_{2} \mathrm{O}_{7}=$ have been divided by 2 to make the spectral data directly applicable to predicting the direction and magnitude of the deviations from Beer's Law.

5. Agreement Between Experimental and Calculated Values of Apparent Molar Absorptivity

As previously shown in figure 6, the absorption spectrum of a weakly acidic solution of $\mathrm{K}_{2} \mathrm{Cr}_{2} \mathrm{O}_{7}$ exhibits two broad maxima at 350 and $257 \mathrm{~nm}$ and two broad minima at 313 and $235 \mathrm{~nm}$. These maxima and minima do not shift significantly 


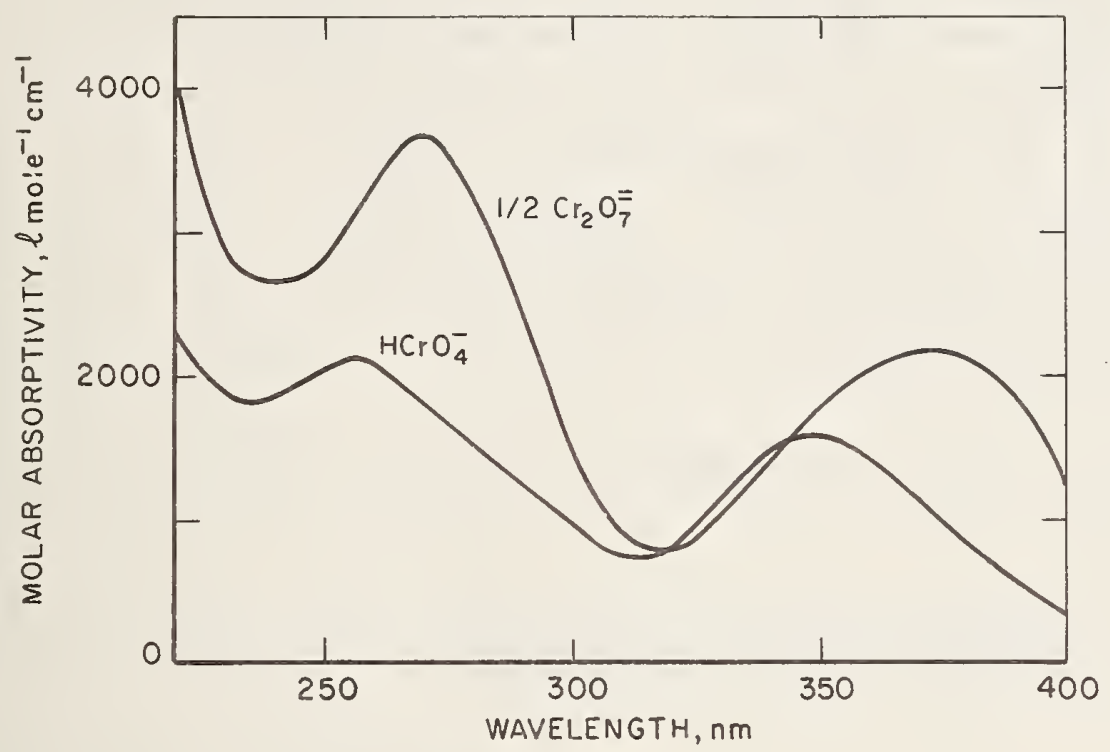

Figure 9. Absorption spectra of $\mathrm{HCrO}_{4}^{-}$and $\mathrm{Cr}_{2} \mathrm{O}_{7}=$ from
$220-400$. over the concentration range of $20-100 \mathrm{mg} \mathrm{K}_{2} \mathrm{Cr}_{2} \mathrm{O}_{7} / \mathrm{l}$. This is considered a practical range since it yields absorbance values of about $0.1-1.5$ for a $10 \mathrm{~mm}$ cuvette.

The molar absorptivities of $\mathrm{HCrO}_{4}{ }^{-}$and $\mathrm{Cr}_{2} \mathrm{O}_{7}{ }^{2}$ at 350 , 313, 257 and $235 \mathrm{~nm}$ were determined by the procedure described above. These values are given in table 10. Although

Table 10. Provisional molar absorptivities of $\mathrm{HCrO}_{4}{ }^{-}$ and $\mathrm{Cr}_{2} \mathrm{O}_{7}=$ at $25^{\circ} \mathrm{C}$.

$\underline{\varepsilon, I \mathrm{~mole}}{ }^{-1} \mathrm{~cm}^{-1}$ Wavelength and Spectral Bandpass, $\mathrm{nm}$ $\underline{350(1.1)} \quad \underline{313(0.7)} \quad \underline{57(1.0)} \quad 235(0.7)$
$\mathrm{HCrO}_{4}^{-}$
1576
711
2100
1804
$1 / 2 \mathrm{Cr}_{2} \mathrm{O}_{7}=$
1788
823
3156
2688 
no direct comparison has been made between our instrument and the NBS high accuracy spectrophotometer, the agreement between measurements on glass filters in the visible region suggests that the $\varepsilon\left(\mathrm{HCrO}_{4}^{-}\right)$values are accurate to \pm 0.5 percent. However, because of the uncertainty in $\mathrm{K}_{3}$ and therefore $\alpha$, the inaccuracy of the $\varepsilon\left(\mathrm{Cr}_{2} \mathrm{O}_{7}{ }^{=}\right)$results is approximately \pm 5 percent. As will be seen subsequently, this will not seriously limit the usefulness of dilute acidic potassium dichromate solutions as potential absorbance standards.

Table 11 shows the agreement between the calculated and

Table 11. Experimental and calculated values (E,C) of apparent molar absorptivity, $\varepsilon_{m}$, at $25^{\circ} \mathrm{C}$.

\begin{tabular}{|c|c|c|c|c|c|}
\hline \multirow{2}{*}{$\begin{array}{c}\mathrm{K}_{2} \mathrm{Cr}_{2} \mathrm{O}_{7} \text { Conc. } \\
\mathrm{mg} / \mathrm{I}\end{array}$} & \multirow{2}{*}{${ }_{101 \mathrm{e}^{-1} \mathrm{~cm}^{-1}}^{\varepsilon_{\mathrm{m}}}$} & \multicolumn{4}{|c|}{$\begin{array}{c}\text { Wavelength and Spectral } \\
\text { Bandpass, } \mathrm{nm}\end{array}$} \\
\hline & & $350(1.1)$ & $313(0.7)$ & $257(1.0)$ & $235(0.7)$ \\
\hline 20.22 & $\begin{array}{c}E \\
\text { C } \\
\text { Diff. }\end{array}$ & $\begin{array}{r}1577.6 \\
1577.9 \\
-0.3\end{array}$ & $\begin{array}{r}713.5 \\
711.9 \\
+1.6\end{array}$ & $\begin{array}{r}2113.6 \\
2108.7 \\
+4.9\end{array}$ & $\begin{array}{r}1814.7 \\
1812.1 \\
+2.6\end{array}$ \\
\hline 40.09 & $\begin{array}{c}E \\
C \\
\text { Diff. }\end{array}$ & $\begin{array}{r}1579.9 \\
1579.8 \\
+0.1\end{array}$ & $\begin{array}{r}713.3 \\
713.0 \\
+0.3\end{array}$ & $\begin{array}{r}2120.8 \\
2118.8 \\
+2.0\end{array}$ & $\begin{array}{r}1820.2 \\
1819.7 \\
+0.5\end{array}$ \\
\hline 60.12 & $\begin{array}{c}E \\
\text { C } \\
\text { Diff. }\end{array}$ & $\begin{array}{r}1581.4 \\
1581.5 \\
-0.1\end{array}$ & $\begin{array}{r}713.8 \\
713.8 \\
0.0\end{array}$ & $\begin{array}{r}2127.2 \\
2126.7 \\
+0.5\end{array}$ & $\begin{array}{r}1827.1 \\
1827.2 \\
-0.1\end{array}$ \\
\hline 80.17 & $\begin{array}{c}E \\
\text { C } \\
\text { Diff. }\end{array}$ & $\begin{array}{r}1584.0 \\
1583.3 \\
+0.7\end{array}$ & $\begin{array}{r}715.0 \\
714.8 \\
+0.2\end{array}$ & $\begin{array}{r}2137.6 \\
2135.3 \\
+2.3\end{array}$ & $\begin{array}{r}1835.8 \\
1834.4 \\
+1.4\end{array}$ \\
\hline 99.92 & $\begin{array}{c}E \\
C \\
\text { Diff. }\end{array}$ & $\begin{array}{r}1585.5 \\
1584.0 \\
+1.5\end{array}$ & $\begin{array}{r}715.6 \\
715.0 \\
+0.6\end{array}$ & $\begin{array}{r}2144.0 \\
2143.7 \\
+0.3\end{array}$ & $\begin{array}{r}1841.5 \\
1841.4 \\
+0.1\end{array}$ \\
\hline
\end{tabular}


experimental apparent molar absorptivity values for five concentrations of potassium dichromate. The experimental values are the averages obtained on five individual samples run at each concentration. The precision of any given set of measurements was approximately 0.1 percent at the 95 percent confidence level for each wavelength. Approximately IN perchloric acid was used to maintain $\mathrm{pH}$ at $3.0 \pm 0.1$. The increasing values of the apparent molar absorptivity with increasing chromium(VI) concentration at these four wavelengths is readily apparent. Moreover, the difference between the calculated and measured values does not exceed \pm 0.3 percent. Referring to figure 9 again, there are two wavelengths where weakly acidic dichromate solutions should obey Beer's Law $\sim 319$ and $345 \mathrm{~nm}$ - whereas, in the region between these wavelengths, negative deviations should be observed. Similar conclusions can be drawn also from the difference spectrum shown in figure 7 .

6. Using Acidic Dichromate Solutions to Check Linearity in the Ultraviolet

While the accuracy of the molar absorptivity data in table 10 must be more carefully assessed before acidic $\mathrm{K}_{2} \mathrm{Cr}_{2} \mathrm{O}_{7}$ solutions can be used to their fullest capabilities as absorbance standards, it is felt that equilibrium and molar absorptivity data are now sufficiently established that these solutions can be employed to check linearity to \pm 0.2 percert at the wavelengths of $350,313,257$ and $235 \mathrm{~nm}$. This claim is supported by the fact that, even in the most concentrated $\mathrm{K}_{2} \mathrm{Cr}_{2} \mathrm{O}_{7}$ solution studied ( $100 \mathrm{mg} / \mathrm{l}$ ), only approximately 4.2 percent of the chromium(VI) is in the $\mathrm{Cr}_{2} \mathrm{O}_{7}=$ form. At lower concentrations this percentage becomes even smaller. Moreover, even though the errors in $\alpha$ and $\varepsilon\left(\mathrm{Cr}_{2} \mathrm{O}_{7}{ }^{=}\right)$are approximately equal and may be as large as 5 percent, it is their product, $\alpha \cdot \varepsilon\left(\mathrm{Cr}_{2} \mathrm{O}_{7}{ }^{=}\right)$, that is required. Since these errors have opposite signs, this product quite likely is known to better than 5 percent. 
One approach to employing weakly acidic $\mathrm{K}_{2} \mathrm{Cr}_{2} \mathrm{O}_{7}$ solutions to assess spectrophotometric linearity and, eventually, accuracy, is by the concept of apparent weights. These would be determined as follows:

Apparent Wt. = Actual Wt. X Apparent Wt. Factor

Apparent wt. Factor $=\frac{[1-\alpha] \cdot \varepsilon\left(\mathrm{HCrO}_{4}^{-}\right)+\alpha \cdot 1 / 2 \cdot \varepsilon\left(\mathrm{Cr}_{2} \mathrm{O}_{7}{ }^{-}\right)}{\varepsilon\left(\mathrm{HCrO}_{4}^{-}\right)}$

A plot of absorbance against apparent weight should yield a straight line (within \pm 0.2 percent) whose slope would be used to calculate $\varepsilon\left(\mathrm{HCrO}_{4}{ }^{-}\right)$. The agreement between this $\varepsilon\left(\mathrm{HCrO}_{4}{ }^{-}\right)$value and a certified value would, in turn, be a measure of spectrophotometric accuracy. Table 12 gives the apparent weight factors calculated for $\mathrm{K}_{2} \mathrm{Cr}_{2} \mathrm{O}_{7}$ concentrations of 20-100 mg/l. These have been tabulated only for $20 \mathrm{mg} / \mathrm{l}$ increments. However, since $\alpha$ is seen to vary almost linearly for this range of concentrations, the appropriate factors for any $\mathrm{K}_{2} \mathrm{Cr}_{2} \mathrm{O}_{7}$ concentration not given, can be obtained with sufficient accuracy by linear interpolation.

Table 12. $\alpha, 1-\alpha$, and apparent weight factors at $25^{\circ} \mathrm{C}$ for selected concentrations of $\mathrm{K}_{2} \mathrm{Cr}_{2} \mathrm{O}_{7}$.

$\mathrm{K}_{2} \mathrm{Cr}_{2} \mathrm{O}_{7}$ Conc.

$\mathrm{mg} / \mathrm{I}$
20.0
40.0
60.0
80.0
100.0

$\begin{array}{ll}\alpha & 1-\alpha \\ 0.0091 & 0.9909 \\ .0178 & .9822 \\ .0262 & .9738 \\ .0344 & .9656 \\ .0423 & .9577\end{array}$

Apparent Weight Factor

$350 \mathrm{~nm} \quad 313 \mathrm{~nm} 257 \mathrm{~nm} 235 \mathrm{~nm}$

$1.0012 \quad 1.0014$

$1.0024 \quad 1.0028$

1.0035

1.0046

1.0041

1.0054

1.0057

1.0067

1.0046

1.0090

1.0132

1.0173

1.0213

1.0045

1.0087

1.0128

1.0169

1.0207 
7. Optimum $\mathrm{pH}$ and Choice of Acid for Preparing Acidic Chromium(VI) Solutions

A $0.01 \mathrm{~N} \mathrm{H}_{2} \mathrm{SO}_{4}$ has frequently been employed in the preparation of acidic chromium(VI) solutions. This medium possesses two disadvantages when compared to a perchloric acid solution of approximately pH 3. These are: (1) larger ionic strength and $\mathrm{pH}$ effects and (2) possible formation of mixed chromate-sulfate complexes.

The higher ionic strength of the $\mathrm{pH} 2$ solutions yields a larger value for $\mathrm{K}_{3}$ and thus increases the deviations from Beer's Law. In addition, chromium(VI) solutions at pH 2 contain not only $\mathrm{HCrO}_{4}{ }^{-}$and $\mathrm{Cr}_{2} \mathrm{O}_{7}{ }^{2}$ ions, but also a small amount of a third species, $\mathrm{H}_{2} \mathrm{CrO}_{4}$. As several investigators have shown [41], [46], this is the least absorbing ion of the three and its presence decreases apparent molar absorptivities. Thus, opposing the increase in $\mathrm{K}_{3}$ and thereby higher absorbance, is the enhanced formation of $\mathrm{H}_{2} \mathrm{CrO}_{4}$ which leads to lower absorbance values. The net effect of these two factors depends on the spectral properties of $\mathrm{H}_{2} \mathrm{CrO}_{4}$ at the wavelengths of interest. At $350 \mathrm{~nm}$, for example, the apparent molar absorptivities decreased 0.2 percent by decreasing the $\mathrm{pH}$ from 3 to 2 with perchloric acid ( $50 \mathrm{mg} \mathrm{K}_{2} \mathrm{Cr}_{2} \mathrm{O}_{7} / \mathrm{I}$ ). At the three other wavelengths - 313, 257 and $235 \mathrm{~nm}$ - these combined effects did not exceed 0.1 percent.

Regarding the choice of acid, both Tong and King [42] and Davies and Prue [43] observed small differences in the absorbances of dilute perchloric and sulfuric acid solutions of $\mathrm{K}_{2} \mathrm{Cr}_{2} \mathrm{O}_{7}$, after correcting for differences in ionic strength. They attributed these differences to the formation of mixed chromate-sulfate complexes. More recently, Haight et al [46] have shown that the conversion of $\mathrm{HCrO}_{4}{ }^{-}$to $\mathrm{CrSO}_{7}{ }^{=}$is practically complete in $\mathrm{IM} \mathrm{HSO}_{4}{ }^{-}$solutions and that the 
absorption spectrum of this complex is significantly different from the $\mathrm{HCrO}_{4}{ }^{-}$spectrum. At 350, 313, 257 and $235 \mathrm{~nm}$ our absorbance measurements at $\mathrm{pH} 2$ in either $\mathrm{HClO}_{4}$. or $\mathrm{H}_{2} \mathrm{SO}_{4}$ agreed within 0.1 percent, however.

In conclusion, a $\mathrm{pH}$ near 3 is preferred over $\mathrm{pH} 2$, since it yields a simpler mixture of chromium(VI) species. A $\mathrm{pH}$ much higher than 3 is not recommended, however, since it is difficult to reproduce and could lead to the formation of small amounts of $\mathrm{CrO}_{4}=$. The choice of either $\mathrm{H}_{2} \mathrm{SO}_{4}$ or $\mathrm{HClO}_{4}$ to obtain a $\mathrm{pH}$ of 3 appears less critical at the 0.1 percent level. Nevertheless, we prefer perchloric acid, since there is no evidence that $\mathrm{ClO}_{4}=$ forms mixed complexes with $\mathrm{HCrO}_{4}^{-}$.

8. Effect of Temperature on the Absorbance of $\underline{\mathrm{K}}_{2} \underline{\mathrm{Cr}}_{2} \underline{\mathrm{O}}_{7}$ at $\mathrm{pH} 3$

The absorbances of a solution containing approximately $60 \mathrm{mg} \mathrm{K}_{2} \mathrm{Cr}_{2} \mathrm{O}_{7} / \mathrm{I}$ at $\mathrm{pH} 3\left(\mathrm{HClO}_{4}\right)$ were measured as a function of temperature over the range, $17-37^{\circ} \mathrm{C}$. Figure 10 shows

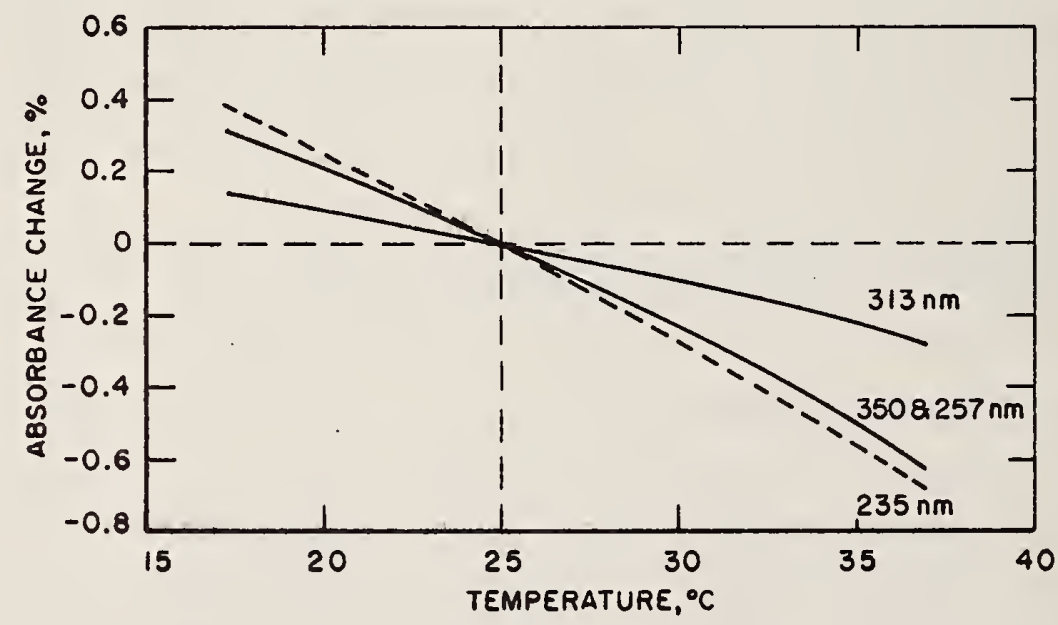

Figure 10. Temperature dependence of a solution of $\mathrm{K}_{2} \mathrm{Cr}_{2} \mathrm{O}_{7}$ at $\mathrm{pH} 3$. 
the results obtained for wavelengths of 350, 313, 257 and $235 \mathrm{~nm}$. All absorbance changes are uncorrected for thermal expansion of the solvent. The absorption minimum at $313 \mathrm{~nm}$ exhibits the smallest temperature coefficient (approximately $-0.02 \% /{ }^{\circ} \mathrm{C}$ ) while the maxima at 350 and $257 \mathrm{~nm}$ and the minimum at $235 \mathrm{~nm}$ have temperature coefficients of about $-0.05 \% /{ }^{\circ} \mathrm{C}$ over the range of $20-30{ }^{\circ} \mathrm{C}$.

9. $\mathrm{K}_{2} \mathrm{Cr}_{2}-_{7}$ in $0.05 \mathrm{M} \mathrm{Na} 2 \mathrm{HPO}_{4}$ and $0.05 \mathrm{M} \mathrm{KOH}$

To overcome some of the difficulties in handling highly alkaline potassium chromate solutions, Johnson [47] has recommended dissolving $\mathrm{K}_{2} \mathrm{Cr}_{2} \mathrm{O}_{7}$ in $0.05 \mathrm{M} \mathrm{Na}{ }_{2} \mathrm{HPO}_{4}$ ( $\mathrm{pH} \sim 9.1)$. This system has been examined briefly and tentative molar absorptivity values are reported for it and the corresponding $0.05 \mathrm{M} \mathrm{KOH}$ system in table 13 . Over the relatively narrow concentration ranges studied, both systems

Table 13. Tentative molar absorptivity values of $\mathrm{K}_{2} \mathrm{Cr}_{2} \mathrm{O}_{7}$ in $0.05 \mathrm{M} \mathrm{Na}_{2} \mathrm{HPO}_{4}$ and $0.05 \mathrm{M} \mathrm{KOH}$ at $25^{\circ} \mathrm{C}$.

$$
\underline{0.05 \mathrm{M} \mathrm{Na}_{2}} \mathrm{HPO}_{4}
$$

$\mathrm{K}_{2} \mathrm{Cr}_{2} \mathrm{O}_{7}$ Conc.

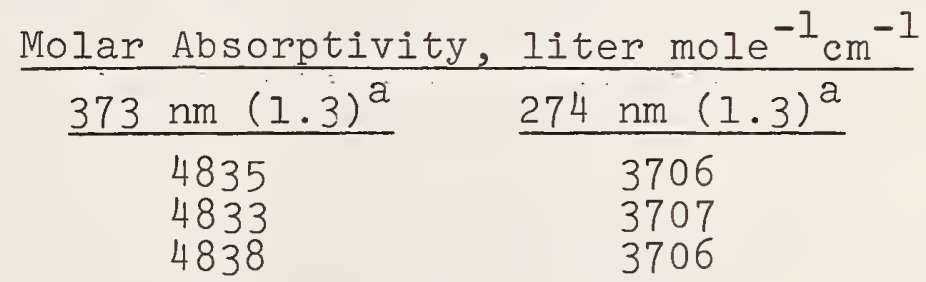

$\underline{0.05 \mathrm{M} \mathrm{KOH}}$

11.098

19.466

29.875

\section{$\underline{\mathrm{pH}}$ \\ 9.2 \\ 9.1 \\ 9.1}

${ }^{a}$ Spectral Bandpass, $\mathrm{nm}$. 
obey Beer's Law to \pm 0.1 percent. Furthermore, the molar absorptivity values in the two systems agree within the limits predicted from the equilibrium data. For example, the ionic strength of the $0.05 \mathrm{M} \mathrm{Na}_{2} \mathrm{HPO}_{4}$ solution is 0.15 and, from Neuss and Rieman's work [44], one would estimate the corresponding concentration equilibrium constant for the reaction $\mathrm{HCrO}_{11}^{-}=\mathrm{H}^{+}+\mathrm{CrO}_{4}=$ to be approximately $9 \times 10^{-7}$ mole liter ${ }^{-1}$ at $25^{\circ} \mathrm{C}$. Thus at $\mathrm{pH} 9.1$, the contribution of $\mathrm{HCrO}_{4}^{-}$is approximately 1 part in 900. The molar absorptivity values in $0.05 \mathrm{M} \mathrm{Na}_{2} \mathrm{HPO}_{4}$ should therefore agree with the $0.05 \mathrm{M} \mathrm{KOH}$ results to within 0.1 percent.

10. Conclusion

The deviation from Beer's Jaw of weakly acidic solutions of $\mathrm{K}_{2} \mathrm{Cr}_{2} \mathrm{O}_{7}$ have been re-examined from the standpoints of ionic equilibria and the differing absorption spectra of the pertinent chromium(VI) species. As a result of this study, the present uncertainties in the requisite equilibrium and molar absorptivity data in acidic chromium(VI) systems limit the potential usefulness of $\mathrm{K}_{2} \mathrm{Cr}_{2} \mathrm{O}_{7}$ as an absorbance standard by approximately \pm 0.2 percent.

At any given chromium concentration, the reproducibility of the apparent molar absorptivity valles was about \pm 0.1 percent at the 95 percent confidence level. Equally significant, the precision did not vary with wavelength. The results obtained at $235 \mathrm{~nm}$, for example, were comparable to those obtained at $350 \mathrm{~nm}$. Two precautions were taken for these measurements. The cuvette was never removed from the spectrophotometer between measurements of the "blank" and sample (each measured against air) and all solutions were transferred tc and from this cuvette with Pasteur-type pipettes equipped with rubber bulbs. 
The various molar absorptivity values given in this report are tentative since the accuracy of the spectrophotometer in the UV region has not been unequivocally established. This information will be available in the near future when comparative measurements will be made on this instrument and on the high accuracy NBS spectrophotometer (see section lc).

G. The Absorptivity of Bilirubin, SRM 916 - R. W. Burke and E. R. Deardorff

1. Introduction

The Office of Standard Reference Materials has announced the availability of a high-purity bilirubin for use as a standard for clinical determinations and for verifying the quality of bilirubin working standards. This standard Reference Material, identified as SRM 916, is provisionally certified at 99.0 percent purity. The principal impurity is occluded chloroform.

Solutions of bilirubin are highly colored and absorptivity measurements are frequently employed to establish relative purity. The procedure used for the analysis of chloroform solutions of the NBS material is described below.

2. Experimental

Because of the volatility of the chloroform solvent, special attention was given to transferring the bilirubin solutions from the volumetric flasks to the measuring cuvette. A closed, flow-type system was employed in which nitrogen was used to flush the samples from the flasks through the cuvette. All transfers were made through $1 \mathrm{~mm}$ O.D. Teflon tubing. The cuvette cover was made by milling a groove ( $1 / 8$ inch $x 1 / 8$ inch) into a Teflon sheet of such dimensions that it coincided with the rectangular cross section of the $10 \mathrm{~mm}$ sample cuvette. A neoprene gasket 
provided an airtight seal. Two holes were drilled into the cover and these were fitted with the $1 \mathrm{~mm}$ tubing to form the inlet and outlet to and from the cuvette. A standard taper, No. 22, Teflon stopper was similarly modified for making connections to the flasks.

a. Procedure. The bilirubin samples were weighed on a microbalance and transferred to weighed l-liter volumetric flasks. One hundred $\mathrm{ml}$ of analytical reagent grade chloroform, stabilized with approximately $0.75 \% \mathrm{v} / \mathrm{v}$ ethyl alcohol, was added to each flask and the samples were then warmed for 15 minutes in a $60^{\circ} \mathrm{C}$ water bath to insure complete dissolution. These solutions were diluted to approximately 1 liter with. the chloroform solvent and placed in a temperature-controlled balance room $\left(25.0 \pm 0.2{ }^{\circ} \mathrm{C}\right)$. They were protected from light at all times either by working in a darkened room or by covering the flasks with aluminum foil. After thermal equilibrium, the solutions were weighed and the corresponding volumes were calculated. The measured density of the chloroform-ethanol solvent was $1.473 \mathrm{~g}$ per $\mathrm{cm}^{3}$ at $25.0^{\circ} \mathrm{C}$. Absorbances were measured at $25.0 \pm 0.2{ }^{\circ} \mathrm{C}$ in a glass-covered, $10.00 \pm 0.01 \mathrm{~mm}$ cuvette at $453 \mathrm{~nm}$ with a high precision ( 1 part in 1000) spectrophotometer.

b. Results. Using the nitrogen transfer procedure, the following results were obtained for the absorptivity of SRM 916, Bilirubin, in chloroform (table 14).

3. Conclusions

A closed-system transfer employing an inert gas such as nitrogen is recommended when absorptivity measurements are made on chloroform solutions of bilirubin. Taking into account possible sources of error, a value of $104.5 \pm 0.5$ liter $\mathrm{g}^{-1} \mathrm{~cm}^{-1}$ is recommended for the absorptivity of NBS bilirubin in chloroform at $453 \mathrm{~nm}$ and at $25^{\circ} \mathrm{C}$. It may be of interest to point out that these solutions were relatively stable when stored in the dark at room temperature. Absorb- 
ance measurements on several solutions covered with aluminum foil decreased less than 1 percent over a period of six weeks.

Table 14. Apparent absorptivity of SRM 916, Bilirubin, in chloroform at $25^{\circ} \mathrm{C}$.

\begin{tabular}{rcc} 
Sample No. Wt., mg & Absorptivity ${ }^{\mathrm{a}}(453) \mathrm{nm}$ ) liter $\mathrm{cm}^{-1} \mathrm{~g}^{-1}$ \\
\hline 88 & 5.354 & 104.46 \\
1568 & 7.893 & 104.38 \\
758 & 3.700 & 104.53 \\
341 & 7.756 & 104.43 \\
1053 & 6.765 & 104.58 \\
1933 & 6.707 & 104.74 \\
& & Avg. 105.52 \\
& & S.D. 0.13 \\
& & Rel. S.D. $0.12 \%$
\end{tabular}

$a_{\text {Sample contains }} 0.8$ percent of chloroform.

H. Spectrophotometric Study of the Dye Ratio in Sample of Ballpoint Ink - R. W. Burke

1. Introduction

A brief study was undertaken to determine the applicability of dual-wavelength spectrophotometry to the determination of the dye ratio in a sample of ballpoint ink. The ultimate purpose of this investigation was to establish the accuracy of this procedure for identifying a possible manufacturer of ink used in signing a document.

\section{Experimental}

The dye content of the sample was believed to be a 60/40 weight mixture of Methyl Violet and Victoria Blue. Small samples of these two dyes identified as Methyl Violet DY Base and Victoria Pure Blue BO Base were obtained from a major ink manufacturer. A sample of bulk ink, reportedly having the $60 / 40$ dye composition, and several scribble charts prepared from this ink were also obtained from the same manufacturer. 
a. Calibration. Absorption spectra were measured on ethanolic solutions of the two dyes. A peak at $580 \mathrm{~nm}$ was obtained for Methyl Violet (MV). Victoria Blue (VB) produced a maximum at $590 \mathrm{~nm}$ and a pronounced shoulder at $620 \mathrm{~nm}$. Additional measurements on the MV system showed a continual increase in absorbance, while the VB solution appeared relatively stable. The addition of 1-2 drops of concentrated hydrochloric, however, immediately increased ( 20 percent) and stabilized the absorbance of the MV solution. Under these conditions, the absorption peak shifted from 580 to $583 \mathrm{~nm}$. Acidification of the VB solution did not change the absorbance at the 590 peak, but did increase the absorbance in the shoulder region near $620 \mathrm{~nm}$. The resulting absorption spectrum now exhibited a double peak instead of the previous peak-shoulder relationship. Apparently, some acid is necessary to hasten the conversion of the colorless carbinol base into the colored dye. Following these studies, approximately $0.3 \mathrm{ml}$ of $12 \mathrm{~N} \mathrm{HCl}$ per liter was added to all ethanolic solutions of the dyes.

The absorption spectra of the acidified ethanolic solutions of MV and VB are shown in figure 1l. The two wavelengths selected for the simultaneous determination of MV and VB were 583 and $640 \mathrm{~nm}$. Absorbance measurements were made on individual solutions of these dyes over a range of concentrations (the dyes were used as received to prepare these "standard" solutions). The following two equations were obtained from this set of measurements.

$$
\begin{aligned}
& 0.100(V B)+0.242(\mathrm{NV})=A_{S}(583 \mathrm{~nm}) \\
& 0.080(V B)+0.011(\mathrm{MV})=A_{S}(640 \mathrm{~nm})
\end{aligned}
$$

The coefficients correspond to the absorbances measured in a $1.00 \mathrm{~cm}$ cuvette for dye concentrations of $1.00 \mathrm{mg} / \mathrm{l}$. Beer's 
Law was obeyed by both dye solutions over the absorbance range of $0-1.2$.

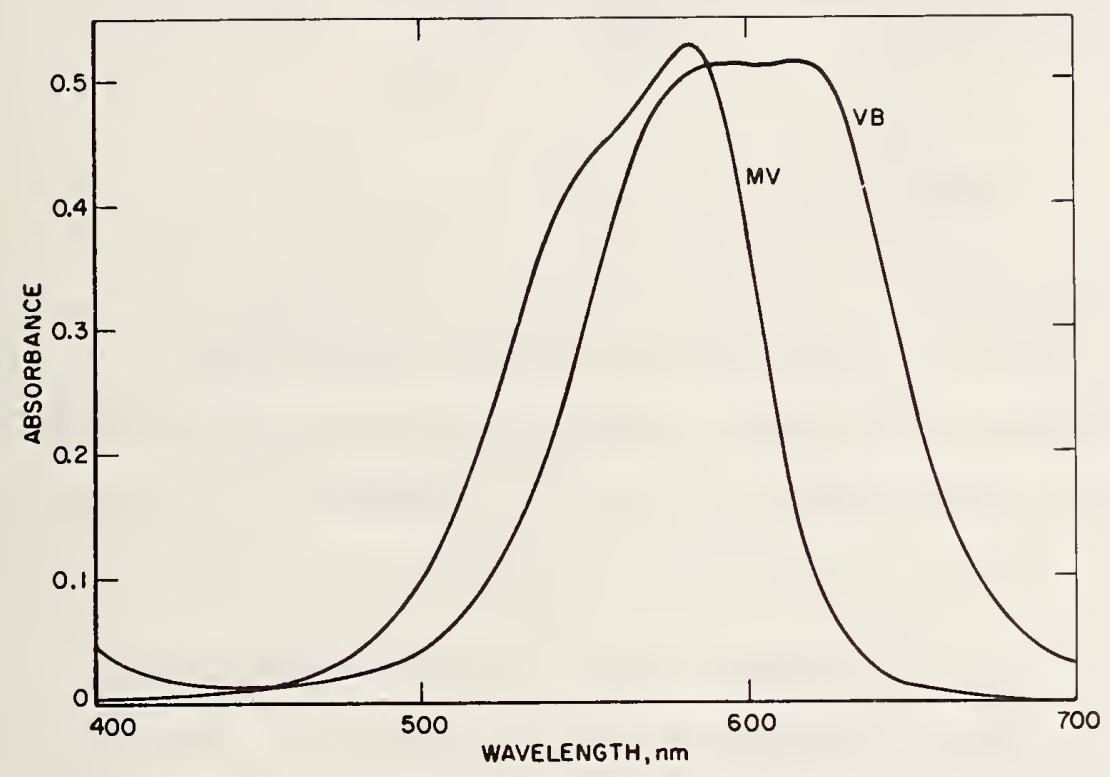

Figure 11. Absorption spectra of acidified ethanolic solutions of Methyl Violet DY Base (MV) and Victoria Pure Blue BO Base (VB).

b. Analysis of Composite Dye Solutions. Two

composite dye solutions were prepared by dissolving weighed amounts of each of the dyes in absolute ethanol, acidifying with $0.3 \mathrm{ml}$ of $12 \mathrm{~N} \mathrm{HCl}$ and diluting to 1 liter with ethanol. Absorbances were measured at 583 and $640 \mathrm{~nm}$ in a $1.00 \mathrm{~cm}$ cuvette. Equations (1) and (2) were then solved simultaneously to obtain the measured composition of the two solutions. The results are summarized in table 15. 
Table 15. Analysis of known mixtures of Methyl Violet DY Base (MV) and Victoria Pure Blue BO Base (VB).

Sample Dye Conc., mg/l Rel. Wt. \%, Theor. Rel. Wt. \%, Found

\begin{tabular}{|c|c|c|c|c|c|c|}
\hline & MV & $\underline{\mathrm{VB}}$ & $\underline{\mathrm{MV}}$ & $\underline{\mathrm{VB}}$ & MV & $\underline{\mathrm{VB}}$ \\
\hline & $\begin{array}{l}3.52 \\
3.52\end{array}$ & $\begin{array}{l}2.37 \\
3.54\end{array}$ & $\begin{array}{l}59.8 \\
49.9\end{array}$ & $\begin{array}{l}40.2 \\
50.1\end{array}$ & $\begin{array}{l}59.6 \\
49.1\end{array}$ & $\begin{array}{l}40.4 \\
50.9\end{array}$ \\
\hline
\end{tabular}

c. Analysis of the Bulk Ink. Samples of the bulk ink were analyzed in the same manner as the known mixtures, but with one modification. To remove the graphite suspension, the solutions were filtered through 0.25 micron solvent-resistant filters. Hydrochloric acid was added, although $\mathrm{pH}$ measurements on aqueous suspensions of the bulk ink showed that it was already slightly acidic. Therefore, the bulk ink was expected to be free of carbinol base. This was verified by measurements on both acidified and nonacidified samples in which identical results were obtained. Some typical values are given in table 16 .

Table 16. Analysis of bulk ink.

\begin{tabular}{ccc} 
Sample & \multicolumn{3}{c}{ Relative Dye } & Composition, Wt. $\%$ \\
\cline { 2 - 3 } 1 & MV & VB \\
2 & 60.2 & 39.8 \\
3 & 61.5 & 38.5 \\
4 & 61.2 & 38.8 \\
& 61.9 & 38.1
\end{tabular}

d. Analysis of Bulk Ink After Application to

Bond Paper. A small portion of the bulk ink was placed in an empty ballpoint cartridge and several writing samples were then made on bond paper. Sections were cut from this paper and reserved for analysis. Several were analyzed immediately; others were stored and analyzed over a period of 4-5 days. All samples were eluted with slightly acidic ethanol. Although the major portion of the graphite remained on the filter paper, the filtration was nevertineless performed as a precautionary measure. No trend in results was observed. 
Table 17 gives the results of these analyses.

Table 17. Analysis of bulk ink following application and elution from bond paper.

\begin{tabular}{ccc} 
Sample & \multicolumn{3}{c}{ Relative Dye Composition, Wt. $\%$} \\
\cline { 2 - 3 } 1 & MV & VB \\
2 & 60.1 & 39.9 \\
3 & 60.1 & 39.9 \\
60.6 & 39.4
\end{tabular}

e. Dye Composition of Manufacturer's Scribble Chart Ink. Small portions of the manufacturer's scribble chart were analyzed in the same manner as the bond paper writing samples. However, the results differed considerably, as shown in table 18 . Having been assured that the scribble

Table 18. Analysis of ink on manufacturer's scribble chart.

\begin{tabular}{ccc} 
Sample & \multicolumn{2}{c}{ Relative Dye Composition, Wt. \% } \\
\cline { 2 - 3 } 1 & $\underline{\text { MV }}$ & VB \\
2 & 53.4 & 46.6 \\
3 & 52.8 & 47.2 \\
4 & 53.7 & 46.3 \\
& 52.7 & 47.3
\end{tabular}

chart was prepared from a sample of the bulk ink, only two explanations were possible to account for the differing results: (1) Preferential elution of the VB component following prolonged drying and/or (2) Preferential fading of the MV component. Experiments on the effects of drying were carried out by heating writing samples of the bulk ink at $75^{\circ} \mathrm{C}$ for 2 to 14 hours. No differences were observed with heating times, and the average values obtained were 60.5 percent MV and 39.5 percent VB. f. Light Fastness. Since the effects of drying did not explain the disparity in the bulk ink and scribble chart results, the second alternative of preferential fading of the MV component was then examined. Nine 
writing samples of the bulk ink on bond paper were prepared and exposed in an accelerometer provided by the Building Research Division. The acceleration factor of this instrument for fluorescent and ordinary sunlight is about 100X. The results of this study are given in table 19.

Table 19. Variation of relative dye concentration after exposure to light.

\begin{tabular}{|c|c|c|c|}
\hline \multirow[t]{2}{*}{ Sample } & $\begin{array}{c}\text { Simulated Exposure, } \\
\text { days }\end{array}$ & \multicolumn{2}{|c|}{$\begin{array}{l}\text { Relative Dye } \\
\text { Concentration, wt. \% } \\
\end{array}$} \\
\hline & & MV & $\underline{\mathrm{VB}}$ \\
\hline 1 & 1 & 59.5 & 40.5 \\
\hline 2 & 2 & 57.8 & 42.2 \\
\hline 3 & 3 & 57.0 & 43.0 \\
\hline 4 & 4 & 54.0 & 46.0 \\
\hline 5 & 5 & 53.4 & 46.6 \\
\hline 6 & 6 & 52.0 & 48.0 \\
\hline 7 & 7 & 52.0 & 48.0 \\
\hline 8 & 8 & 50.1 & 49.9 \\
\hline 9 & 100 & 29.8 & 70.2 \\
\hline
\end{tabular}

Visual inspection indicated that samples 4-9 had faded perceptibly. In fact, only the graphite residue was apparent for the sample subjected to the 100 day exposure (sample 9). Thus, while both dyes fade on exposure to light, the results in table 19 clearly indicate that MV fades more rapidly than VB. Relative light fastness seems to explain the differences observed between the bulk ink and scribble chart ink analyses.

3. Conclusion

The original objective of this investigation was to determine if a dye ratio could be used to identify, or narrow substantially, the commercial sources of a given ballpoint ink that may have been used to sign a document. The light fastness studies clearly show that for those inks containing DY Base and Victoria Pure Blue BO Base, additional information the light exposure is needed. Otherwise only qualitative identification is possible. 


\section{FLUORESCENCE}

A. Introduction

Spectrofluorometry is a sensitive and selective analytical technique of widespread use in many areas such as clinical, environmental, analytical and biological chemistry. Important research using this technique is being done on biological and metabolic processes, enzyme interactions and characterization of binding sites, determination of pollutants, trace metal analysis and fundamental studies on energy transfer and manifolds.

It has long been an accepted fact that fluorescence standards are necessary to obtain meaningful and comparative data which are of use in these research areas [48]. A general program was devised [1] and research was started to develop a series of fluorescence standards to cover the wavelength range 350 to $700 \mathrm{~nm}$.

Research this past year at NBS was concerned mainly with investigations into experimental determinations, conditions, stabilities and reproducibilities of solution and solid samples using commercial instruments. Relative reproducibilities of sample fluorescence intensities were found to have a standard deviation of 4 percent for glass samples and 6 percent for solutions on a day-to-day basis and 0.5 to 1.5 percent on measurements made during an eight hour period. It is evident from these investigations that for more reproducible results required for SRM certification, a high accuracy spectrofluorometer with closely controlled instrumental parameters is needed. Work at Hebrew University with Dr. R. Reisfeld under a NBS PL 480 grant was concerned mainly with the evaluation of inorganic ions in glass matrices for SRM's. Two ions, thallium(I) and cerium(III) showed good potential qualities as SRM's. Lead(II), manganese(II) and copper(II) - Copper(I) 
were also investigated briefly, and exhibited suitable properties for a SRM series covering the desired wavelength regions.

Research with rare earth ions in glass matrices also suggests their use as SRM's for special cases based on their sharp spectral characteristics. Preliminary results also show that energy transfer between pairs of these ions provide a good method for exciting acceptor ions at the donor's excitation wavelength.

More work is needed on the evaluation of stabilities and physical and fluorescent properties of these glasses under various experimental conditions. B. Instrumentation Evaluation - R. A. Velapoldi

Preliminary investigations largely concerned instrumental reproducibilities and stabilities using the well studied quinine sulfate in $0.1 \mathrm{~N}_{2} \mathrm{SO}_{4}$ [49] and a uranium glass [50] as comparative standards.

Two representative spectrofluorometers were used; instrument (A) which provided corrected emission and excitation spectra and instrument $B$ which produced uncorrected spectra. Both have a xenon arc source, excitation and emission monochromators and photomultiplier detectors. One was previously described [51] and may be operated in corrected or uncorrected fluorescence modes. In the corrected mode, excitation spectra are corrected to constant excitation energy. Emission spectra are presented in quanta/unit bandwidth.

Before determining instrumental parameters, it was necessary to investigate the characteristics of the quinine sulfate solutions and the reproducibility of repetitive solution preparation. Excitation and emission maxima for quinine sulfate in $0.1 \mathrm{~N}_{2} \mathrm{SO}_{4}$ were $350 \mathrm{~nm}$ and $455 \mathrm{~nm}$, respectively. 
Figure 12 shows the corrected and uncorrected excitation and emission spectra for quinine sulfate, purified according to Fletcher [52], in $0.1 \mathrm{~N}_{2} \mathrm{SO}_{4}$. Note the dependence of the excitation spectrum on the xenon lamp intensity in the uncorrected spectra. On the other hand, since emission occurs over a wavelength range of relative linearity of detector response and by one excitation wavelength, no significant dependence can be observed.

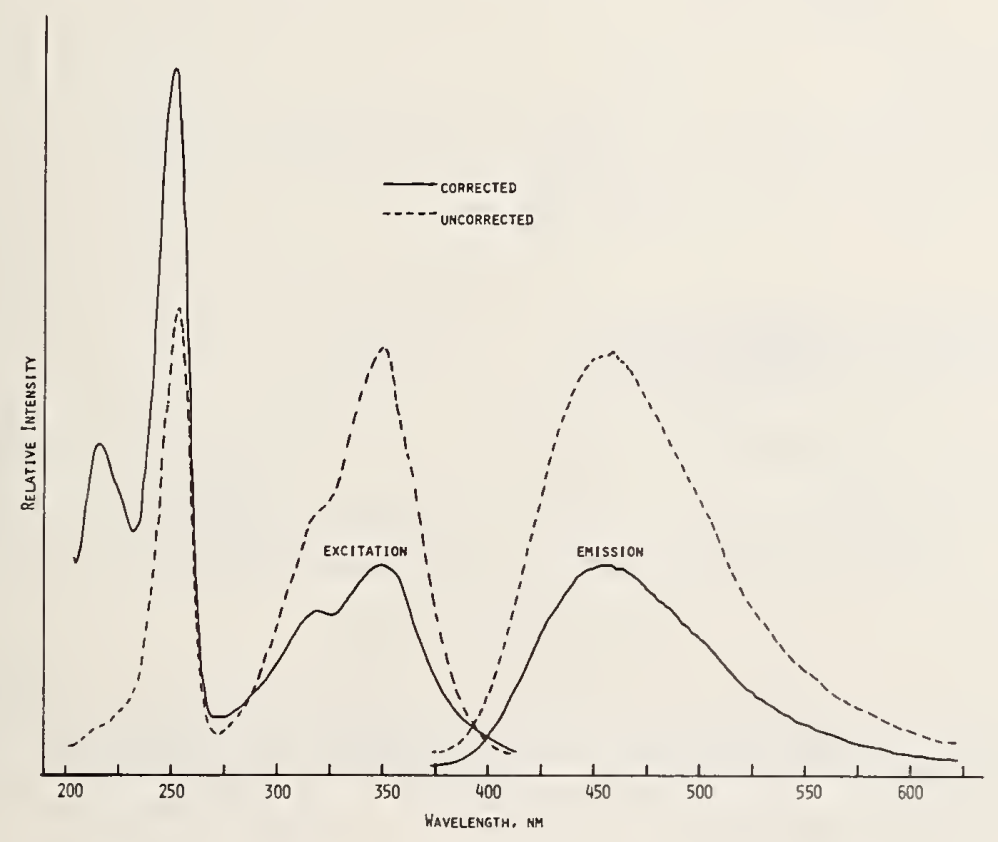

Figure 12. Corrected and uncorrected emission and excitation spectra of quinine sulfate in $0.1 \mathrm{~N} \mathrm{H}_{2} \mathrm{SO}_{4}$.

Fluorescence emission spectra are usually measured as total fluorescence area under the emission peak. Measurements show, figure 13, that peak height is directly proportional to peak area and thus peak height may be used as a measure of emission area. This relationship is generally true with species in which excited state energy levels do not change for reasons such as agglomeration or dimerization with increasing concentration. 


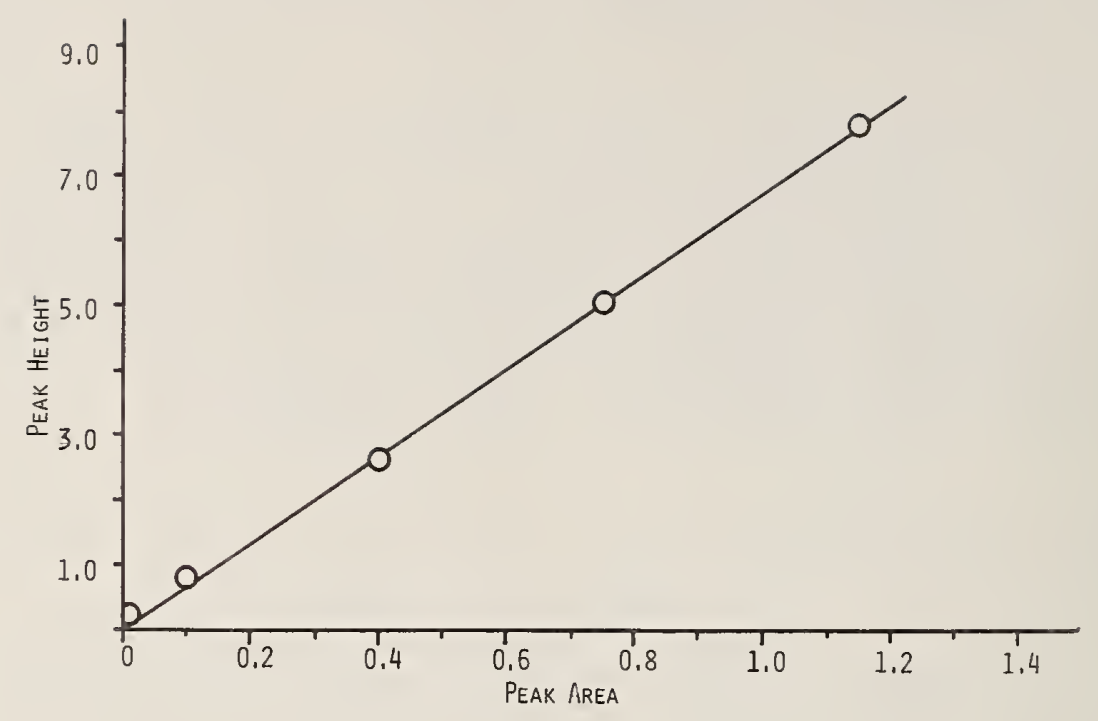

Figure 13. Emission peak height is directly proportional to emission peak area.

Three samples of quinine sulfate were weighed and prepared as stock solutions ( $1000 \mathrm{ppm}$ in $0.1 \mathrm{~N} \mathrm{H}_{2} \mathrm{SO}_{4}$ ) and dilutions were made in duplicate or triplicate to provide working solutions ( 0.01 to $20.0 \mathrm{ppm}$ ).

Figure 14 is a plot of relative fluorescence versus quinine sulfate concentration. Linearity of response was observed to a concentration of $6 \mathrm{ppm}$. Concentration quenching (inner filter effects) was noted at concentrations of solute greater than $6 \mathrm{ppm}$. An absorbance versus concentration plot is linear to higher concentrations ( $100 \mathrm{ppm}$ ).

Table 20 shows the reproducibility of the three quinine sulfate solutions, each value being the average of 10 determinations. There were no apparent trends for the various solutions; thus the differences for the three samples apparently show instrumental but not methodological errors. In the method using dilution by weight, the instrumental 


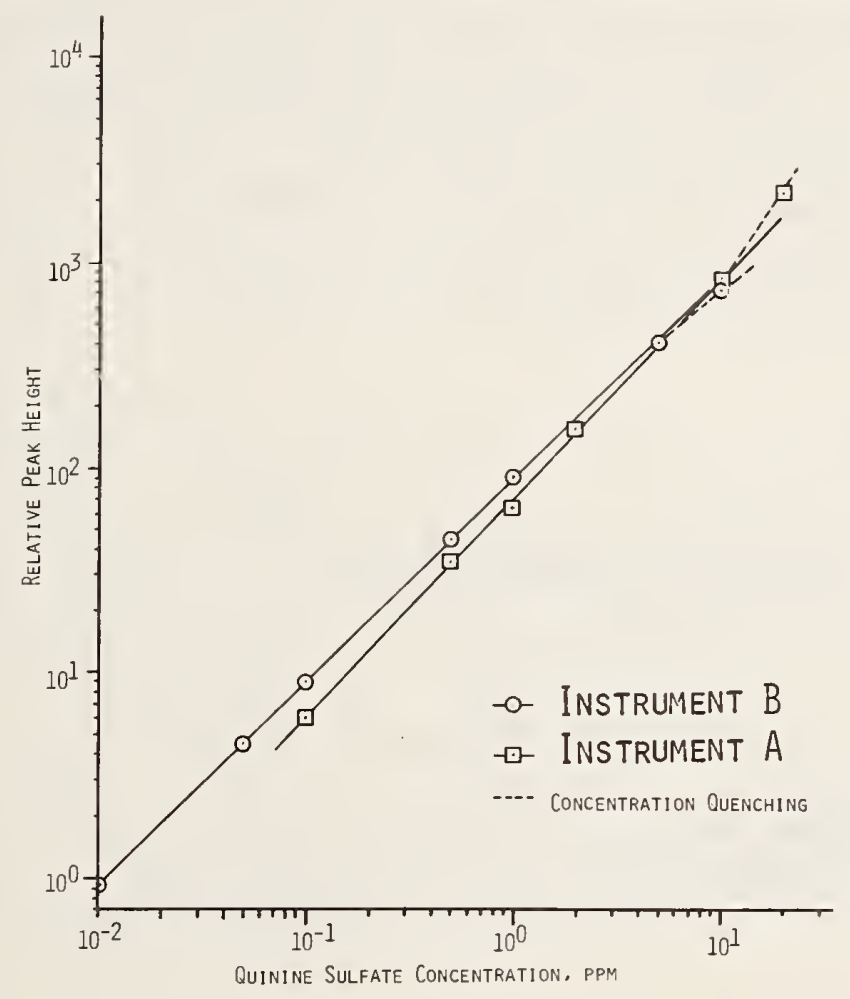

Figure 14. Relative fluorescence intensity versus quinine sulfate concentration showing "concentration quenching." - instrument B, instrument A

Table 20. Reproducibility of preparation and measurement of quinine sulfate solutions in $0.1 \mathrm{~N}_{2} \mathrm{H}_{4}$ peakheight measurements.

\begin{tabular}{|c|c|c|c|c|c|c|c|}
\hline \multirow{2}{*}{$\begin{array}{l}\text { Concen- } \\
\text { tration } \\
\text { Sample }\end{array}$} & \multicolumn{7}{|c|}{ Peak Heights } \\
\hline & $0.5 \mathrm{ppm}$ & $1 \mathrm{ppm}$ & $1 \mathrm{ppm}^{\mathrm{a}}$ & $5 \mathrm{ppm}$ & $5 \mathrm{ppm}^{\mathrm{a}}$ & $10 \mathrm{ppm}$ & \\
\hline 1 & $\begin{array}{r}0.058 \\
.057 \\
.061\end{array}$ & $\begin{array}{r}0.100 \\
.107 \\
.103\end{array}$ & $\begin{array}{r}0.103 \\
.104 \\
.105\end{array}$ & $\begin{array}{r}0.496 \\
.501 \\
.492\end{array}$ & $\begin{array}{r}0.514 \\
.512 \\
.515\end{array}$ & $\begin{array}{r}0.900 \\
.907 \\
.917\end{array}$ & $\begin{array}{r}0.907 \\
.915 \\
.911\end{array}$ \\
\hline
\end{tabular}

$\mathrm{a}_{\text {Dilution by weight. }}$ 
variation is the limiting factor ( 1 percent), while dilution by volumetric techniques shows a 1.5 to 2 percent variation.

Fluorescence measurements of the emission maxima and spectra were made on a day-to-day basis at the same instrumental settings. Substantiation for instrumental variations of measurements on a day-to-day basis are shown in figure 15 . Statistical analyses for these data (38 days $B$ instrument, 25 days $A$ instrument) are given in table 21 . With the

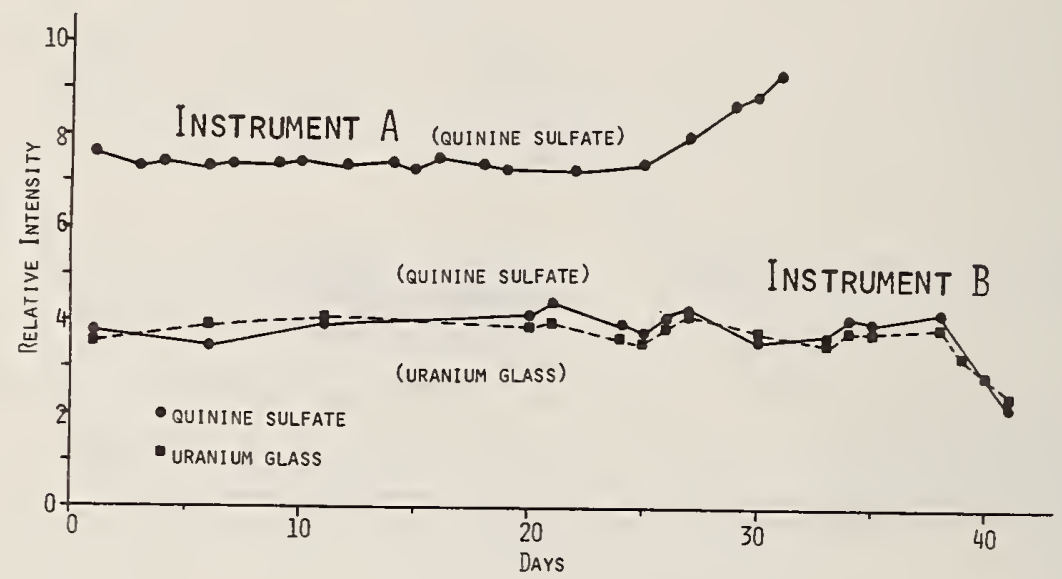

Figure 15. Instrumental stability and reproducibility as a function of time using liquid and solid samples.

Table 21. Statistical analysis of instrumental stabilities using quinine sulfate and uranium glass as standards.

\begin{tabular}{|c|c|c|c|}
\hline & \multirow{2}{*}{ 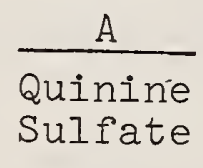 } & \multicolumn{2}{|c|}{$B$} \\
\hline & & $\begin{array}{l}\text { Quinine } \\
\text { Sulfate }\end{array}$ & $\begin{array}{l}\text { Uranium } \\
\text { Glass }\end{array}$ \\
\hline $\begin{array}{c}\text { Average Peak } \\
\text { Height }\end{array}$ & 0.739 & 0.398 & 0.383 \\
\hline$\sigma$ & .011 & .027 & .018 \\
\hline$\% \quad \sigma$ & 1.49 & 6.89 & 4.80 \\
\hline
\end{tabular}


corrected instrument, instrumental variations are less than those for the uncorrected spectrofluorometer. Evidence for xenon lamp deterioration is seen for both instruments after 25 days (Instrument A) and 38 days (Instrument B) by the definite change in emission intensities. These observations could also be interpreted as quinine sulfate deterioration; however, the uranium glass measured in the uncorrected instrument also follows the same trend, and it is unlikely that two 'standards' would show similar degradation characteristics.

For a single day, good instrumental stability can be obtained, as shown by data evaluation in table 22. The large percent standard deviation for the 1 ppm solution is undoubtedly due to errors in measuring small areas.

Table 22. Statistical analysis for eleven fluorescence determinations of quinine sulfate during an eight hour span using a corrected spectrofluoro meter.

$\begin{array}{llll}\text { ppm } & 1 & 5 & 10\end{array}$

$\begin{array}{cccc}\text { Avg. Peak Area } & 0.1047 & 0.557 & 1.116 \\ \sigma & .0045 & .0033 & .0050 \\ \% & 0.34 & 0.59 & 0.49\end{array}$

Operating Instrument $A$ in an uncorrected mode necessitates longer warm-up times for lamp and detector response reproducibility, figure 16. An aluminum plate, placed at a $45^{\circ}$ angle in the same compartment served as the sample. Approximately $2-1 / 2$ hours instrumental warm-up time are needed. Most of this time is required for source stabilization. In the corrected mode, fifteen minutes warm-up is sufficient to give reproducible results, since fluctuations in source intensity are eliminated by emission to source intensity ratioing. 


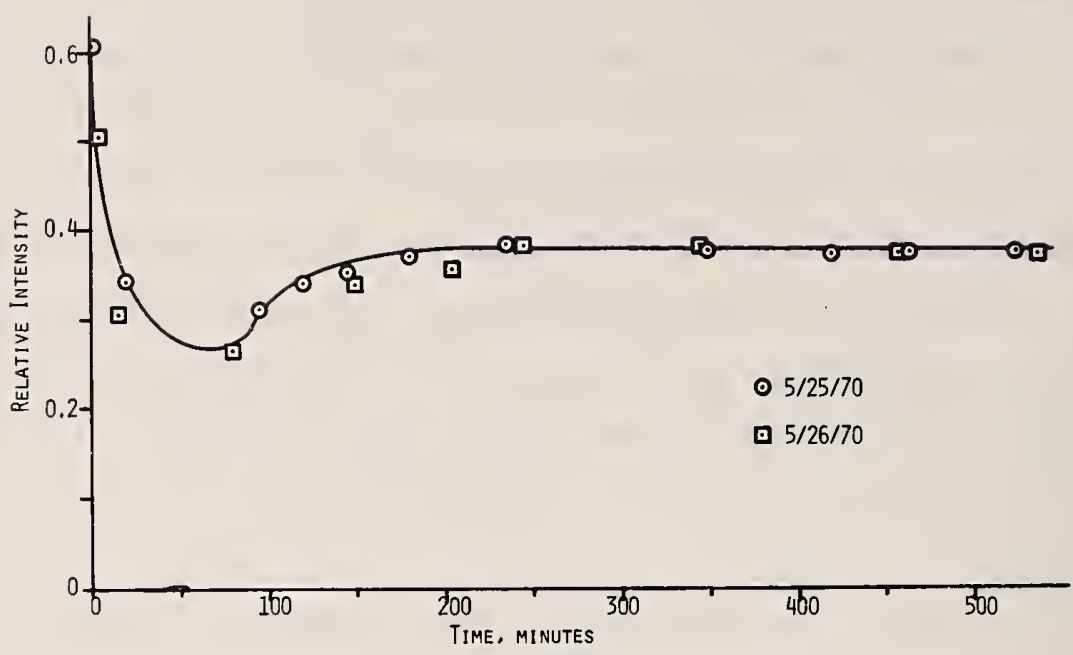

Figure 16. Typical warm-up times for a commercial instrument in uncorrected mode using aluminum foil as reflecting sample.

Standards are very useful in determining instrumental characteristics and are diagnostic tools for detecting instrumental problems. Standards evaluation is limited to reproducibilities of 2-5 percent, depending on instrumentation used. No discussion is presented on the accuracy of these determinations, because all measurements were made in a relative and not absolute manner. Greater reproducibility and accuracy can be obtained with a high accuracy spectrofluorometer. The design and construction of such an instrument is one of the objectives of the fluorescence program.

One prerequisite for providing a standard is the determination of quantum efficiencies. The quantum efficiency of quinine sulfate has been reported between 0.4 and $0.6[49,53]$. Although some questions have been raised as to the suitability of quinine sulfate as a standard, it has been extensively studied and very widely used as a comparative standard. Statistical analyses of quantum efficiency data from fourteen 
laboratories (using several different methods and acid concentrations) indicate a value of $0.544 \pm 0.033$.

Using these data, a comparative quantum efficiency for purified fluorescein [54] was determined in quadruplicate and a value of $0.87 \pm 0.03$ was obtained. Literature values reported in sixteen studies give an average quantum efficiency of $0.884 \pm 0.041$ for fluorescein. However, there does appear to be a significant increase in the quantum efficiency for quinine sulfate in different acid concentrations, e. g., 0.546 for $\mathrm{IN} \mathrm{H}_{2} \mathrm{SO}_{4}$ [53]. Preliminary results in this laboratory show a 6 percent relative decrease between $\mathrm{IN}_{2} \mathrm{H}_{2} \mathrm{SO}_{4}$ and $0.1 \mathrm{~N}_{2} \mathrm{SO}_{4}$. C. Fluorescence - Inorganic Ions in Glass Matrices -

R. A. Velapoldi and R. Reisfeld [55]

Fluorescence standards may be solids or solutions. The research at Hebrew University was to investigate and determine the fluorescence characteristics of various metal ions in glass matrices. The use of these solids as standards is attractive for several reasons: they are rapidly and easily used; have low temperature coefficients of expansion; have only two reflections; scattering is controlled; are stable; and have no cell dimension problems; all of which decrease methodological errors. In addition, solids are convenient for cooperative testing.

The research at Hebrew University covered investigations of (a) fluorescence of inorganic ions in glasses which have broad excitation and emission spectra, (b) rare earth fluorescence and (c) energy transfer between pairs of ions. D. Inorganic Ions with Broad Spectra

1. General

Three metals, thallium(I), cerium(III) and lead(II), were found suitable for standards considering positions of emission wavelengths and half-bandwidths. Thallium and 
cerium are two good non-organic UV emitters, while lead emits in the blue region. All have relatively broad emission and excitation half-bandwidths (see table 23).

Table 23. Emission and excitation wavelength dependence on matrix for lead, cerium and thallium.

\begin{tabular}{|c|c|c|c|c|}
\hline Ion & Matrix & $\begin{array}{l}\text { Waveler } \\
\text { Excitation }\end{array}$ & Emission & $\begin{array}{c}\text { Emission } \\
\text { Half Bandwidths } \\
\text { nm }\end{array}$ \\
\hline $\begin{array}{l}\text { TI } \\
\text { T1 } \\
\text { T1 }\end{array}$ & $\begin{array}{l}\text { KCl } \\
\text { Phosphate } \\
\text { Borate }\end{array}$ & $\begin{array}{l}247.5 \\
219.0 \\
233.0\end{array}$ & $\begin{array}{l}300 \\
302 \\
325\end{array}$ & $\begin{array}{l}40 \\
70 \\
90\end{array}$ \\
\hline $\begin{array}{l}\mathrm{Ce} \\
\mathrm{Ce} \\
\mathrm{Ce} \\
\mathrm{Ce}^{\mathrm{C}}\end{array}$ & $\begin{array}{l}\text { Phosphate } \\
\text { Boratea } \\
\text { Borax } \\
\text { Silicate }\end{array}$ & $\begin{array}{l}297.0 \\
310.0 \\
311.0 \\
317.0\end{array}$ & $\begin{array}{l}334 \\
364 \\
365 \\
380\end{array}$ & $\begin{array}{l}55 \\
80 \\
65 \\
85\end{array}$ \\
\hline $\begin{array}{l}\mathrm{Pb} \\
\mathrm{Pb} \\
\mathrm{Pb} \\
\mathrm{Pb}\end{array}$ & $\begin{array}{l}\text { Phosphate } \\
\text { Borateat } \\
\text { Borax } \\
\text { Germanate }\end{array}$ & $\begin{array}{l}241.5 \\
261.0 \\
241.0 \\
295.0\end{array}$ & $\begin{array}{l}309 \\
424 \\
425 \\
440\end{array}$ & $\begin{array}{l}70 \\
140 \\
165 \\
125\end{array}$ \\
\hline
\end{tabular}

Cerium(III) is included because of its similar spectral characteristics to the other ions.

The glasses used in these studies are disks prepared as previously described [56]. In some cases, these disks are susceptible to air and water vapor degradation (fogging) which affects the optical properties, thus making the glasses unsuitable as standards. This problem can be circumvented by use of stable phosphate, borate and silicate base glasses developed at NBS by the Inorganic Glass Section, Inorganic Materials Division [57].

2. Quantitative and Qualitative Analysis

Each ion has specific excitation and emission spectra and may be qualitatively identified by fluorescence. For 
low concentrations, a plot of the relative fluorescence intensity versus concentration is linear, figure 17, and provides a means for the quantitative determination of these ions.

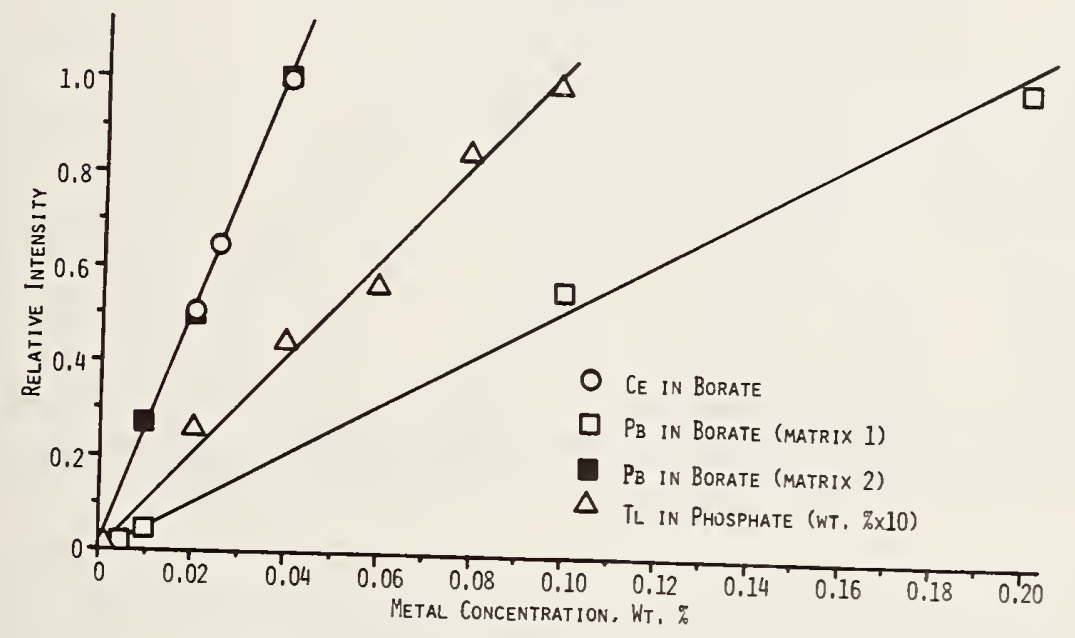

Figure 17. Relative fluorescence intensity versus concentration in weight percent for cerium(III), lead(II) and thallium(I).

3. Matrix Effects

The positions of the emission and excitation band maxima are dependent on the type of glass matrix used. The variation of band position for cerium, thallium and lead are shown in figure 18 and tabulated in table 23. These effects are attributable to fluorescent center-matrix interactions. 


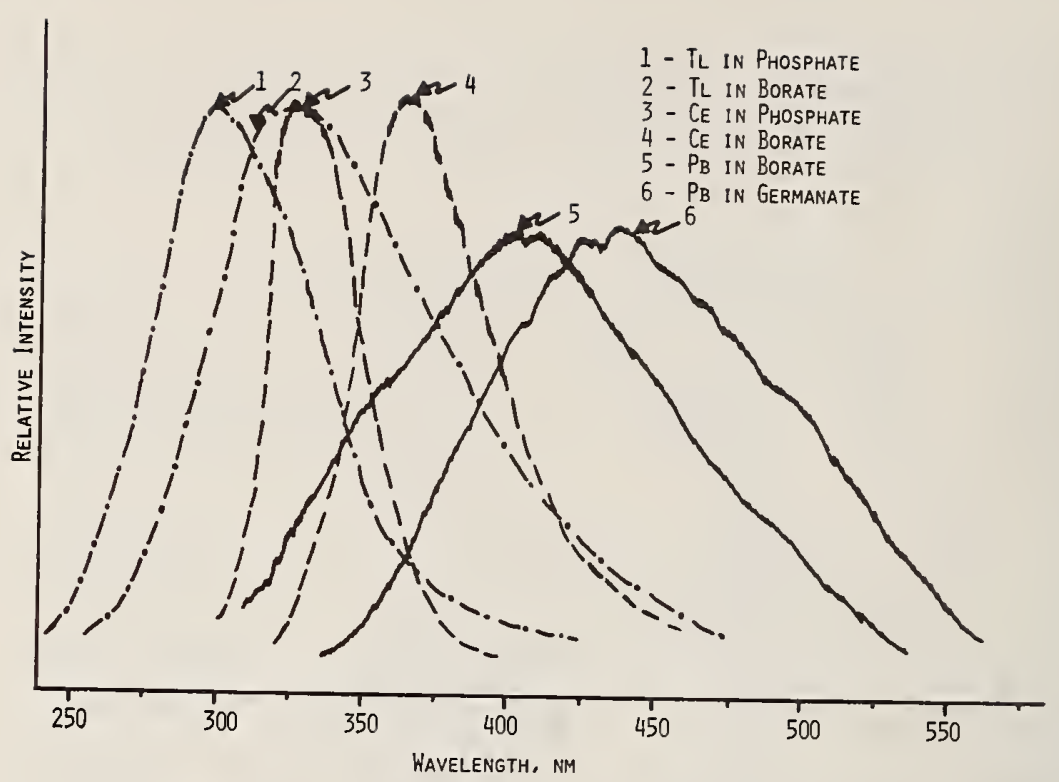

Figure 18. Wavelength dependence of emission peaks on matrix for cerium, lead and thallium.

The coulombic field of the active ion is approximated

by (1)

$$
F=\frac{z_{i}}{r^{2}}
$$

where $F=$ coulombic field

$$
r=\text { ionic radius }
$$

$Z_{i}=$ ionic charge.

Calculations of the coulombic fields for various ions are presented in table 24 and show that inorganic ions, including rare earths, enter the glass matrix as network modifying ions. 
Table 24. Ionic field strengths of cations in glasses.

\begin{tabular}{|c|c|c|c|}
\hline Ion & $\begin{array}{l}\text { Ionic Radius, } A \\
{[58]} \\
\end{array}$ & $\begin{array}{l}\text { Field Strength } \\
\mathrm{z} / \mathrm{r}^{2} \\
\end{array}$ & Effect \\
\hline $\begin{array}{l}(\text { III }) \\
(\mathrm{V}) \\
i(\mathrm{IV})\end{array}$ & $\begin{array}{r}0.20 \\
.34 \\
.41\end{array}$ & $\begin{array}{l}75.0 \\
43.2 \\
23.8\end{array}$ & Network Forming Ions \\
\hline $\begin{array}{l}e(I I I) \\
l(I) \\
\text { (III) } \\
\text { (II) } \\
\text { (III) } \\
\text { (III) } \\
\text { (III) } \\
\text { (III) } \\
\text { (III) }\end{array}$ & $\begin{array}{l}1.18 \\
1.49 \\
0.99 \\
.95 \\
.95 \\
.964 \\
.923 \\
.908 \\
.938\end{array}$ & $\begin{array}{l}2.16 \\
.45 \\
2.04 \\
1.11 \\
3.32 \\
3.23 \\
3.52 \\
3.64 \\
3.41\end{array}$ & Network Modifying Ions \\
\hline
\end{tabular}

The observed matrix effects (actual ligand field perturbations) may be approximated also by (2) [56]:

$$
E=\Sigma \frac{z_{i} z_{j}}{r}+\frac{b}{r^{n}}
$$

where $b, r, Z$, and $E$ represent the accepted terms. It is seen from table 24 that stronger matrix perturbations are in the order borate > phosphate > silicate resulting in shifts of emission spectra to longer wavelengths. Cerium in silicate does not follow this pattern; however, NBS matrices had different starting compounds, were higher melting and were prepared under different melt conditions. In addition, cerium prepared at Hebrew University is quantitatively cerium(III) and not cerium(III)-cerium(IV) mixtures as prepared at NBS. Results are as predicted with rare earths whenever glasses were produced under similar conditions.

Emission shifts may be interpreted by Ligand Field Theory which states: an increase in the separation of the crystal field-split degenerate levels indicates an increase in the ligand field. In cases of transitions between two nondegenerate energy levels, an increase in the ligand field 
causes the upper levels displacement toward lower energy levels, thus causing longer wavelength fluorescence, summarized in figure 19.

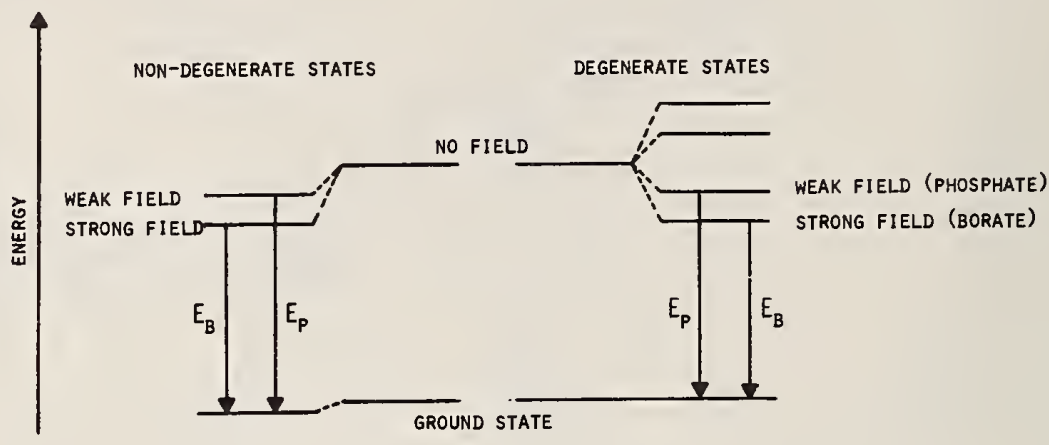

Figure 19. Matrix dependent ligand field effects on degenerate and ion-degenerate states.

In addition, as discussed later for the rare earths, weaker matrix interactions (use of phosphate rather than borate) results in less fluorescent center interactions by energy transfer. The lower probabilities for energy transfer produces less concentration quenching, thus making phosphate a somewhat better matrix for standards.

Infrared studies of the matrices show that borate has the highest stretching frequency, table 25, which is more compatible with the energy gaps of transitions for rare earths and thus has a higher probability of phonon assisted energy transfer from the metal to the borate matrix resulting in increased radiationless transitions. Shorter bond lengths similarly show higher 'effective' ion charge-to-size ratios again resulting in increased matrix-metal ion interactions. 
Table 25. Infrared stretching frequencies and bond lengths for active ion-oxygen interactions in the matrix.

\begin{tabular}{llr} 
Matrix & $\begin{array}{c}\text { Stretching } \\
\text { Frequency }[59] \\
\left(\mathrm{cm}^{-1}\right)\end{array}$ & $\begin{array}{r}\text { Bond Len } \\
(\mathrm{A})\end{array}$ \\
\hline licate (Si-O) & $1010-1115$ & 1.62 \\
taphosphate $(\mathrm{P}-0)$ & $1140-1300$ & 1.57 \\
rate $(\mathrm{B}-\mathrm{O})$ & $1310-1380$ & 1.39
\end{tabular}

4. Quantum Eficiencies

Quantum efficiencies are measures of the efficiency through which ions or molecules convert absorbed light into emitted light, equation 3, and are characteristic of the individual

$$
Q=\frac{\text { energy emitted }}{\text { energy absorbed }}=\frac{\text { photons emitted }}{\text { photons absorbed }}
$$

species. Quantum efficiencies are of practical and theoretical importance since they: (I) permit evaluation of sensitivity of proposed methodology, (2) permit evaluation of material purity, (3) permit evaluation of quenching and specie interferences, (4) are needed for calculating thresholds for laser action, (5) determine suitabilities of species as energy donors, (6) permit assignments of electronic transitions, (7) determine extent of radiationless transitions, etc. They may be calculated by several methods:

(a) Absolute [60]

(b) Comparative [52, 61]

(c) Lifetime measurements [62]

(d) Calorimetrically [63].

We are currently performing quantum efficiency measurements by the comparative (b) and lifetime (c) methods because of rapidity and ease of measurements; however absolute methods 
will be developed. Method ( $b$ ) will be discussed here and method (c) will be discussed later.

Comparative quantum yield and oscillator strength have been determined for the 'A' band of thallium(I) chloride in pressed polycrystalline disks of $\mathrm{KCl}$ [64] using solutions of quinine sulfate (QS) in $0.1 \mathrm{~N} \mathrm{H}_{2} \mathrm{SO}_{4}$ as the standard. Maximization of the emission intensity was necessary since disks ( $1 \mathrm{~cm}$ diameter, $1-2 \mathrm{~mm}$ thick) or disk-shaped cuvettes were used. Emission intensity is dependent on the angle of excitation, figure 20, with the result that angles of $15-20^{\circ}$ give maximum relative intensity.
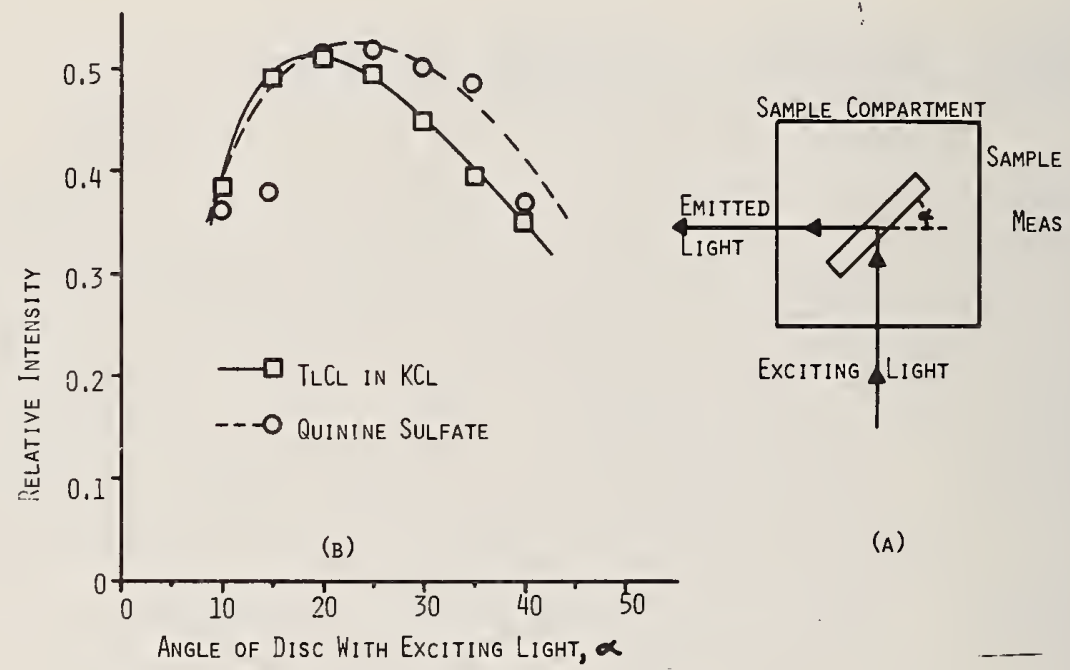

Figure 20. Fluorescence intensity dependence on sample angle for thallium(I) in $\mathrm{KCl}$ and quinine sulfate in $0.1 \mathrm{~N} \mathrm{H}_{2} \mathrm{SO}_{4}$.

The quantum efficiency was calculated from (4) [51,61].

$$
Q_{T I}=Q_{Q S} \frac{F A_{T I} A_{Q S} \lambda \operatorname{ex}_{Q S} n^{2} T I}{F A_{Q S} A_{T I} \lambda \operatorname{ex}_{T I} \eta^{2} Q S}
$$


where

Q = quantum efficiency

$\mathrm{FA}$ = integrated area under emission peak

A $\quad=$ absorbance

$\lambda_{\text {ex }}=$ exciting wavelength

$\eta \quad=$ refractive index

Both thallium and quinine sulfate were excited at a wavelength of $247.5 \mathrm{~nm}$. Although the absorption maximum is at $250 \mathrm{~nm}$, it has been reported that the quantum efficiency of quinine sulfate does not vary by more than 5 percent over the excitation wavelength range of $240-390 \mathrm{~nm}$ (except for position of minimal absorbance at $272 \mathrm{~nm}$ ) (Eq. 5). The refractive indices of the $\mathrm{KCl}$ were taken from LandoltBornstein Tables. An average of the respective indices of the silicate windows and solution was calculated. Absorbance was measured with a Cary Model 14 double-beam spectrophotometer with expanded scale and $1-\mathrm{cm}$ cells or the pressed disks.

The calculated quantum efficiency of $0.51 \pm 0.04$ for thallium is in excellent agreement with another experimental value of $0.52[65]$.

The oscillator strength, calculated from Smakula's [66] equation ( 5$)$, was $0.073 \pm 0.003$ which agreed well with other results, table 26 .

$$
f=\left(\frac{m^{*} \eta c}{2 \pi^{2} h e^{2} N}\right)\left(\frac{E_{O}}{E_{\text {eff }}}\right)^{2} \int \alpha(E) d E
$$

where

f $\quad$ oscillator strength

$\mathrm{N}=$ number of luminescent centers per $\mathrm{cm}^{3}$

$\mathrm{m}^{*}=$ mass of electron

$n$ = refractive index of matrix

$\mathrm{E}_{\mathrm{O}} \quad=$ electric field in matrix

$E_{\text {eff }}=$ electric field in vicinity of ion 
$\alpha=$ absorbance $/ \mathrm{cm}$ as a function of energy

$c, e, h$ are physical constants.

Table 26. Oscillator strengths for TlCl in $\mathrm{KCl}$.

$\begin{array}{ccccc}\begin{array}{c}\text { Temper- } \\ \text { ature } \\ \text { oK }\end{array} & \begin{array}{c}\text { Absorption } \\ \text { Peak } \\ \text { nm }\end{array} & \begin{array}{c}\text { Band } \\ \text { Half Widh } \\ \text { ev }\end{array} & \begin{array}{c}\text { Oscillator } \\ \text { Strength } \\ \text { f }\end{array} & \text { Reference } \\ 293 & 248.2 & 0.199 & 0.0764 & {[67]} \\ 77 & 247.0 & .11 & .075 & {[68]} \\ 77 & 247.0 & .12 & .075 & {[69]} \\ 293 & 247.5 & .200 & .073 & \text { this work }\end{array}$

The oscillator strength is related to radiative lifetime as expressed by equation (6) [70].

$$
f=\frac{1.499 \times 10^{-8} \lambda^{2}}{\tau_{\text {nat }}}
$$

where

$$
\begin{aligned}
\tau_{\text {nai }} & =\text { calculated radiative lifetime } \\
\lambda & =\text { wavelength in microns }
\end{aligned}
$$

Quantum efficiency may be determined by method (c) (discussed later) from equation (7)

$$
Q=\frac{\tau}{\tau_{\text {nat }}}
$$

where

$$
\tau=\text { measured lifetime }
$$

Thus a check on the experimentally determined quantum efficiency may be calculated from $\tau$ and the absorbance spectrum. Unfortunately, available instrumentation only allows measurements of $\tau$ in the milli- to microsecond range and not the nanosecond range. An excitation source with a very fast rise and decay time ( $I$ nanosecond) such as a tunable dye laser is needed. 


\section{Future Research}

It is necessary to determine the stabilities of these species in various matrices. It has been reported [71] that cerium(III) is photo-oxidized to cerium(IV); however, preliminary results here show that only a limited amount of cerium(III) is photo-oxidized and thus a stable condition may be reached by pre-irradiation.

The determination of comparative quantum efficiencies for thallium, cerium and lead in various glass matrices is also planned. These three species have maxima which cover the wavelength range $300-480 \mathrm{~nm}$. It would also be of interest to study the manganese(II) and copper(II)-copper(I) ions in glass matrices to complete a series of glass standards. The emission maxima for manganese(II) are 540 and $620 \mathrm{~nm}$ [72] while copper emission maximum is at $530 \mathrm{~nm}$.

E. Lanthanides

1. Analytical

The lanthanides, as with cerium, thallium and lead, may be determined analytically by the linearity of a plot of relative fluorescence intensity versus concentration,

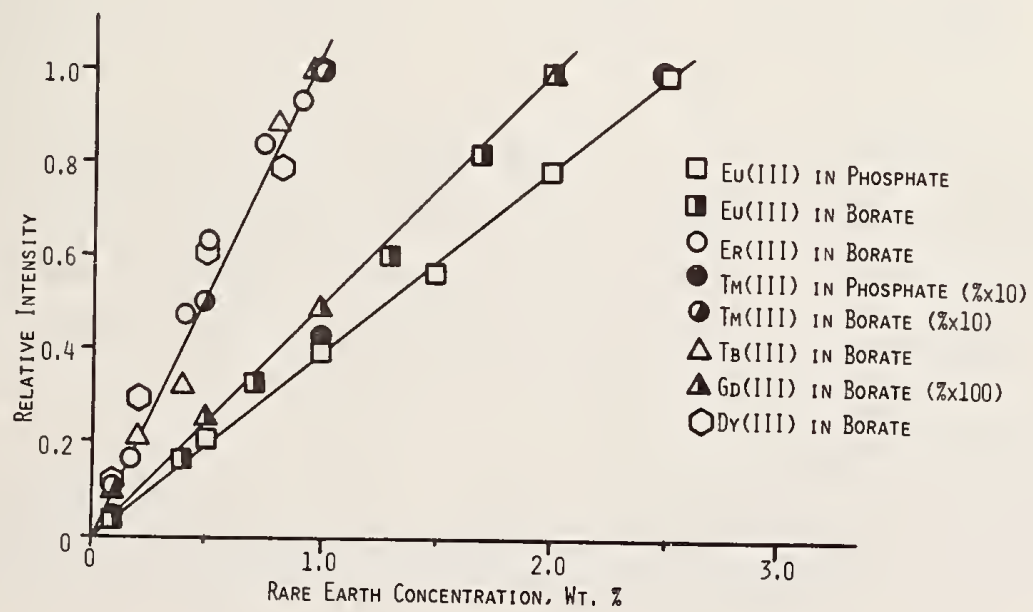

Figure 21. Relative fluorescence intensity versus rare earth concentration in weight percent. 
figure 21. These relative fluorescence intensities were determined using excitation wavelengths and emission wavelengths in table 27 which gave maximum emission intensities.

Table 27. Excitation and emission wavelengths for lanthanides in glass matrices yielding maximum emission intensities.

Metal Ion Matrix

$$
\underset{n m}{\operatorname{Excitation}} \lambda
$$

365

365

378

394

394

394

265

265

274
Emission $\lambda$ nm

546 578 543 617 612 610 457 453 312

The lanthanides have several excitation and emission peaks, any of which may be used for analytical determinations, if convenient or when necessary, because of interferring fluorescent species.

The usual narrow band (half widths are $0.5-5 \mathrm{~nm}$ ) emission spectra of the rare earths, exemplified by europium(III) in silicate, figure 22, are due to $f$ shell electronic transitions which are 'LaPorte forbidden' for centrosymmetric fields. In solids or liquids where the center of symmetry is lowered or destroyed, the electronic transitions become "allowed" and due to mixing of $f$ orbital transitions and interactions with the effective crystal field of the glass matrices, broadening and splitting of the rare earth energy levels occur.

2. Matrix Effects

Analogous to the matrix effects discussed earlier in this report, similar effects are noted with the rare earths, table 28. 


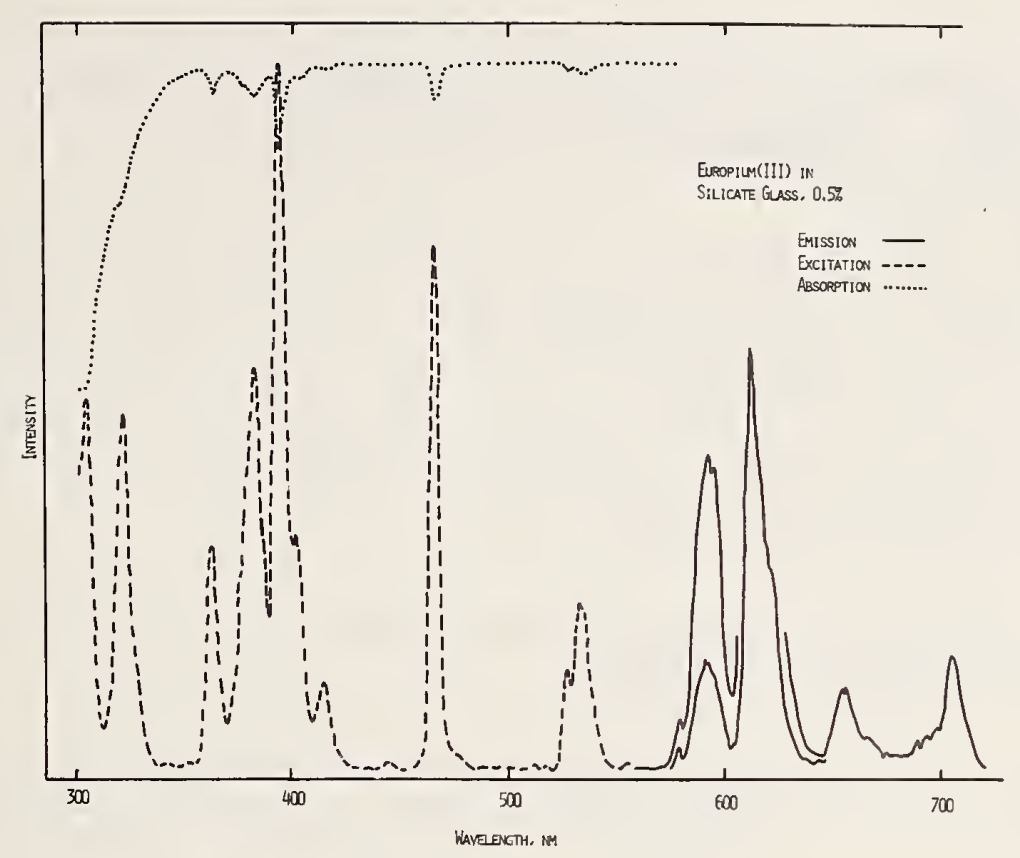

Figure 22. Corrected excitation, emission and absorbance spectra for europium(III) in a silicate matrix.

Table 28. Shifts of major europium, samarium and thulium emission peaks as a function of matrix.

Emission Maximum, nm

Matrix

$\mathrm{Eu}(\mathrm{III})$

$\operatorname{Sm}(I I I)$

$\operatorname{Tm}(I I I)$

Silicate

610

Phosphate

612

Borate

617

596

601

605

553

557

Lower matrix interactions are also supported by less quenching in the matrices which exert weaker perturbations on the fluorescent center: e.g. 0.5 wt percent samarium(III) in a borate matrix showed concentration quenching, while 3 wt percent samarium(III) in silicate showed no concentration quenching [73].

Further evidence for rare earth-matrix interactions were obtained by the measurement of fluorescence lifetimes, presented in table 29. On the average, fluorescence lifetimes were shorter in the order borate > phosphate > silicate 
showing better facilitation of energy dissipation through stronger rare earth-matrix interactions and thus shorter lifetimes.

Higher intensities of fluorescence were obtained by use of borate versus silicate matrices, table 30 , although preliminary results for thallium in borate and phosphate appear to give equal emission intensities when corrected exciting lamp intensities are used.

Table 29. Average fluorescence lifetimes of rare earths in various matrices.

\section{Lifetimes, Milliseconds}

$\begin{array}{cccc}\text { R.E. }(I I I)^{a} & \text { Silicate } & \text { Phosphate } & \text { Borate } \\ & & & \\ \text { Eu } & 2.55 & 2.32 & 2.05 \\ \text { Sm } & 2.60 & 1.87 & 1.60 \\ \text { Ti } & 3.90 & 3.30 & 2.80 \\ \text { Dy } & 0.95 & 0.87 & 1.00 \\ \text { Gd } & 4.32 & 5.25 & 4.30\end{array}$

$a_{\text {Rare earth }}$ concentration $=1$ wt. percent .

Table 30. Effects of glass matrix on fluorescence intensities of the rare earth ions.

$$
\text { R.E. (III) }
$$

Eu

$\mathrm{Sm}$

$\mathrm{Tb}$

Dy

Gd
Fluorescence Ratio Silicate/Borate

3. Quantum Efficiency Determinations of Eu(III) in Silicate Matrix

Quantum efficiencies have been determined for europium(III) in solution, in crystals or doped in other rare earth matrices [74], but essentially no research has been done on the determination of quantum efficiencies in glass matrices. 
The quantum efficiency of europium(III) has been determined in a silicate matrix by two methods, comparative and lifetime measurements for the ${ }^{5} \mathrm{D}_{0}$ to ${ }^{7} \mathrm{~F}$ transitions [75]. The comparative quantum efficiency measurement was made by using $\mathrm{Eu}\left(\mathrm{NO}_{3}\right)_{3}$ in water as the standard [74a]. The solution and solid were excited at the ${ }^{7} \mathrm{~F}_{1} \rightarrow{ }^{5} \mathrm{D}_{0}$ wavelength $(592.5 \mathrm{~nm}$ for solution and $587.5 \mathrm{rm}$ for solid). Major emission peaks obtained for these excitation wavelengths are given in table 31. It is necessary, however, to sum the areas under all emission peaks when determining comparative quantum efficiencies (FA in equation 3). Figure 23 presents emission

Table 31. Major emission peaks for europium(III) in water and silicate matrices.

$\begin{array}{llc}\text { Assignment } & \begin{array}{c}\text { Emission } \\ \mathrm{H}_{2} \mathrm{O}\end{array} & \begin{array}{c}\text { Welength, } \\ \text { Silicate }\end{array} \\ { }^{5} \mathrm{D}_{0} \rightarrow{ }^{7} \mathrm{~F}_{0} & 580.0 & 578.5 \\ { }^{5} \mathrm{D}_{0} \rightarrow{ }^{7} \mathrm{~F}_{1} & 592.5 & 592.2 \\ { }^{5} \mathrm{D}_{0} \rightarrow{ }^{7} \mathrm{~F}_{2} & 617.0^{\mathrm{a}} & 610.2^{\mathrm{a}} \\ { }^{5} \mathrm{D}_{0} \rightarrow{ }^{7} \mathrm{~F}_{3} & 652^{\mathrm{a}} & 655.7^{\mathrm{a}} \\ { }^{5} \mathrm{D}_{0} \rightarrow{ }^{7} \mathrm{~F}_{4} & 695^{\mathrm{a}} & 693.2^{\mathrm{a}} \\ { }^{5} \mathrm{D}_{0} \rightarrow{ }^{7} \mathrm{~F}_{4} & & 706.2^{\mathrm{a}}\end{array}$

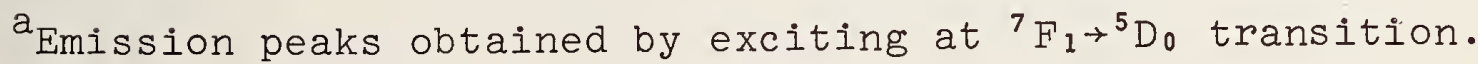

spectra for europium(III) in water and silicate when excited at 396 and $393.8 \mathrm{~nm}$, respectively. The ratios of the emission areas are constant regardless of excitation wavelength, thus ratios may be made for the emission areas when excited at 396 and $590 \mathrm{~nm}$ for the solution, and the total emission area at 590 excitation determined. Similar calculations were made for the europium(III) in the glass matrix.

Use of equation 3 necessitates careful absorbance measurements. Dawson and Kropp [74b] have shown that corrections must be made if the absorption band is smaller than a triangle constructed on the absorption spectra from 


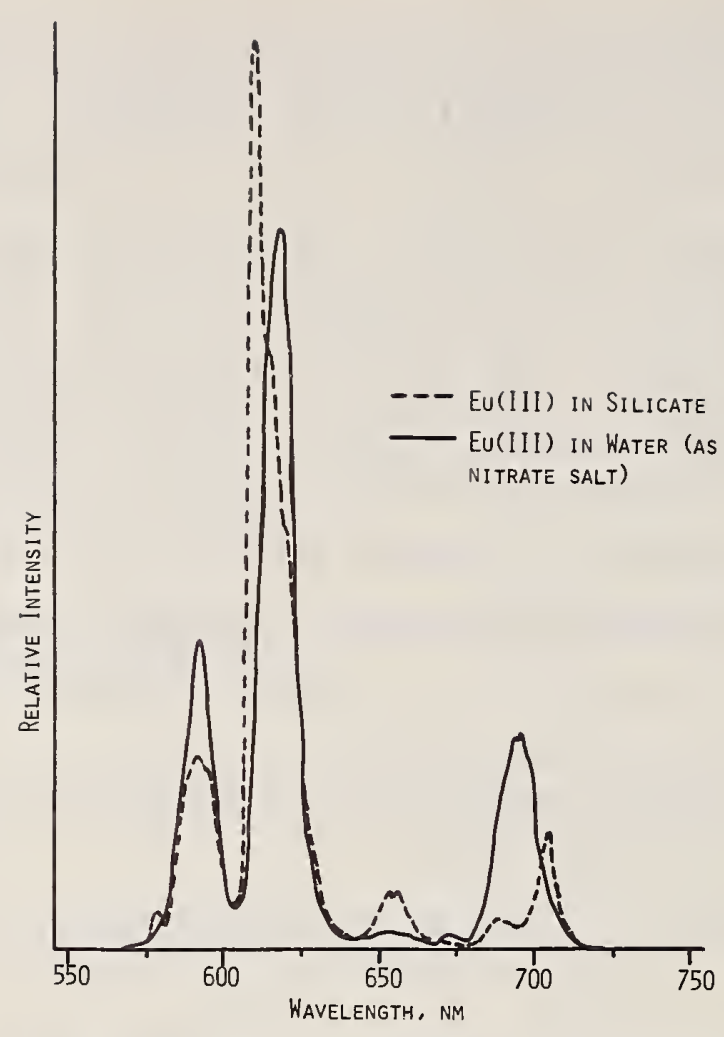

Figure 23. Major emission peaks of europium(III) in silicate matrix and water solution.

an experimental determination of the half-bandwidth for the excitation wavelength. In our case, no correction was necessary since the half-bandwidth of the excitation wavelength $(2.5 \mathrm{~nm})$ was smaller by factors of $2-4$ than the half-bandwidth of the absorption peaks as determined from absorption spectra. The quantum efficiency as determined by the comparative method, was $0.93 \pm 0.05$, a value expected for species with no or few radiationless transitions.

Lifetime measurements were also made. The measured lifetime, $\tau$, was determined by an apparatus previously described [76] and found to be $2.73 \pm 0.03 \mathrm{msec}$. As known, $\tau$ was independent of excitation wavelength and emission wavelength as long as the emission was measured for a ${ }^{5} \mathrm{D}_{0} \rightarrow{ }^{7} \mathrm{~F}$ transition.

The natural radiative lifetime, ' ${ }_{\text {nat }}$, was calculated using the absorption spectrum for the ${ }^{7} \mathrm{~F}_{0} \rightarrow{ }^{5} \mathrm{D}_{0}$ transition. 
It was necessary to perform Gaussian analyses on the absorption spectrum because of overlap with the ${ }_{\mathrm{F}_{1}} \rightarrow{ }^{5} \mathrm{D}_{0}$ transition, figure 24. The lifetime is calculated from the Lewis-Kasha [77] equation (8)

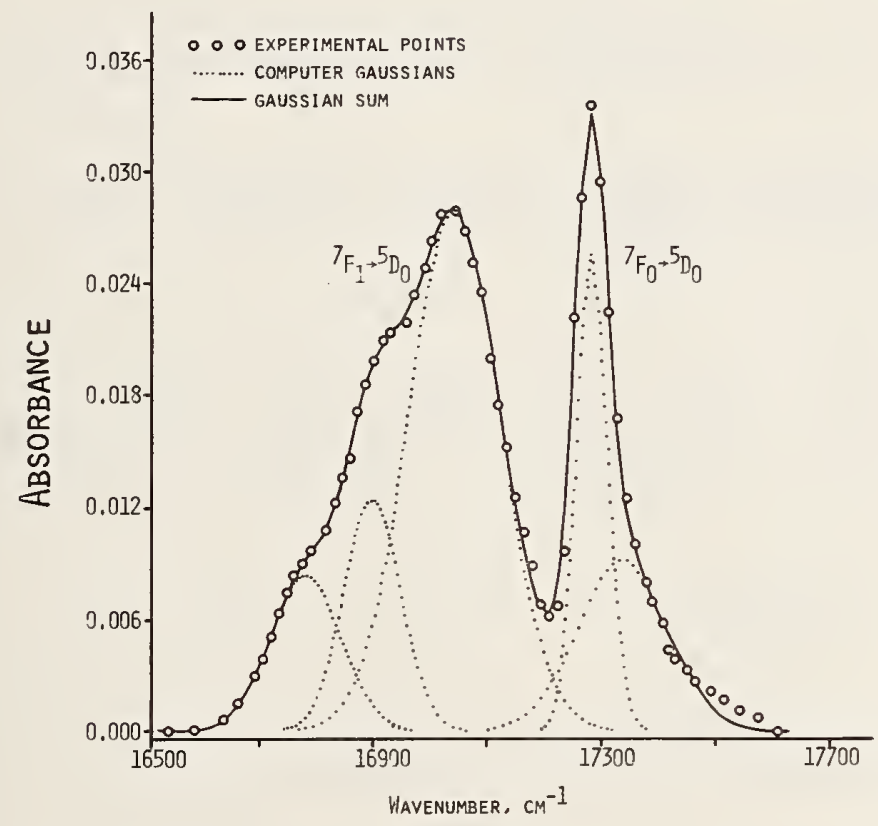

Figure 24. Gaussian Analysis for absorbance spectra of europium in silicate ${ }^{7} \mathrm{~F}_{0,1} \rightarrow^{5} \mathrm{D}_{0}$ transitions.

$$
\frac{1}{\tau_{\text {nat }}}=\sum A_{u \rightarrow 1}=2.88 \times 10^{-9}\left(g_{1} / g_{u}\right) n^{2} v^{2} s \varepsilon(\nu) d v
$$

where

$A_{u \rightarrow I}=$ transition probabilities from upper to lower state

g $\quad$ degeneracies

$\eta \quad=$ refractive index

$\nu \quad=$ wavenumber of emission maximum

$\varepsilon \quad=$ molar absorptivity as a function of wavenumber

$1, u=$ lower and upper states

Although there are some "Stokes' shifts" ( $25 \mathrm{~nm}$ ), it was not necessary to use the lifetime equation (9) given by Forster 
[78], since calculations using both equations yielded the same results:

$$
\frac{1}{\tau_{\text {nat }}}=2.88 \times 10^{-9}\left(g_{1} / g_{u}\right) n^{2} s \frac{\left(2 \nu_{o}-v\right)^{3}}{\nu} \varepsilon(\nu) d \nu
$$

where $\nu_{0}$ is the wavenumber center for the mirror image relation.

For europium, $\frac{1}{\tau_{\text {nat }}}=\sum \mathrm{A}_{\mathrm{u} \rightarrow 1}$ expands into equation (10)

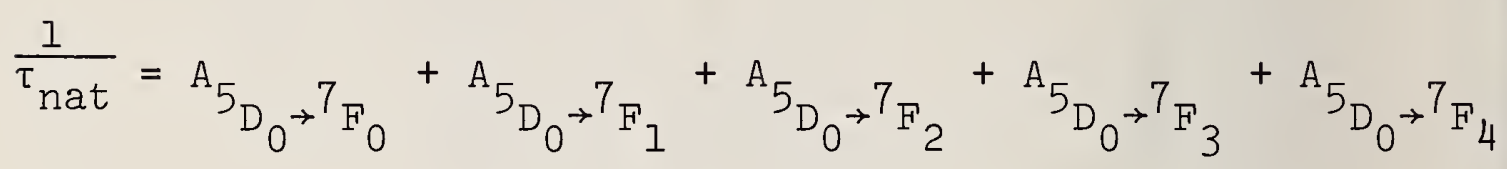

$+{ }^{A}{ }_{D_{0} \rightarrow}{ }^{7} F_{5}+{ }^{A} 5_{D_{0}} \rightarrow{ }^{7} F_{6}$

It was determined that ${ }^{A_{5}}{ }_{D_{0} \rightarrow{ }^{7}}$ and ${ }^{A_{5}}{ }_{D_{0} \rightarrow{ }^{F}}{ }_{6}$

are small (less than 1 percent) as compared to the other transition probabilities and may be neglected for all practical purposes. Equation (10) may now be written in shorthand notation as (II)

$$
\frac{1}{\tau_{\text {nat }}}=A_{0 \rightarrow 0}+A_{0 \rightarrow 1}+A_{0 \rightarrow 2}+A_{0 \rightarrow 3}+A_{0 \rightarrow 4} \text {. }
$$

By using the absorption spectrum and only the ${ }^{7} \mathrm{~F}_{0} \rightarrow{ }^{5} \mathrm{D}_{0}$ transition, we calculate only $l / \tau_{0 \rightarrow 0}$ since $\mathrm{A}_{7 \mathrm{~F}_{0} \rightarrow{ }^{5} \mathrm{D}_{0}}=$ ${ }^{A_{D_{0}} \rightarrow{ }^{7}} F_{0}[79]$. The areas of the fluorescence spectrum, figure 23, for the europium(III) in silicate are directly proportional to the transition probabilities from ${ }^{5} \mathrm{D}_{0}$ to each ${ }^{7}$ F state. Thus, $\frac{1}{\tau_{\text {nat }}}$ was calculated by equation (12) 


$$
\frac{I}{\tau_{\text {nat }}}=A_{0 \rightarrow 0}\left(I+\frac{A_{0 \rightarrow 1}}{A_{0 \rightarrow 0}}+\frac{A_{0 \rightarrow 2}}{A_{0 \rightarrow 0}}+\frac{A_{0 \rightarrow 3}}{A_{0 \rightarrow 0}}+\frac{A_{0 \rightarrow 4}}{A_{0 \rightarrow 0}}\right)
$$

and found to be $3.10 \mathrm{msec}$. The quantum efficiency was calculated from equation (7) and was equal to 0.90 , which is in excellent agreement with the comparative quantum efficiency of $0.93 \pm 0.05$.

F. Energy Transfer

Energy transfer has been observed between donor and acceptor sites for pairs of different rare earth ions.

The objectives of this research include the enhancement of emission intensities and excitation of fluorescent species at higher wavelengths and thus lower energies so that degradative problems such as photo-oxidation is minimized. Two rare earth pairs have been studied - samarium(III) europium(III) and gadolinium(III)-terbium(III).

The emission intensity of europium(III) is increased, figure 25, when excited at the samarium(III) excitation wavelength of $402 \mathrm{~nm}$.

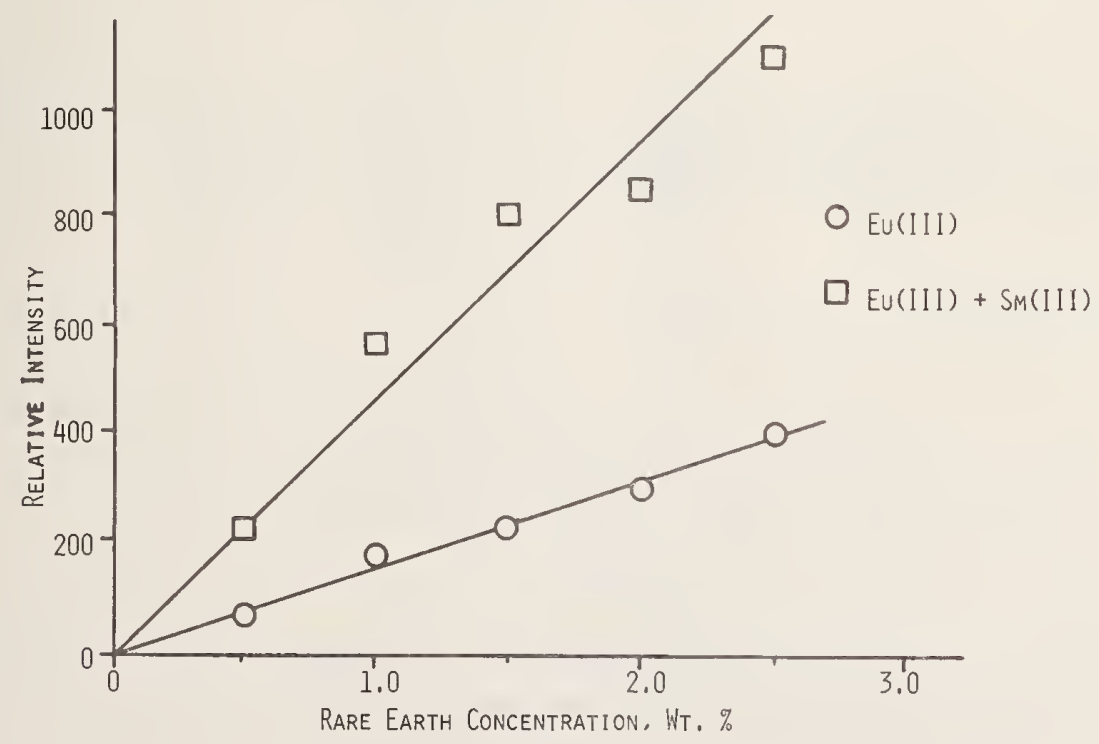

Figure 25. Fluorescence intensity enhancement of europium(III) by energy transfer from samarium(III) to europium(III), $\lambda_{\text {exc }}=402.0 \mathrm{~nm}$. 
Terbium and gadolinium also gave interesting results. Excitation at $275 \mathrm{~nm}$ (Gd excitation wavelength) resulted in terbium emission enhancement by at least 50 percent, figure 26. The excitation spectrum of a mixture of terbium + gadolinium monitored at the terbium emission wavelength of $480 \mathrm{~nm}$, showed excitation peaks at $275 \mathrm{~nm}$ (Gd excitation) and 312 (usual Gd emission), figure 27, proving energy transfer from gadolinium to terbium. Calculations are in progress which will lead to the estimation of some of the system transition probabilities, integral overlaps [79, 80], quantum efficiencies by lifetime measurements and whether the transfers are

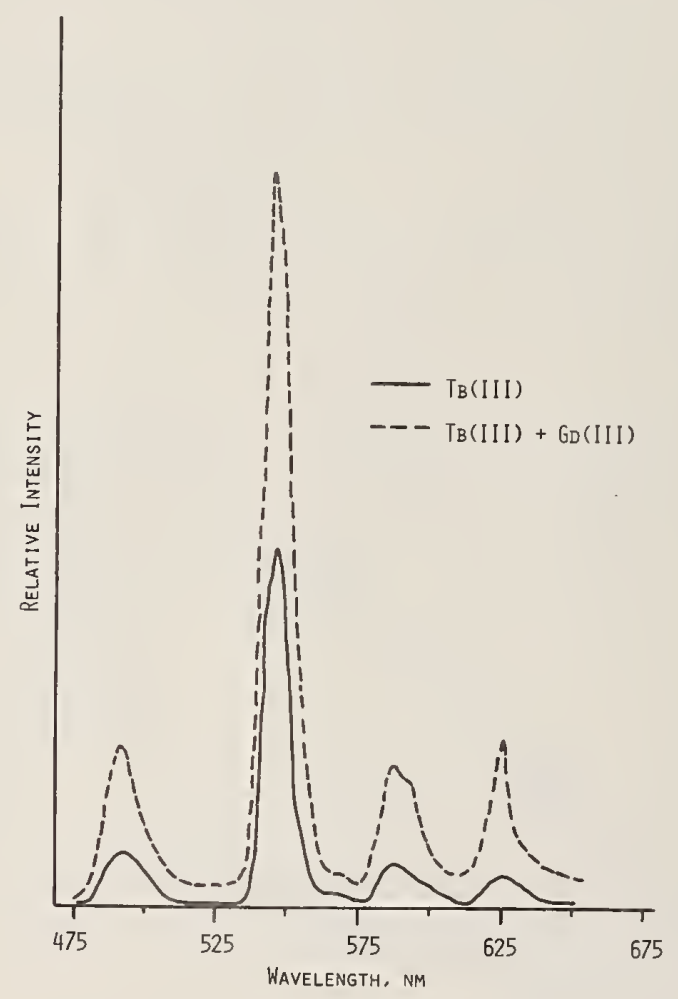

Figure 26. Fluorescence intensity enhancement of terbium(III) by energy transfer from gadolinium(III) to terbium(III), $\lambda_{\text {exc }}=275.0 \mathrm{~nm}$. 


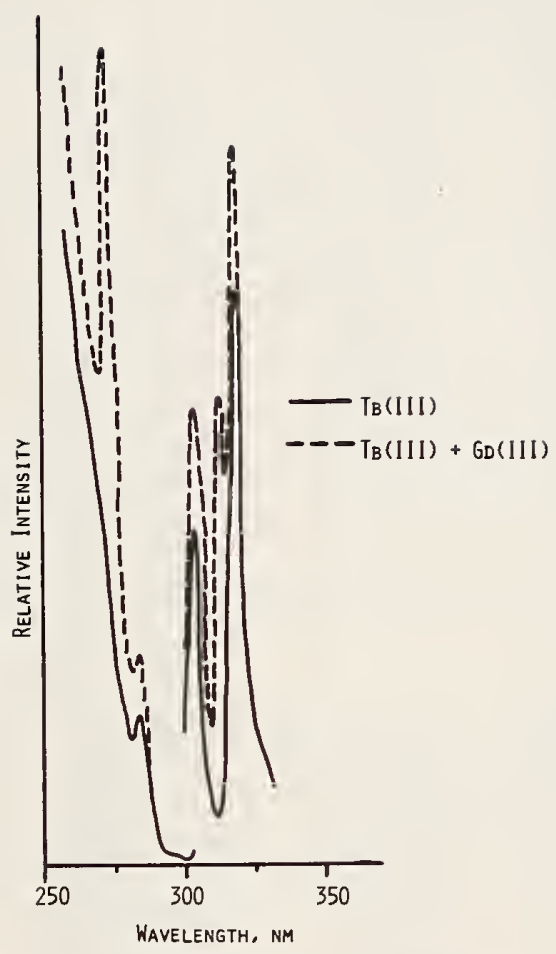

Figure 27. Excitation spectra obtained showing gadolinium(III) spectra $(275.0,312.0 \mathrm{~nm})$ when monitoring terbium(III) emission at $490.0 \mathrm{~nm}$, ${ }^{5} \mathrm{D}_{4} \rightarrow{ }^{7} \mathrm{~F}_{6}$ transition.

due to dipole-dipole or dipole-quadrupole interactions.

G.. Data and Spectra Storage

One of the objectives of this research was the compilation, storage and presentation (see computer section) of corrected excitation and emission spectra of the rare earths and other species in various matrices. Typical corrected spectra are presented in figure 22. The transition assignments and relative peak intensities (areas for emission peaks) are given in table 32. The intensities are given relative to the most intense peak [393.9 $\mathrm{nm}$ for europium(III)] excluding the very intense charge transfer band found in the 200-250 nm region. 
Table 32. Transition assignments and relative intensities of major emission and excitation bands for europium(III) in silicate and phosphate matrices.

\section{Emission}

Silicate

Phosphate

$\nu \mathrm{cm}^{-1} \lambda, \mathrm{nm} \nu \mathrm{cm}^{-1} \lambda, \mathrm{nm}$

$\begin{array}{llll}17.25 & 579.7 & 17.29 & 578.5\end{array}$

$\begin{array}{llll}16.88 & 542.2 & 16.90 & 591.7\end{array}$

16.38

610.2

$16 \cdot 34$

15.25

655.7

15.30

14.42

$693.2 \mathrm{~S} / 14.43$

14.16

706.2

14.26

13.24

755.2

12.71788 .2

612.1

653.7

693.1

701.2
Assignment

siginment
[81]

Relative Intensity Silicate Phosphate

${ }^{5} \mathrm{D}_{0} \rightarrow{ }^{7} \mathrm{~F}_{0}$

${ }^{5} \mathrm{D}_{0} \rightarrow{ }^{7} \mathrm{~F}_{1}$

${ }^{5} \mathrm{D}_{0} \rightarrow{ }^{7} \mathrm{~F}_{2}$

${ }^{5} \mathrm{D}_{0} \rightarrow{ }^{7} \mathrm{~F}_{3}$

${ }^{5} \mathrm{D}_{0} \rightarrow{ }^{7} \mathrm{~F}_{4}$

${ }^{5} \mathrm{D}_{0} \rightarrow{ }^{7} \mathrm{~F}_{4}$

${ }^{5} \mathrm{D}_{0} \rightarrow{ }^{7} \mathrm{~F}_{5}$

${ }^{5} \mathrm{D}_{0} \rightarrow{ }^{7} \mathrm{~F}_{6}$

\section{Excitation}

$\begin{array}{lll}32.84 & 304.5 & 32.87\end{array}$

31.13

321.2

31.31

304.2

${ }^{7} \mathrm{~F}_{1} \rightarrow{ }^{5} \mathrm{~F}_{3}$

319.4

${ }^{7} \mathrm{~F}_{0} \rightarrow{ }^{5} \mathrm{H}_{0}$

$362.7 \quad{ }^{7} \mathrm{~F}_{0} \rightarrow{ }^{5} \mathrm{D}_{4}$

27.58

362.6

27.57

377.0

26.56

376.5

${ }^{7} \mathrm{~F}_{0} \rightarrow{ }^{5} \mathrm{G}_{3}$

382.2

${ }^{7} \mathrm{~F}_{1} \rightarrow{ }^{5} \mathrm{G}_{3}$

393.9

${ }^{7} \mathrm{~F}_{0} \rightarrow{ }^{5} \mathrm{~L}_{6}$

25.38

393.9

25.38

403.3

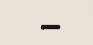

24.06

415.7

24.01

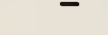

416.5

${ }^{7} \mathrm{~F}_{2} \rightarrow{ }^{5}$ lo 6

21.54

464.2

21.49

465.3

${ }^{7} \mathrm{~F}_{0} \rightarrow{ }^{5} \mathrm{D}_{3}$

${ }^{7} \mathrm{~F}_{0} \rightarrow{ }^{5} \mathrm{D}_{2}$

526.4

${ }^{7} \mathrm{~F}_{0} \rightarrow{ }^{5} \mathrm{D}_{1}$

534.7

${ }^{7} \mathrm{~F}_{2} \rightarrow{ }^{5} \mathrm{D}_{2}$

580.6

${ }^{7} \mathrm{~F}_{0} \rightarrow{ }^{5} \mathrm{D}_{0}$

592.2

${ }^{7} \mathrm{~F}_{1} \rightarrow{ }^{5} \mathrm{D}_{0}$
.378

.320

.352

.229

.361

.202

.163

.350

.231

1.000

.208

.077

.017

.528

.173

.122

.019

.162

.034

.028

.008

.036
587.5

16.89

s shoulder.

Emission - relative peak areas; Excitation - relative peak heights. 
This compilation will eventually be produced for all fluorescent spectra recorded here at NBS and circulars will be issued containing these spectra with all operating conditions.

H. Computer Programs - R. A. Velapoldi

In any compilation of spectra and data, it is necessary to develop computer programs for data handling, feedback, etc. Programs were developed for simple data conversion to wavenumbers or energy from wavelength. A BMDX85 (Health Sciences Computing Facilities, University of California at Los Angeles) program was used for Gaussian analyses (see for example figure 14). From this it is possible to separate overlapping absorption or emission bands and determine areas and percent areas of each band and each Gausian. A Gaussian plot program shows graphically the results of the Gaussian analyses program.

A simple cal-com plot program was developed which will plot with different symbols up to 10 data sets with various options on the same plot. This is very useful for comparison and presentation of data.

other programs will be developed to store and recall data sets for spectra on tape. 
A. Introduction

Flame emission and atomic absorption spectroscopy continue to play an important role in helping to solve some of the analytical problems associated with our current concerns in health and environmental pollution. As in the past year, emphasis in this section was placed on instrumentation and methodology to improve the sensitivity and maintain the desired precision and accuracy. Again as in previous years these competences contributed a great deal to the characterization of Standard Reference Materials (SRM's). The new developments encompassed both instrumental designs and testing of procedures for handling special materials. The research in instrumentation included the construction and evaluation of components while the methodology studies dealt with simultaneous analyses of multicomponent systems and the analysis of a volatile element in an organic matrix.

The present report describes some of the developments of flame sources, multipath light gathering systems, ultrasonic nebulization of sample, simultaneous analysis of six elements or species, a repetitive optical scan for background correction, and a non-flame method for mercury. These efforts provided manifold improvements in sensitivity and yielded data for establishing the accuracy of simultaneous determinations of sodium, potassium, magnesium and calcium. Finally, these studies involved newer methods or modifications for the determination of aluminum in steel and eight elements including mercury in orchard leaves for the SRM program. B. Evaluation of the Multichannel Direct Reading Spectrometer - R. Mavrodineanu

The spectrometer described previously [1] was designed and built to take advantage of the fundamental properties of flames which emit and absorb simultaneously at all 
transitions originating from the chemical species. As a consequence of this property, the measuring system was designed to detect and measure simultaneously a number of individual radiations emitted or absorbed by the excitation source in the wavelength interval of about $2000 \AA$ to 10,000 $\AA$. This instrument was tested for stability and accuracy and the results obtained are given in this section.

A multichannel direct reading spectrometer for simultaneous flame emission and atomic absorption measurements using electronic integration of the optical signal and digital readout was described in NBS Technical Note 544 [1]. This spectrometer was tested to determine its characteristics using the emission and atomic absorption modes in conjunction with a premixed acetylene-air flame and pneumatic sprayer.

The stability of the 8 channel electronic circuitry, including the photomultipliers, was measured previously using a constant light source provided by a fluorescent screen activated with 2 Ci of tritium [82]. This source, having an output of about $56 \mu \mathrm{lm}$, was placed at the focal plane preceding the photomultiplier tubes. An integration time of 10 sec was used for each channel and a series of measurements was obtained for each photomultiplier tube. The standard deviation of a single measurement of the constant illumination was 0.1 to 0.3 percent.

Calcium, sodium and potassium were determined by emission, and magnesium was determined in the atomic absorption mode. Lithium was used as an internal standard for the emission mode. These elements were selected because of their importance in biochemistry and their compatibility with the excitation capabilities of combustion flames.

The pneumatic sprayer is supplied through a twoway Teflon stopcock in succession with the analytical solution or with the blank solution of distilled water [83]. This dual arrangement simulates to some extent a double- 
beam operation. Indeed, if one assumes that the emission source (hollow cathode) and the flame, with its supply syste are stable during the interval required to change from the sample to the blank, the system is equivalent to a double beam operation. This interval of 15 sec which is required to change from sample to blank is determined by the memory of the sprayer and burner units. Since we use 20 sec integrations for the sample and the blank, the total time required to measure the analytical sample and the blank is 35. sec, respectiyely. Hence, one sample-blank cycle requires 70 sec. This technique was used to obtain the analytical data reported in table 33. For these measure-

Table 33. Accuracy of analytical results for magnesium, potassium, calcium and sodium determined simultaneously

Element Determined, $\mu \mathrm{g} / \mathrm{ml}$

\begin{tabular}{|c|c|c|c|c|c|c|c|c|}
\hline & $\mathrm{Mg}^{\mathrm{a}}=$ & 4.00 & $\mathrm{~K}^{\mathrm{b}}=$ & .00 & $\mathrm{Ca}^{\mathrm{b}}=$ & 15.00 & $\mathrm{Na}^{\mathrm{b}}=$ & 8.00 \\
\hline $\begin{array}{l}\text { of } \\
\text { Runs }\end{array}$ & Found & $\begin{array}{c}\% \\
\text { Diff }\end{array}$ & Found & $\begin{array}{c}\frac{\circ}{\circ} \\
\text { Diff }\end{array}$ & Found & $\begin{array}{c}\frac{\circ}{0} \\
\text { Diff }\end{array}$ & Found & $\begin{array}{c}\frac{\circ}{0} \\
\text { Diff }\end{array}$ \\
\hline $\begin{array}{r}3 \\
5 \\
8 \\
12 \\
15 \\
20 \\
25\end{array}$ & $\begin{array}{l}4.02 \\
3.99 \\
3.90 \\
3.97 \\
3.95 \\
3.92 \\
3.90\end{array}$ & $\begin{array}{l}+0.50 \\
-0.25 \\
-2.5 \\
-0.75 \\
-1.25 \\
-2.0 \\
-2.5\end{array}$ & $\begin{array}{l}59.14 \\
58.32 \\
57.81 \\
58.66 \\
58.32 \\
58.04 \\
57.68\end{array}$ & $\begin{array}{l}-1.43 \\
-2.80 \\
-3.65 \\
-2.23 \\
-2.80 \\
-3.27 \\
-3.87\end{array}$ & $\begin{array}{l}15.26 \\
14.81 \\
14.88 \\
15.01 \\
14.92 \\
14.88 \\
14.84\end{array}$ & $\begin{array}{l}+1.73 \\
-1.27 \\
-0.80 \\
+0.07 \\
-0.53 \\
-0.80 \\
-1.07\end{array}$ & $\begin{array}{l}8.06 \\
7.89 \\
7.99 \\
8.00 \\
7.97 \\
7.96 \\
7.93\end{array}$ & $\begin{array}{l}+0.75 \\
-1.38 \\
-0.13 \\
0.0 \\
-0.38 \\
-0.50 \\
-0.88\end{array}$ \\
\hline
\end{tabular}

$\mathrm{a}_{\mathrm{By}}$ flame atomic absorption. $\mathrm{b}_{\mathrm{By}}$ flame emission.

ments, the instrument was calibrated with 8 standard solutions containing all four elements and lithium in aqueous media was used as an internal standard. Each standard solution was run in 6 replications, each measurement consisting of a blank and a sample reading. To determine the accuracy of the measurements, while avoiding the interferences due tc matrix effects, the "unknown" sample was selected from the standard solution and run from 3 to 25 times. Each determi86 
nation consisted of a blank and sample solution. The results, table 33, show that the differences between the true values and the values found vary from 0.0 to 3.87 percent and that, in general, a systematic negative bias is evident. The reasons for this bias are not known at this time.

C. Long Path Flames

Further work was carried out to improve the sensitivity of the measurement without losing accuracy. Gouy and Lundegardh demonstrated that the emission intensity of radiations from a flame can be increased by lengthening the optical path; similarly, Walsh has shown that the absorption of a flame can be augmented by increasing its length. This can be achieved by producing a long flame or by increasing the optical path through the flame using multiple reflection arrangements. Both means are discussed here.

The prototype long path burner made of copper and described previously produced a 30-cm long flame [1, pg. 69], and was reproduced from stainless steel SAE type 316. This was then adapted to a Teflon spraying vessel and burner body. The pneumatic sprayer was also made of 316 stainless and was provided with an impact wall. The air was supplied to the sprayer at a pressure of $39 \mathrm{psi}$, and at a rate of 2100 liters per hr.

Acetylene was supplied to the burner body through a tantalum nozzle to produce a stoichiometric premixed flame. The consumption by the sprayer of the analytical solution was $25 \mathrm{ml} / \mathrm{min}$ and the sample entering the flame was $1.3 \mathrm{~g} / \mathrm{min}$. The optical system used with the $30-\mathrm{cm}$ flame consists of two quartz lenses which produce an optical beam having an average cross section of about $10 \mathrm{~mm}$ to $15 \mathrm{~mm}$. Under these conditions, the sensitivity was increased by a factor of 3 , when magnesium was determined in the atomic absorption mode using the electronics discussed previously [1, pg. 59, fig. 60]. 
The optical system just described which uses two lenses will be replaced with a two Cassegrain mirror arrangement [84] to eliminate the chromatic aberrations common to all lens systems.

D. A Triple Pass On-Axis Optical System for Analytical Flame Spectroscopy - R. Mavrodineanu and W. MưllerHerget (a)

The on-axis optical system is designed for atomic absorption and emission measurements and provides for three passes through a given flame. A chopper wheel can be included. It is based on the use of Mangin-type mirrors in conjunction with an asymmetric biconvex quartz lens. The specified dimensions and the schematic arrangement of the proposed system are shown in figure 28. The

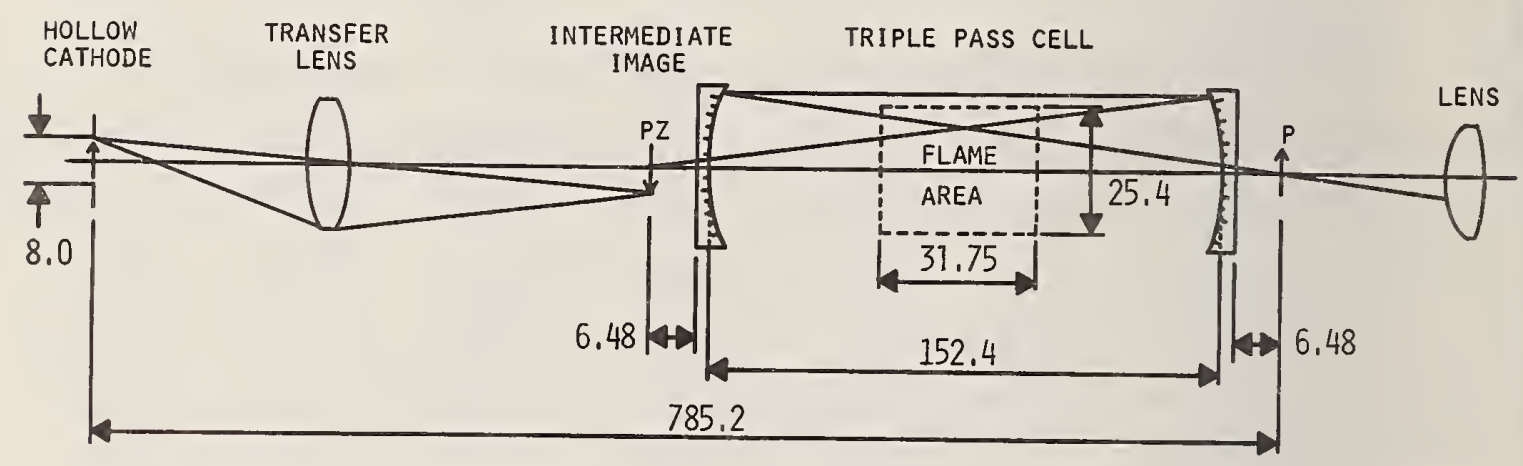

Figure 28. Proposed system and basic dimensions for the triple pass, on-axis optical arrangement (dimensions in $\mathrm{mm}$ ).

spectral range is $240 \mathrm{~nm}$ to $440 \mathrm{~nm}$ and can be extended to cover the visible regions of the spectrum. A minimum clearance of $6.0 \mathrm{~mm}$ is provided for the chopper assembly at the intermediate image position $(\mathrm{Pz})$.

(a) Philips Laboratories, Briarcliff Manor, New York, N. Y. 10510 . 
The flame cavity is designed as a concentric triplepass system with parallel light in the second pass. Because of heat and corrosion, it is advantageous to use rearsurface mirrors made of fused quartz. The optical elements are Mangin-type mirrors with a center bore. The cavity has been designed to minimize spherical and primary color aberrations in the spectral range from $240 \mathrm{~nm}$ to $436 \mathrm{~nm}$ with the design center at $330 \mathrm{~nm}$. The object (at $\mathrm{Pz}$ ) is imaged through the cavity with unit magnification. The conjugate points are both outside, providing $6.48 \mathrm{~mm}$ clearance beyond the mirror's back surface. The minimum optical diameters required are $6.80 \mathrm{~mm}$ for the bore and $35.0 \mathrm{~mm}$ outside diameter of the mirror.

The hollow cathode is imaged by an asymmetric biconvex quartz lens at the intermediate image position. It is designed for the same spectral range with the design center at $330 \mathrm{~nm}$. The spherochromatics are minimized, but are not suppressed in a simple lens. The aberrations of the Mangin cell are only 2 percent of the transfer lens-blur illustrated in figure 28.

The hollow cathode image is demagnified $(1: 0.635)$ and is inverted at position $\mathrm{Pz}$ and upright at position $\mathrm{P}$ (figure 28).

If five passes through the flame are required, both Mangin mirrors may be exchanged for two other mirrors of corresponding design, while retaining all previous dimensions. The focal length $f$, of the mirrors for the five-pass cell will be, in approximation:

$$
f=2.618 \times d=398.98 \mathrm{~mm}
$$


for required clearance of $d=152.4 \mathrm{~mm}$ between the mirrors. The required diameter will be approximately 30 percent larger.

The two Mangin-mirror arrangement is illustrated in figure 29 which gives the dimensions for reproducing the system. The triple-pass unit is placed on the optical bench along the optical axis of the spectrometer. The analytical flame is placed symmetrically between the two mirrors and at a height selected for best sensitivity. This system was tested with the equipment described in [ [1], $\mathrm{pg} .58$ to 65]. When measurements were made in the atomic

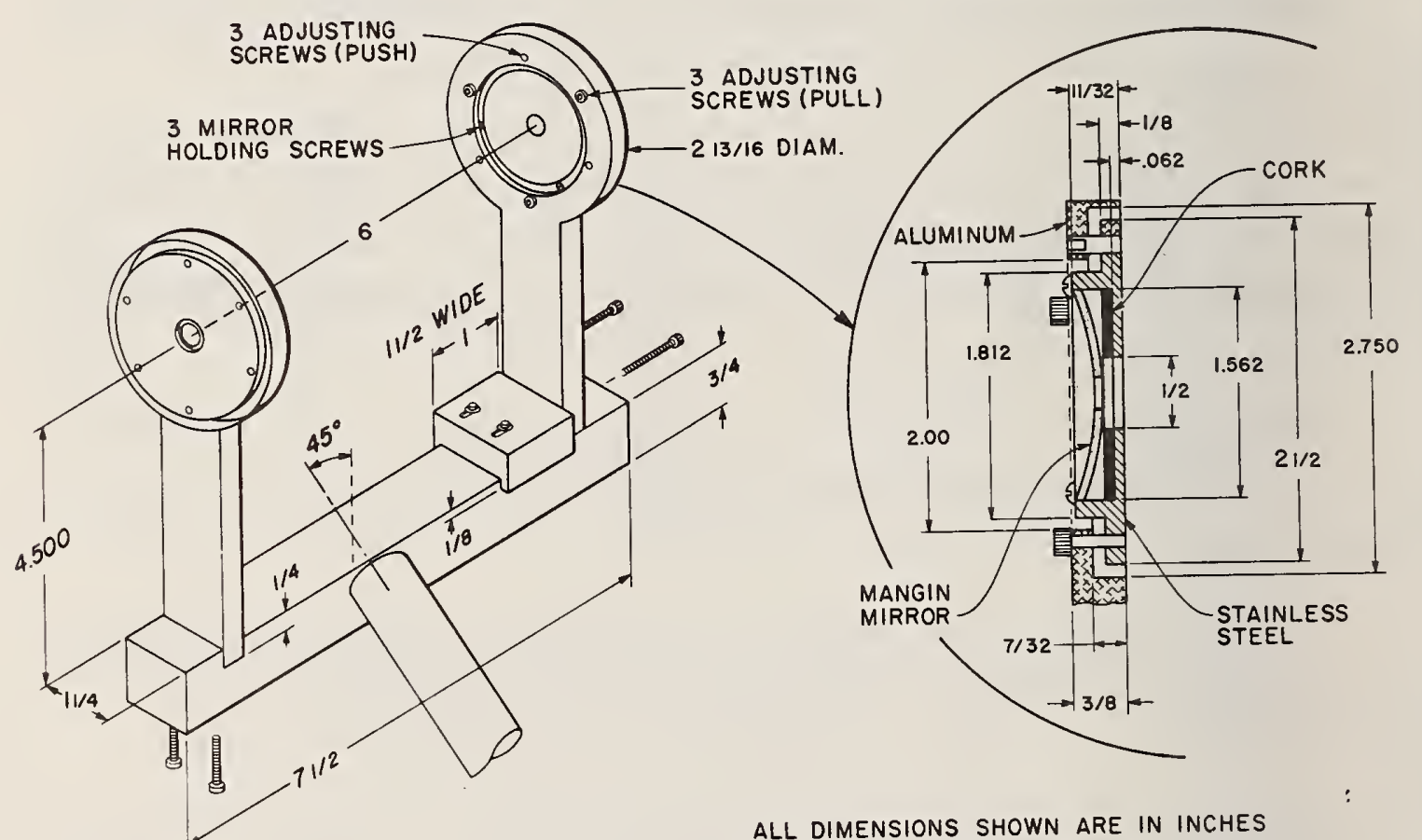

Figure 29. Schematic drawing of the on-axis triple pass system. 
absorption mode, using magnesium, an increased sensitivity of 2.7 was observed when compared with the sensitivity obtained without the triple pass unit. In the emission mode, sodium was used for measurements with the following results: When the rear Mangin mirror was blocked out, an increase in the emission signal of 3.3 percent was observed when compared with the signal obtained without the triple pass unit. When the front Mangin mirror was blocked-out, the increase was 43 percent. When both Mangin mirrors were unobstructed, the increase was 70 percent. Finally, when a flat mirror was placed at the opening of the rear Mangin mirror, the increase in the sodium signal was 158 percent. The increased sensitivity of flame measurements, using the on-axis Mangin triple-pass mirror system, recommends its use. This system requires careful optical alignment and is somewhat wavelength dependent. This dependence can be eliminated by using reflecting, rather than refracting, optics to replace the two lenses mentioned above.

E. Premixed Acetylene-Oxygen Flame Supplied Through an Ultrasonic Spraying System - L. Owen (a) and

R. Mavrodineanu

The purpose of this work was to combine the high temperatures of premixed acetylene-oxygen flames with the highly efficient ultrasonic nebulizers.

The burner used to provide the premixed $\mathrm{C}_{2} \mathrm{H}_{2} \mathrm{-O}_{2}$ flames was developed following the principle and design of a unit described earlier [85]. It consists of a ring-shaped enclosure of stainless steel SAE type 316 and is provided with two separate chambers. The premixed $\mathrm{C}_{2} \mathrm{H}_{2} \mathrm{O}_{2}$ obtained from a miniature welding torch unit is supplied to the lower chamber. The gas mixture passes through a number of small

(a) Guest worker associate at NBS. 
tubes which connect the lower chamber with the upper surface of the burner. These tubes are water cooled in the upper chamber. The entire unit is assembled by welding in a hydrogen furnace and is flash-proof. The sample is supplied to the premixed $\mathrm{C}_{2} \mathrm{H}_{2}-\mathrm{O}_{2}$ flames, which burn at the extremity of the tubings, and indirectly through the central opening of the unit, as illustrated in figures 30,31 and 32 .

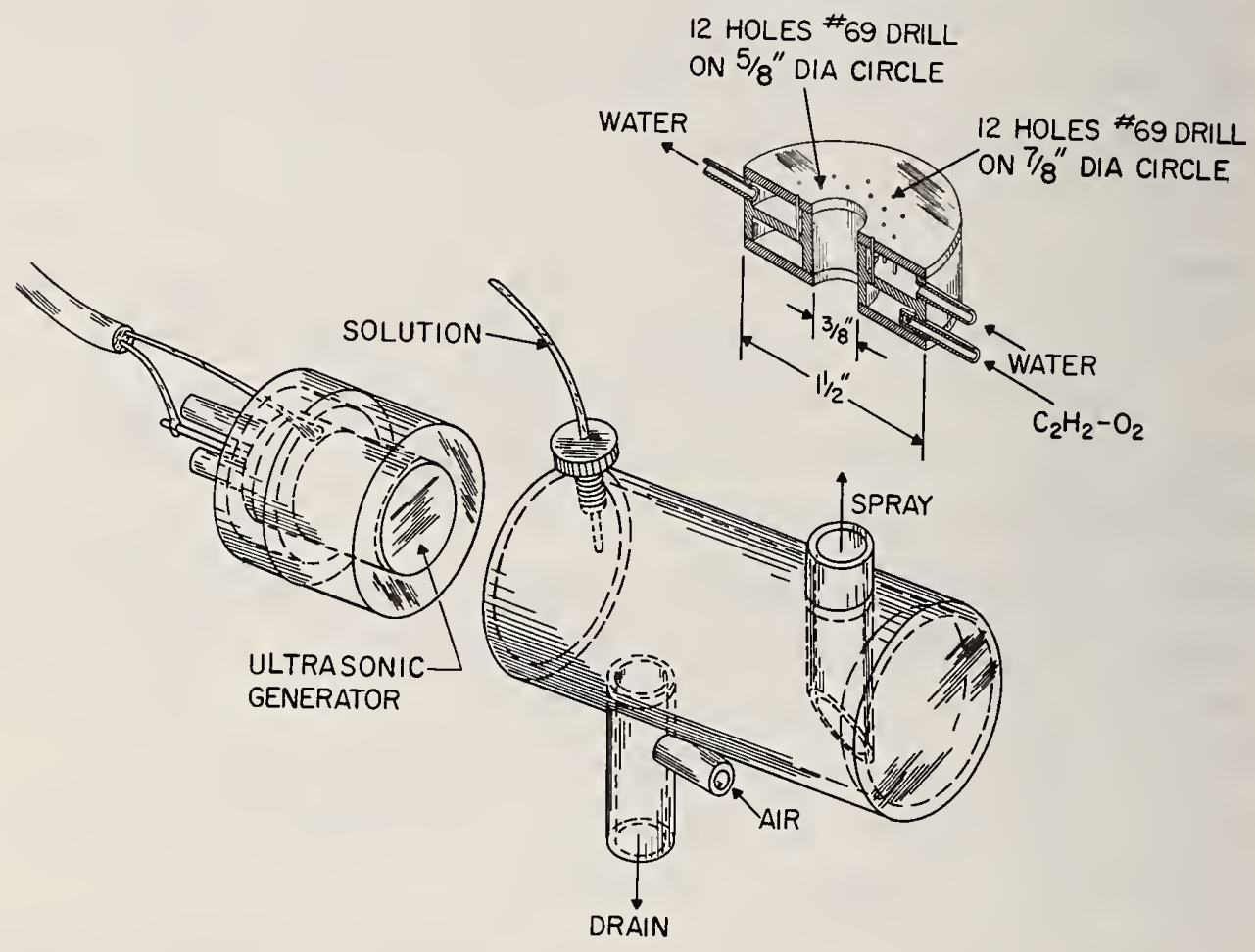

Figure 30. Premixed $\mathrm{C}_{2} \mathrm{H}_{2}-\mathrm{O}_{2}$ burner and ultrasonic nebulizer.

The sample solution aerosol is produced in a newly designed ultrasonic generator [86]. The solution is pumped directly across the vibrating face of a piezoelectric transducer ( $1.4 \mathrm{MHz}$ ) at a flow rate from 0.25 to $3 \mathrm{ml} / \mathrm{min}$. The efficiency of nebulization is about 50 percent. 


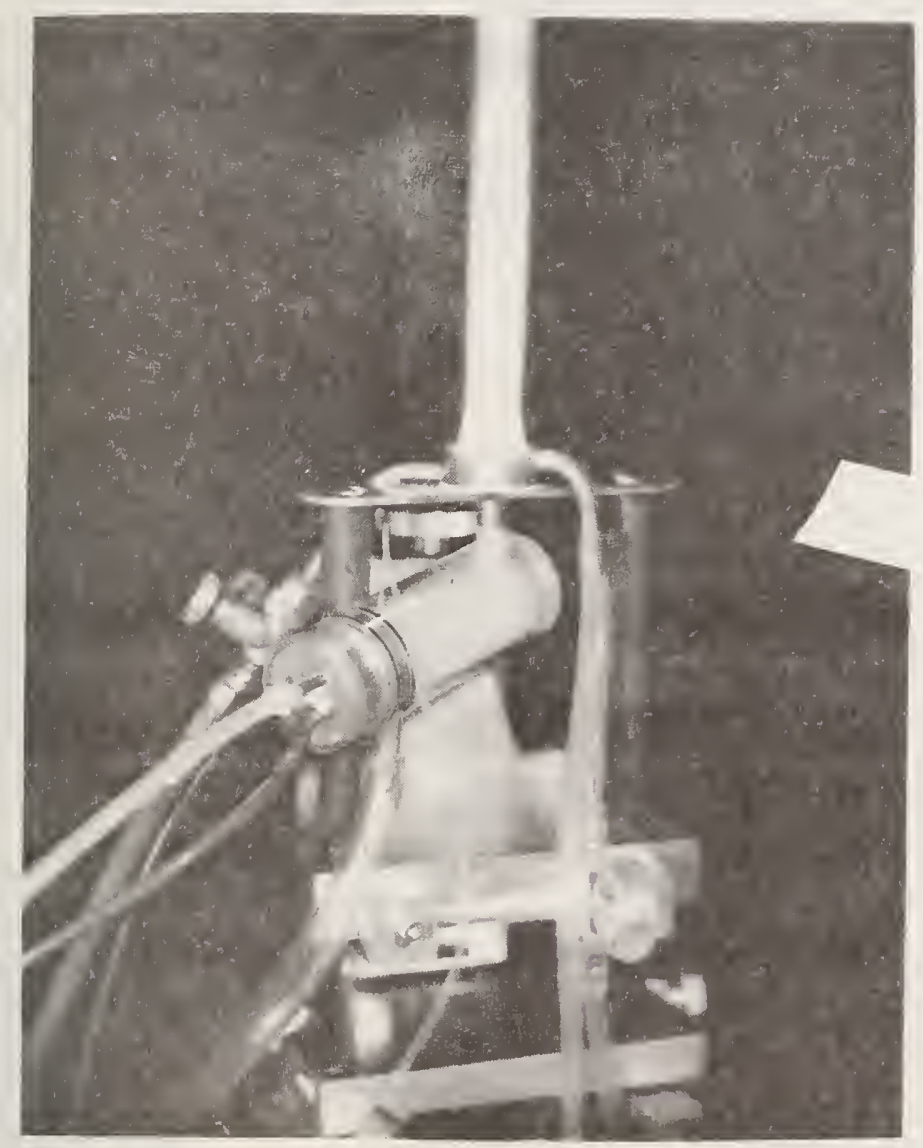

Figure 31. The unit from figure 30 in operation.

This ultrasonic nebulizer $-\mathrm{C}_{2} \mathrm{H}_{2}-\mathrm{O}_{2}$ burner system was tested by atomic absorption measurements using magnesium as the analyte. An absorbance of 0.09 was obtained with $0.1 \mu \mathrm{g}$ per $\mathrm{ml}$ of solution which is an indication of the good efficiency of the system. Further work is planned to assess the characteristics of the unit for other elements.

F. Flame Emission Spectrometry With Optical Scanning T. C. Rains

Aluminum is an element of interest in a variety of materials in the NBS Standard Reference Materials Program. Hence, a detailed study of aluminum by flame emission was 


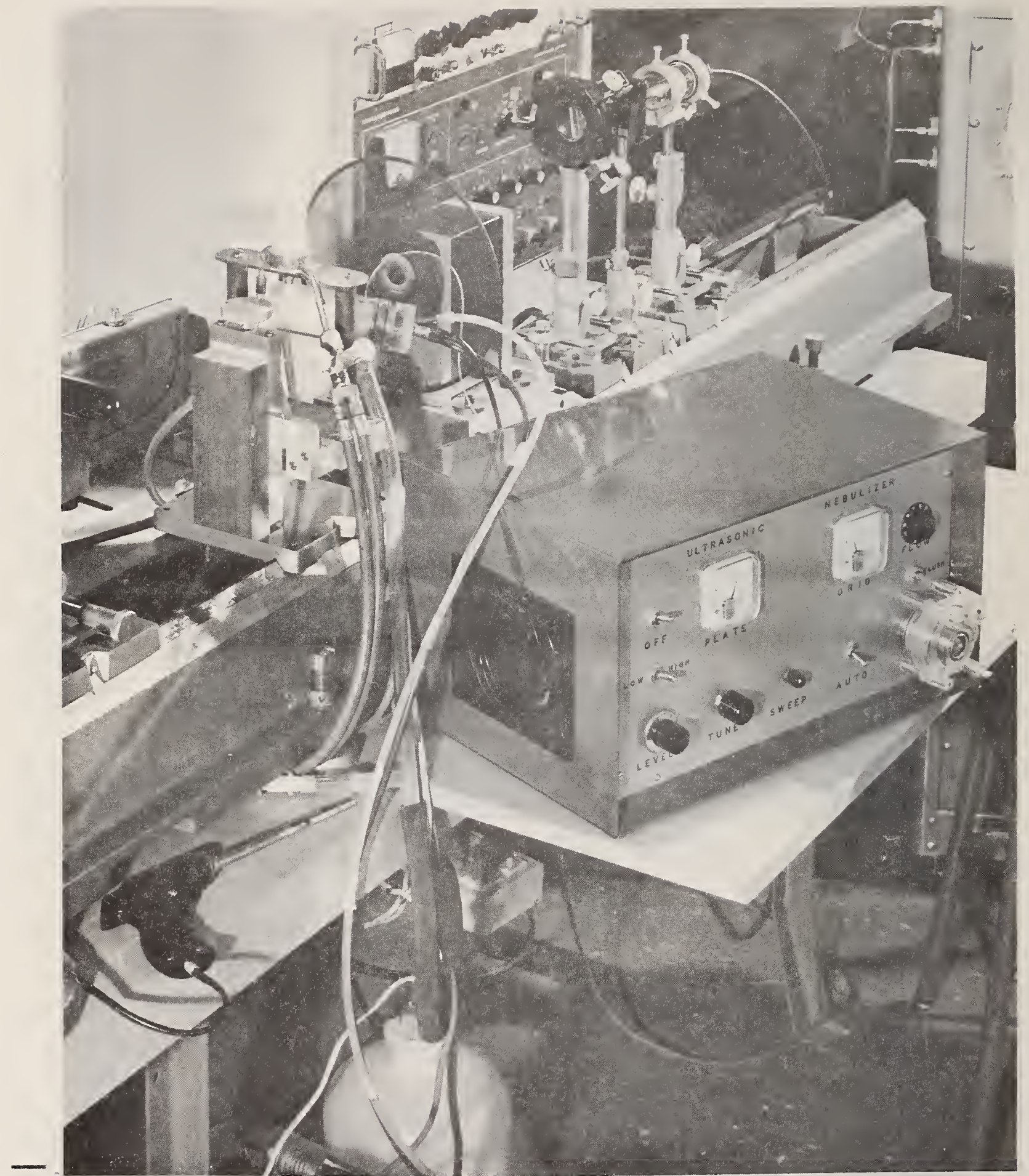

Figure 32. The unit from figures 30 and 31 placed on the optical bench in front of a lm grating spectrometer; shown here for measurements in the atomic mode. At right, the hollow cathode followed by a lens and a chopper. At lower right, the generator which drives the ultrasonic generator and the electrically operated sample pump which supplies the ultrasonic sprayer with the analytical sample solution. 
undertaken. In an oxygen-hydrogen flame, the aluminum lines at 3944 and $3962 \AA$ are not observed. However, under reducing conditions using a nitrous oxide-acetylene flame, these lines are quite intense. The major interference, however, is the strong $\mathrm{CH}$ band system which lies directly under these lines, as shown in figure 33. The band structure

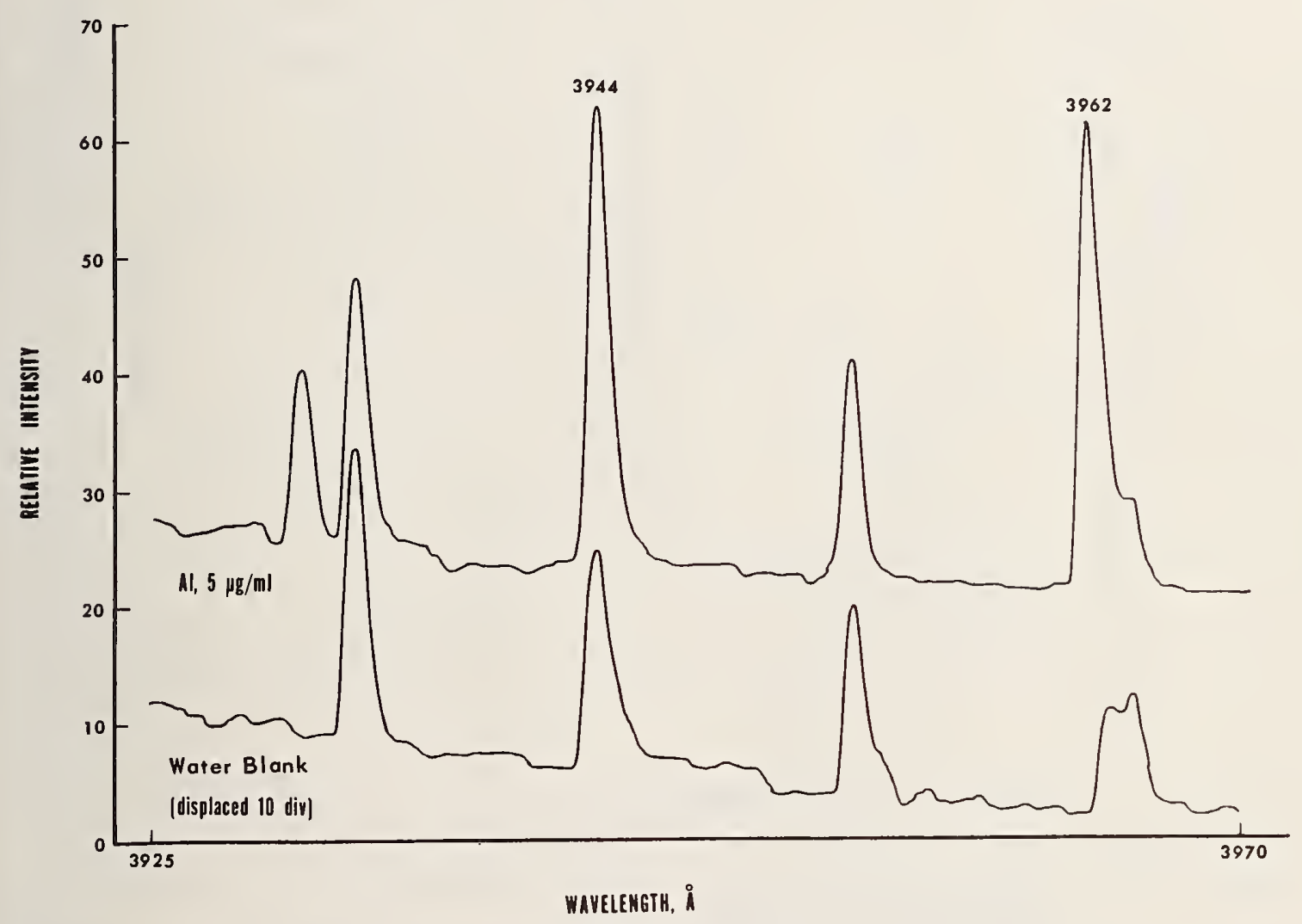

Figure 33. Flame emission spectra of aluminum over wavelength region of 3925 to 3970 A from a nitrous oxide-acetylene flame (amplifier gain $20 \mathrm{mV}$ ).

under the $3944 \AA$ aluminum line could not be resolved with the present $0.75 \mathrm{~m}$ monochromator; hence, further study of this line was discontinued. On the other hand, the aluminum line at $3962 \AA$ has two undefined bands which lie under its peak. By repetitive optical scanning [87, 88, 1] and by selecting the length of scan, it was possible to correct for any contri- 
bution to the aluminum signal by this band structure. A typical calibration curve is shown in figure 34. The
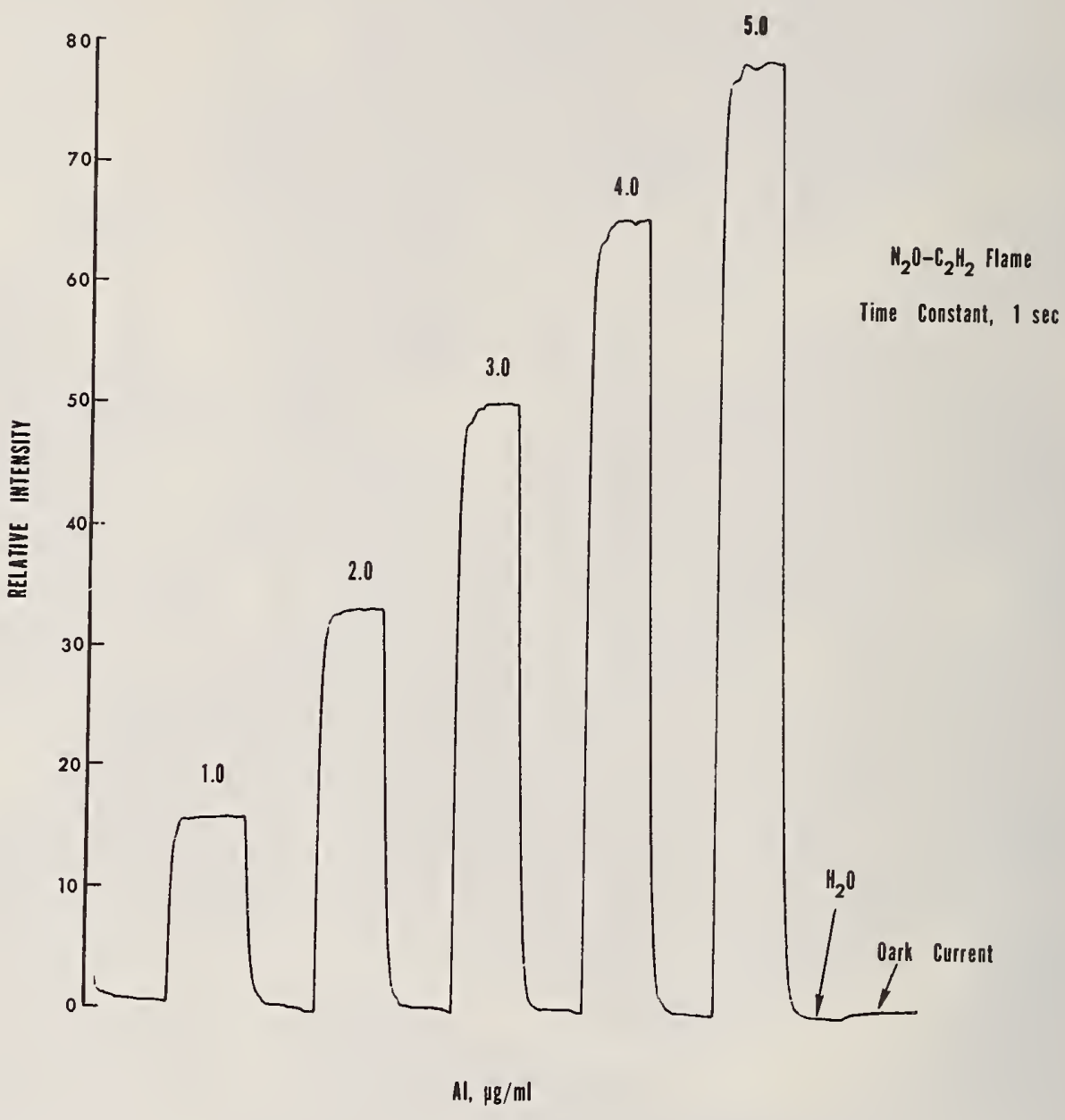

Figure 34. Calibration curve for aluminum using repetitive optical scanning.

contribution to the emission signal from water and from flame gases was about the same as that obtained with the dark current (excluding all light from photodetector).

The height of the nitrous oxide-acetylene flame was scanned under varying flame conditions. The optimum for the best signal-to-noise ratio was to focus on the center of the pink plume within the flame when the pink plume was 1 to 1.5 inches in height. 
By comparing the data in figure 35, obtained with normal

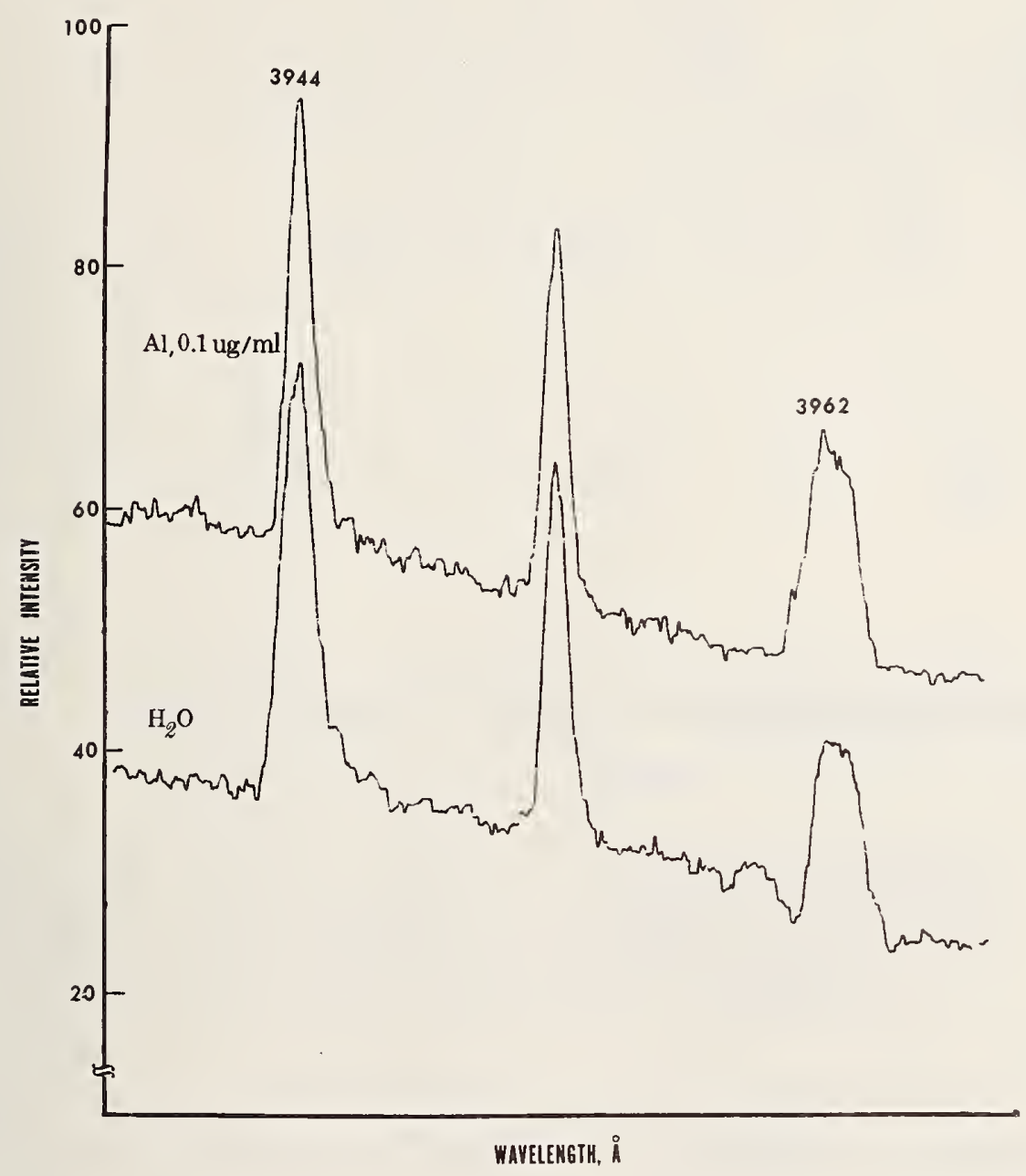

Figure 35. Comparison of flame emission spectrum of $0.1 \mu g /$ $\mathrm{ml}$ of aluminum and $\mathrm{H}_{0} \mathrm{O}$ using a nitrous oxideacetylene flame." Conditions: Time constant, 1 sec; voltage applied to photomultiplier tube, $1000 \mathrm{~V}$; amplifier gain, $1 \mathrm{mV}$; flame, fuel rich (1-l/2 inch pink plume).

wavelength scan, and the data in figure 36, the relative advantages of the latter method are apparent. The scan in figure 35 was made with and without $0.1 \mu \mathrm{g} / \mathrm{ml}$ of aluminum. In a series of measurements of the intensity of the aluminum line at $3962 \AA, 0.1 \mu \mathrm{g} / \mathrm{ml}$ could not be repeatedly 


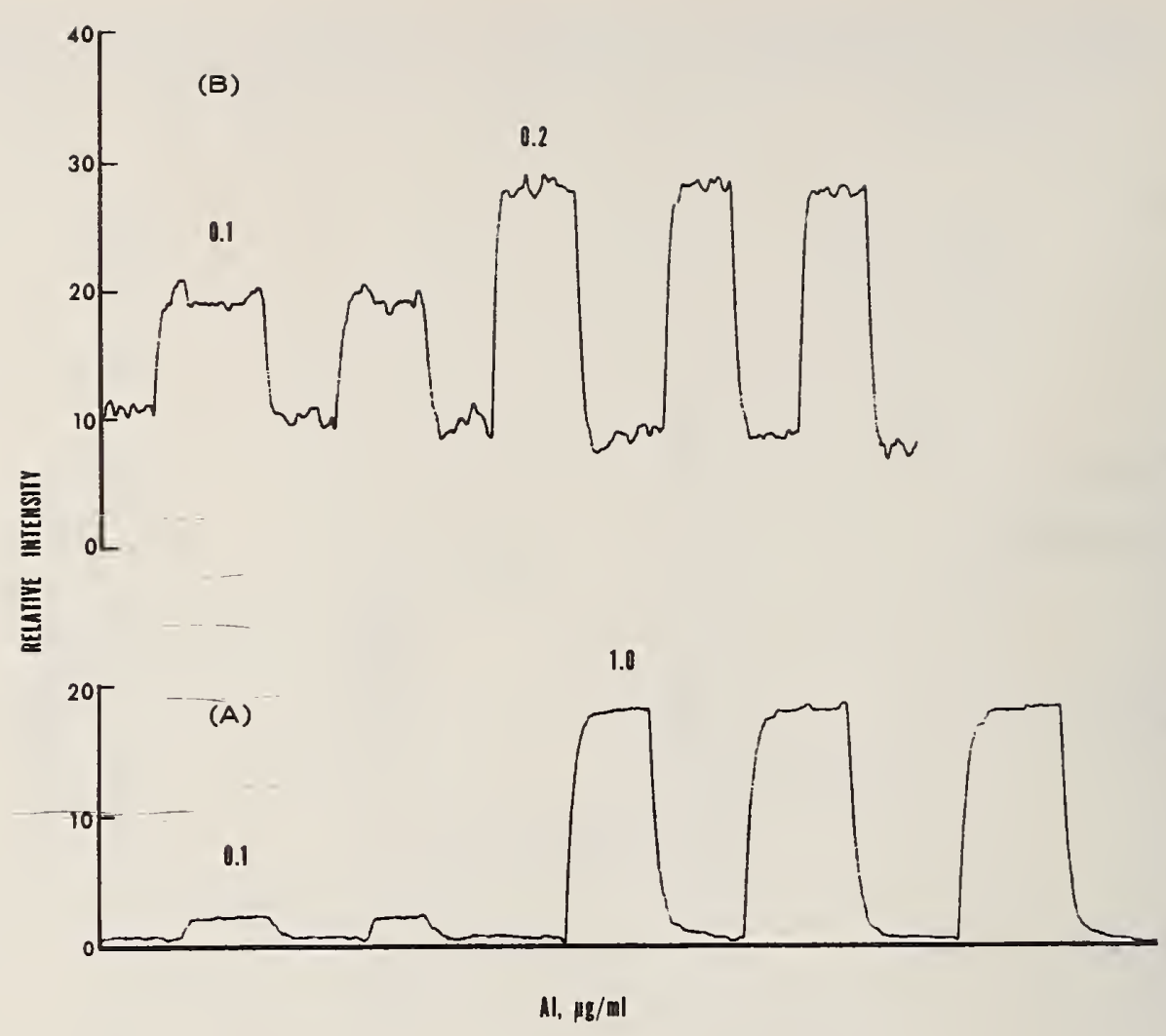

Figure 36. Relative intensity of aluminum using repetitive optical scanning.

(A) Optical conditions the same as in figure 35.

(B) Voltage applied to photomultiplier tube increased to $1200 \mathrm{~V}$.

detected in the presence of the band structure. Under the same instrumental conditions (voltage to photodetector and gain to amplifier), $0.1 \mu \mathrm{g} / \mathrm{ml}$ of aluminum was positively detected using repetitive optical scanning, as shown in figure 36 .

A detection limit of $0.01 \mu \mathrm{g} / \mathrm{ml}$ of aluminum, which is equivalent to two sigma above the flame background, was obtained for repetitive optical scanning with a RC time constant of $I$ second on the lock-in amplifier. See figure 37 .

The selection of time constants from 0.1 to 10 seconds was also evaluated. It was found that detection limits could be improved with a longer time constant. At 3 and 10 
Al, $0.1 \mu \mathrm{g} / \mathrm{ml}$

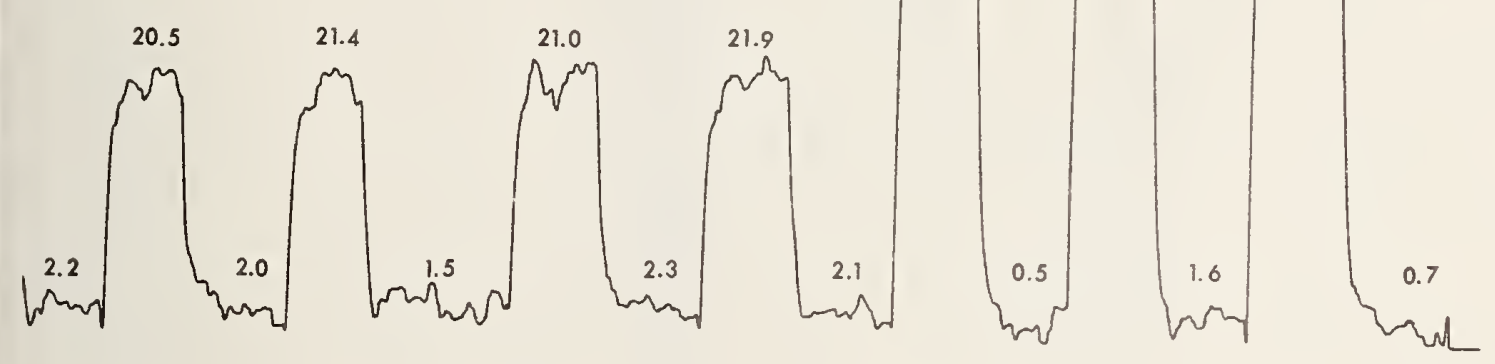

Figure 37. Relative intensity of 0.1 and $0.2 \mu \mathrm{g}$ of aluminum with repetitive optical scanning using a nitrous oxide-acetylene flame. Conditions: Same as in figure 35, except voltage applied to photomultiplier tube, $1300 \mathrm{~V}$.

seconds and a signal of 50 percent transmittance, maximum peak heights were obtained in 15 and 60 seconds, respectively. The slight improvement in detection limits did not justify the longer time constant which consumed a larger amount of analyte.

Table 34 lists the values for aluminum in 0.4 percent carbon steel (20g). This Standard Reference Material was analyzed by three cooperating laboratories using different methods. The certified value is 0.040 percent aluminum.

G. High-Preaision Atomic Absorption Spectrometry for

Major Components - T. C. Rains

In an effort to improve our precision and accuracy in the determination of major components by atomic absorption spectrometry, zinc and chromium were investigated respectively in a lead-base alloy and a steel. 
Table 34. Determination of aluminum in $0.4 \%$ carbon steel by flame emission spectrometry.

\begin{tabular}{|c|c|}
\hline Sample & $A l, \mu g / g$ \\
\hline $\begin{array}{r}\text { Ic } \\
\text { d }\end{array}$ & $\begin{array}{l}396 \\
396\end{array}$ \\
\hline $\begin{array}{r}5 c \\
d\end{array}$ & $\begin{array}{l}400 \\
396\end{array}$ \\
\hline $\begin{array}{r}8 c \\
d\end{array}$ & $\begin{array}{l}399 \\
398\end{array}$ \\
\hline $\begin{array}{r}\text { IIc } \\
\text { d }\end{array}$ & $\begin{array}{l}396 \\
402\end{array}$ \\
\hline $\begin{array}{r}13 c \\
d\end{array}$ & $\begin{array}{l}392 \\
396\end{array}$ \\
\hline $\begin{array}{r}17 \mathrm{c} \\
\mathrm{d}\end{array}$ & $\begin{array}{l}399 \\
397\end{array}$ \\
\hline & $\begin{array}{cc}\overline{\mathrm{X}} & 397 \\
& 6 \\
\% & 1.6\end{array}$ \\
\hline
\end{tabular}

The determination of zinc by atomic absorption is extremely sensitive; however, its sensitivity is dependent upon the path length of the flame. Sensitivity is defined by the slope of the calibration curve. As shown in figure 38,1 and $10-\mathrm{cm}$ flame cell path-lengths were evaluated.

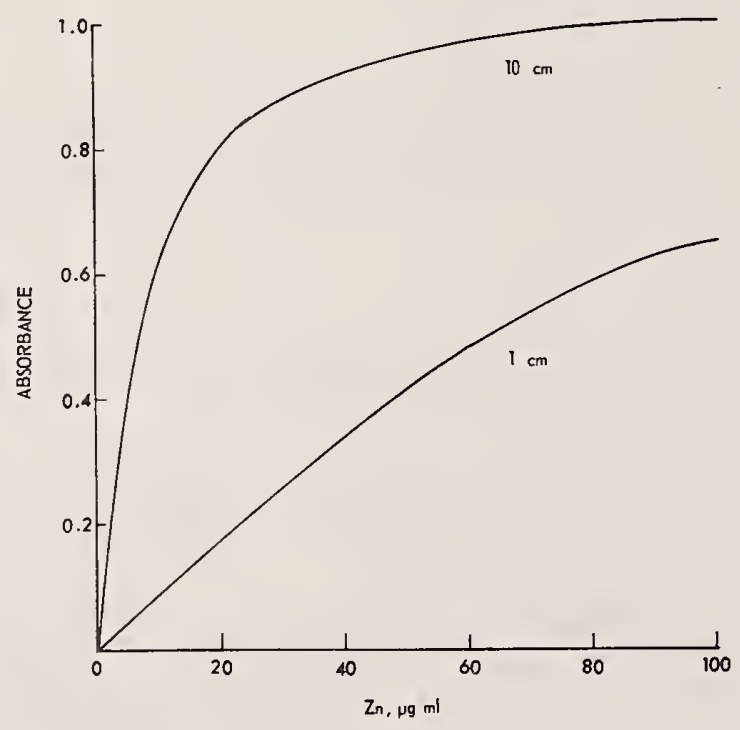

Figure 38. Effect of flame cell path-length on the absorbance of zinc at $138 \mathrm{~A}$. 
While the l-cm flame cell path-length extended the operating range to $100 \mu \mathrm{g} / \mathrm{ml}$ of zinc, the precision was not improved, due to the lower slope of the curve over a wider range of concentrations. With a $10-\mathrm{cm}$ flame cell path-length, a slope of 6 was obtained over the concentration range from 0 to $10 \mu \mathrm{g} / \mathrm{ml}$. Also, the slope dropped to 1.2 over the concentration range from 10 to $20 \mu \mathrm{g} / \mathrm{ml}$. Maximum precision was attained with a double-beam spectrometer at concentrations from 12 to $14 \mu \mathrm{g} / \mathrm{ml}$ and operating with scale expansion to give an absorbance reading of 2.100 to 2.500. A summary of the results and a comparison with classical procedures are given in table 35. The values reported by the cooperators

Table 35. Determination of zinc in SRM 124d (ounce metal).

AAS

\begin{tabular}{|c|c|c|c|c|}
\hline Sample & Replicates & $\underline{\mathrm{Zn}}, \%$ & S.D. & S.D. \\
\hline $\begin{array}{l}\text { A } \\
\text { B } \\
\text { C } \\
\text { D }\end{array}$ & $\begin{array}{l}6 \\
4 \\
3 \\
4\end{array}$ & $\begin{array}{l}5.087 \\
5.082 \\
5.073 \\
5.030\end{array}$ & $\begin{array}{r}0.075 \\
.023 \\
.012 \\
.023\end{array}$ & $\begin{array}{r}0.15 \\
.45 \\
.23 \\
.45\end{array}$ \\
\hline
\end{tabular}

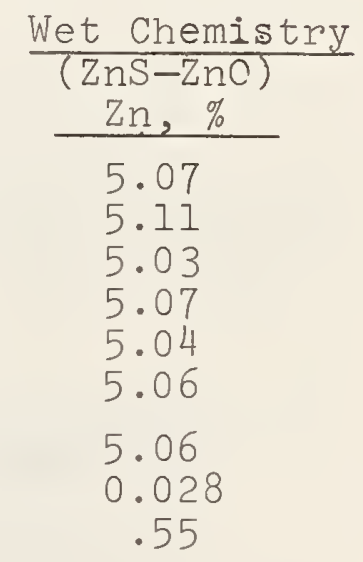

were determined by the classical method (the ZnS-ZnO method). The technique for the determination of zinc was applied to the determination of chromium in $\mathrm{Cr}$ 18-Ni 10 stainless steel samples. However, several interferences were encountered in the determination of chromium that were not present when zinc was determined. Using an air-acetylene flame, nickel severely interfered in the determination of chromium. A slight change in acidity $\left(\mathrm{H}_{2} \mathrm{SO}_{4}\right.$ or $\mathrm{H}_{2} \mathrm{SO}_{4}-$ $\mathrm{H}_{3} \mathrm{PO}_{4}$ ) greatly affected the absorbance of chromium. In a nitrous oxide-acetylene flame the interference of nickel and variations in acid concentration were removed. 
The higher temperature flame ionized the chromium and reduced its sensitivity. To overcome these difficulties, $500 \mathrm{\mu g} / \mathrm{ml}$ of potassium was added to the standards and unknown solutions. The results are summarized in table 36 .

Table 36. Determination of chromium in SRM 121 d.

\begin{tabular}{|c|c|c|}
\hline \multicolumn{2}{|c|}{ AAS } & Potentiometric Titration ${ }^{a}$ \\
\hline Sample & $\mathrm{Cr}, \%$ & $\mathrm{Cr}, \%$ \\
\hline A & $\begin{array}{l}17.67 \\
17.50 \\
17.54 \\
17.54\end{array}$ & $\begin{array}{l}17.58 \\
17.59 \\
17.56 \\
17.58\end{array}$ \\
\hline B & $\begin{array}{l}17.62 \\
17.49 \\
17.56 \\
17.58\end{array}$ & 17.62 \\
\hline $\begin{array}{r}\text { S } \\
\text { Rel. }\end{array}$ & $\begin{array}{r}\bar{X} 17.56 \\
0.06 \\
\% \quad .34\end{array}$ & $\begin{array}{r}17.59 \\
.02 \\
.12\end{array}$ \\
\hline
\end{tabular}

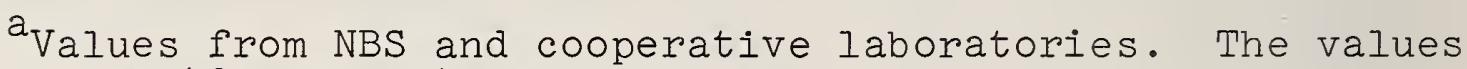
of 17.48 and $17.43 \%$ from two laboratories were excluded.

H. Effect of Spectral Bandwidth in Atomic Absorption Spectrometry - T. C. Rains

Any radiation in the monochromator bandwidth which is not due to the analytical line has a detrimental effect. By increasing the proportion of the undesired radiation, the slope of the working curve and the sensitivity of the analyte are decreased. There is also an increase in nonlinearity. A typical example of this type of interference is illustrated with iron. The spectrum over the wavelength region of 2450 to $2505 \AA$, as shown previously [1], is rich in iron lines. The most sensitive ground state resonant line of iron commonly used in atomic absorption is located at $2483 \AA$. However, it is very close to a nonresonant line at $2484 \AA$ A having a lower energy level of 888 kaysers. Only by means of a high resolving mono102 
chromator can these two lines be completely resolved. If the extraneous radiation cannot be eliminated by selecting a narrow slit width, the working curve will become more nonlinear, as shown in figure 39. The wider slit width

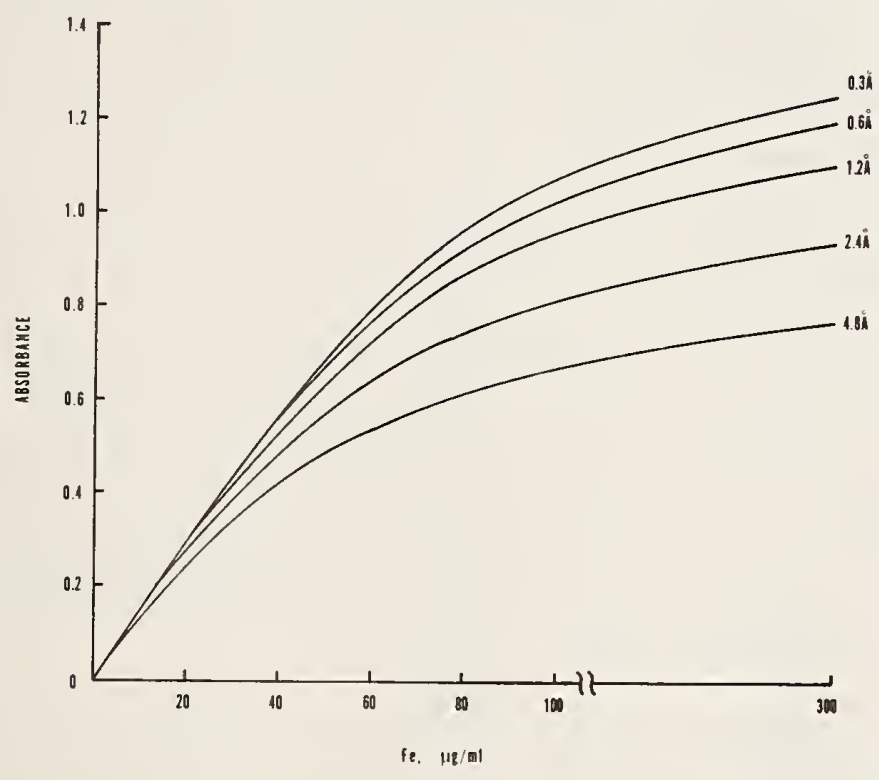

Figure 39. Effect of spectral bandwidth on absorbance of iron at $248 \overline{3} \mathrm{~A}$.

does contribute to a lower signal-to-noise ratio. In our work we have selected a $0.6 \stackrel{\circ}{\AA}$ bandpass.

I. Analytical Application to Standard Reference Materials T. A. Rush and T. C. Rains

1. Determination of Calcium, Magnesium, Silver and Zinc in Special steel

The determination of these trace elements in special steel containing a low concentration of impurities is a challenge to the flame photometrist. The first major problem is the dissolution of the sample without contamination. To overcome this difficulty, a mixture of $\mathrm{HNO}_{3}, \mathrm{HClO}_{4}$ and $\mathrm{HF}$ was used to dissolve the samples in Teflon beakers with covers. Excess fluoride was removed by heating to fumes of perchlorate. 
Calcium was determined by flame emission with optical scanning. Since iron suppressed the radiant intensity of calcium, the standard solutions were prepared to contain the same concentration of iron as the unknown. The iron used in the preparation of the standards was high-purity Mossbauer iron. To increase the sensitivity of the determination of calcium in a high iron matrix, the final working solutions were diluted with acetone to provide a 40 percent solution. A nitrous oxide and air (80:20)-acetylene flame was used to excite the calcium resonant line at $4227 \AA$. The addition of acetone to the aqueous solution produced extreme fuel rich conditions which required an adjustment in the normal acetylene flow rate. To prevent flame-flashback due to the lower fuel flow, a 40 percent acetone solution was nebulized between standards and unknowns.

Magnesium, silver and zinc were determined by atomic absorption spectrometry using a double-beam system with an air-acetylene flame. The standard solutions were prepared to contain the same concentration of iron as the unknowns. However, due to the high solid content in the standard and unknown solutions, the deuterium arc was used to correct for light scatter. Similar results were obtained by using an

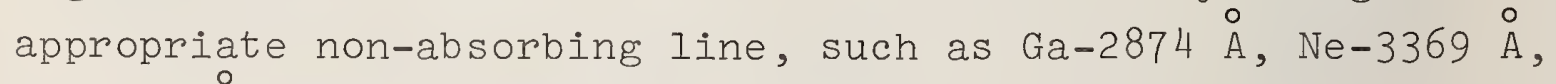
Re-2214 $\mathrm{A}$ and subtracting the absorbance due to light scatter. The results are given in table 37 .

2. Determination of Calcium, Potassium, Magnesium, Sodium, Rubidium, Cadmium, Zinc and Manganese in Orchard Leaves - T. C. Rains and T. A. Rush

It is of interest to recall that the application of flame methods to agronomic problems played an important role in the development of flame spectroscopy. In the 1920's and early $1930^{\prime} \mathrm{s}$ the Swedish agronomist, H. Lundegardh, developed the technique of flame spectroscopy for the analysis of plant material. In this early work, an air-acetylene flame and photographic detectors were used. Today the flame photo- 
Table 37. Summary of SRM analyses by flame emission and atomic absorption spectrometry.

$\begin{array}{lll} & \text { No. } & \text { Rel. } \\ \text { NBS- } & \text { Mle- of } & \text { Material } \\ \text { SRM } & \text { ment Detms. Conc. } & \text { S.D. S.D., \% }\end{array}$

121D $18 \mathrm{Cr}-10 \mathrm{Ni}$ Steel $\mathrm{Cr}^{\mathrm{a}} \quad 2 \quad \frac{176.3}{1.8} \quad 1.0$

$\mathrm{Cu}^{\mathrm{a}} 21.209 \cdot 0.0010 .1$

1171

$\mathrm{Cr}^{\mathrm{a}} 4$

174.9

$1.6 \quad .9$

$\mathrm{Cu}^{\mathrm{a}} \quad 4$

1.206

$0.008 \quad .6$

$123 c$

$\mathrm{Cr}^{\mathrm{a}} 6$

175.5

$.7 \quad .4$

$\mathrm{Cu}^{\mathrm{a}} \quad 4$

1.040

$.003 \quad .3$

1172

$\mathrm{Cr}^{\mathrm{a}} 4$

174.9

1.6

.9

$\mathrm{Cu}^{\mathrm{a}} 4$

1.039

$0.008 \quad .8$

1571 Orchard Leaves

$\mathrm{Ca}^{\mathrm{b}} 24$

20.95

.20

.95

$\mathrm{Ca}^{\mathrm{a}} 6$

$\mathrm{K}^{\mathrm{b}}$

$\mathrm{K}^{\mathrm{a}}$

19

20.77

.15

.74

14.73

$.17 \quad 1.1$

$\mathrm{Mg}$

14.65

.09

0.66

6.21

$.07 \quad 1.2$

$\mathrm{Na} \quad 20$

$\mathrm{Rb} \quad 20$

$\mathrm{Cd} \quad 12$

$\mathrm{Zn}$

11

$\mathrm{Mn}$

11

$\frac{\mu \mathrm{g} / \mathrm{g}}{82}$

1261 Special Steel

$\mathrm{Ca}$

$\mathrm{Mg}$

11.9

0.11

25.2

91.9

6

0.3

7

$<1$

$\begin{array}{ll}\mathrm{Ag} & 3 \\ \mathrm{Zn} & 3\end{array}$

.01

3.0

1.4

2.0

9

5

2.2

361 Special Steel

$\mathrm{Ca}$

$\mathrm{Mg}$

$\mathrm{Ag}$

$\mathrm{Zn}$

2
2
3
3

1.2

4.0

+0.5
\pm
\pm
\pm
\pm

1.0

$<1$

2.0

4.0

1.0

$+0 \cdot 5$
\pm
\pm
\pm

1262 Special Steel

Ca

2.0

$\pm 0.5$

$\mathrm{Mg}$

6.0

10.0

5.0

.5 
Table 37 Cont'd

362 Special Steel

$\begin{array}{rrrr}\mathrm{Ca} & 2 & 2.0 & \pm 0.5 \\ \mathrm{Mg} & 2 & 6.0 & .5 \\ \mathrm{Ag} & 2 & 10.0 & .5\end{array}$

$a_{\text {Atomic absorption. }}$

blame emission.

metrist has at his command a variety of oxidant-fuels and photodetectors for flame emission or atomic absorption.

In 1968, the Association of Official Analytical Chemists (A.O.A.C.) was the first organization to adopt atomic absorption spectrometry as an "official" method for the determination of selected major and minor elements in fertilizer and feeds. Since that date, other organizations such as ASTM have recognized AAS methods as official. The lack of certified standards is a major problem in the analysis of agronomic materials. The preparation and certification of Standard Reference Materials such as orchard leaves and related materials is the first attempt to fill this void.

Atomic absorption and flame emission methods have been developed for the determination of major and trace elements in orchard leaves. Both techniques were applied to the determination of the major components such as calcium, potassium and magnesium, while the technique with the highest sensitivity was used in the determination of the trace elements such as sodium, rubidium, cadmium, zinc and manganese.

a. Preparation of Samples. The samples are dried in a vacuum oven at $90^{\circ} \mathrm{C}$ for 24 hours and then cooled in a desiccator over anhydrous calcium sulfate. Depending upon the concentration of the analyte, a 0.5 to $2 \mathrm{~g}$ test portion is transferred to a Teflon beaker, and dissolved in a mixture of $\mathrm{HNO}_{3}, \mathrm{HF}$ and $\mathrm{HClO}_{4}$. After evaporation to strong fumes 
of perchlorate, the solution is transferred to a volumetric flask and diluted to calibrated volume.

b. Determination of Constituents. Calcium and potassium are two of the major inorganic constituents in orchard leaves. Calcium was determined by flame emission with optical scanning using an oxygen-hydrogen flame and an air-acetylene flame was used to obtain the absorption measurements. Since high concentrations of phosphate suppress the radiant intensity and absorption of calcium, glycerol and perchloric acids [89] were used as releasing agents. As shown in table 37, the values, 20.95 and 20.77 $\mathrm{mg} / \mathrm{g}$ of calcium for the two techniques are in good agreement and indicate comparable precision.

As an alternate method, the nitrous oxide-acetylene flame was investigated and the interference of phosphate was eliminated; however, additional potassium was added to standards and unknowns to suppress ionization. The average value for calcium using the nitrous oxide-acetylene flame compares with oxygen-hydrogen or air-acetylene, but the precision was 1.5 to 2.0 percent.

In the determination of potassium, both the emission and absorption techniques were used and show good agreement between values (table 37). An improvement in precision was obtained by atomic absorption, and no interferences were observed by either method. Additional information will be necessary before concluding that the determination of potassium by atomic absorption is more precise than by flame emission.

Magnesium, a minor constituent in orchard leaves, was determined by atomic absorption using an air-acetylene flame. Under our experimental conditions, phosphate did not interfere, and no releasing agents were added to either standards or unknowns. 
Sodium, rubidium, manganese, cadmium, zinc and mercury are present as trace constituents in orchard leaves. Sodium and rubidium were determined by flame emission while manganese, cadmium and zinc were determined by atomic absorption. In the determination of rubidium, manganese and zinc, standards were adjusted to contain an equal concentration of the major cations that were present in the orchard leaves. This procedure compensates for some of the minor chemical effects which suppress or enhance the signal of the analyte.

Since cadmium was present at less than $l \mu \mathrm{g} / \mathrm{g}$, it was preconcentrated by extraction with ammonium pyrrolidinodithiocarbamate in a mixture of methyl isobutyl ketonecyclohexone $(3: 1)$. The cadmium was stripped from the organic phase with IN HCl prior to the nebulization and the absorption measurement was made at $2288 \AA$.

The results are summarized in table 37.

3. Determination of Mercury in Orchard Leaves T. C. Rains

An increasing awareness of environmental pollution and the need for Standard Reference Materials have led to an investigation of the flameless atomic absorption technique for determining mercury. This technique is possible because mercury has a favorable vapor pressure.

As early as 1930 Müller [90] took advantage of the high vapor pressure of mercury to determine it in air. In 1939 Woodson [91] described an instrument used in the determination of mercury in air. Since the publication of Müller, many workers have used the same general approach, but the final analysis was completed by colorimetric or volumetric methods.

In atomic absorption studies using an air-acetylene flame, Poluektov and Vitkun [92] observed an increase in sensitivity when stannous chloride was added. They also observed that the absorption of mercury could be measured 
in the vapor phase without the use of a flame. Hatch and ott [93] applied the same technique to a closed system in which the mercury vapor was continuously recirculated until a maximum signal was attained. The system was then opened to exhaust the mercury vapor. The technique developed by Hatch and ott was first investigated but the precision and accuracy required for standard Reference Materials could not be attained. This led to the investigation of various parameters which included the dissolution of sample, reduction of mercury to the atomic state, trapping of volatile vapors and the absorption measurement. A schematic diagram of our system is shown in figure 40 .

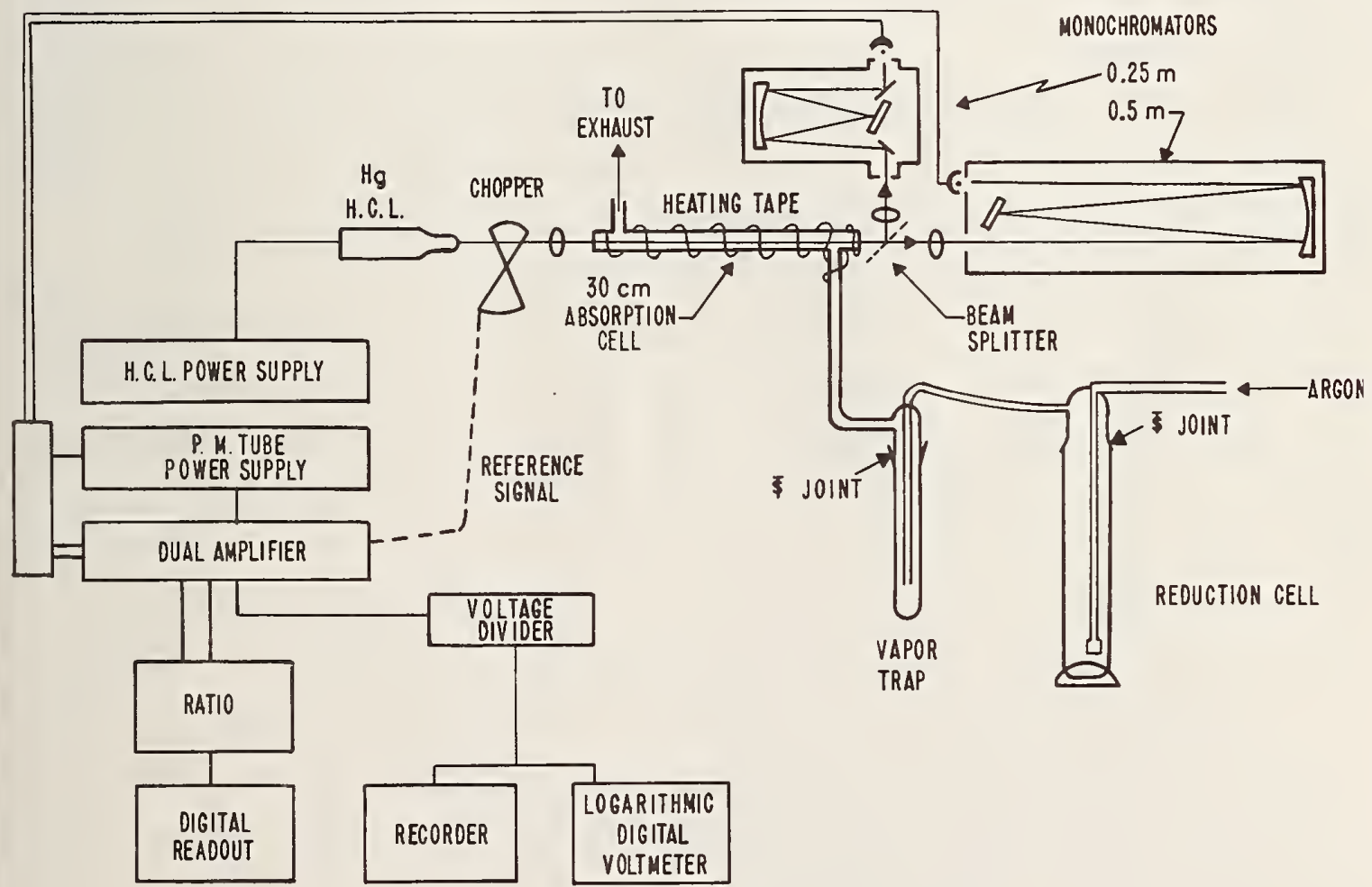

Figure 40. Schematic diagram of flameless atomic absorption apparatus for mercury determination. 
a. Dissolution of Sample. Since mercury is easily reduced and subsequently lost in the vapor phase during the destruction of organic material, several methods of dissolution were tested. Combustion by the Schöenger method was examined; however, this technique is limited to the amount of solids or organic material which can be ignited. The sealed tube method [94] employing nitric and sulfuric acids was used to dissolve organic material (orchard leaves); however, two difficulties arose. The sample size was limited to $0.2 \mathrm{~g}$ and the oxides of nitrogen which were liberated during the dissolution caused excessive frothing in the subsequent reduction step. The oxides of nitrogen were removed after transferring the solution from the sealed tube by gentle heating, but the possible loss of mercury existed.

The most successful dissolution procedure is a modification of the one described by Munns and Holland [95]. The sample ( 1 to $5 \mathrm{~g}$ of orchard leaves) is transferred to a 250-ml flat bottom digestion flask equipped with a 24/40 standard taper joint. After adding $25 \mathrm{ml}$ of $1: 1$ sulfuric acid and $20 \mathrm{ml}$ of $1: 1$ nitric acid, an Allihn condenser with circular water was attached to the flask. (The condenser was filled to a height of $50 \mathrm{~mm}$ with Raschig rings and glass beads.) The sample was gently heated at $155{ }^{\circ} \mathrm{C}$ for 15 minutes using a heating mantle. The temperature was then raised to $190^{\circ} \mathrm{C}$ and maintained for 45 minutes. After the solution was cooled for $10 \mathrm{~min}$, a mixture of nitric and perchloric acids was added to the condenser, followed by a rinse with water. The water to the condenser was removed and the sample was heated at a temperature of 200-220 ${ }^{\circ} \mathrm{C}$, with a heating mantle, until dense fumes of perchlorate appeared, and then heated for an additional 10 minutes. The sample was cooled and transferred to a clean 100-ml volumetric flask. The heating mantle provides more uniform heating and reduces frothing during dissolution. This 110 
dissolution procedure was checked with ${ }^{203} \mathrm{Hg}$ and the recovery of the tracer was complete within the counting statistics of the counter, i.e. \pm 1 percent. Without the addition of Raschig rings and beads to the Allihn condenser, the loss of ${ }^{203} \mathrm{Hg}$ was 5-10 percent. If the dissolution was made in an Erlenmeyer flask equipped with a tightly-fitted cover, the loss of $203 \mathrm{Hg}$ was $10-15$ percent. Using a beaker, the loss of ${ }^{203} \mathrm{Hg}$ was 60-70 percent. In one test, a solution dissolved under reflux conditions, was transferred to a beaker and evaporated to a $2-\mathrm{ml}$ volume. The loss of the ${ }^{203} \mathrm{Hg}$ tracer was 25 percent.

b. Reduction of Mercury. Two methods for reducing mercury to atomic vapor were investigated. In one, the mercury was reduced to the free atomic state with a solution of hydroxylamine hydrochloride and stannous chloride. The atomic vapor was flushed from the reduction cell with argon into a heated $30-\mathrm{cm}$ absorption cell.

Hypophosphorous acid was also used to reduce mercury and it was about as effective as stannous chloride for solutions of mercury in dilute nitric acid. In a solution of orchard leaves, excess foaming occurred and was swept into the vapor trap and into the absorption cell. This excessive foaming resulted in the discontinuance of the work with $\mathrm{H}_{3} \mathrm{PO}_{3}$.

In some tests foaming also occurred with stannous chloride. To overcome this difficulty, the system was purged with argon prior to the addition of the reducing solution. Under these conditions, 25 to 75 percent of the mercury was lost. To overcome the problem of foaming, it was determined that all organic material must be removed from the sample solution. To aid in the removal of organic material after the sample was fumed with $\mathrm{HClO}_{4}$, the reflux condenser was rinsed with water and the sample was reheated to strong fumes of perchlorate. 
c. Trapping of Volatile Vapors. Several methods are used to trap volatile vapors which contribute to light scattering or molecular absorption. A cold trap in a mixture of salt and ice $\left(-10^{\circ} \mathrm{C}\right)$ or drying agents, such as magnesium perchlorate or anhydrous calcium sulfate are often used. Each method was tested and found satisfactory for short operating periods only. The procedure then is to remove the drying agent, clean and dry the trap and recharge the drying agent. The vapors were passed intc a clean, dry glass chamber where the large droplets would collect on the walls of the container. The fine particles and mercury vapors are then swept into a heated absorption cell where the absorption measurement is made.

d. Absorption Cells. A number of absorption cells having the following sizes were investigated: 1 x 10-, $0.8 \times 20$ - and $0.8 \times 30-\mathrm{cm}$. As expected, the longer cellpath gave an improvement in absorbance of $1: 2: 2.5$, respectively. With our optical arrangement, the $30-\mathrm{cm}$ cell was selected. To prevent slight memory effects, molecular absorption and fogging of end windows, the cell was heated to $170{ }^{\circ} \mathrm{C}$ with heating tape.

e. Contamination Problems. The first major problem was contamination of glassware and reagents with mercury. All glassware was rinsed with 10 percent nitric acid. Polypropylene flasks were best suited for storage, over a period of several days, of sample solutions. When samples were stored in glass volumetric flasks, mercury values increased by 50-100 percent over a one-week period. To illustrate the degree of contamination of reagents by mercury, three bottles of hydroxylamine hydrochloride, all from the same lot, were analyzed and contained $0.0008,0.027$ and $0.031 \mu \mathrm{g} \mathrm{Hg} / \mathrm{g}$. In another lot, the mercury was present at $<0.001 \mu \mathrm{g} / \mathrm{g}$. Ultra-high purity 
acids were also tested, since some lots of nitric acid contained $0.03 \mu \mathrm{g}$ of $\mathrm{Hg} / \mathrm{ml}$.

Samples of orchard leaves, dried in a vacuum oven at $90^{\circ} \mathrm{C}$ for 24 hours and then cooled in a desiccator over anhydrous calcium sulfate, showed mercury values which were 25 to 50 percent higher than the undried samples. The source of this contamination is under investigation.

f. Measurement. Absorption measurements were made with a single-beam and a double-beam (ratio method [1]) system. A schematic diagram of ratio system is shown in figure 40. With this ratio method, a non-absorbing aluminum line at $2652 \AA$ is compared with the absorption of mercury at $2537 \AA$ and a ratio is taken. The values for mercury in orchard leaves, obtained with the single beam and ratio method, are given in table 38 .

Table 38. Determination of mercury in orchard leaves by flameless atomic absorption.

\begin{tabular}{|c|c|c|}
\hline \multirow[b]{2}{*}{ Sample } & \multicolumn{2}{|c|}{$\mathrm{Hg}, \mu \mathrm{g} / \mathrm{g}$} \\
\hline & Single-Beam System & Ratio System \\
\hline Number 1 & $\begin{array}{r}0.155 \\
.153 \\
.155 \\
.155 \\
.167 \\
.164 \\
.170\end{array}$ & $\begin{array}{r}0.159 \\
.153 \\
.160 \\
.157 \\
.165 \\
- \\
.172\end{array}$ \\
\hline Rel. & $\begin{array}{cc} & \bar{X} 0.160 \\
. D \% & 4.006 \\
\% & 4.0\end{array}$ & $\begin{array}{l}0.160 \\
.006 \\
4.0\end{array}$ \\
\hline
\end{tabular}

4. Service Analysis - T. A. Rush and T. C. Rains Atomic absorption and flame emission spectrometry were applied to a wide variety of samples submitted by Divisions of the Bureau as well as other Government agencies. The elements determined and the types of materials analyzed include: lead in paint; chromium and zinc in solutions used in paper products; mercury in lithium bromide coolant; 
sodium, potassium, magnesium and strontium in reagent grade calcium carbonate; nickel and silver in reagent grade sodium hydroxide; sodium in organic dyes; $\mathrm{Cd}, \mathrm{Ni}, \mathrm{Ca}, \mathrm{Cu}, \mathrm{Mg}$ : $\mathrm{Zn}, \mathrm{Pb}, \mathrm{Mn}$ and $\mathrm{Hg}$ in effluent from river sediments; $\mathrm{Al}, \mathrm{B}$, $\mathrm{Ba}, \mathrm{Cr}, \mathrm{Cu}, \mathrm{Fe}, \mathrm{Mn}, \mathrm{Mo}, \mathrm{Pb}, \mathrm{Sr}$ and $\mathrm{Zn}$ in effluent from sewage treatment facilities.

Lead was determined by atomic absorption spectrometry in a variety of paints submitted by the National Commission on Product Safety. The range of lead concentrations was from 0.12 to 9.5 percent. Samples of the dried paint were wet oxidized with $\mathrm{HNO}_{3}$ and $\mathrm{HClO}_{4}$ and lead was determined using the lead line at $2833 \AA$. Over the concentration range investigated, no interferences were encountered and the precision of the method was one percent.

Mercury was determined in lithium bromide coolant for the National Institutes of Health. The flameless technique described earlier was used; however, bromide interfered. This interference was removed by repeated evaporations with nitric acid. As a check on mercury loses, 50 and $100 \mathrm{ng}$ of mercury were added to test portions of the sample and then determined. The recovery was complete in each test.

A study was made of the extract of trace elements with $20 \mathrm{\mu g} / \mathrm{ml}$ of NTA from river sediments. In natural water effluents, few interferences are encountered by atomic absorption spectrometry. Phosphate and sulfate are known to interfere in the determination of calcium and magnesium using an air-acetylene flame; however, under the test conditions, these anions did not extract or they were so low in concentration that no interference was observed. The analytical conditions and range of concentrations of cations under various extraction conditions are summarized in table 39. 
Table 39. Analytical conditions and concentration ranges for trace elements in water effluents with and without NTA.

Range of

Ele- Wavelength
ment

$\begin{array}{ll}\mathrm{Ca} & 4227 \\ \mathrm{Cd} & 2288 \\ \mathrm{Cu} & 3247 \\ \mathrm{Hg} & 2537 \\ \mathrm{Mg} & 2852 \\ \mathrm{Mn} & 2795 \\ \mathrm{Ni} & 2320 \\ \mathrm{~Pb} & 2833 \\ \mathrm{Zn} & 2138\end{array}$

$\mu \mathrm{g} / \mathrm{ml}$

$$
\begin{aligned}
& 0.1-1.0 \\
& .1-1.0 \\
& .1-1.0 \\
& .001-0.005 \\
& 2.0-10.0 \\
& 0.1-1.0 \\
& .1-1.0 \\
& .2-1.0 \\
& .1-1.0
\end{aligned}
$$

Scale Expansion Concentration

Factor Range, $\mu \mathrm{g} / \mathrm{ml}$

$\begin{array}{rr}1.0 & 0.02-200 \\ 2.5 & .02-0.04 \\ 7.0 & .03-.03 \\ 2.5 & <.0005-.016 \\ - & .60 \\ 5.0 & <.005-60 \\ 10.0 & <.01-0.2 \\ 5.0 & <.05-.3 \\ 6.0 & <.001-.5\end{array}$


A. Introduction

Differential Thermal Analysis (DTA) as a physical, analytical method for characterizing materials is gaining wider interest. Both from the theoretical standpoint and quality control the effects of phase changes with temperature on the physical and chemical properties of materials provide useful information. These investigations extend over a broad spectrum of science and technology and include biochemical or health systems such as the studies of lipid systems in reference to artherosclerosis; or space technology involving high temperature refractories; or properties of polymers in controlling the quality of new material and the manufactured product. In a current symposium sponsored by this section at NBS a few of these areas of applications have been described and were published [96].

Further evidence of the growth of this field is indicated by the activities of national and international societies. The Third International Conference on Thermal Analysis is to be held at Davos, Switzerland in 1971, and the Third Annual Meeting of the North American Thermal Analysis Society will be held on February 7 and 8, 1972 in Waco, Texas. Finally, one can note from the records of the current Analytical Chemistry Laboratory Guide that over thirty-three commercial instruments are available indicating a continual increase in number over the past years.

To the present, the Section's efforts have been limited to providing temperature scale calibration SRM's in the temperature region of $125^{\circ} \mathrm{C}$ to $940^{\circ} \mathrm{C}$. This work is summarized in the following section.

There is at present a further need to extend the temperature range to subambient and to higher temperature $\left(\sim-150{ }^{\circ} \mathrm{C}\right.$ to $2500^{\circ} \mathrm{C}$ ) to cover the diverse areas of interest. 
B. Certification of SRM's for Calibrating the Temperature Scale of DTA Apparatus - D. S. Bright and O. Mienis

In conjunction with the International Confederation on Thermal Analysis (ICTA) a series of materials was certified for temperature scale calibrations of Differential Thermal Analysis (DTA) apparatus. This represents the culmination of efforts described more fully last year [1]. These materials consisted of eight inorganic substances, exhibiting solid I=Solid II transition and two metals, and covered the temperature range from $125{ }^{\circ} \mathrm{C}$ to $940{ }^{\circ} \mathrm{C}$.

As shown in table 40 and figure 41 , the mean temperature

Table 40. Mean values of onset heat temperatures of ICTA substances.

\begin{tabular}{lccc} 
& \multicolumn{3}{c}{ Temperature Value ${ }^{\circ} \mathrm{C}$} \\
\cline { 2 - 4 } Substance & Literature & $\begin{array}{l}\text { ICTA } \\
\text { Mean }\end{array}$ & Std. Dev. \\
\hline $\mathrm{KNO}_{3}$ & 127.7 & 127.6 & 4.9 \\
$\mathrm{KClO}_{4}$ & 299.5 & 299.4 & 6.4 \\
$\mathrm{Ag}_{2} \mathrm{SO}_{4}$ & - & 424.1 & 7.5 \\
$\mathrm{SiO}_{2}$ & 573 & 570.7 & 5.0 \\
$\mathrm{~K}_{2} \mathrm{SO}_{4}$ & 583 & 581.6 & 7.1 \\
$\mathrm{~K}_{2} \mathrm{CrO}_{4}$ & 665 & 664.4 & 7.3 \\
$\mathrm{BaCO}_{3}$ & 810 & 807.7 & 8.4 \\
$\mathrm{SrCO}_{3}$ & 925 & 928.4 & 7.6 \\
$\mathrm{In}$ & 157 & 154.6 & 5.4 \\
$\mathrm{Sn}$ & 232 & 230.5 & 5.0
\end{tabular}

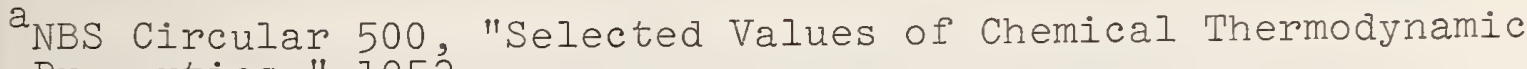
Properties," 1952 .

values are based on data obtained by 34 cooperating laboratories in 13 countries employing 28 different commercial or custom-made instruments. From these data, the mean values of onset heating temperatures by DTA are only one to two degrees higher than the literature equilibrium values. The standard deviation, independent of the 


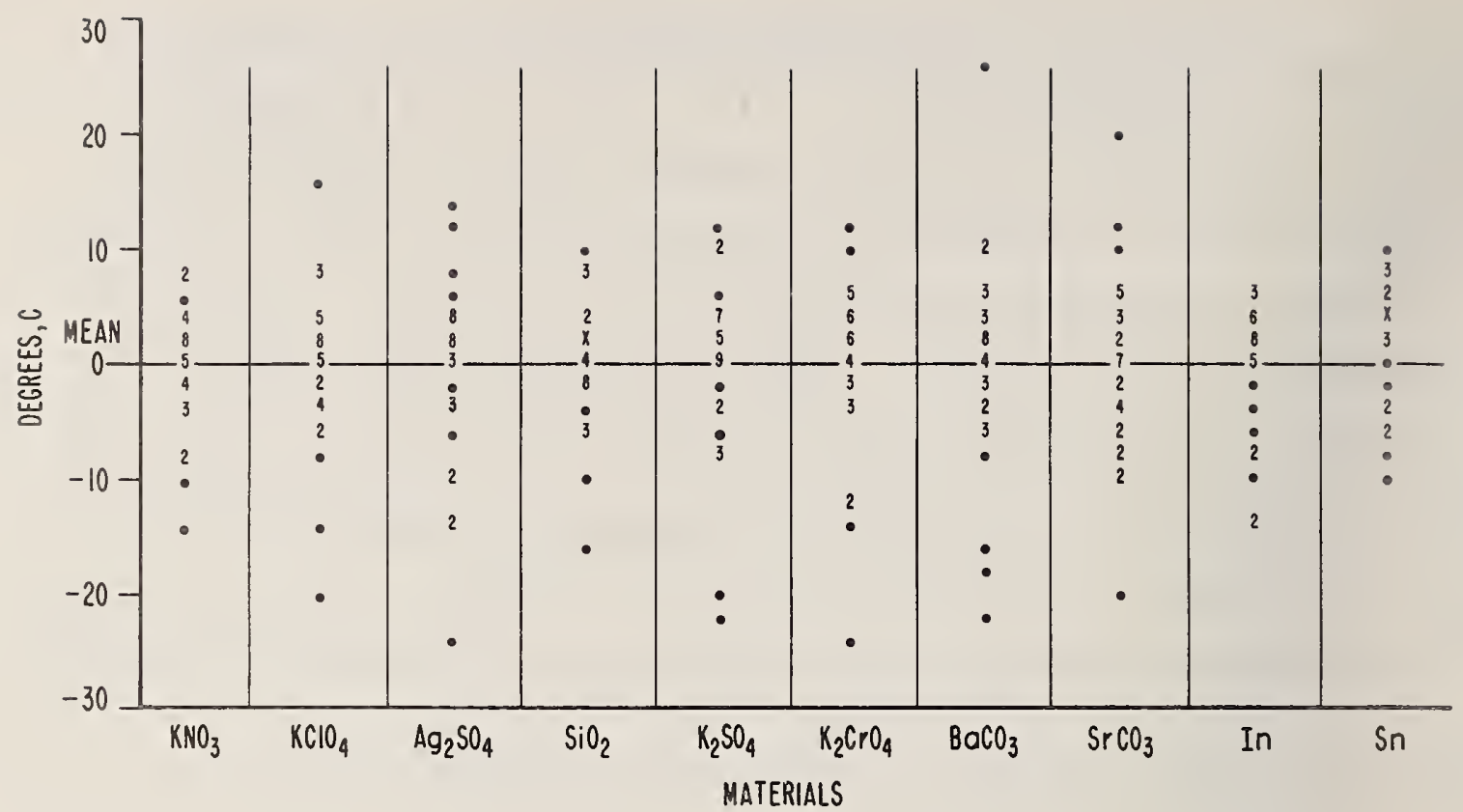

Figure 41. Data from 34 cooperating investigators for each of the 10 substances (submitted to the Standards Committee of ICTA).

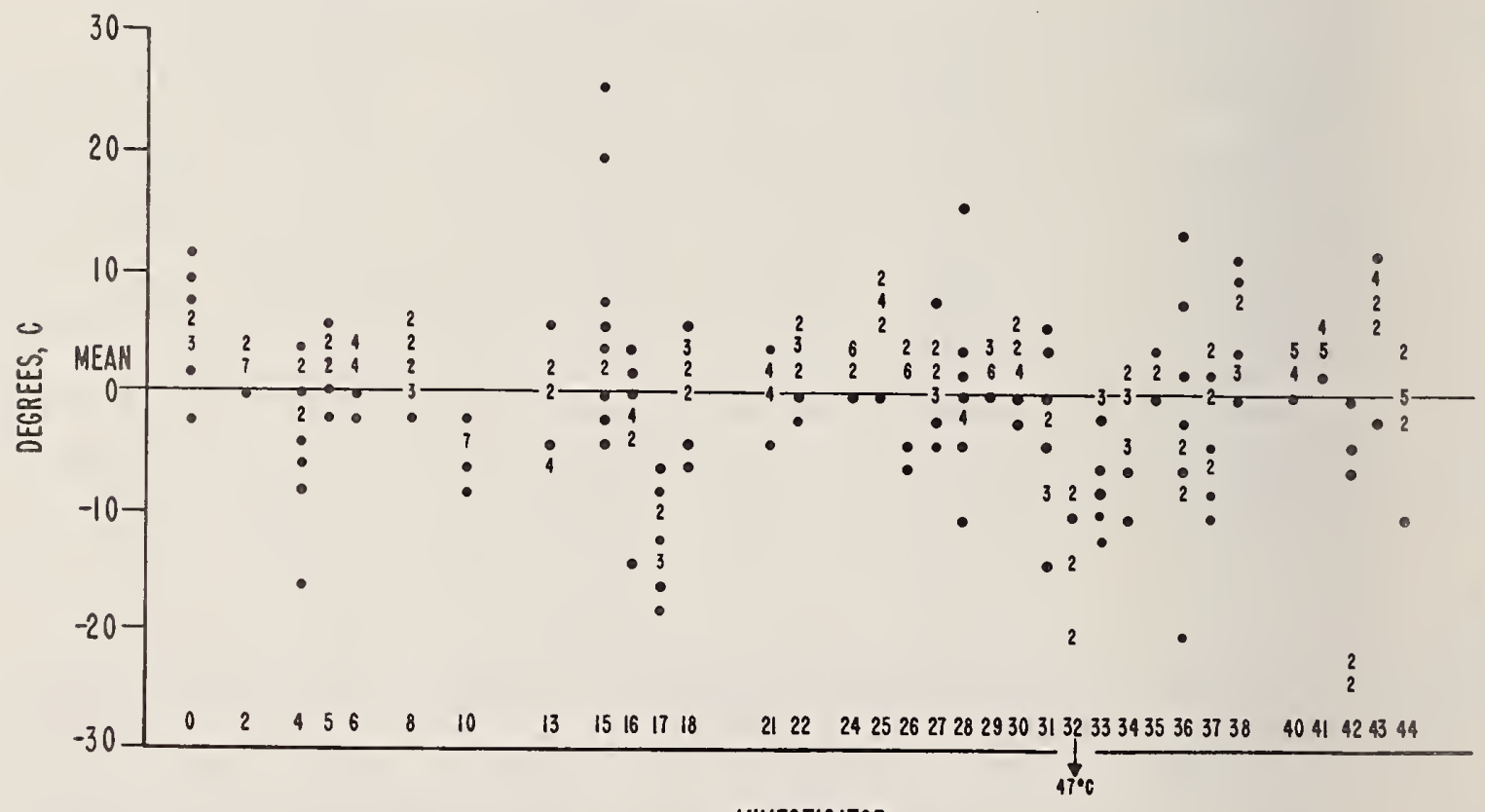

INVESTIGATOR

Figure 42. Deviations from the mean value as reported by the 34 investigators (submitted to the Standards Committee of ICTA).

substance measured was 5 to $8^{\circ} \mathrm{C}$. This reflects the

bias among laboratories as well as the measurement errors. As shown in figure 42 , some of the investigators had 
more pronounced differences, however, their values were included. The complete discussion of these data will be published in the Proceedings of the Third International Conference on Thermal Analysis, Davos, Switzerland 1971 , and in a NBS Special Publication - 260 series. The SRM's 758,759 and 760 were issued to cover three temperature ranges and the certificates are reproduced in the following pages.

Finally, as chairman of the Standard Section of the ASTM Provisional Committee on Thermal Analysis, in cooperation with Dr. P. Garn of the University of Akron, an ASTM procedure, "Standard Method of Calibration of Temperature Scale for Differential Thermal Analysis" was written and submitted for membership approval.

C. Scanning Calorimetry - D. S. Bright, E. Prosen (a) and

1. Introduction

In addition to the Standard Reference Materials already available for use in checking the performance of DTA equipment [1], there is a need for establishing accurate enthalpy values for these transition temperatures. While calorimetric data for many of these compounds are available in the literature, there is a continuing demand to verify these values or to obtain data on new materials. The classical calorimetric methods, while capable of providing very accurate values are time-consuming and require complex measuring techniques. Ozawa described a relatively simple scanning calorimeter which could be calibrated independently by electrical means and for which he claimed an accuracy of 1 to 2 percent [97].

A brief exploratory experiment was undertaken to evaluate ozawa's design and procedure. A rudimentary

(a)E. Prosen, Physical Chemistry Divition, IMR. 


\section{NBS-ICTA Standard Reference Material 758 DTA Temperature Standards $\quad\left(125-435^{\circ} \mathrm{C}\right)$}

These standards include: high-purity potassium nitrate, indium, tin, commercial grade potassium perchloratc, and analyzed reagent silver sulfate. They are for use in calibrating the temperature sealc on differential thermal analysis and related thermoanalytical equipment under the operating condilions. They are to be used only in the heating mode.

Transition Temperature Data $\left({ }^{\circ} \mathrm{C}\right)$

\begin{tabular}{lccc} 
Material & $\begin{array}{c}\text { Equilibrium } \\
\text { Value [1] }\end{array}$ & $\begin{array}{c}\text { DTA Mean Values } \\
\text { Extrapolated } \\
\text { Onset }\end{array}$ & $\underline{\text { Peak }}$ \\
\cline { 2 - 2 } & 127.7 & 128 & 135 \\
$\mathrm{KNO}_{3}$ & 157 & 154 & 159 \\
$\mathrm{In}($ metal) & 231.9 & 230 & 237 \\
$\mathrm{KClO}_{4}$ & 299.5 & 299 & 309 \\
$\mathrm{Ag}_{2} \mathrm{SO}_{4}$ & - (a) & 424 & 433
\end{tabular}

(a) The value for the transition temperature reported for this material [1] is currently under review. A more recent value of $430^{\circ} \mathrm{C}$ lias been reported [2].

For potassium nitrate only, the first heating of the material is not a reliable measure of the transition tcmperature. This sample must be eycled through the transition temperature in situ before recording data.

The extrapolated onset temperature is defined (Point A, Figure 1) as that temperature found by extrapolating the base line, prior to the peak, and the leading side of the peak to their intersection. The peak temperature (Point B, Figure 1) is defined as the temperature corresponding to the point of maximum deflection of the differential temperature curve.

Based on the mean value from 34 cooperating laboratories, the standard deviation was $5-8{ }^{\circ} \mathrm{C}$, which includes the bias among laboratories as well as measurement errors. In the heating mode, onsel and peak temperatures have about equal precision. However, the mean extrapolated onset temperatures are closer to the equilibrium transition temperatures. ICTA.

The materials for these standards were furnished by the Committee on Standardization of the

The: International Test Program leading to the data on which certification is based was coordiualed lis II. G. McAdie, Chairman, ICTA Comınit tee on Standardization.

Coordinalion of efforts l'arling to certificalion by NBS was under the chairmanship of O. Menis.

The Iorhnical and support aspects involved in the preparation, eertification, and issuanee of these: Standard Reference Materials were coordinaled through the Office of Standard Referenee Malcrials by T. W'. Mears.

Washington, D.C. 20234

J. Paul Cali, Chicf

June 11, 1971

Offiec of Standard Reference Materials 
The transition temperatures given are the means of values obtained on 28 different types of commercial or custom-made instruments, and do not necessarily agree with the equilibrium values $[1,2]$. Generally, values from DTA are somewhat higher than the equilibrium values and vary in a complex manner for different instruments and heating rates. Details of the instruments used, the test conditions and complete data will be given in an NBS Special Publication in the 260 series (in publication).

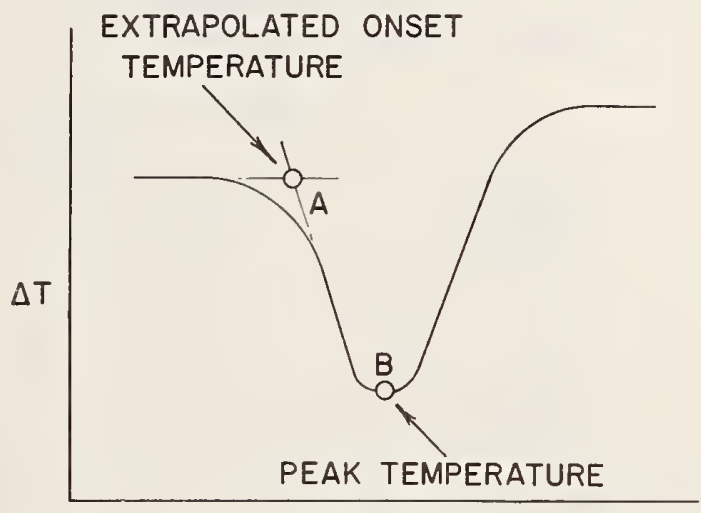

$\mathrm{T}$

[1] Nat. Bur. Stand. (U.S.), Circ. 500 (1952).

[2] Hedvall, J. A., Lindner, R., and Hartler, N., Acta. Chem. Scand. 4, 1099 (1950). 


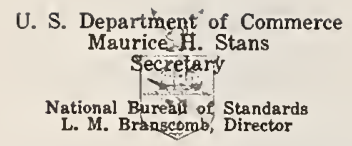

\section{Urertifirate}

\section{NBS-ICTA Standard Reference Material 759 DTA Temperature Standards $\left(295-675{ }^{\circ} \mathrm{C}\right)$}

These standards include: analyzed reagent silver sulfate, potassium sulfate, potassium chromate; commereial grade potassium perehlorate; and natural quartz. They are for use in ealibrating the temperature seale on differential thermal analysis and related thermoanalytieal equipment under operating eonditions. They are to be used only in the heating mode.

Transition Temperature Data $\left({ }^{\circ} \mathrm{C}\right)$

\begin{tabular}{|c|c|c|c|}
\hline \multirow[b]{2}{*}{ Material } & \multirow[b]{2}{*}{$\begin{array}{l}\text { Equilibrium } \\
\text { Value [1] }\end{array}$} & \multicolumn{2}{|c|}{ DTA Mean Values } \\
\hline & & $\begin{array}{c}\text { Extrapolated } \\
\text { Onset } \\
\end{array}$ & Peak \\
\hline $\mathrm{KClO}_{4}$ & 299.5 & 299 & 309 \\
\hline $\mathrm{Ag}_{2} \mathrm{SO}_{4}$ & (a) & 424 & 433 \\
\hline $\mathrm{SiO}_{2}$ & 573 & 571 & 574 \\
\hline $\mathrm{K}_{2} \mathrm{SO}_{4}$ & 583 & 582 & 588 \\
\hline $\mathrm{K}_{2} \mathrm{CrO}_{4}$ & 665 & 665 & 673 \\
\hline
\end{tabular}

(a) The value tor the transition temperature reported for this material [1] is currently under review. A more recent value of $430{ }^{\circ} \mathrm{C}$ has been reported [2].

The extrapolated onset temperature is defined (Point A, Figure 1) as that temperature found by extrapolating the base line, prior to the peak, and the leading side of the peak to their interseetion. The peak temperature (Point B, Figure 1) is defined as the temperature corresponding to the point of maximum deflection of the differential temperature curve.

Based on the mean value from 34 cooperating laboratories, the standard deviation was $5-8{ }^{\circ} \mathrm{C}$, which includes the bias among laboratories as well as measurement errors. In the heating mode, onset and peak temperatures have about equal preeision. However, the mean extrapolated onset temperatures are eloser to the equilibrium transition temperatures. ICTA.

The materials for these standards were furnished by the Committee on Standardization of the

The International Test Program leading to the data on which certification is based was coordinated by H. G. MeAdie, Chairman, ICTA Committee on Standardization.

Coordination of efforts leading to eertification by NBS was under the chairmanship of O. Menis.

The technical and support aspects involved in the preparation, certification, and issuance of these Standard Reference Materials were coordinated through the Office of Standard Reference Materials by T. W. Mears.

Washington, D. C. 20234

June 11, 1971
J. Paul Cali, Chief

Office of Standard Reference Materials 
The transition temperatures given arc the means of values obtained on 28 different typcs of commercial or custom-made instruments, and do not necessarily agree with the cquilibrium values $[1,2]$. Generally, values from DTA are somewhat higher than the equilibrium values and vary in a complex manner for differcnt instruments and heating rates. Details of the instrumcnts used, the test conditions and complcte data will be given in an NBS Special Publication in the 260 series (in publication).

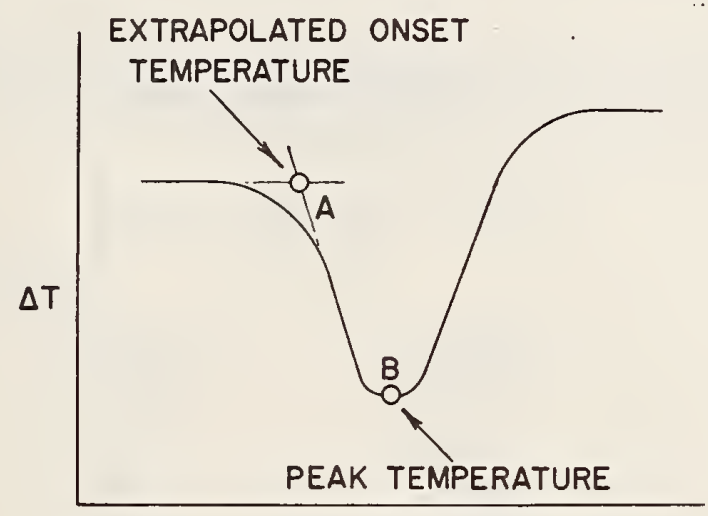

$\mathrm{T}$

[1] Nat. Bur. Stand. (U.S.), Circ. 500 (1952).

[2] Hedvall, J. A., Lindner, R., and Hartler, N., Acta. Chem. Scand. 4, 1099 (1950). 


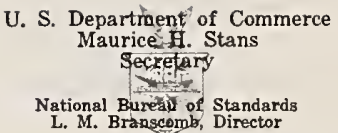

\section{Ulertifirate \\ NBS-ICTA Standard Reference Material 760 \\ DTA Temperature Standards $\quad\left(570-940{ }^{\circ} \mathrm{C}\right)$}

These standards include: natural quartz; analyzed reagent potassium sulfate, potassium chromate, barium carbonate, and strontium carbonate. They are for use in calibrating the temperature scale on differential thermal analysis and related thermoanalytical equipment under operating conditions. They are to be used only in the heating mode.

\section{Transition Temperature $\mathrm{Data}\left({ }^{\circ} \mathrm{C}\right)$}

\begin{tabular}{lccc} 
Material & $\begin{array}{c}\text { Equilibrium } \\
\text { Value [1] }\end{array}$ & $\begin{array}{c}\text { DTA Mean Values } \\
\text { Extrapolated } \\
\text { Onset }\end{array}$ & Peak \\
\cline { 2 - 3 } $\mathrm{SiO}_{2}$ & 573 & 571 & 574 \\
$\mathrm{~K}_{2} \mathrm{SO}_{4}$ & 583 & 582 & 588 \\
$\mathrm{~K}_{2} \mathrm{CrO}_{4}$ & 665 & 665 & 673 \\
$\mathrm{BaCO}_{3}$ & 810 & 808 & 819 \\
$\mathrm{SrCO}_{3}$ & 925 & 928 & 938
\end{tabular}

The extrapolated onset temperature is defined (Point A, Figure 1) as that temperature found by extrapolating the base line, prior to the peak, and the leading side of the peak to their intersection. The peak temperature (Point B, Figure 1 ) is defined as the temperature corresponding to the point of maximum deflection of the differential temperature curve.

Based on the mean value from 34 cooperating laboratories, the standard deviation was $5-8^{\circ} \mathrm{C}$, which includes the bias among laboratorics as well as measurement errors. In the heating mode, onset and peak temperatures have about equal precision. However, the mean extrapolated onset temperatures are closer to the equilibrium transition temperatures. ICTA.

The materials for these standards were furnished by the Committee on Standardization of the

The International Test Program leading to the data on which certification is based was coordinated by H. G. McAdie, Chairman, ICTA Committee on Standardization.

Coordination of efforts leading to certification by NBS was under the chairmanship of O. Menis.

The technical and support aspects involved in the preparation, certification, and issuance of thesc Standard Reference Materials werc coordinated through the Office of Standard Reference Materials by T. W. Mears.

Washington, D. C. 20234

June 11, 1971
J. Paul Cali, Chief

Office of Standard Referencc Materials 
The transition temperatures given are the means of values obtained on 28 different types of commercial or custom-made instruments, and do not necessarily agree with the equilibrium values [1]. Generally, values from DTA are somewhat higher than the equilibrium values and vary in a complex manner for different instruments and heating rates. Details of the instruments used, the test conditions and complete data will be given in an NBS Special Publication in the 260 series (in publication).

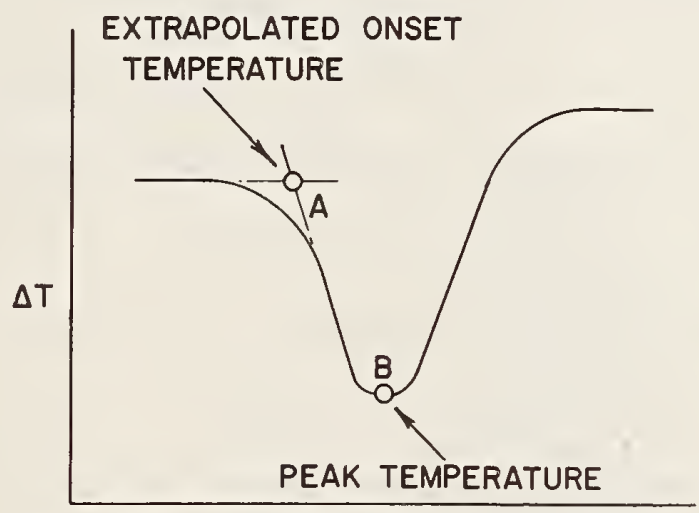

[1] Nat. Bur. Stand. (U.S.), Circ. 500 (1952). 
Dr. David E. Baum, Monsanto Australia Limited, West Footscray, Victoria, Australia Prof. Marcel Bourgon, Université de Montréal, Montréal, Quebec, Canada

Dr. H. G. McAdie, Ontario Research Foundation, Sheridan Park, Ontario, Canada

Dr. Klaus Heide, Friedrich-Schiller-Universität, Jena, Germany

Dr. J. Wiegmann, Berlin, Germany

Dr. G. R. Cizeron, Université de Paris, Paris, France

Dr. M. Harmelin, C.N.R.S., Paris, France

Mme. J. Jegoudez, Université de Paris, Paris, France

Dr. M. Foldvari, Hungarian Geological Institute, Budapest, Hungary

Mr. J. Paulik, Technical University of Budapest, Budapest, Hungary

Prof. H. Kambe, University of Tokyo, Tokyo, Japan

Prof. C. Kato, Waseda University, Tokyo, Japan

Prof. K. Oinuma, Tokyo University, Tokyo, Japan

Prof. R. Otsuka, Waseda University, Tokyo, Japan

Mr. J. E. Kruger, National Building Research Institute, Pretoria, South Africa

Dr. R. S. Forsyth, Aktiebolaget A tomenergi, Studsvik-Nyköping, Sweden

Dr. G. Krien, Institut für Chemisch-Techn. Untersuchungen, Leverkusen, Germany

Prof. H. R. Oswald, Universität Zurich, Zurich, Switzerland

Dr. T. Peters, Universität Berne, Berne, Switzerland

Dr. H. G. Wiedemann, Mettler Instrumentc A. G., Greifensee, Switzerland

Prof. L. F. Berg, Gosuniversitet, Kazan, U.S.S.R.

Prof. E. K. Koehler, Academy of Scicnces of the USSR, Novosibirsk, USSR

Dr. I. S. Rassonskaya, Institut Obshchei i Neorganicheskoi Khimii, Moscow, USSR

Dr. G. O. Piloyan, Academy of Sciences of the USSR, Moscow, USSR

Mr. E. L. Charsley, Stanton Rederoft Limited, London, England

Dr. R. C. Mackenzie, The Macaulay Institute for Soil Research, Aberdeen, Scotland 
Prof. D. A. Smith and Mr. J. Youren, Queen Mary College, University of London, London, England Dr. P. K. Gallagher, Bell Telephone Laboratories, Murray Hill, N.J..U.S.A.

Prof. P. D. Garn, University of Akron, Akron, Ohio, U.S.A.

Dr. O. Menis, D. S. Bright, and J. T. Sterling, National Bureau of Standards, Washington, D.C., U.S.A.

Mr. T. D. Oulton, Englehard Minerals \& Chemicals Corp., Edison, N.J.,U.S.A.

Dr. R. K. Ware, Owens-Illinois, Toledo, Ohio, U.S.A.

\section{International Confederation for Thermal Analysis Committee on Standardization:}

\section{Chairman \\ Vice-Chairman \\ Secretary \\ National Delegates}

Representative

Delegates

Ex-Officio

Delegates
(Canada)

(U.S.A.)

(U.K.)

(France)

(German)

(Hungary)

(Japan)

(Sweden)

(Switzerland)

(U.S.S.R.)

(U.K.)

(U.S.A.)

(U.S.A.)

ASTM

ISO

NBS

Soc.Anal.Chem.

SAMA

ICTA
(U.K.)

(U.S.A.)

(U.S.S.R.)

(U.S.A.)

(U.K.)

(U.K.)
H. G. McAdie

P. D. Garn

R. C. Mackenzie

C. Mazieres

K. Heide

F. Paulik

H. Kambe

R. S. Forsyth

H. G. Wiedemann

I. S. R assonskaya

D. A. Smith

R. W. Pfeil

Vacant

Vacant

O. Menis

C. J. Keattch

Vacant

L. G. Berg

C. B. Murphy

R. C. Mackenzie

J. P. Redfern 
scanning calorimeter similar to Ozawa's was assembled. Several compounds, whose enthalpy values ranged from room temperature to $300^{\circ} \mathrm{C}$, were measured to determine the characteristics of the instrument. Essentially, these materials were used to measure the proportionality coefficient, $k$, of the instrument. At the same time, independent proportionality coefficients were measured by an electric heat source. The measured values of the coefficient, $k$, showed a relative spread of 15 percent which indicates that this cell design is suitable for calorimetric enthalpy transition measurements to within only about 10 percent.

\section{Principle and Measurements}

Calorimetric measurements are based on the determinations of heat flow to a sample cell across a thermal barrier. If the temperature gradient across the barrier is linear, then the temperature differential is proportional to the heat flowing through the barrier.

A system used in such measurements is described in figures 43 and 44. The sample and a reference material are placed in a sample holder which, in turn, is contained in a ceramic thermal barrier. They are placed in a copper block which is heated at a slow and uniform rate.

The temperature difference between $A$ and $B(A-B)$, measured with "small" thermocouples, will be proportional to the rate of heat flowing into the sample, both to heat the sample and thermocouple and to supply heat for any transitions. Also, (C-D) is proportional to the rate of heat flowing into the reference material and will be constant, if the heat capacity of the reference material remains constant. If the reference material has the same heat capacity as the sample material, then $(C-D)-(A-B)$ will be zero between phase transitions, and will be proportional to the rate of heat flowing into the sample due to the transition only. In an 


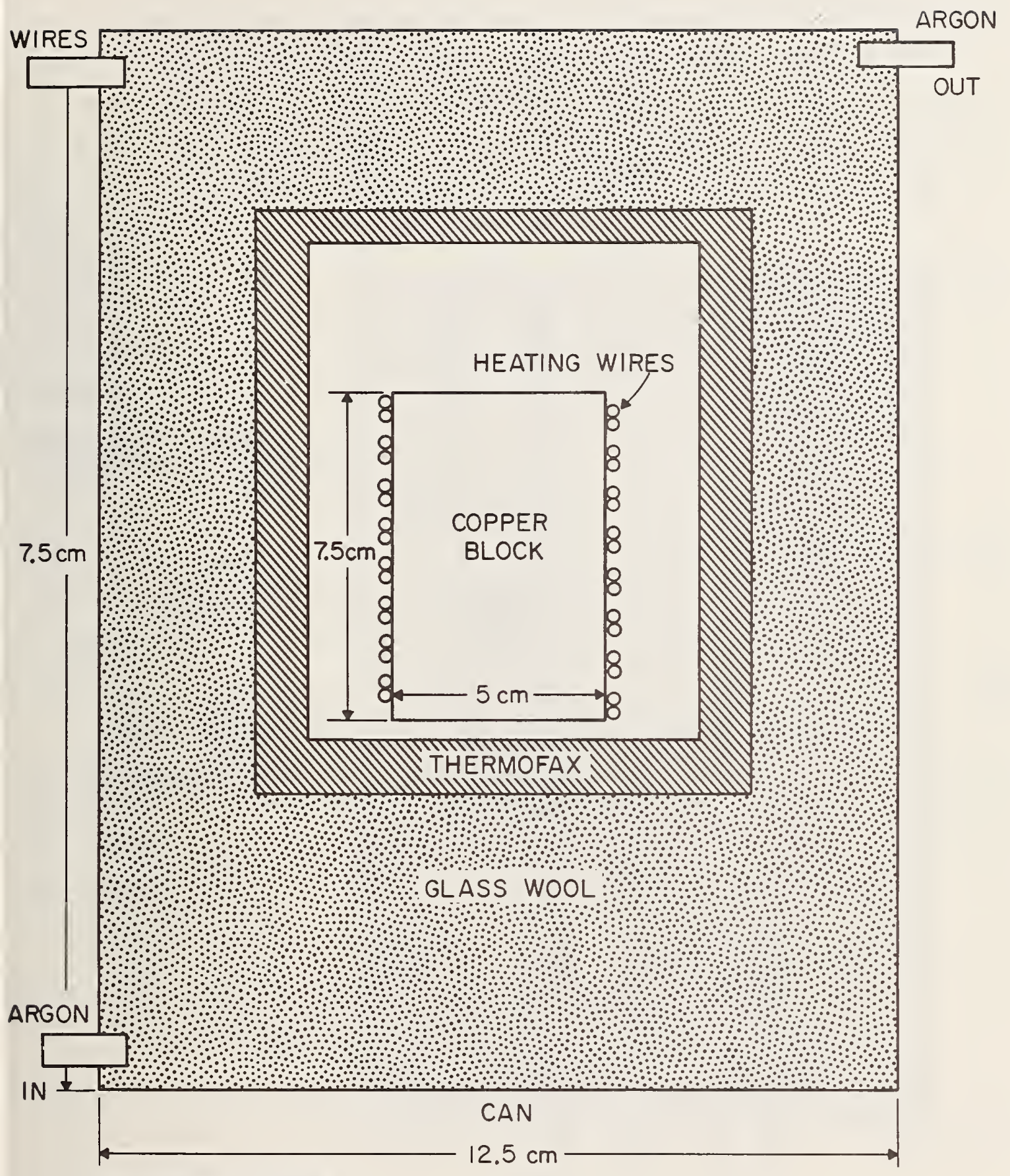

(NOT DRAWN TO SCALE)

Figure 43. Cross section of calorimeter chamber. 


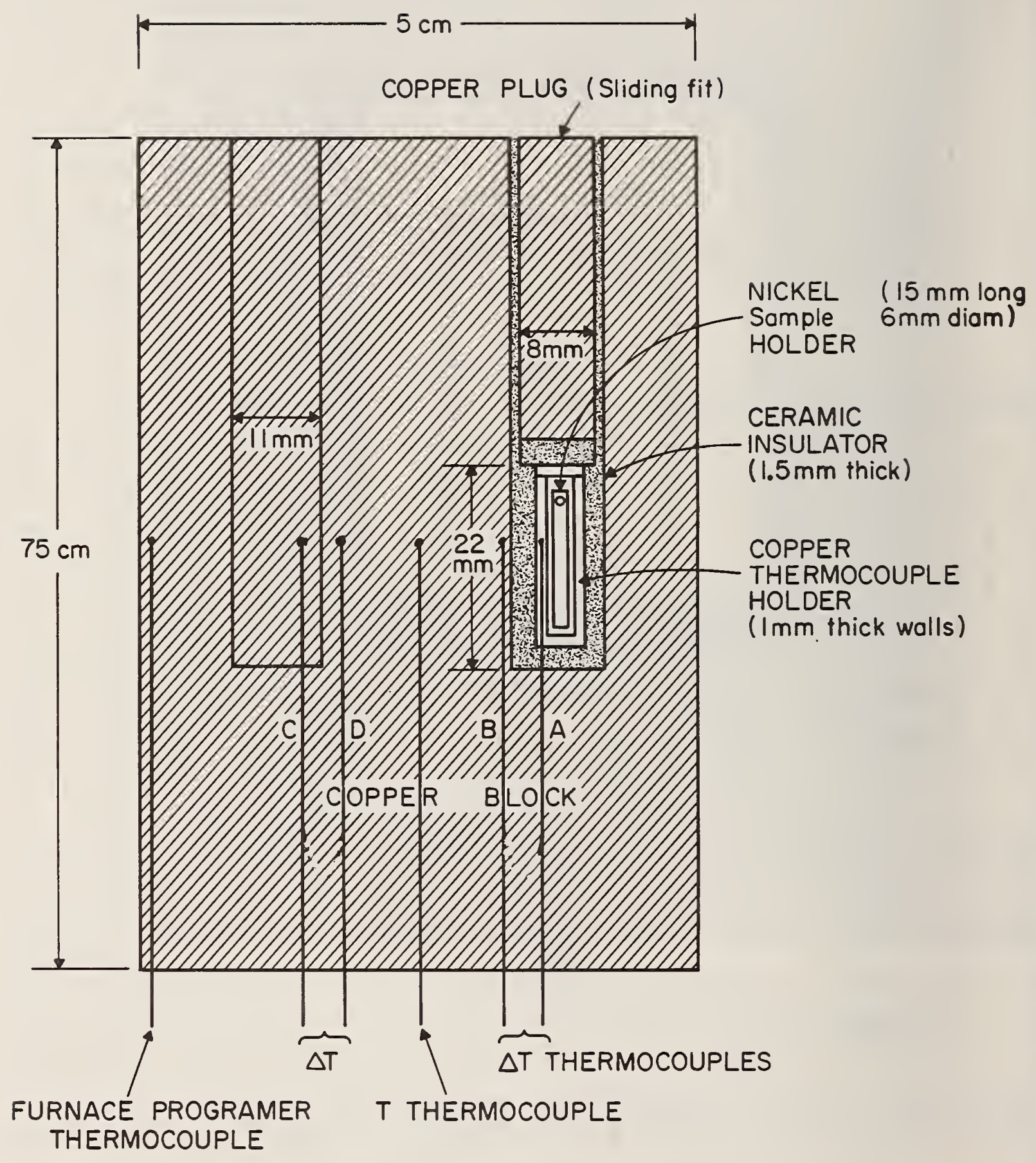

Figure 44. Cross section of copper block. 
ideal case, if the copper block is at a uniform temperature, $(C-D)-(A-B)=B-D$, then only temperatures at $B$ and $D$ need to be monitored. If the reference material differs in heat capacity from the sample, then (C-D)-(A-B) will not be zero, but a constant value called the baseline, and the area of a peak above the baseline is still proportional to the heat of transition. Since this is also true for $A-B$, the reference cell is not needed, but with a reference cell, there would be a smaller baseline signal than just ( $A-B$ ), making the baseline less susceptible to changes in the heating rate.

3. Apparatus

a. Sample Holder. Ozawa [98] has recently used cylindrical sample holders containing 10 thermocouple junctions on each side of the thermal barrier. The apparatus used in this work is similar to Ozawa's earlier design (figure 44) consisting of only one thermocouple on the inside of each thermal barrier.

The copper block and heater were enclosed in a container which was insulated by air, loose thermofax and glass wool (figure 43). All wires leading from the container were enclosed in a rubber hose which could be pinched off by a clamp to provide seals suitable for maintaining an argon atmosphere.

This apparatus differed from Ozawa's [97], [99] in the following five ways:

1. Instead of splitting the block to provide access to the sample chamber, small plugs were provided in the block. The one-piece block promotes more homogeneous block temperature.

2. For increased sensitivity, the inside $\Delta T$ thermocouples were inserted into the copper cup wall rather than touching the side. 
3. To more closely approach the ideal case, the thermal barrier was split at the top, rather than near the middle, making thermal gradients in the barrier more constant near the sample itself. In our experiments, the nickel sample cup was partially filled and fitted smoothly into the copper cup.

4. The temperature of the copper block was measured as near as possible to each thermocouple in the copper cup (figure 44) to help compensate for nonuniformities in block temperature. Ozawa's later design also had this feature [98].

5. The copper thermocouple holder, corresponding to Ozawa's cell [99] did not contain a screw-on cap. The cap was part of the plug and merely rested on the holder. Subsequent experiments indicate that this thermal contact was not sufficient to maintain the required uniform temperature around the sample.

b. Copper Block and Housing for Heater and Thermocouples. For convenience, the heater consisted of heavy chromel-alumel glass insulated thermocouple wire which was attached directly to the copper block with Colco furnace cement. The heater voltage was supplied by a conventional Stone Model B furnace programmer.

The $\Delta \mathrm{T}$ signal was transmitted by fine-wire glass insulated thermocouples (see figure 44 for connections) and amplified by a DC amplifier.

The temperature of the copper block was measured with chromel-alumel thermocouples referenced to an ice bath, and recorded with one channel of a Honeywell Electronik 19 dual pen recorder. The recorder scale was calibrated with a Leeds and Northrup K-3 potentiometer.

4. Electrical Calibration

Electrical calibration was made with an Ohmite Series 99 $3000 \mathrm{ohm}$ resistor heater. Any heat generated by the lead 
wires was less than 0.5 percent of the total calibration heat.

Voltage was monitored with a 3-digit voltmeter and was supplied by a Fluke Model 406 power supply. Current was monitored by measuring the voltage across a Leeds and Northrup 4025-B precision 10 ohm resistor in series with the heater with an NLS U34A digital voltmeter ( 4 digits). Time was monitored with a Hewlett Packard 5216 Electronic Counter referenced to the NBS $1 \mathrm{kHz}$ frequency standard and switched with auxillary contacts of the heater switch. The timing was estimated to be good to $\pm 0.001 \mathrm{sec}$.

The resistor was inserted into the reference copper thermocouple holder and connected to the power source by No. 40 glass insulated wire which extended through grooves cut along the copper plug to the copper wire. All wire connections were made with silver solder.

5. Observations

AII peak areas were normalized to the same amplifier gain. Typically, peaks were 5-8 in. broad and 5-8 in. high, where $1 \mathrm{in} .=1 \mathrm{~min}$, time scale, and $1 \mathrm{in} .=1.10 \mu \mathrm{V}\left(0.02^{\circ}\right.$ to $0.2{ }^{\circ} \mathrm{C}$ for copper-constantan thermocouples). This varies by 50 percent over the range $100-300{ }^{\circ} \mathrm{C}$.

When calibrated, heat is equal to the normalized area of the curve times the proportionality coefficient, $k$, where $\mathrm{k}$ is dependent on the geometry and thermal conductivity of the thermal barrier. In this work, the results, in table 41 are given in terms of $k$, because, the purpose was to determine the calorimetric characteristics of this scanning calorimeter cell design and not to determine heats of transition by means of electrical calibration.

The proportionality coefficient, $k$, was also affected by the heating rate, the type gas surrounding the copper block, and the time of heat during calibration. 
Table 41. Calibration data - determination of proportionality coefficient, $k$, for transition (melting) on heating.

\begin{tabular}{|c|c|c|c|c|c|}
\hline Material & $\begin{array}{l}\text { Temo. } \\
{ }^{\circ} \mathrm{C} \\
\end{array}$ & $\begin{array}{l}\text { Weight } \\
\frac{\mathrm{g}}{}\end{array}$ & $\begin{array}{l}\text { Lit. } \\
\text { Value } \\
\text { cal/g } \\
\end{array}$ & $\begin{array}{l}\text { Normalized } \\
\text { Area }^{\mathrm{b}} \\
\end{array}$ & $\underline{k^{a}}$ \\
\hline Stearic acid & 71 & 0.0753 & $47 \cdot 5$ & 0.8252 & 4.33 \\
\hline Benzoic acid ${ }^{c}$ & 125 & .1183 & 35 & 1.081 & 3.83 \\
\hline $\begin{array}{l}\text { Potasium nitrate } \\
\text { lst heating } \\
\text { subsequent heating }\end{array}$ & $\begin{array}{l}127 \\
127\end{array}$ & $\begin{array}{l}.2824 \\
.2824\end{array}$ & $\begin{array}{l}12.85 \\
12.85\end{array}$ & $\begin{array}{r}0.9496 \\
.4941\end{array}$ & $\begin{array}{l}3.82 \\
(7.34)\end{array}$ \\
\hline Indium $^{e}$ & 157 & $\begin{array}{c}.0909 \\
1.281\end{array}$ & $\begin{array}{l}6.79 \\
6.79\end{array}$ & $\begin{array}{c}.1654 \\
1.758\end{array}$ & $\begin{array}{l}3.73 \\
4.16\end{array}$ \\
\hline $\operatorname{Tin}^{\mathrm{c}}$ & 235 & 0.5043 & 14.23 & 1.917 & 3.74 \\
\hline Potassium perchlorate & 303 & $.356 !$ & $23 \cdot 7$ & 2.234 & 3.77 \\
\hline Ohmite resistor & $\begin{array}{r}20 \\
280\end{array}$ & - & - & - & $\begin{array}{l}3.8 \\
4.1\end{array}$ \\
\hline $\begin{array}{l}\text { Potassium dichromate }{ }^{f} \\
a_{k}=\frac{\text { Literature value }}{(\text { area } \mathrm{x} \text { amp. }}\end{array}$ & $\frac{-}{\text { of ent }}$ & $\frac{a l p y / s a}{m p l e ~ w e}$ & $\frac{\text { ple w }}{\text { ght) }}$ & ght or & - \\
\hline
\end{tabular}

$\mathrm{b}_{\text {The }} \Delta \mathrm{T}$ curves, as in figures 47 and 48 , were obtained at a chart speed of 1 in./min, to make a broad peak for more accurate measurement of the area. Areas were measured twice with a Dietzgen Or-planimeter, usually duplicating areas to better than 0.5 percent. The baseline is extremely important for accurate measurement, as demonstrated by the lower left point of figure 45. The 2 percent correction up to the line corresponded in raising one end of the baseline (figure 46) about .05 inch so that it falls on the line in figure 45. Very small errors in the baseline change the area by a few percent.

${ }^{c}$ Some curves such as the tin melt (figure.47) have the straight left edge, expected for a pure substance, plus the expected rapid fall-off. Other curves such as the benzoic acid melt (figure 48) had a leading tail, plus a levelling off, which may $13 \frac{1}{4}$ due to poor thermal conductiv- 
ity within the sample. The benzoic acid was NBS Standard 350 , and therefore pure, but it may have reacted with the nickel sample cup.

$\mathrm{d}_{\text {For }} \mathrm{KNO}_{3}$, the $\mathrm{k}$ of $7.34+3$ percent was obtained for heating rates of $1.2^{\circ} / \mathrm{min}$ to $4.5^{\circ} / \mathrm{min}$. The first heating value of $k$ was characteristically smaller than the subsequent heating values. The standard heat of transition is, therefore, for a non-preheated sample. For the subsequent heating values, the sample is cooled through only one apparent transition, and immediately heated. The heat of transition is about $6.7 \mathrm{cal} / \mathrm{g}$. Although a run was omitted because both sample weight and the thermal conductivity of the thermal barrier was uncertain, it did show that when the sample was cooled $25^{\circ} \mathrm{C}$ below the first cooling transition, taking about one-half hour, a very slow transition takes place. The sample was heated before the transition was complete, and the $127^{\circ} \mathrm{C}$ transition on heating was about as large as on initial heating. On the subsequent heating this $127^{\circ} \mathrm{C}$ transition was half as large as noted above. This is in agreement with the early observations by Kracek, who reported three transition phases [99].

${ }^{e}$ Indium and $\mathrm{KNO}_{3}$ were measured with and without argon. Two Indium measurenents were made in air and two in argon. There was a relative 5 percent spread within the pair, 16 percent spread between pairs, which may be a result of the design in the apparatus. It might explain the apparent spread of 15 percent in $k$ for the 6 samples.

${ }^{f}$ Compound determined but not reported. The transition rates were four times as slow as for other substances and covered four times the temperature range. The average temperature of heating and cooling was within 2 percent of the $242^{\circ} \mathrm{C}$ of the literature value, but the relative standard deviation of the area was 15 percent or about three times that for other compounds studied. The shape of the peaks suggest poor packing of the sample, or poor thermal conductivity of the sample. This was the only crystalline sample. The others were powders or very small beads (metals). The data were omitted because of the high relative standard deviation and because of the odd shapes of the peaks.

The data collected are presented in figure 45. If the cell was heated at $1.2^{\circ} / \mathrm{min}$ (the rate at which the samples were run) in an argon atmosphere, and the calibrating time was 25 sec or less, than $k$ was within 0.8 percent standard deviation of the straight line shown in figure 45. The change in $k$, shown in figure 45, with temperature is 


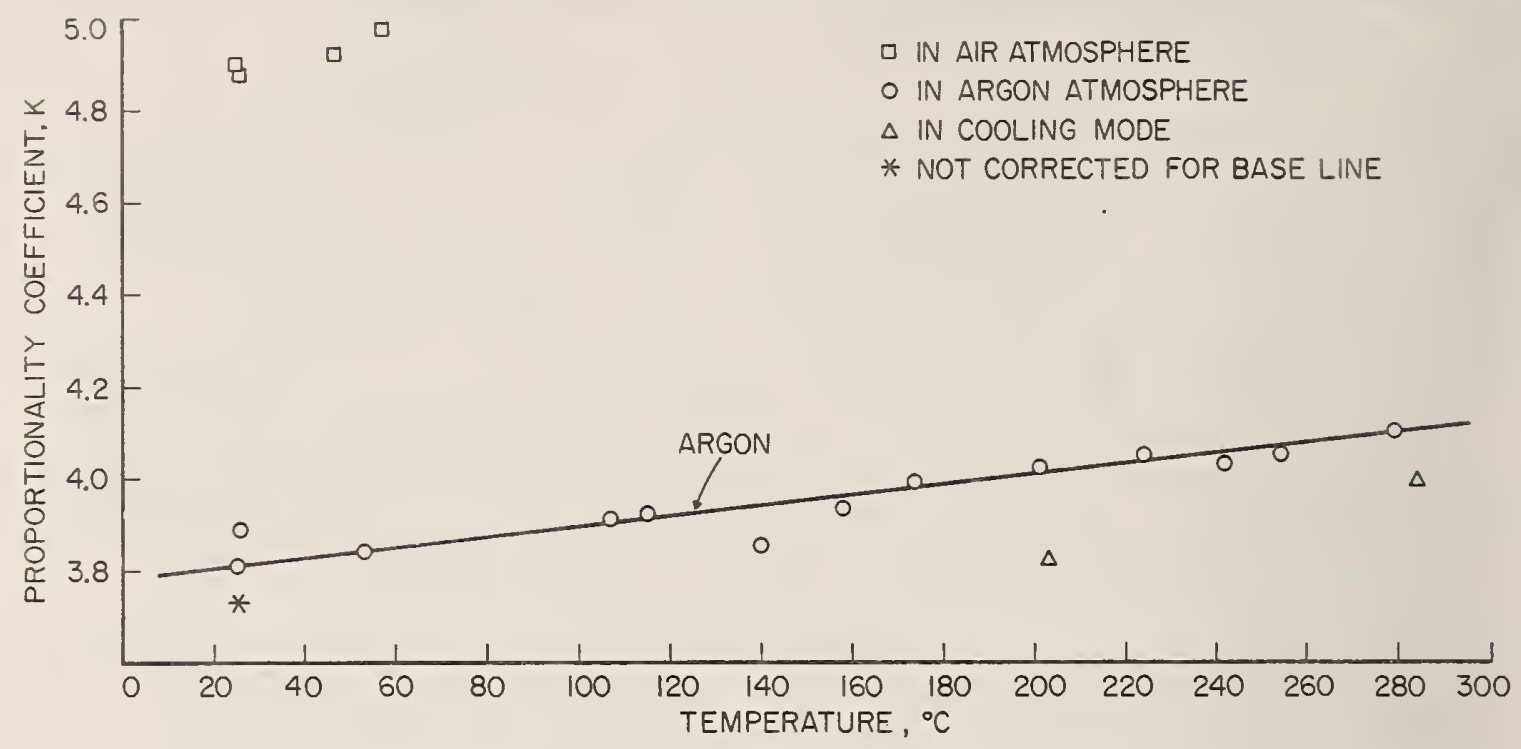

Figure 45. Proportionality coefficient, k, vs temperature.

presumably a combined effect. While the thermal conductivity of the thermal barrier increases with temperature, this effect is partially cancelled by the increase of sensitivity of the copper-constantan thermocouples. The two values of $k$, which were measured when the apparatus was cooling at the rate of $1 \% / \mathrm{min}$, were 5 percent low (shown in figure 45 as $\Delta$ ). The $k$ value measured in an atmosphere of ambient air instead of argon was about 30 percent high. For the data presented in this figure, the current was maintained for less than 20 sec. When the current was applied to the resistor for more than $40 \mathrm{sec}$, the $\Delta \mathrm{T}$ curve was different from figure 46 ( $18 \mathrm{sec}$ ). It tended to round off at the top, and the value for $k$ was high, which indicated heat loss.

The change of $k$ with a change of atmosphere suggests heat leakage from the cell that has not been accounted for. The following is postulated as a cause of this leakage: The Ohmite resistor barely fitted the sample chamber; the original leads were cut to $<0.5 \mathrm{~mm}$. A No. 40 wire was silver 


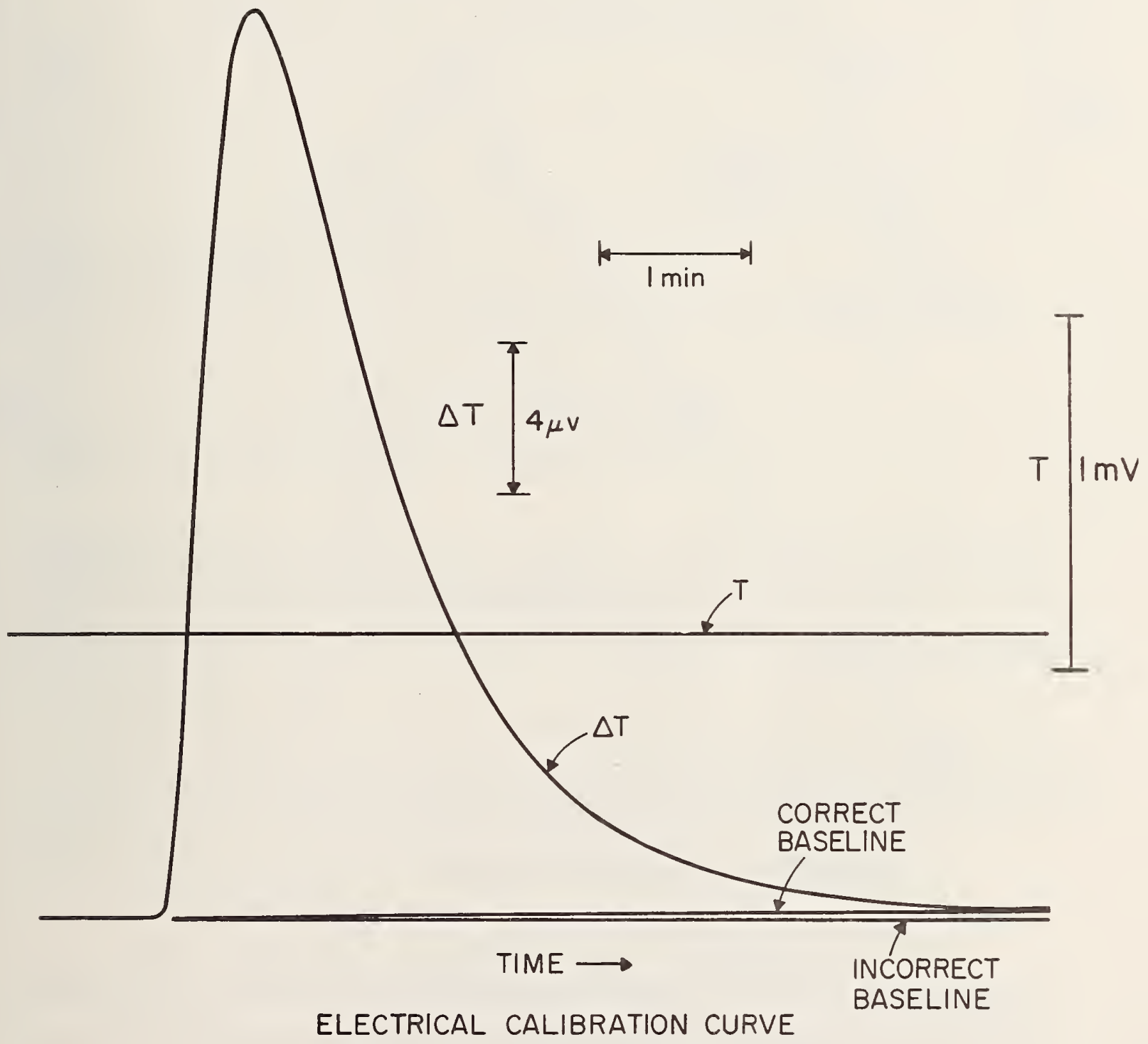

Figure 46. Electrical calibration curve. 


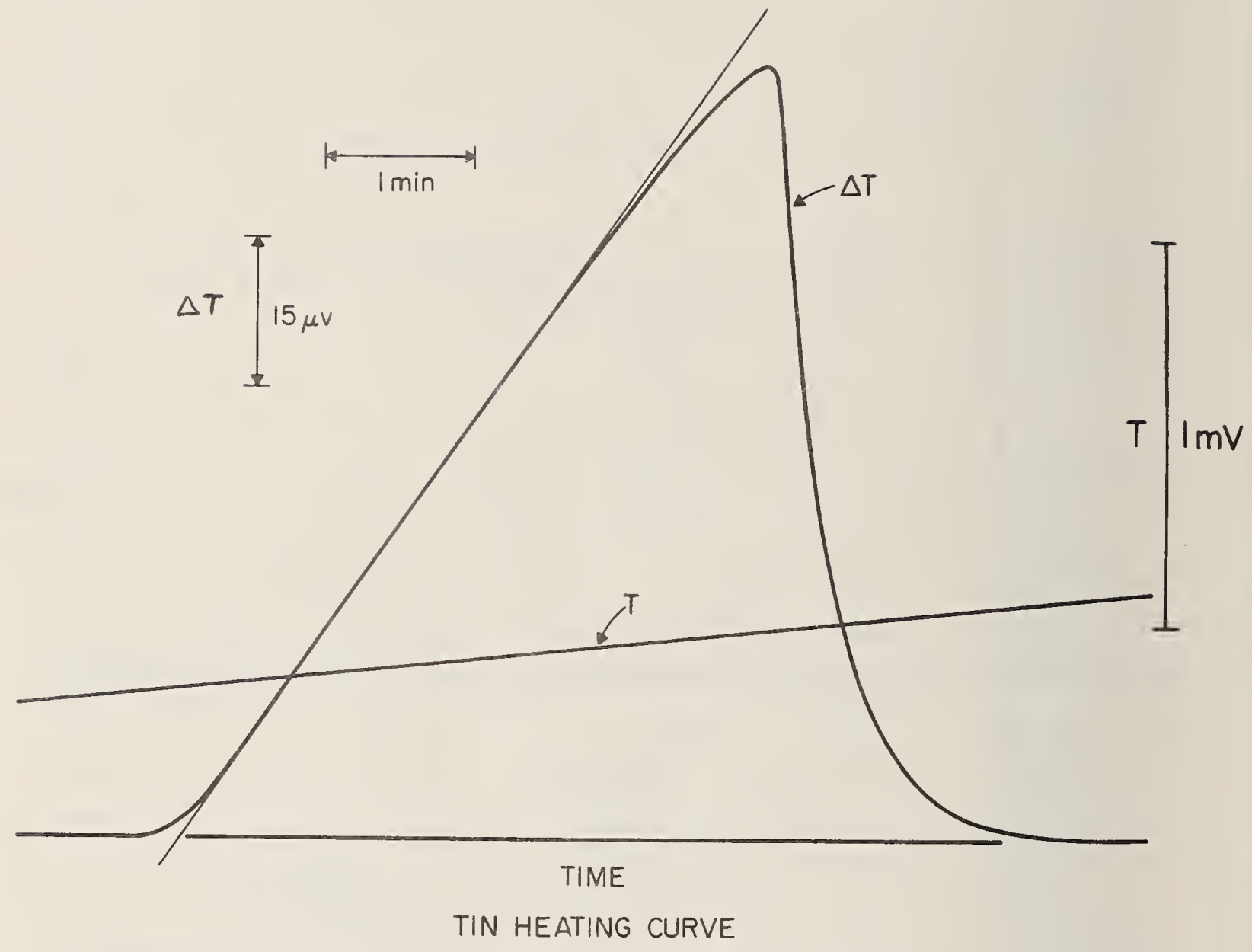

Figure 47. Tin heating curve.

soldered to the remaining leads forming protrusions at each end of the resistor. There was no packing between the resistor and the copper holder; instead it contained thin Teflon tape electrically insulating the bottom protrusion on the resistor from the bottom of the thermocouple holder. The top protrusion of the resistor nearly touched the cover cap of the thermocouple holder. Since the protrusions were 


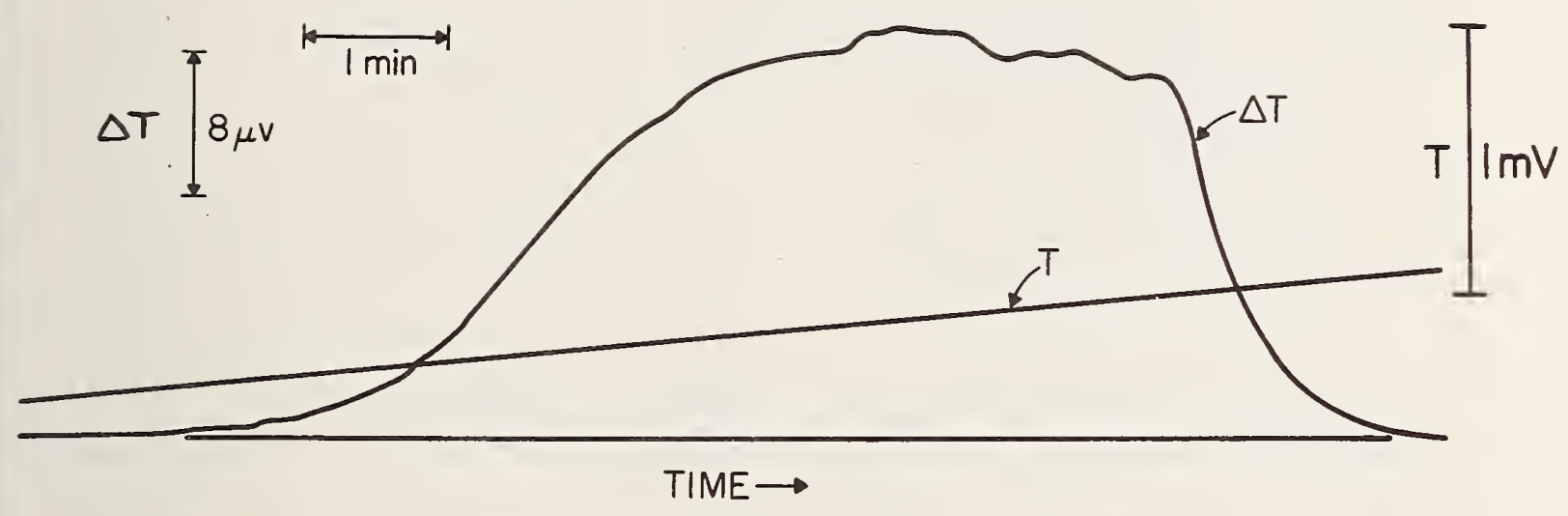

BENZOIC ACID HEATING CURVE

Figure 48. Benzoic acid heating curve.

probably hot spots on the resistor, the top one presumably heated the cap above the thermocouple holder. This hot cap would serve as a path for heat leakage which could miss the thermocouple.

The possibility of unaccounted heat loss introduces

a bias on the electrical calibration value of $k$. This value of $k$ (with an argon atmosphere), however, approached that obtained for the materials under the same conditions.

6. Conclusion

This very brief experimental exploration of the scanning calorimetric system indicates a potential usefulness of the method for obtaining, conveniently, accurate enthalpy values. It served to acquaint ourselves with this technique. Moreover, it provided the necessary information for a design which would extend the accuracy from 10 percent to at least 2 to 1 percent. 
A. Introduction - J. I. Shultz

The characterization of approximately 40 Standard Reference Materials covering a wide range of materials accounted for about 35 percent of the activities of the Section. The variety of materials submitted for analysis and the analytical techniques employed reflect the adaptability and flexability of the staff. The analytical problems become more complex as new types of materials are encountered or as additional elements are certified in replacement Standard Reference Materials. Newly developed high-temperature alloys, for example, containing combinations of elements such as niobium, tantalum, titanium, zirconium, cobalt, nickel, etc. frequently require complex separations involving cation and anion exchangers for preconcentration prior to the final determinations by gravimetric or spectrophotometric techniques.

Atomic absorption and flame emission spectrometry, spectrophotometry and gas evolution thermal conductivity techniques continue as effective means for determining many elements whose concentrations may be at the parts-per-million level. While the application of gravimetry and titrimetry to Standard Reference Materials certification have been relatively limited during the period, they remain as important and reliable techniques for determining many major constituents of metals and alloys, biochemical, botanical and clinical materials.

New Standard Reference Materials were developed in the areas of spectrophotometry and differential thermal analysis. Recently, calibrated glass filters have been issued for use in the calibration of the photometric scale of spectrophotometers. Transmittance values of the filters are certified with a relative uncertainty of \pm 0.5 percent. The accuracy of calibration was confirmed by the high-accuracy spectrophotometer which was designed and constructed in the 140 
Section. The accuracy of this instrument was established by light-addition measurements .

Complementing the two DTA standards $\left(\mathrm{KNO}_{3}\right.$ and $\left.\mathrm{SiO}_{2}\right)$, already available, are an additional 3 sets ( 5 samples per set) of temperature standards covering the range from $125{ }^{\circ} \mathrm{C}$ to $940^{\circ} \mathrm{C}$. Each set includes overlaping temperature ranges. These materials comprise a total of 8 inorganic substances which exhibit phase transitions and 2 high-purity metals. The certification of these new standards was carried out in collaboration with the International Confederation for 'l'hermal Analysis.

Homogeneity testing of proposed Standard Reference Materials is a continuing important role of the section. This testing, which precedes the general analysis, verifies the aim composition of a given material and provides a measure of acceptable uniformity of composition. When homogeneity is established, quantitative analyses by at least 2 independent methods, together with data from cooperating laboratories, provide for the provisional and eventual final certification.

The magnitude of the Standard Reference Materials activity in the Section is graphically illustrated in figure 49.

B. Standard Reference Materials Information and Summary

The following background information on selected Standard Reference Materials which were analyzed during the year may be of interest.

1. Stainless Steels 12ld and 1171

These low carbon stainless steels (AISI type 321) containing $17 \mathrm{Cr}, 11 \mathrm{Ni}$, and $0.3 \mathrm{Ti}$ are being issued in the form of chips (12ld) for checking "wet" chemical methods of analysis, and in solid form (1171) for use in calibrating optical emission and X-ray spectrometric methods of analysis. The materials are austenitic and are stabilized against 


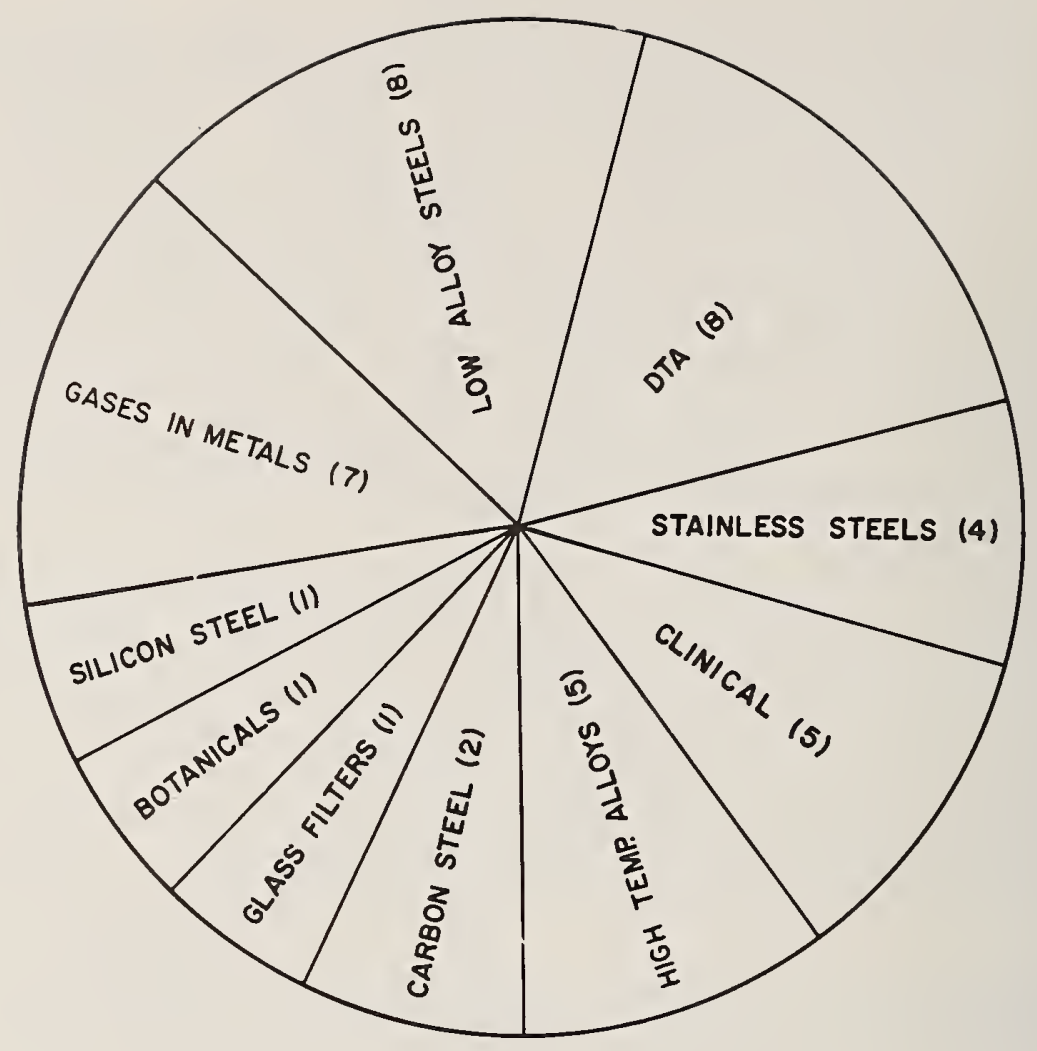

Figure 49. Types of Standard Reference Materials characterized.

intercrystalline corrosion at elevated temperatures by the addition of titanium. The standards will be especially useful in control analyses for elements such as carbon, nickel, chromium and titanium; however, they are certified for 11 elements (table 42).

2. Stainless Steels $123 \mathrm{c}$ and 1172

Two austenitic stainless steels (AISI type 348) are stabilized 18-8 steels for service at elevated temperatures, and are similar in composition to Standards $121 d$ and 1172 , except that niobium ( 0.6 percent) instead of titanium, has been added as the stabilizer. They will serve as "wet" chemical and spectrochemical standards respectively, in the same manner as Standards $121 d$ and 1171. Their primary use will probably be as controls for niobium + tantalum determi142 
Table 42. Stainless Steels 12ld and 1171.

Ele- No. Detms.

ment 12ld - 1171

$\begin{array}{rll}\mathrm{C} & 4 & 4 \\ \mathrm{Mn} & 3 & - \\ \mathrm{P} & 4 & 4 \\ \mathrm{~S} & 7 & 6 \\ \mathrm{Si} & 3 & 2 \\ \mathrm{Cu} & 2 & 4 \\ \mathrm{Ni} & 2 & - \\ \mathrm{Cr} & 4 & - \\ \mathrm{Mo} & 4 & 2 \\ \mathrm{Ti} & 3 & - \\ \mathrm{Co} & 4 & -\end{array}$

Method

Thermal conductivity

Periodate photometric

Molybdenum-blue photometric

Combustion-titration

$\mathrm{HClO}_{4}$ gravimetric

Atomic absorption

Dimethylglyoxime-gravimetric

$\mathrm{S}_{2} \mathrm{O}$ oxidation, $\mathrm{Fe}^{++}$

Thiocyanate photometric

Diantipyrrylmethane photometric

Nitroso R photometric
Average, \%

$121 d-1171$

$0.067,0.068$

1.80

$-$

$0.018,0.018$

$.012, \quad .013$

$.535, .537$

$11.161, .121$

17.46

$0.164,0.164$

.341

$.104 \quad$

nations in these and similar types of alloy steels, although in addition, they are certified for 12 additional elements (table 43).

Table 43. Stainless Steels $123 \mathrm{c}$ and 1172.

Ele- No. Detms.

ment 123c- -1172

$\begin{array}{rll}\mathrm{C} & 4 & 4 \\ \mathrm{Mn} & 4 & 1 \\ \mathrm{P} & 4 & 4 \\ \mathrm{~S} & 4 & 5 \\ \mathrm{Si} & 3 & 2 \\ \mathrm{Cu} & 4 & 4 \\ \mathrm{Ni} & 2 & 2\end{array}$

$\operatorname{Cr} \quad 4 \quad 4$

$\mathrm{Mo}$
$\mathrm{Nb}$
$\mathrm{Ta}$
$\mathrm{Co}$
Method

Thermal conductivity

Periodate photometric

Molybdenum-blue photometric

Combustion-titration

$\mathrm{HClO}_{4}$ gravimetric

Atomic absorption

Dimethylglyoxime-gravi-metric

$\mathrm{S}_{2}$ Ooxidation, $\mathrm{Fe}^{++}$

Thiocyanate photometric

Ion-exchange-gravimetric

Ion-exchange-photometric

Nitroso $\mathrm{R}$ photometric
Average, \% $123 c-1172$

$0.056,0.056$

$1.76,1.72$

$0.024,0.024$ $.015, \quad .014$ $.585, .592$ $.104, .104$

$17.41,17.44$

$0.21,0.21$

$.654-$

$<.001 \quad-$

$.130, .131$

3. Special Steels 361, 1261; 362, 1262; 363, 1263; 1264

In previous reports, we reported on the progress of the certification of the 300 to 1200 series of Special Steels which were designed to replace the very popular 1100 series 
of spectrographic steel standards. During the year, work continued on the project which resulted in the determination of 14 elements, each, for 363 and 1263 involving 112 determinations. Atomic absorption, flame emission, volumetric, gravimetric, spectrophotometric and combustion techniques were used in this certification work. Samples were analyzed by 4 cooperating laboratories and the provisional certificates were issued in September 1970.

The analysis of another of the series, SRM 1264, was completed at NBS for 10 of the major elements and approximately 17 of the minor and trace elements. The sample has been analyzed by selected cooperator laboratories and is being issued with a provisional certificate of analysis. The 10 major elements, involving 57 determinations, were $\mathrm{C}, \mathrm{Mn}, \mathrm{P}, \mathrm{S}, \mathrm{Si}, \mathrm{Cu}, \mathrm{Ni}, \mathrm{Cr}, \mathrm{V}, \mathrm{Mo}$. The minor and trace elements included: $\mathrm{B}, \mathrm{Mg}, \mathrm{Ca}, \mathrm{Sb}, \mathrm{Ag}, \mathrm{Zn}, \mathrm{La}, \mathrm{Au}, \mathrm{W}, \mathrm{As}$, $\mathrm{Ti}, \mathrm{Pb}, \mathrm{Zr}, \mathrm{Ta}, \mathrm{Nb}$ and $\mathrm{Co}$ and $\mathrm{N}$.

Standards 362 and 1262, also in the series, were issued with provisional certification after analyses by' 4 cooperating laboratories. During the period, 9 elements each for 362 and 1262 were determined in the Section involving 67 determinations.

As the program continues toward final certification of approximately 35 elements on each standard in the 1200 series, the Section will undoubtedly be involved in the determinations of many of the minor and trace elements that remain before the final certification is complete.
J. R. Baldwin
T. C. Rains
R. K. Bell
T. A. Rush
E. R. Deardorff
S. A. Wicks
R. W. Burke 
6. PERSONNEL AND ACTIVITIES

A. Personnel Listing

Oscar Menis, Section Chief

James I. Shultz, Assistant Section Chief

Mary B. Pantazis, Section Secretary

J. R. Baldwin

R. Mavrodineanu

R. K. Bell

T. C. Rains

D. S. Bright (part time) T. A. Rush

R. W. Burke

R. A. Velapoldi

E. R. Deardorff

S. A. Wicks

B. Diamondstone

B. Publications

1. O. Menis and T. C. Rains, "Sensitivity, Detection Limit, Precision and Accuracy in Flame Emission and Atomic Absorption Spectrometry, "Analytical Flame Spectroscopy Selected Topics (R. Mavrodineanu, ed.), Springer-Verlag, New York, 1971, pp. 47-7\%.

2. John A. Dean and T. C. Rains, "Standard Solution for Flame Spectrometry" in Flame Emission and Atomic Absorption Spectrometry (John A. Dean and Theodore C. Rains, eds.), Dekker, New York, 1971, pp. 327-339.

3. John A. Dean and Theodore C. Rains, eds., Flame Emission and Atomic Absorption Spectrometry, Dekker, New York, 1971.

4. R. A. Velapoldi and O. Menis, "Formation and Stabilities of Free Bilirubin and Complexes with Transition and Rare-Earth Elements, accepted for publication in Clinical Chemistry .

5. R. Reisfeld, A. Honigbaum and R. A. Velapoldi, "Thallium Doped Potassium Chloride Discs as UV Fluorescence Standards, accepted for publication in J. Opt. Soc. Amer.

6. R. A. Velapoldi, R. Reisfeld and L. Boehn, "Spectral Characteristics and Quantum Efficiencies of Eu(III) in a Silicate Matrix," Proceedings of 9 th Rare Earth Research Conference. 
7. R. Reisfeld, R. A. Velapoldi and L. Boehm, "Transition Probabilities of Eu(III) in Phosphate Glasses," submitted for publication to J. Phys. Chem.

8. R. Reisfeld, R. A. Velapoldi and L. Boehm, "Quantum Efficiency and Radiationless Transitions of Eu(III) in Phosphate Glasses," submitted for publication to J. Phys. Chem.

9. O. Menis, Editor, "Status of Thermal Analysis," NBS Special Publication 338, oct. 1970.

10. O. Menis and C. S. P. Iyer, "Spectrophotometric Determination of Vanadium and Iron with $\beta$-Isopropyltropolone," Anal. Chim. Acta 55, 89 (1971).

11. R. Mavrodineanu, Editor, "Analytical Flame Spectroscopy, Selected Topics," 772 pp., McMillan, London; Springer, New York, 1970.

12. R. Mavrodineanu, "Bibliography on Flame Spectroscopy, Analytical Applications," pp. 651 to 752 in Analytical Flame Spectroscopy, Selected Topics, R. Mavrodineanu, Editor, McMillan-Springer, 1970.

13. R. Mavrodineanu, "Discussion of Some Experimental and Fundamental Conditions in Analytical Flame Spectroscopy," in Methodes Physiques d'Analyse, Proceedings from the 3rd International Congress of Atomic Absorption and Flame Fluorescence, Paris, France, 1971.

14. R. C. Hughes, R. Sweet, R. Mavrodineanu, "Ferrite Analysis" in Vol. 7 of Encyclopedia of Industrial Chemical Analysis, Interscience, Wiley, 1971.

15. R. Mavrodineanu and J. R. Baldwin, SRM-930, Glass Filter for Spectrophotometry, NBS, 1971.

16. 0. Menis and J. I. Shultz, "Analytical Coordination Chemistry Section: Summary of Activities July 1969 to June 1970," NBS Technical Note 544, Sept. 1970. 
C. Talks

1. T. C. Rains and O. Menis, "Determination of Trace Elements by Flame Emission Spectrometry with Repetitive Optical Scanning," Rock Mountain Section of Society for Applied Spectroscopy, Denver, Colorado, Aug. 3-4, 1970.

2. T.C. Rains, "Atomic Absorption and Flame Emission Spectrometry Trends for the Future," Analytical Chemistry Division, Oak Ridge National Laboratory, Oak Ridge, Tennessee (Invited Presentation).

3. T.C. Rains, "Applications of Atomic Absorption Spectrometry in the Analysis of Major Constituents in NonFerrous Material," 9th Annual National Meeting of the Society for Applied Spectroscopy, New Orleans, Louisiana, oct. 4-9, 1970 (Invited Presentation and Session Chairman.)

4. T. C. Rains, Clinical Standards for Atomic Absorption Spectrometry," (In association with NIH Symposium.) Standardization for Clinical Analysis, NBS, Oct. 9, 1970.

5. T. C. Rains, T. A. Rush and O. Menis, "The Analysis of Simulated Lunar Glass by Atomic Emission and Absorption Spectrometry," NBS, Oct. 12, 1970.

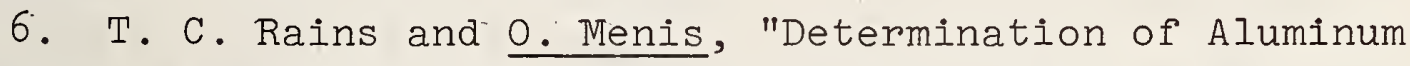
in Ferrous Material by Flame Emission Spectrometry with Repetitive Optical Scanning," 18th Anachem. Conference, Detroit, Michigan, oct. 14-16, 1970.

7. O. Menis and T.C.Rains, "Application of Flame Emission and Atomic Absorption Spectrometry to Particulate Matter," 14th Conference on Analytical Chemistry in Nuclear Technology, Gatlinburgh, Tennessee, Oct. 13-15, 1970.

8. T. C. Rains and O. Menis, "Application of Repetitive Optical Scanning for Flame Emission spectrometry," 17th Spectroscopy Symposium, Ottawa, Canada, Oct. 26-27, 1970 (Invited Presentation, Session Chairman and Discussion Leader). 
9. T. C. Rains, T. A. Rush and O. Menis, "Critical Evaluation of Resonant Lines for Atomic Absorption Spectrometry," Eastern Analytical Symposium, New York, New York, Nov. 18-20, 1970 (Invited Presentation and Session (hairman).

10. T. C. Rains, "Atomic Absorption Spectrometry," American Chemical Society Short Courses on AAS, New York, March 19-20, 1971.

11. T. C. Rains and O. Menis, "Flame Emission Spectrometry with Optical Scanning," 161st National Meeting of ACS, Los Angeles, California, March 28-April 2, 1971 (Invited Presentation.)

12. T. C. Rains and O. Menis, "An Evaluation of Atomic Absorption and Flame Emission Spectrometry for Air Pollution Analysis," 16lst National Meeting of ACS for Los Angeles, California, March 28-April 2, 1971 (Invited Presentation).

13. T. C. Rains, "Atomic Absorption and Flame Emission Spectrometry in a National Laboratory," Montana State University, Bozeman, Montana, April 5, 1971 (Invited Ppresentation.)

14. O. Menis, R. W. Burke and E. R. Deardorff, Solution Standards for Checking the Absorbance Scales of Spectrophotometers in the Wavelength Region of 200-600 nm," Anachem Meeting, Detroit, Michigan, October 13-15, 1970.

15. E. R. Deardorff, R. W. Burke and O. Menis, "Spectrophotometric Characterization of the 500 and $50 \mathrm{ppm}$ Trace Element Glasses for Iron, Nickel, Manganese and Gold," Trace Glass Symposium, ASTM Committees E-2 and C-14, National Bureau of Standards, Gaithersburg, Maryland, April 13-14, 1971.

16. R. A. Velapoldi, "Series on Determination of Absolute Quantum Efficiencies, Hebrew University, Jerusalem, Israel, January 10-15, 1971.

17. R. A. Velapoldi, "Metalloporphyrins: Novel Preparation and Reactions," Hebrew University, Jerusalem, Israel, February 20, 1971. 148 
18. R. Mavrodineanu, "Multichannel Simultaneous Flame Emission and Atomic Absorption Spectrophotometer," Pittsburgh Conference on Analytical Chemistry and Applied Spectroscopy, 1971.

19. R. Mavrodineanu, "Discussion de Quelques Conditions Experimentales et Fondamentales en Spectrophotometrie de Flamme," invited plenary lecture at the 3rd International Congress of Atomic Absorption and Flame Fluorescence, Paris, France, 1971.

20. L. Owen ${ }^{I^{-}}$and R. Mavrodineanu, "Premixed Acetylene-Oxygen Flame with Separate Sample Supplying Arrangement," ibid.

21. L. Owen ${ }^{1}$ and R. Mavrodineanu, "A Premixed OxygenAcetylene Burner with Independent Aerosol Introduction," loth National SAS Meeting, Oct. 1971, St. Louis, Missouri.

22. O. Menis, "Optical Scanning Methods in Flame Spectroscopy," Chemistry Department, University of Maryland, College Park, Maryland.

23. O. Menis, "Current Development in Spectrophotometric Standards," Pittsburgh Conference on Analytical Chemistry and Applied Spectroscopy, 1971.

24. O. Menis, "Clinical Standards for Spectrophotometry," Standardization for Clinical Analysis Symposium (in association with NIH), NBS, Oct. 9, 1970.

D. Committee Activities

Oscar Menis

Member ASTM, Subcommittee E13.01, Apparatus Specifications .

Member ASTM, Committee E-3, Div. I., Thermal Analytical Test Methods Subcommittee on Standards.

$I_{\text {Guest Worker }}$ 
Member ASTM, Committee E-10 Subcommittee I.

Editorial Board Member, Chemical Instrumentation, A Journal of Experimental Techniques in Chemistry and Biochemistry.

Member American Chemical Society.

Member American Association for the Advancement of Science.

Institutional Representative, Standards Committee, International Confederation on Thermal Analysis.

Participant, National Committee Clinical Laboratory Standards (NCCLS) - Instrumentation.

Titular member of the International Union of Pure and Applied Chemistry Commission V3 on Analytical Nomenclature.

Referee, "Critical Review in Analytical Report."

Recipient of the Department of Commerce Silver Medal Award.

\section{James I. Shultz}

Member ASTM, Advisory Board, Committee E-3.

Member ASTM, Vice Chairman, Div. F., Committee E-3.

Member ASTM, Secretary Editorial Subcommittee, Committee $\mathrm{E}-3$.

Nember ASTM, Committee E-3, Div. M.

Member ASTM, Committee E-3, Div. G.

Coeditor, ASTM Handbook of Methods of Chemical Analysis of Metals.

Member American Chemical Society

U. S. Delegate to ISO, Technical Committee 17 , Subcommittee 1 .

Recipient of the 1971 Lundell-Bright Memorial Award, presented by ASTM at Atlantic City, New Jersey, June 1971. 
T. C. Rains

Member ASTM, Committee E-2, Subcommittee X.

Eastern Analytical Symposium, Governing Board.

Society of Analytical Chemists, Editorial Board.

R. K. Bell

Member ASTM, Committee E-3, Div. N.

Member American Chemical Society.

E. R. Deardorff

Member ASTM, Task Force Chairman, Div. F.,

Committee E-3.

R. W. Burke

Member National Committee Clinical Laboratory

Standards (NCCLS) - Instrumentation (UV-Vis

Spectrophotometry).

B. Diamondstone

Member American Chemical Society.

S. A. Wicks

Member American Chemical Society.

$\underline{\text { Radu Mavrodineanu }}$

Honorary member of Groupement pour I'Avancement

des Methodes Physiques d'Analyse.

R. A. Velapoldi

Member American Chemical Society.

Member Sigma Xi.

Member Japanese-United States Chemists Association 
[1] Menis, O. and Shultz, J. I., Editors, NBS Technical Note 544, 1970.

[2] Beattie, I. R., J. Soc. Glass Technol. 36, 37 (1952).

[3] Morey, G.W., "The Properties of Glass", 2nd ed. Reinhold, New York, 1954.

[4] Shand, E. B., "Glass Engineering Handbook", McGraw Hill Book, London, 1958.

[5] Putner, T., Brit. J. Appl. Phys. 10, 332 (1959).

[6] Elster, J. and Geitel, H., On the Comparison of Light Intensities by Photoelectric Methods, Ann. Physik, Chemie 48, 625-635 (1893).

[7] Elster, J. and Geitel, H., The Photoelectric Effect on Potassium at Low Light Levels, Phys. Ztsch. 13, 468976 (1912).

[8] Koller, L. R. and Breeding, H. A., Characteristics of Photoelectric Tubes, General Electric Rev. 31, 476-479 (1928).

[9] Campbell, N. R., The Experimental Proof of a Fundamental Photoelectric Law, Trans. Opt. Soc. (London) 32, 61-65 (1930-1931).

[10] Fleury, P., An Addition Method for the Precise Study of the Variation of the Current Output of a Photoelectric Cell as a Function of the Incident Luminous Flux, Compt. Rend. Acad. Sci. (France) 199, 195-197 (1934).

[11] Preston, J.S. and McDermott, L. H., The Illumination Response Characteristics of Vacuum Photoelectric Cells of the Elster-Geitel Type, Proc. Phys. Soc. (London) 46, 256-272 (1934).

[12] Preston, J. S. and Cuckow, F. W., A Photoelectric Spectrophotometer of High Accuracy, Proc. Phys. Soc. (London) 48, 869-880 (1936). 
[13] Buchmüller, F and König, H., Precision Measurements on Incandescent Lamps Using Selenium Photocells, Assoc. Suisse Electriciens, Bulletin 28, 89-99 (1937).

[14] Atkinson, J.R., Campbell, N. R., Palmer, E. H. and Winch, G. T., The Accuracy of Rectifier-Photoelectric Cells, Proc. Phys. Soc. (London) 50, 934-946 (1938).

[15] Barbrow, L., A Photometric Procedure Using BarrierLayer Photocells, NBS Research Paper RP 1348, J. Res. NBS 25, 703-710 (1940).

[16] Kaiser, H., Photographic-Photometric Calibration of Step Filters, Spectrochimica Acta $\underline{3}$, 518-537 (1947-1949).

[17] Harding, H. G. W., Precautions Necessary for Accurate Measurements of Optical Density Standards, Photoelectric Spectrometry Group Bulletin 4, 79-86 (1951).

[18] Kortüm, G. and Maier, H., Dependence of Photo Current and Illuminating Intensity in Photocells and Photomultipliers, Z. Naturforschung 8A, 235-245 (1953).

[19] Hansen, G., Check of Photometric Function of Spectrophotometers, Mikrochimica Acta 1955, 410-415.

[20] Hermann, W., Noise and Linearity Check on Photomultipliers, Z. Naturforschung 12A, 1006-1013 (1957).

[21] Reule, A., Checking the Photometric Scale of Absorption Measuring Instruments., Zeiss-Mitt. 1, 283-299 (1959).

[22] Hoppmann, H., An Instrument for Checking the Proportionality of Physical Radiation Receivers, Technisch-Wissenschaftliche Abhandlungen der OsramGesellschaft I, 306-312 (1958).

[23] Gibson, G. L., Hammond, H. K. III, Holford, W. L. and Nimeroff, I., Calibration of Photometers, NBS Manuscript, Nov. I, 1960, (Personal Communication).

[24] Bischoff, K., Measurement of Proportionality of Radiation Receivers Over a Large Radiation Intensity Range, $Z$. Instr. 69, 143-147 (1961). 
[25] Jones, O. C. and Clarke, F. J. J., A New Photometric Technique Using a Variable Shutter Device, Nature 191, 1290 (1961).

[26] Cordle, I. C. and Habell, K. J., Photometry of Telescopes and Binoculars, National Physical Laboratory, Notes on Applied Science No. 14, 18 pp (1962).

[27] Sanders, C. L., A Photocell Iinearity Tester, Applied Optics I, 207-271 (1962).

[28] Nonaka, M. and Kashima, T., Linearity Characteristics of Multiplier Phototubes, Japanese Journal Applied Physics 2, 785-791 (1963).

[29] Höfert, H. J. and Loof, H., Calibration of Photometric Scales of a Reflection Photometer, Z. Instrumentenkunde 72, 139-143(1964).

[30] Clarke, F. J. J., Time Ratio Photometry, Lecture to the Optical Group of the Institute of Physics and the Physical Society, June 9th 1966.

[31] Clarke, F. J. J., High Accuracy Spectrophotometry of Three Glass Filters, NPL Report No. 3042, 14 pp, Nov. 4, 1968.

[32] Reule, A., Testing Spectrophotometer Linearity, Appl. Optics I, 1023-1028 (1968).

[33] Kunz, H., Representation of the Temperature Scale Above $1337.58 \mathrm{~K}$ with Photoelectric Direct Current Pyrometers, Metrologia 5, 88-102 (1969).

[34] Kostkowski, H. J., Personal Communication.

[35] Edisbury, J. R., "Practical Hints on Absorption Spectrometry", p. 190, Plenum Press, New York, 1967.

[36] Thomson, I. C., Trans. Faraday Soc. 42, 663 (1946).

[37] Haupt, G. W., NBS J. Res. 48, 414 (1952).

[38] Gridgeman, N. T., Photoelectric Spectrometry Group Bulletin, No. 4, 67 (1951).

[39] Ketelaar, J.A. A., Fahrenfort, J., Haas, C. and Brinkman, G. A., Photoelectric Spectrometry Group Bulletin, No. 8, 176 (1955). 
[40] Vandenbelt, J.M., J. Opt. Soc. Am. 50, 24 (1960).

[41] Bailey, N., Carrington, A., Lott, K. A. K. and Symons, M. C. R., J. Chem. Soc., p. 290 (1960).

[42] Tong, J. and King, E. L., J. Amer. Chem. Soc. 75, 6180 (1953).

[43] Davies, W. G. and Prue, J. E., Trans. Faraday Soc. 51, 104.5 ( 1955 ).

[44] Neuss, J. D. and Rieman, W., J. Amer. Chem. Soc. 56, 2238 ( 1934 ).

[45] Howard, J. R., Nair, V. S. K. and Nancollas, G. H., Trans. Faraday Soc. 54, 1034 (1958).

[46] Haight, G. P., Jr., Richardson, D. C. and Coburn, N. H., J. Inorg. Chem. 3, 1777 (1964).

[47] Johnson, E. A., Photoelectric Spectrometry Group No. 17, 505 (1967).

[48] Chapman, J.H., Föster, G., Kortüm, G., Parker, C. A., Lippert, E., MeIhuish, W. H. and Nebbia, G., Applied Spectry. 17, 431 (1963).

[49] See for example: C. A. Parker, "Photoluminescence of Solutions," Elsevier Publishing Co., New York, N. Y., 1968; D. M. Hercules, "Fluorescence and Phosphorescence Analysis," Interscience Publishers, New York, N. Y., 1966; W. H. Melhuish, J. Opt. Soc. Amer. 54, 183 (1964).

[50] C. Zeiss Inc., Silver Spring, Md.

[51] Turner, G. K., Science 146, 183 (1964).

[52] Fletcher, A. N., Photochem. and Photobiol. 9, 439 (1969).

[53] Dawson, W. R. and Windsor, M. W. J. Phys. Chem. $\underline{72}$, 3251 (1968); G. K. Turner Associates, "Notes on the Determination of Quantum Efficiency", Palo Alto, California; Drobnik, J., and Yeargers, E., J. Mol. Spectry. 19, 454 (1966); Ruskawicz, R. and Testa, A. C. J. Phys. Chem. 72, 793 (1968); Eastman, J.W., Photochem. Photobiol. 6, 55 (1967); Chen, R. F., Anal. Biochem. 19, 374 (1967); Borreson, H. C., Acta Chem. Scand. 19, 2089 (1965). 
54] Koch, L., J. Assoc. Off. Agr. Chem. 39, 397 (1956).

55] Hebrew University, Jerusalem, Israel, PL 480 grant continuation.

56] See for example: Reisfeld, R. and Greenberg, E., Anal. Chim. Acta 47, 155 (1969); Reisfeld, R. and Biron, E., Talanta 17, 105 (1970).

i7] Cleek, G., Inorganic Glass Section, Inorganic Materials Division, NBS.

i8] McMillan, P. W., "Glass Ceramics," Academic Press, New York, N. Y. (1964); Moeller, T., "Chemistry of the Lanthanides," Reinhold, New York, N. Y., 1963.

i9] Colthup, N. B., Daly, L. H. and Wiberly, S. E., "Introduction to Infrared and Raman Spectroscopy," Academic Press, New York, N. Y., 1964.

i0 ] a. Parker, C. A. and Rees, W. T., Analyst 85, 587 (1960);

b. Weber, G. and Teale, F. W. J., Trans. Faraday Soc.

53, 646 (1957); c. Melhuish, W. H., J. Phys. Chem. 65, 229 (1961).

i1 Himel, A. M. and Mayer, R. T., Anal. Chem. 42, 130 (1970).

2] Strickler, S. J, and Berg, R. A., J. Chem. Phys. 37, 814 (1962).

3] Seybold, P. G., Gouterman, M. and Callis, J., Photochem. Photobiol. 9, 229 (1969).

4] Reisfeld, R., Honigbaum, A. and Velapoldi, R. A., submitted for publication to J. Opt. Soc. Amer., 1971.

5] Halperin, E. and Braner, A., Private communication, Physics Department, Hebrew University, Jerusalem, Israel.

6] Dexter, D. L., Solid State Physics 6, 353 (1958); Dexter, D. L., Phys. Rev. 101, 48 (1956).

7] Wagner, W. V., Z. Phys. 181, 143 (1964).

8] Fukuda, A., Sci. Light 13, 64 (1964).

9] Delbecq, Ch. J., Ghosh, A. K. and Yuster, Ph. H., Phys. Rev. 151 (1966). 
[70] Mavrodineanu, R. and Boiteux, H., 'Flame Spectroscopy,' J. Wiley and Sons, New York, N. Y., 1965, p. 516.

[71] Stroud, J.S., J. Chem. Phys. 35, 844 (1961).

[72] Turner, W. H. and Turner, J. E., J. Amer. Ceram. Soc. 53, 329 (1970); Goldberg, P., Ed., "Luminescence of Inorganic Solids", Academic Press, New York, N. Y., 1966.

[73] Reisfeld, R. and Kirshenbaum, L., unpiblished results. [74] a. Haas, Y. and Stein, G., Accepted by J. Phys. Chem., (1971); b. Dawson, W. R. and Kropp, J. L., J. Opt. Soc. Amer. 55, 822 (1965); c. Rinck, B., Z. Naturforschg. 4l2b, 406 (1948); d. Weber, M. J. and Schaufele, R. F., J. Chem. Phys. 43, 1702 (1965); e. Blasse, G. and Bril, A., Philips Res. Repts. 23, 189, 201 (1968).

[75] Velapoldi, R. A., Reisfeld, R. and Kirshenbaum, L., to be published.

[76] Reisfeld, R., Honigbaum, A., Michaeli, G., Harel, L. and Ish-Shalom, M., Israel J. Chem. 7, 613 (1969).

[77] Lewis, G. N. and Kasha, M., J. Amer. Chem. Soc. 67, 994 (1945).

[78] Forster, Th., "Fluoreszenz Organischen Verbindungen," Vandenhoeck and Ruprecht, Gottingen, 1957.

[79] Inokuti, M. and Hirayama, F., J. Chem. Phys. 43, 1978 ( 1965 ).

[80] Nakazawa, E. and Shionoya, S., J. Chem. Phys. 47, 3211 ( 1967 ).

[81] Carnall, W. T., Fields, P. R. and Rajnak, K., J. Chem. Phys. 49, 4550 (1968); Dieke, G. H., "Spectra and Energy Levels of Rare Earth Ions in Crystals," Interscience Publishers, New York, N. Y., 1968, pages 242-7.

[82] Mavrodineanu, R. and Hughes, R. C., A Multichannel Spectrometer for Simultaneous Atomic Absorption and Flame Emission Analysis, Applied Optics 7, 1281-1285 (1968). 
[83] Mavrodineanu, R., Sprayer and Burner Units for Flame Emission and Atomic Absorption Measurements, Develop. Appl. Spectry. 8, 18-32 (1970).

[84] Müller-Herget, W., Some Considerations on Optical Design and Selection of Spectroscopic instruments, Chapter 3, pg. 79 to 144 in "Analytical Flame Spectroscopy, Selected Topics", R. Mavrodineanu Editor, Springer-McMillan, 1970.

[85] Mavrodineanu, R., Some Considerations on Burner for Flame Spectroscopy, Develop. Appl. Spectrosc. 5, 371-401 (1965).

[86] Owen, L. E., AFML-TR-68-354, AF Materials Laboratory,, WPAFB, OH 45433.

[87] Snelleman, W., Rains, T. C., Yee, K. W., Cook, H. D. and Menis, 0., Anal. Chem. 42, 394 (1970).

[88] Menis, 0., Editor, NBS Technical Note 504, 1969.

[89] Rains, T. C., Zittel, H. E. and Ferguson, M., Talanta 10, 367 (1963).

[90] Müller, K., Z. Physik. 65, 739 (1930).

[91] Woodson, T. T., Rev. Sci. Instr. 10, 308 (1939).

[92] Poluektov, N. S. and Vitkun, R. A., Zh. Anal. Khim. 18, 33 (1963).

[93] Hatch, W. R. and Ott, W. L., Anal. Chem. 40, 2085 (1968).

[94] Hillebrand, W. F., Lundell, G. E. F., Bright, H. A. and Hoffman, J. I., "Applied Inorganic Analysis" 2nd ed., pp. 347-51, Wiley, New York, 1953.

[95] Munns, R. K., and Holland, D. C., private communication with Food and Drug Administration, Dec. 1970.

[96] Menis, 0., "Status of Thermal Analysis," NBS Special Publication 338, Oct. 1970 . 
[97] Ozawa, T., Monota, M., Osozaki, H., Bull. Chem. Soc. Japan 40, 1583 (1967).

[98] Ozawa, T., Osozaki, H., Negishi, A., Thermochimica Acta 1, 545 (1970).

[99] Ozawa, T., Bull. Chem. Soc. Japan 39, 2071 (1966). 
FORM NBS-114A (1-71)

U.S. DEPT. OF COMM.

BIBLIOGRAPHIC DATA

SHEET

1. PUBLICATION OR REPORT NO.

2. Gov't Accession

3. Recipient's Accession No. NBS-TN 584

No.

4. TIT LE AND SUBTITLE

Analytical Coordination Chemistry Section: Summary of Activities July 1970 to June 1971

5. Publication Date December 1971

6. Performing Organization Code

7. AUTHOR(S) Menis and James I. Shultz, Editors

9. PERFORMING ORGANIZATION NAME AND ADDRESS

NATIONAL BUREAU OF STAND ARDS

DEPARTMENT OF COMMERCE

WASHINGTON, D.C. 20234

8. Performing Organization

10. Project/Task/Work Unit No. 3100900

11. Contract/Grant No.

12. Sponsoring Organization Name and Address

13. Type of Report \& Period Covered Interim

Same July 1970 to June 197

14. Sponsoring Agency Code

15. SUPPLEMENTARY NOTES

16. ABSTRACT (A 200-word or less factual summary of most significant information. If document includes a significant bibliography or literature survey, mention it here.) Progress in research in spectrophotometry spectrofluorometry, flame emission, atomic absorption, thermal analysis and related programs is described. Efforts to improve accuracy of spectrophotometric measurements led to the construction of a high accuracy spectrophotometer, certification of glass filters, establishment of a more accurate yalue for molar absorptivity of the acid dichromate system, and the eyaluation of spectrally neutral filters of interest for automation in clinical studies. The linearity of the single beam spectrophotometer was calibrated by the light addition technique. Glass filters were calibrated at 4 wavelengths with an uncertainty of 0.5 percent. Data for the dichromate system in perchloric acid led to new values for the dimerization equilibrium constant.

Studies were made of new fluorescence filters incorporating Ti(I), $\mathrm{Ce}(\mathrm{III}), \mathrm{Pb}$ (II) and rare earths in a variety of glass matrices. Quantum efficiencies of Tl in $\mathrm{KCl}$ and Eu in a silicate matrix were determined.

Developments in instrumentation led to increased sensitivity and improved precision and accuracy by flame spectroscopy. $\mathrm{Mg}, \mathrm{Ca}, \mathrm{K}$ and $\mathrm{Na}$ were determined with the multichannel spectrometer. A newly designed optical system and an ultrasonic spraying system provided increased signal and efficiency. The repetitiye optical scan of flame emission oyercame matrix and flame background problems for the determination of aluminum in steel. Certification was made on eight new materials in cooperation with the International Confederation on Thermal Analysis.

17. KEY WORDS (Alphabetical order, separated by semicolons) Aluminum in steel; bilirubin; DTA standards; fluorescence filters TI(I), Ce(III), Pb(II); glass filters (SRM 230); mercury in botanical; quantum efficiencies.

\begin{tabular}{|c|c|c|}
\hline $\begin{array}{l}\text { 18. AVAILABILITY STATEMENT } \\
\qquad \times \text { UNLIMITED. }\end{array}$ & $\begin{array}{l}\text { 19. SECURITY CLASS } \\
\text { (THIS REPORT) } \\
\text { UNCL ASSIFIED }\end{array}$ & $\begin{array}{l}\text { 21. NO. OF PAGES } \\
175\end{array}$ \\
\hline $\begin{array}{l}\square \text { FOR OFFICIAL DISTRIBUTION. DO NOT RELEASE } \\
\text { TO NTIS. }\end{array}$ & $\begin{array}{l}\text { 20. SECURITY CLASS } \\
\text { (THIS PAGE) } \\
\text { UNCL ASSIFIED }\end{array}$ & $\begin{array}{l}\text { 22. Price } \\
\qquad 1.50\end{array}$ \\
\hline
\end{tabular}





\section{PERIODICALS}

JOURNAL OF RESEARCH reports National Bureau of Standards research and development in physics, mathematics, chemistry, and engineering. Comprehensive scientific papers give complete details of the work, including laboratory data, experimental procedures, and theoretical and mathematical analyses. Illustrated with photographs, drawings, and charts.

Published in three sections, available separately:

\section{Physics and Chemistry}

Papers of interest primarily to scientists working in these fields. This section covers a broad range of physical and chemical research, with major emphasis on standards of physical measurement, fundamental constants, and properties of matter. Issued six times a year. Annual subscription: Domestic, $\$ 9.50 ; \$ 2.25$ additional for foreign mailing.

\section{- Mathematical Sciences}

Studies and compilations designed mainly for the mathematician and theoretical physicist. Topics in mathematical statistics, theory of experiment design, numerical analysis, theoretical physics and chemisty, logical design and programming of computers and computer systems. Short numerical tables. Issued quarterly. Annual subscription: Domestic, $\$ 5.00$; $\$ 1.25$ additional for foreign mailing.

\section{- Engineering and Instrumentation}

Reporting results of interest chiefly to the engineer and the applied scientist. This section includes many of the new developments in instrumentation resulting from the Bureau's work in physical measurement, data processing, and development of test methods. It will also cover some of the work in acoustics, applied mechanics, building research, and cryogenic engineering. Issued quarterly. Annual subscription: Domestic, $\$ 5.00 ; \$ 1.25$ additional for foreign mailing.

\section{TECHNICAL NEWS BULLETIN}

The best single source of information concerning the Bureau's research, developmental, cooperative, and publication activities, this monthly publication is designed for the industry-oriented individual whose daily work involves intimate contact with science and technology-for engineers, chemists, physicists, research managers, product-development managers, and company executives. Annual subscription: Domestic, $\$ 3.00 ; \$ 1.00$ additional for foreign mailing.

\section{NONPERIODICALS}

Applied Mathematics Series. Mathematical tables, manuals, and studies.

Building Science Series. Research results, test methods, and performance criteria of building materials, components, systems, and structures.

Handbooks. Recommended codes of engineering and industrial practice (including safety codes) developed in ccoperation with interested industries, professional organizations, and regulatory bodies.

Special Publications. Proceedings of NBS conferences, bibliographies, annual reports, wall charts, pamphlets, etc.

Monographs. Major contributions to the technical literature on various subjects related to the Bureau's scientific and technical activities.

\section{National Standard Reference Data Series.}

NSRDS provides quantitative data on the physical and chemical properties of materials, compiled from the world's literature and critically evaluated.

Product Standards. Provide requirements for sizes, types, quality, and methods for testing various industrial products. These standards are developed cooperatively with interested Government and industry groups and provide the basis for common understanding of product characteristics for both buyers and sellers. Their use is voluntary.

Technical Notes. This series consists of communications and reports (covering both other agency and NBS-sponsored work) of limited or transitory interest.

Federal Information Processing Standards Publications. This series is the official publication within the Federal Government for information on standards adopted and promulgated under the Public Law 89-306, and Bureau of the Budget Circular A-86 entitled, Standardization of Data Elements and Codes in Data Systems.

Consumer Information Series. Practical information, based on NBS research and experience, covering areas of interest to the consumer. Easily understandable language and illustrations provide useful background knowledge for shopping in today's technological marketplace.

NBS Special Publication 305, Supplement 1, Publications of the NBS, 1968-1969. When ordering, include Catalog No. C13.10:305. Price \$4.50; $\$ 1.25$ additional for foreign mailing. 
U.S. DEPARTMENT OF COMMERCE

National Bureau of Standards

Washington, D.C. 20234

POSTAGE AND FEES PAID

OFFICIAL BUSINESS

U.S. DEPARTMENT OF COMMERCE

Penalty for Private Use, $\$ 300$ 